\title{
Estudo do Escoamento de Ar sobre a Carroceria de um Ônibus usando um Programa de CFD e Comparação com Dados Experimentais
}

André Luiz Carregari

Dissertação apresentada à Escola de Engenharia de São Carlos da Universidade de São Paulo, como parte dos requisitos para a obtenção do Título de Mestre em Engenharia Mecânica.

Orientador: Prof. Dr. Paulo Celso Greco Júnior

São Carlos

2006 
Dedico este trabalho, aos meus pais, à minha irmã, ao meu cunhado, aos meus sobrinhos, e aos meus tios. 


\section{AGRADECIMENTOS}

Ao Professor Paulo Celso Greco Junior, pela oportunidade de realização deste trabalho e pela orientação;

Aos colegas do Laboratório de Aerodinâmica Experimental (LAE) e Laboratório de Aeroelasticidade, Dinâmica de Vôo e Controle (LADINC) pela amizade e pelo companheirismo e colaboração durante a realização deste trabalho;

À Coordenadoria de Aperfeiçoamento de Pessoal de Nível Superior (CAPES), pelo apoio financeiro concedido;

Aos professores do Laboratório de Aerodinâmica Experimental (LAE), pela atenção e colaboração em todos os momentos;

Aos técnicos e funcionários do Laboratório de Aerodinâmica Experimental (LAE), Laboratório de Máquinas e Ferramentas (LAMAFE) e Departamento de Engenharia Mecânica (SEM) pelo auxílio e serviços prestados ao longo deste trabalho. 


\section{SUMÁRIO}

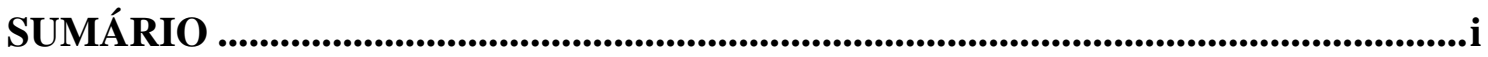

LISTA DE FIGURAS ..........................................................................................................iii

LISTA DE TABELAS ...............................................................................................vii

LISTA DE SIGLAS ....................................................................................................viii

LISTA DE SÍMBOLOS.....................................................................................

RESUMO .......................................................................................................................

ABSTRACT ...........................................................................................................................

1 INTRODUÇÃO.......................................................................................................1

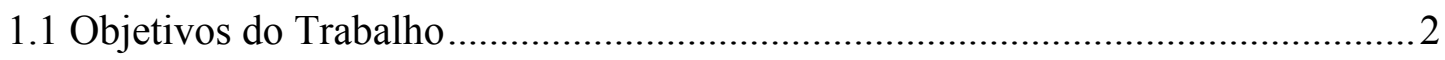

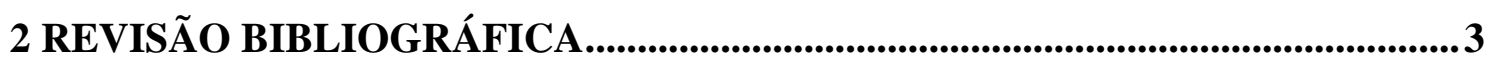

2.1 Influência do arredondamento das arestas laterais dos veículos e da inclinação da

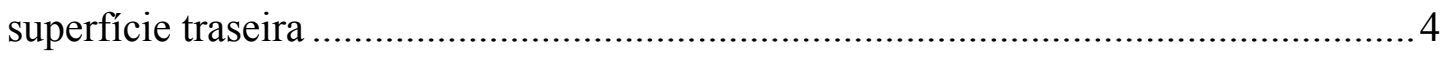

2.2 Configurações para simulação de movimento do piso..........................................

2.3 Influência de dispositivos no escoamento de ar ao redor de um veículo ................ 8

2.4 Aplicação da Dinâmica de Fluidos Computacional ............................................11

2.5 Descrição do trabalho ora desenvolvido ............................................................ 13

3 APARATO E DESCRIÇÃO DOS EXPERIMENTOS.......................................14

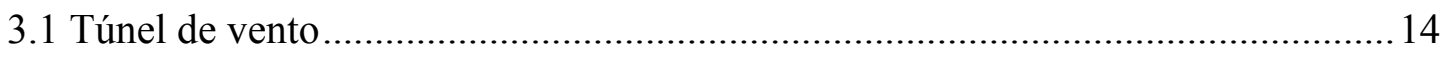

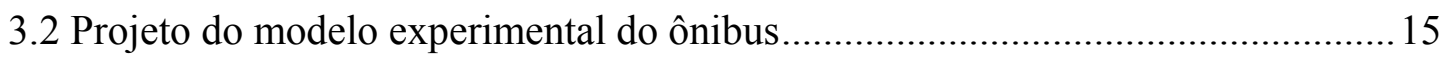




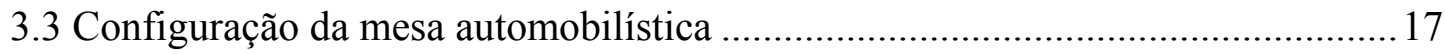

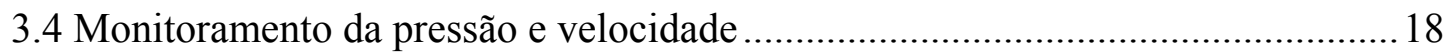

3.5 Medição das forças e distribuição de pressão ......................................................... 19

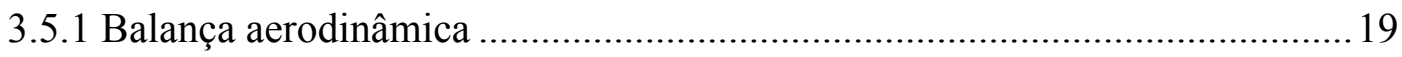

3.5.2 Distribuição de pressão nas superfícies do modelo .....................................23

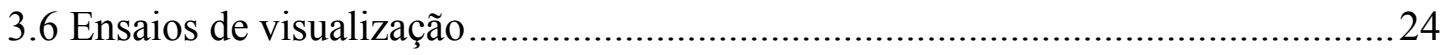

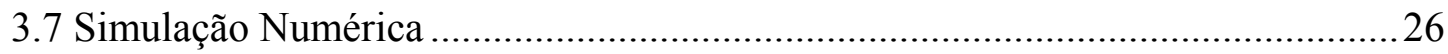

3.7.1 Equacionamento matemático da simulação numérica ....................................34

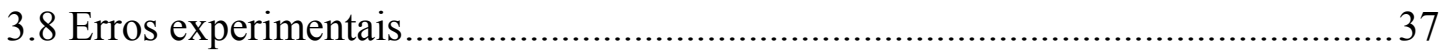

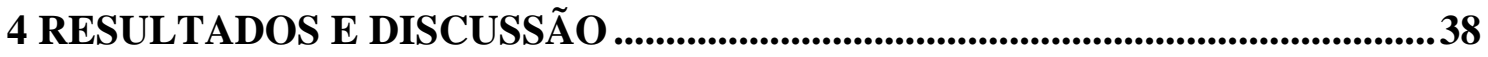

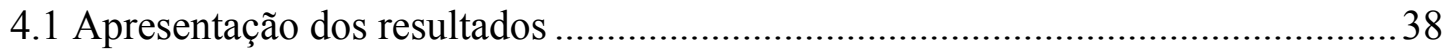

4.1.1 Resultados com vão livre entre o modelo e a mesa. ........................................ 38

4.1.2 Resultados sem vão livre entre o modelo e a mesa.........................................48

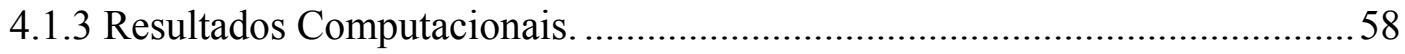

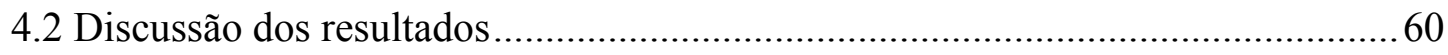

4.3 Apresentação dos ensaios de visualização ......................................................... 67

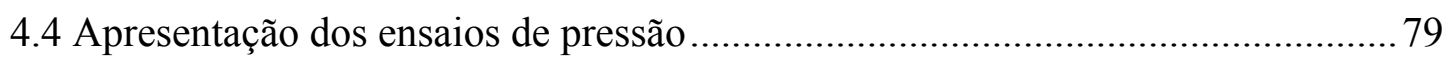

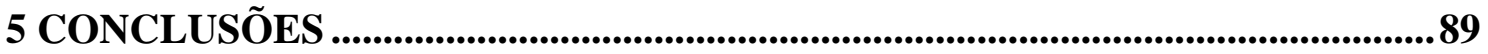

6 REFERÊNCIAS BIBLIOGRÁFICAS ..............................................................992

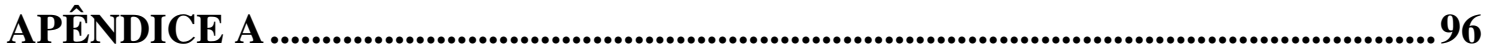

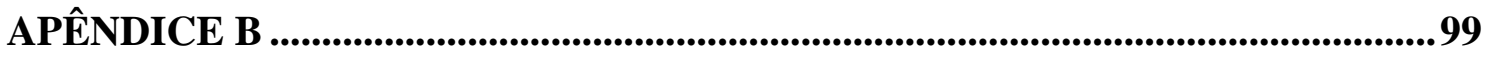

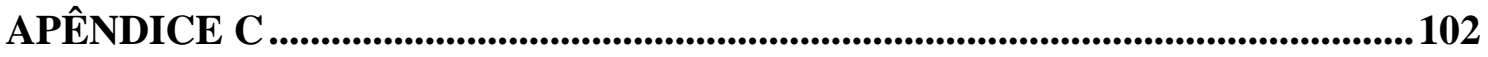




\section{LISTA DE FIGURAS}

FIGURA 1 - Redução do arrasto devido a diferentes geometrias em um modelo de

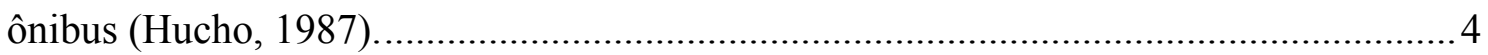
FIGURA 2 - Curva de Coeficiente de Arrasto e Sustentação para vários ângulos de

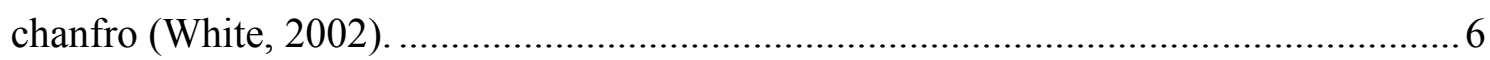

FIGURA 3 - Estrutura geométrica de cada aleta em forma de "U" (Garry, 1981).......... 9 FIGURA 4 - Influência do sistema pneumático de sopro na esteira (Englar, 2000): (a) sistema desligado, grande região de escoamento separado; (b) sistema ligado, pequena região de escoamento separado.

FIGURA 5 - Vista do túnel de vento subsônico tipo soprador.

FIGURA 6 - Vista do modelo construído no LAE: (a) planta do modelo; (b) modelo concluído.

FIGURA 7 - Micromanômetro digital modelo 8705 DP-Calc usado nos experimentos.19

FIGURA 8 - Barômetro de Torricelli situado no LAE. .19

FIGURA 9 - Esquema da balança aerodinâmica. 21

FIGURA 10 - Circuito de uma Ponte de "Wheatstone". 22

FIGURA 11 - Instrumentos de medição de pressão: (a) decodificador de sinal; (b) controlador de solenóide; (c) válvula comutadora de pressão tipo "scanivalve"..........23

FIGURA 12 - Posição das tomadas de pressão em cada superfície.................................24

FIGURA 13 - Disposição dos fios de lã (“tufts”) na superfície do modelo.....................25

FIGURA 14 - Aplicação do composto de dióxido de titânio na superfície do modelo. .25 FIGURA 15 - Domínio computacional com a respectiva malha tetraédrica e sua dimensão: 2900 x 1650 x 1100 (mm).

FIGURA 16 - Curva do coeficiente de arrasto $C_{D}$ em função do ângulo de guinada para a Medição 1 com vão livre entre o modelo e a mesa.

FIGURA 17 - Curva do coeficiente de força lateral $\mathrm{C}_{\mathrm{N}}$ em função do ângulo de guinada para a Medição 1 com vão livre entre o modelo e a mesa. 
FIGURA 18 - Curva do coeficiente de arrasto $\mathrm{C}_{\mathrm{D}}$ em função do ângulo de guinada para a Medição 2 com vão livre entre o modelo e a mesa.

FIGURA 19 - Curva do coeficiente de força lateral $\mathrm{C}_{\mathrm{N}}$ em função do ângulo de guinada para a Medição 2 com vão livre entre o modelo e a mesa.

FIGURA 20 - Curva do coeficiente de arrasto $C_{D}$ em função do ângulo de guinada para a Medição 3 com vão livre entre o modelo e a mesa.

FIGURA 21 - Curva do coeficiente de força lateral $\mathrm{C}_{\mathrm{N}}$ em função do ângulo de guinada para a Medição 3 com vão livre entre o modelo e a mesa.

FIGURA 22 - Curva do coeficiente de arrasto $C_{D}$ em função do ângulo de guinada para a Medição 4 com vão livre entre o modelo e a mesa.

FIGURA 23 - Curva do coeficiente de força lateral $\mathrm{C}_{\mathrm{N}}$ em função do ângulo de guinada para a Medição 4 com vão livre entre o modelo e a mesa. 46

FIGURA 24 - Curva do coeficiente de arrasto $C_{D}$ em função do ângulo de guinada para a Medição 5 com vão livre entre o modelo e a mesa.

FIGURA 25 - Curva do coeficiente de força lateral $\mathrm{C}_{\mathrm{N}}$ em função do ângulo de guinada para a Medição 5 com vão livre entre o modelo e a mesa.

FIGURA 26 - Curva do coeficiente de arrasto $C_{D}$ em função do ângulo de guinada para a Medição 1 sem vão livre entre o modelo e a mesa.

FIGURA 27 - Curva do coeficiente de força lateral $\mathrm{C}_{\mathrm{N}}$ em função do ângulo de guinada para a Medição 1 sem vão livre entre o modelo e a mesa. .50

FIGURA 28 - Curva do coeficiente de arrasto $C_{D}$ em função do ângulo de guinada para a Medição 2 sem vão livre entre o modelo e a mesa.

FIGURA 29 - Curva do coeficiente de força lateral $C_{N}$ em função do ângulo de guinada para a Medição 2 sem vão livre entre o modelo e a mesa.

FIGURA 30 - Curva do coeficiente de arrasto $C_{D}$ em função do ângulo de guinada para a Medição 3 sem vão livre entre o modelo e a mesa.

FIGURA 31 - Curva do coeficiente de força lateral $C_{N}$ em função do ângulo de guinada para a Medição 3 sem vão livre entre o modelo e a mesa.....

FIGURA 32 - Curva do coeficiente de arrasto $C_{D}$ em função do ângulo de guinada para a Medição 4 sem vão livre entre o modelo e a mesa.

FIGURA 33 - Curva do coeficiente de força lateral $\mathrm{C}_{\mathrm{N}}$ em função do ângulo de guinada para a Medição 4 sem vão livre entre o modelo e a mesa. .56

FIGURA 34 - Curva do coeficiente de arrasto $C_{D}$ em função do ângulo de guinada para a Medição 5 sem vão livre entre o modelo e a mesa. 
FIGURA 35 - Curva do coeficiente de força lateral $\mathrm{C}_{\mathrm{N}}$ em função do ângulo de guinada para a Medição 5 sem vão livre entre o modelo e a mesa. .58

FIGURA 36 - Curva do coeficiente de arrasto computacional $\mathrm{C}_{\mathrm{Dc}}$ em função do ângulo de guinada $\beta$.

FIGURA 37 - Curva do coeficiente de força lateral computacional $\mathrm{C}_{\mathrm{Nc}}$ em função do ângulo de guinada $\beta$.

FIGURA 38 - Curva média do coeficiente de arrasto $C_{D}$ experimental e computacional em função do ângulo de guinada com vão livre entre o modelo e a mesa.

FIGURA 39 - Curva média do coeficiente de arrasto $C_{D}$ experimental e computacional em função do ângulo de guinada sem vão livre entre o modelo e a mesa .

FIGURA 40 - Comparação das curvas médias dos coeficientes de arrasto com e sem vão livre.

FIGURA 41 - Curva média do coeficiente da força lateral $\mathrm{C}_{\mathrm{N}}$ experimental e computacional em função do ângulo de guinada com vão livre entre o modelo e a mesa.

FIGURA 42 - Curva média do coeficiente da força lateral $\mathrm{C}_{\mathrm{N}}$ experimental e computacional em função do ângulo de guinada sem vão livre entre o modelo e a mesa.

FIGURA 43 - Comparação das curvas médias dos coeficientes de força lateral com e sem vão livre. .66

FIGURA 44 - Visualização do escoamento com "tufts", para $\beta=0^{\circ}$.

FIGURA 45 - Visualização do escoamento com "tufts", para $\beta=6^{\circ}$. 70

FIGURA 46 - Visualização do escoamento com "tufts", para $\beta=10^{\circ}$ 71

FIGURA 47 - Visualização do escoamento com "tufts", para $\beta=-6^{\circ}$............................. 72

FIGURA 48 - Visualização do escoamento com "tufts", para $\beta=-10^{\circ}$........................... 72

FIGURA 49 - Visualização do ponto de estagnação. ....................................................... 73

FIGURA 50 - Visualização do escoamento com composto de dióxido de titânio, para $\beta=0^{\circ}$. 73

FIGURA 51 - Visualização do escoamento com composto de dióxido de titânio, para $\beta=4^{\circ}$.

FIGURA 52 - Visualização do escoamento com composto de dióxido de titânio, para $\beta=8^{\circ}$. 75

FIGURA 53 - Linhas de corrente de escoamento sobre o modelo, para $\beta=0^{\circ}$................ 76

FIGURA 54 - Linhas de corrente do escoamento sobre o modelo, para $\beta=4^{\circ}$. ..............76 
FIGURA 55 - Linhas de corrente do escoamento sobre o modelo, para $\beta=6^{\circ}$. 77

FIGURA 56 - Linhas de corrente do escoamento sobre o modelo, para $\beta=8^{\circ}$. .............. 77

FIGURA 57 - Linhas de corrente do escoamento sobre o modelo, para $\beta=10^{\circ}$.............78

FIGURA 58 - Linhas de corrente do escoamento sobre o modelo, para $\beta=-6^{\circ}$..............78

FIGURA 59 - Linhas de corrente do escoamento sobre o modelo, para $\beta=-10^{\circ}$............79

FIGURA 60 - Posição das tomadas de pressão na linha de simetria do modelo. ............ 81

FIGURA 61 - Valores adimensionais dos coeficientes de pressão no plano de simetria do modelo, para $\beta=0^{\circ}$.

FIGURA 62 - Valores adimensionais dos coeficientes de pressão no plano de simetria do modelo, para $\beta=4^{\circ}$

FIGURA 63 - Valores adimensionais dos coeficientes de pressão no plano de simetria do modelo, para $\beta=8^{\circ}$.

FIGURA 64 - Posição das tomadas de pressão na linha frontal, lateral e traseira do modelo.

FIGURA 65 - Valores adimensionais dos coeficientes de pressão na lateral modelo, para $\beta=0^{\circ}$

FIGURA 66 - Valores adimensionais dos coeficientes de pressão na lateral do modelo, para $\beta=4^{\circ}$.

FIGURA 67 - Valores adimensionais dos coeficientes de pressão na lateral do modelo, $\operatorname{para} \beta=8^{\circ}$.

FIGURA 68 - Valores computacionais de coeficiente de pressão no modelo, para $\beta=0^{\circ}$.

FIGURA 69 - Valores computacionais de coeficiente de pressão no modelo, para $\beta=4^{\circ}$.

FIGURA 70 - Valores computacionais de coeficiente de pressão no lado oposto do modelo, para $\beta=4^{\circ}$.

FIGURA 71 - Valores computacionais de coeficiente de pressão no modelo, para $\beta=8^{\circ}$.

FIGURA 72 - Valores computacionais de coeficiente de pressão no lado oposto do modelo, para $\beta=8^{\circ}$.

FIGURA 73 - Valores de distribuição de pressão no plano simétrico do modelo, para $\beta=0^{\circ}$.

FIGURA 74 - Valores de velocidade no plano simétrico do modelo, para $\beta=0^{\circ}$. 88

FIGURA 75 - Linhas de corrente do escoamento na traseira do modelo, para $\beta=0^{\circ}$..... .88 


\section{LISTA DE TABELAS}

TABELA 1 - Dimensões do túnel de vento. ................................................................ 15

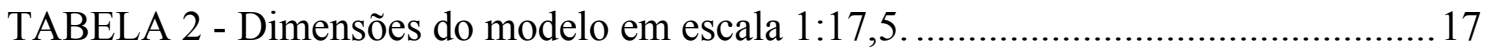

TABELA 3 - Valores correspondentes a diferentes ângulos de guinada $\beta$ da Medição 1 com vão livre entre o modelo e a mesa.

TABELA 4 - Valores correspondentes a diferentes ângulos de guinada $\beta$ da Medição 2 com vão livre entre o modelo e a mesa.

TABELA 5 - Valores correspondentes a diferentes ângulos de guinada $\beta$ da Medição 3 com vão livre entre o modelo e a mesa.

TABELA 6 - Valores correspondentes a diferentes ângulos de guinada $\beta$ da Medição 4 com vão livre entre o modelo e a mesa.

TABELA 7 - Valores correspondentes a diferentes ângulos de guinada $\beta$ da Medição 5 com vão livre entre o modelo e a mesa.

TABELA 8 - Valores correspondentes a diferentes ângulos de guinada $\beta$ da Medição 1 sem vão livre entre o modelo e a mesa.

TABELA 9 - Valores correspondentes a diferentes ângulos de guinada $\beta$ da Medição 2 sem vão livre entre o modelo e a mesa.

TABELA 10 - Valores correspondentes a diferentes ângulos de guinada $\beta$ da Medição 3 sem vão livre entre o modelo e a mesa.

TABELA 11 - Valores correspondentes a diferentes ângulos de guinada $\beta$ da Medição 4 sem vão livre entre o modelo e a mesa. 55

TABELA 12 - Valores correspondentes a diferentes ângulos de guinada $\beta$ da Medição 5 sem vão livre entre o modelo e a mesa.

TABELA 13 - Valores computacionais correspondentes a diferentes ângulos de guinada $(\beta)$. 


\section{LISTA DE SIGLAS}

$\begin{array}{ll}\text { CAD } & \text { Computer Aided Design } \\ \text { CAPES } & \text { Coordenadoria de Aperfeiçoamento de Pessoal de Nível Superior } \\ \text { EESC } & \text { Escola de Engenharia de São Carlos } \\ \text { IGES } & \text { International Graphics Exchange Standard } \\ \text { LADINC } & \text { Laboratório de Aeroelasticidade, Dinâmica de Vôo e Controle } \\ \text { LAE } & \text { Laboratório de Aerodinâmica Experimental } \\ \text { LAMAFE } & \text { Laboratório de Máquinas e Ferramentas } \\ \text { NPA } & \text { Núcleo de Pesquisa em Aeronáutica } \\ \text { SEM } & \text { Departamento de Engenharia Mecânica } \\ \text { USP } & \text { Universidade de São Paulo }\end{array}$




\section{LISTA DE SÍMBOLOS}

\begin{tabular}{|c|c|}
\hline A & área frontal do veículo, $\mathrm{m}^{2}$ \\
\hline $\mathrm{Bm}$ & vão do solo, mm \\
\hline $\mathrm{C}_{\mathrm{Dc}}$ & coeficiente de arrasto computacional \\
\hline $\mathrm{C}_{\mathrm{D}}$ & coeficiente de arrasto \\
\hline $\mathrm{Cm}$ & comprimento do modelo, $\mathrm{mm}$ \\
\hline $\mathrm{C}_{\mathrm{L}}$ & coeficiente da força de sustentação \\
\hline $\mathrm{C}_{\mathrm{M}}$ & coeficiente de momento de arfagem \\
\hline $\mathrm{C}_{\mathrm{Nc}}$ & coeficiente de força lateral computacional \\
\hline $\mathrm{C}_{\mathrm{N}}$ & coeficiente de força lateral \\
\hline $\mathrm{C}_{\mathrm{R}}$ & coeficiente de momento de rolamento \\
\hline $\mathrm{C}_{\mathrm{Y}}$ & coeficiente de momento de guinada \\
\hline $\mathrm{D}$ & força de arrasto, $\mathrm{N}$ \\
\hline $\mathrm{Dm}$ & diâmetro do pneu do modelo, mm \\
\hline $\mathrm{Hm}$ & altura do modelo, $\mathrm{mm}$ \\
\hline 1 & comprimento total do veículo, $\mathrm{m}$ \\
\hline $\mathrm{L}$ & força de sustentação, $\mathrm{N}$ \\
\hline $\mathrm{Lm}$ & largura do modelo, $\mathrm{mm}$ \\
\hline M & força de momento de arfagem, $\mathrm{N}$ \\
\hline $\mathrm{N}$ & força lateral, $\mathrm{N}$ \\
\hline $\mathrm{p}^{\prime}$ & pressão modificada \\
\hline $\mathrm{P}_{\kappa}$ & produção turbulenta das forças viscosas \\
\hline $\mathrm{q}_{\infty}$ & pressão dinâmica do escoamento livre, $\mathrm{N} / \mathrm{m}^{2}$ \\
\hline $\mathrm{rm}$ & raio de arredondamento das arestas laterais \\
\hline $\mathrm{R}$ & força de momento de rolamento, $\mathrm{N}$ \\
\hline $\mathrm{Rm}$ & raio de arredondamento da aresta frontal e traseira \\
\hline $\mathrm{Re}$ & número de Reynolds \\
\hline
\end{tabular}




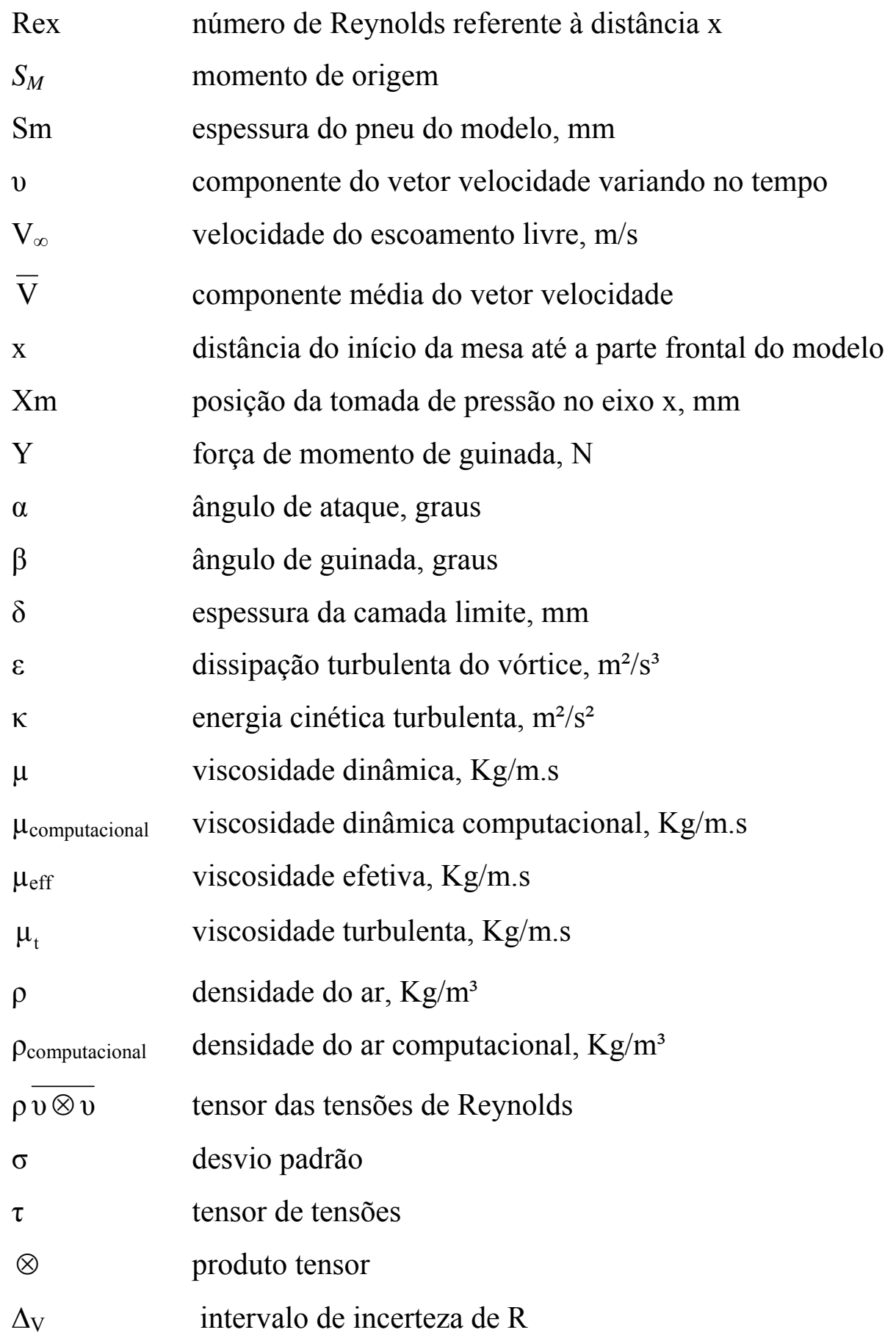




\section{RESUMO}

CARREGARI, ANDRÉ LUIZ (2006). Estudo do Escoamento de Ar sobre a Carroceria de um Ônibus usando um Programa de CFD e Comparação com Dados Experimentais. São Carlos, 2006. Dissertação (Mestrado) - Escola de Engenharia de São Carlos, Universidade de São Paulo.

Dois dos principais objetivos no estudo da aerodinâmica de veículos comerciais são a redução no consumo de combustível e o aumento na eficiência da refrigeração do motor. Esses objetivos podem ser alcançados através do desenvolvimento de dispositivos que modifiquem o escoamento do ar ao redor do veículo e também através da alteração da forma das superfícies externas. A inclinação das superfícies da parte traseira de um ônibus, por exemplo, tem grande influência sobre a esteira turbulenta que se forma atrás do veículo. $\mathrm{O}$ uso de ferramentas computacionais permite uma redução de custo e maior flexibilidade na análise aerodinâmica de autoveículos. Ainda é preciso, no entanto, que o resultado dessas ferramentas computacionais seja verificado com o maior número possível de casos para que se possa escolher e ajustar o modelo matemático de forma adequada. O objetivo do presente trabalho é a verificação dos resultados computacionais e experimentais no desenvolvimento de metodologias que visem à redução no consumo de combustível e aumento na eficiência da refrigeração do motor. Foram comparados resultados experimentais e computacionais do escoamento sobre um modelo de um ônibus comercial em escala 1:17,5. Para a realização do experimento foi utilizado um túnel de vento de seção aberta, onde foram analisadas as distribuições de pressão nas superfícies da carroceria e o arrasto aerodinâmico. Para o teste computacional, foi utilizado um software de dinâmica dos fluidos computacional em que as equações de Navier-Stokes com média de Reynolds são resolvidas pelo método dos volumes finitos usando um modelo de turbulência RNG $\kappa-\varepsilon$.

Palavras chave: Arrasto aerodinâmico, modelo de turbulência RNG $\kappa-\varepsilon$, esteira turbulenta, força lateral, coeficiente de pressão. 


\section{ABSTRACT}

CARREGARI, ANDRÉ LUIZ (2006). Study of the Air Flow around a Bus using CFD software and Comparison with Experimental Data. São Carlos, 2006. MSc Thesis Escola de Engenharia de São Carlos, Universidade de São Paulo.

Two main objectives in the study of commercial vehicle aerodynamics are the reduction in fuel consumption and the improvement in engine refrigeration efficiency. These objectives can be achieved through development of devices which vary the flow characteristics around the vehicle and also through modification of the shape of external surfaces. The slope of rear surfaces, for instance, has large influence over the wake turbulence which forms behind the vehicle. The use of computational tools yields cost reduction and greater flexibility in automotive aerodynamic analysis. There is still a need, however, for verification of results, generated by these computational tools, with the largest possible number of test cases so that the mathematical model is adequately chosen and adjusted. The objective of the present work is the verification of experimental and computational results in the development of methodologies aiming at reduction of fuel consumption and improvement in engine refrigeration efficiency. Experimental and computational aerodynamic results were compared for a commercial bus model with a 1:17.5 scale. The experiments were conducted in an open section wind tunnel where pressure distribution and aerodynamic drag were analyzed. The numerical analysis was conducted using computational fluid dynamics software which solves the Reynolds Averaged Navier-Stokes equations using the finite volume method with a RNG $\kappa-\varepsilon$ turbulence model.

Keywords: aerodynamic drag, RNG $\kappa-\varepsilon$ turbulence model, turbulent wake, side force, pressure coefficient. 


\section{INTRODUÇÃO}

O setor automobilístico nacional tem se destacado com o desenvolvimento de projetos, mostrando sua capacidade de inovação e seu alto nível de tecnologia implementada, tornando-se um dos segmentos mais importantes na economia nacional.

Há décadas, o consumo de combustível e a emissão de poluentes no ar atmosférico são preocupações constantes e a cada novo projeto, ou mesmo em modificações nos modelos já existentes, tornam-se fatores indispensáveis na análise das características aerodinâmicas. Entende-se por aerodinâmica o estudo do comportamento do ar sobre uma determinada superfície. A incidência do ar na superfície ocasiona a geração de forças aerodinâmicas que podem ser responsáveis por um excessivo consumo de combustível.

As forças aerodinâmicas produzidas sobre os veículos provocam arrasto, sustentação, forças laterais e momentos. Estas forças resultam de duas fontes: distribuição de pressão e fricção viscosa. A resistência ao avanço devido à incidência do ar sobre as carrocerias de ônibus e caminhões corresponde à maior parcela destas forças em altas velocidades, e a resistência ao rolamento dos pneus exercem uma parcela menor na geração do coeficiente de arrasto $\left(C_{D}\right)$. $O$ arrasto aerodinâmico é um dos maiores interesses na elaboração de um projeto.

White (2002) mostra que um caminhão, trafegando a uma velocidade de 89 $\mathrm{km} / \mathrm{h}$, com um defletor aerodinâmico instalado no alto da cabine pode ter uma redução de arrasto em torno de $20 \%$. O ângulo do defletor pode ser ajustado para conduzir o escoamento suavemente para o topo e em torno das laterais do compartimento de carga, resultando em uma redução na resistência total do veiculo de cerca de $10 \%$, reduzindo os custos com o combustível. Para baixas velocidades, constata-se que o arrasto total será influenciado em grande parte pela resistência gerada pelos componentes mecânicos 
do veiculo como, por exemplo, a resistência à tração e à aceleração do veículo (ônibus, caminhões ou utilitários).

A melhoria de um projeto aerodinâmico torna-se imprescindível em veículos de transporte de passageiros e de cargas, devido às velocidades desenvolvidas serem elevadas, e também devido à grande área frontal. Esta importância é mais significativa ainda se considerarmos que, no Brasil, quase todo transporte de cargas e passageiros, feito por via terrestre, é realizado por ônibus e caminhões. Se alguma economia de combustível puder ser feita individualmente, no aspecto geral haverá uma expressiva redução de custos operacionais.

Diante dos aspectos econômicos que este assunto possui, devemos dizer também que os fenômenos aerodinâmicos observados ao redor de autoveículos, não são facilmente reproduzíveis em túnel de vento. Como podemos destacar, para um ônibus numa estrada real seu número de Reynolds fica em torno de $\operatorname{Re}=4.0 \times 10^{6}$ enquanto que em um túnel de vento típico atingiremos no máximo $\mathrm{Re}=1.8 \times 10^{5}$. Portanto, alguns dos fenômenos do escoamento podem não ocorrer de maneira idêntica no túnel de vento em relação ao que acontece com um ônibus real. Uma solução computacional, em que se reproduz o número de Reynolds do caso real, pode gerar resultados que auxiliem na análise dos resultados experimentais.

É neste contexto que surge o trabalho ora proposto. Compararam-se resultados numéricos, obtidos com software de dinâmica de fluidos computacional, com resultados experimentais, obtidos em túnel de vento, do escoamento em torno de um ônibus. Para isso, foi construído um modelo em escala reduzida de um ônibus que foi ensaiado em um túnel de vento instalado nas dependências da Escola de Engenharia de São Carlos (EESC), no Núcleo de Pesquisa em Aeronáutica (NPA), no Laboratório de Aerodinâmica (LAE).

\subsection{Objetivos do Trabalho}

O objetivo geral do trabalho é a análise do escoamento em torno de autoveículos visando o aumento da eficiência aerodinâmica. O objetivo específico é a comparação de resultados teóricos, obtidos com software de dinâmica de fluidos computacional, (“Computational Fluid Dynamics" - CFD), e experimentais, obtidos em túnel de vento, para verificação das metodologias de análise aerodinâmica. 


\section{REVISÃO BIBLIOGRÁFICA}

Neste capítulo são apresentados aspectos gerais relacionados aos trabalhos realizados no estudo de aerodinâmica computacional e experimental de veículos comerciais. A forma e o tamanho de um autoveículo comercial são ditados principalmente pela capacidade de carga, ou pelo número de passageiros para o qual foi projetado. Diversas restrições fazem com que não seja viável mudar radicalmente a forma estrutural de um ônibus ou caminhão, mas sim aperfeiçoar as superfícies e desenvolver dispositivos aerodinâmicos, que provoquem variações nas forças aerodinâmicas de arrasto, sustentação e lateral. Estes aperfeiçoamentos e as características de algumas formas construtivas são alguns dos fatores que fizeram surgir o interesse em estudar o comportamento do fluxo de ar ao redor dos autoveículos usando ferramentas computacionais.

Estes efeitos aerodinâmicos influenciaram o aperfeiçoamento das características construtivas dos veículos comerciais através de estudos envolvendo:

- O arredondamento das superfícies laterais dos veículos.

- Configurações adotadas para diferentes simulações de piso, dentro da câmara de ensaios de túneis de vento.

- A utilização de dispositivos aerodinâmicos capazes de orientar o fluxo frontal e traseiro de veículos de grande porte, para minimização o coeficiente de arrasto.

- A influência de ventos laterais em veículos de escala real e reduzida, nos ensaios em túnel de vento.

Estes e outros fatores serão apresentados em alguns trabalhos descritos no decorrer desse capítulo. 


\subsection{Influência do arredondamento das arestas laterais dos veículos e da inclinação da superfície traseira}

Nos atuais veículos comerciais leves, modificações na superfície frontal e no teto estão sendo exploradas com mais freqüência para a redução do coeficiente de arrasto. Uma modificação feita por alguns pesquisadores nos modelos é o arredondamento das arestas. Os estudos mostraram a influência que essa modificação teria sobre o coeficiente de arrasto.

O coeficiente de arrasto de um ônibus é cerca de 1,5 vez maior que de um veículo de passeio e, seu valor, varia na faixa de 0,5 e 0,8 dependendo do projeto aerodinâmico de sua carroceria. Hucho (1987) menciona que um modelo de ônibus com a parte frontal com os cantos sem arredondamento (FIGURA 1(a)) apresenta um $\mathrm{C}_{\mathrm{D}}=0,88$ enquanto que, um modelo com a mesma frente mas com os cantos arredondados (FIGURA 1(b)) apresenta um $\mathrm{C}_{\mathrm{D}}=0,36$. Um terceiro modelo, com um ângulo de inclinação frontal e arredondamento da frente (FIGURA 1(c)), apresenta um $\mathrm{C}_{\mathrm{D}}=0,34$.

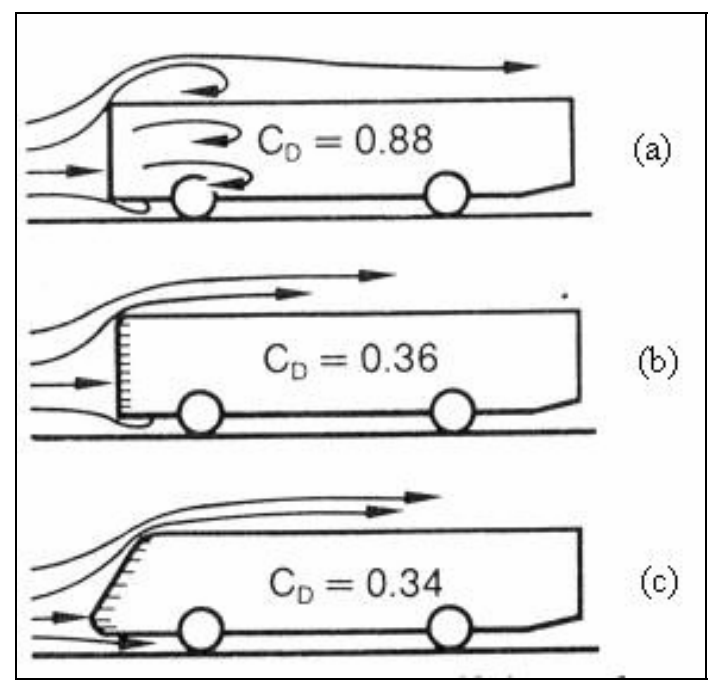

FIGURA 1 - Redução do arrasto devido a diferentes geometrias em um modelo de ônibus (Hucho, 1987).

Schlichting (1979) analisou o escoamento ao redor de dois modelos de vans, sendo um deles com cantos vivos e o outro com cantos arredondados, e seus coeficientes de arrasto $\left(C_{D}\right)$ apresentavam valores de 0,76 e 0,42 , respectivamente. $O$ valor correspondente ao modelo com cantos vivos propiciava o escoamento descolado 
na superfície lateral, gerando uma esteira turbulenta maior. $\mathrm{O}$ valor referente ao outro modelo proporcionava o escoamento colado ao longo da superfície lateral, gerando uma esteira menor.

Gilhaus (1981), ao estudar a influência do arredondamento das arestas frontais e a inclinação da superfície frontal na cabine de caminhões com reboque, obteve redução no coeficiente de arrasto total de $65 \%$ quando comparado com modelo simplificado proposto pelo pesquisador. Entretanto, ao comparar dois modelos por ele simulados: um deles com uma cabine inclinada com arestas arredondadas; e o outro apenas com as arestas arredondadas, observou que o modelo com inclinação apresentava maior arrasto em relação ao outro. Isso porque o escoamento jusante à cabine promovia um aumento do coeficiente de arrasto no reboque.

Experimentos conduzidos com duas configurações de ônibus: uma com arredondamento das arestas; e outra com a adição de uma curvatura em sua superfície frontal, resultaram em uma redução de $27 \%$, no coeficiente de arrasto da segunda em relação à primeira. Ainda para estes dados, considerando-se a correlação de Mcdonald e Palmer (1980), relativa à economia de combustível na redução de arrasto, obteve-se uma redução no consumo de 13,8\% para a velocidade de $90 \mathrm{~km} / \mathrm{h}$ (Fletcher e Stewart, 1986).

O tamanho do raio de curvatura apresenta influência substancial no coeficiente de arrasto de um ônibus, tanto assim que, segundo Hucho (1987), um raio de curvatura de $150 \mathrm{~mm}$ na superfície frontal desse veículo já é suficiente para reduzir significativamente seu coeficiente de arrasto. Na otimização da parte frontal de um ônibus, sua traseira é o principal fator que contribui com o arrasto aerodinâmico ao promover uma esteira turbulenta com grandes vórtices, os quais são gerados a partir da superfície superior, inferior e laterais do ônibus.

Outros fatores importantes a serem considerados, e que ainda não foram muito questionados, referem-se às alterações realizadas nas traseiras dos veículos comerciais e de passeio, as quais influenciam, consideravelmente, nas forças aerodinâmicas. Um dos pioneiros nas pesquisas sobre este assunto foi Ahmed (1981, 1983), ao estudar a influência da inclinação da superfície traseira sobre a variação do coeficiente de arrasto.

De acordo com Ahmed (1981) a estrutura da esteira que é formada na parte traseira dos veículos, depende do formato desta traseira, pois se verifica a existência de uma região de recirculação e a formação de um par de vórtices longitudinais, atrás do veículo, nos diferentes modelos testados. Em outra oportunidade, Ahmed (1983) 
analisou a influência da inclinação da superfície traseira sobre a esteira e também sobre o coeficiente de arrasto, verificando que em uma angulação de $15^{\circ}$ da superfície traseira forma-se uma região de recirculação na superfície traseira. Com angulação de $10^{\circ}$, o escoamento nessa superfície continuava colado, concluindo-se que o menor valor do arrasto era obtido com angulação de $12,5^{\circ}$.

Hucho et al. (1987), ao conduzir uma serie de experimentos com um modelo de ônibus de formas simplificadas em escala 1:10, observaram que a presença de uma superfície mais alongada na parte traseira resultava uma redução de arrasto, em relação ao modelo que não apresentava nenhuma alteração nas superfícies. No entanto, a alteração no formato da carroceria do ônibus ocasionava a redução do número de passageiros e também, com o aumento do comprimento do veículo, uma limitação na sua manobrabilidade.

Os dados de forças obtidos por White (2002), para uma forma idealizada de automóvel com superfície lisa e chanfro em sua parte traseira, mostram que o simples acréscimo de um ângulo de $25^{\circ}$ na parte traseira quadruplica a força aerodinâmica para baixo (“downforce”), gerando maior capacidade de tração nos pneus, mediante a duplicação do arrasto (FIGURA 2).

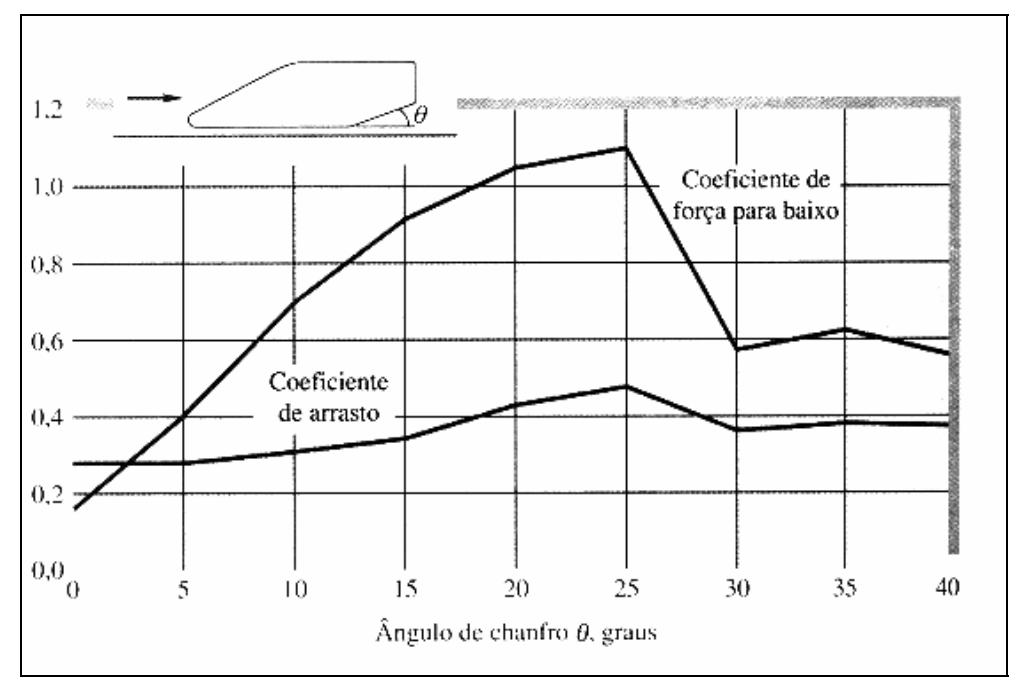

FIGURA 2 - Curva de Coeficiente de Arrasto e Sustentação para vários ângulos de chanfro (White, 2002). 


\subsection{Configurações para simulação de movimento do piso}

Desde os primeiros ensaios de modelos de automóveis em túneis de vento, discute-se a melhor forma para a simulação do efeito solo, pois a camada limite, produzida pelo piso da câmara de ensaio do túnel de vento, pode alterar o comportamento do fluxo na superfície inferior dos modelos a serem testados. Tais estudos foram realizados por alguns pesquisadores no intuito de avaliar a influência do efeito solo nas forças aerodinâmicas que o fluxo exerce sobre o modelo.

Pawlowski (1930) utilizou em seus ensaios o método da imagem refletida ("mirror image"), que consistia na fixação de dois modelos idênticos, dentro do túnel, cada um colocado com sua parte inferior voltada para o outro, evitando que forças próximas ao solo fossem geradas.

Para melhor simular o efeito solo, foi empregado um dispositivo na forma de esteira rotativa ("moving belt"). Lajos e Preszler (1986) utilizaram duas mesas automobilísticas: uma fixa e outra rotativa, verificando as seguintes situações: um significativo aumento de velocidade na superfície inferior do modelo e o posicionamento do ponto de estagnação na superfície traseira quando usava se a mesa rotativa, ao invés da mesa fixa.

Testes com mesa rotativa e fixa para várias escalas de modelos e diferentes vãos entre o solo e a superfície inferior do veículo ("ground clearance") foram conduzidos por Diuzet (1986) que verificou a necessidade de uma simulação correta do solo para estimar a diminuição da força de arrasto proporcionada pelas modificações na parte inferior do veículo. Mediante os resultados com o modelo em escala 1/20 o aumento do arrasto é de aproximadamente $6 \%$ entre a mesa fixa e rotativa; com a parte inferior do veículo lisa este valor depende da variação entre o vão livre do veículo e o piso, sendo de, aproximadamente de 8 a $15 \%$ para a mesa fixa e rotativa, respectivamente.

Utilizando a configuração de mesa rotativa foi verificado por Sardou (1986) que a simulação das rodas e componentes instalados na superfície inferior do veículo, apresentava uma influencia na redução do arrasto. Mediante aos resultados, os componentes dispostos na face (superfície) inferior do veículo representavam 15\% do arrasto total e o valor correspondente ao coeficiente de arrasto $(\mathrm{Cd})$ induzido, produzido pelas rodas, obteve redução de 0,04 para 0,022 . 
Dois métodos foram utilizados por Hucho (1987) para simulação do efeito solo: um deles consistia na redução da camada limite por sucção, mediante a utilização de dois túneis de vento, que proporcionaram redução de $60 \%$ na espessura da camada limite, para uma seção de ensaio vazia. O outro método fundamentava-se na reenergização da camada limite mediante a adição de um fluxo de ar, constatando-se que não houve variação das forças que atuam nos veículos tanto nos ensaios em túneis de vento quanto nos testes de campo.

\subsection{Influência de dispositivos no escoamento de ar ao redor de um veículo}

Estudos referentes aos dispositivos capazes de redirecionar o escoamento de ar sobre a carroceria de ônibus e caminhões, permitindo uma redução do arrasto aerodinâmico para esses veículos tem sido, realizados por Hucho et al. (1987), várias configurações de defletores de fluxo (“cab-spoiler") promoveram redução significativa no coeficiente de arrasto ao serem colocados sobre a cabine de caminhões. Também foram conduzidos vários experimentos, envolvendo dispositivos montados na parte frontal do reboque, no intuito de minimizar a formação de vórtices entre a cabine e o e reboque, reduzindo o arrasto total.

Garry e Stollery (1982) concluíram que para se adquirir maior eficácia na redução do arrasto com dispositivos, depende de muitos aspectos no formato dos veículos, principalmente no espaço entre a cabine e o reboque. No estudo que realizaram obtiveram eficiência maior ao utilizar ângulo de $0^{\circ}$ em relação aos ângulos de guinada, nas configurações com defletor de fluxo e com raios na parte frontal do reboque.

Garry (1981) conduziu experimentos com várias posições das aletas em forma de "U" ("vanes") na parte frontal do reboque, o efeito proporcionado pelas aletas apresentou redução de arrasto de $17 \%$ e 14\% para veículos de chassis rígido e articulado respectivamente, no ângulo de $0^{\circ}$. Analisando seus dados, concluiu que a eficiência das aletas diminui com o aumento do ângulo de guinada. Na FIGURA 3 pode se observar a estrutura de cada aleta em "U" utilizada neste trabalho. 


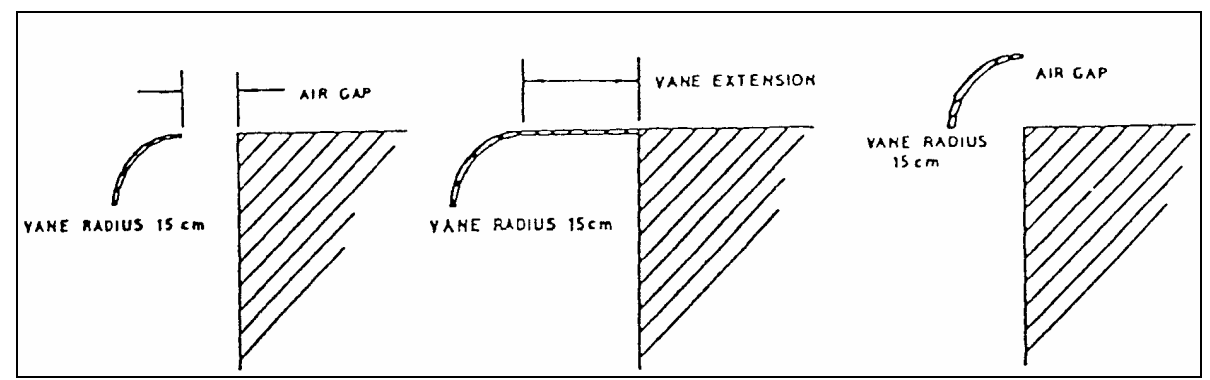

FIGURA 3 - Estrutura geométrica de cada aleta em forma de "U” (Garry, 1981).

Outro estudo referente à posição e ao formato das aletas curvas foi realizado por Marks e Buckley (1978). Primeiramente os ensaios foram realizados com as aletas instaladas na parte frontal da cabine do caminhão e, em seguida, montadas na superfície frontal do reboque, objetivando investigar a interação entre as aletas dos dois corpos. Assim, foi observada uma maior redução do coeficiente de arrasto para a combinação das aletas posicionadas na cabine e no teto do reboque; quando as aletas foram posicionadas em volta de toda a superfície frontal do reboque, ocorreu uma menor redução do arrasto.

Bearman (1965) verificou que a presença da placa plana ("splitter-plate") influência no comprimento da região de formação da esteira turbulenta, o qual está relacionado ao coeficiente de pressão na base (superfície traseira). O afastamento da região de formação da superfície traseira do modelo provocava um incremento no coeficiente de pressão na base, ocasionando a diminuição do coeficiente de arrasto.

Para o estudo de Wong, Cox e Rajan (1981), foram colocados placas planas, placas em forma de "U" e dutos de ar na cabine e na parte frontal do reboque. Assim, obtiveram redução de $30 \%$ do arrasto total em relação ao modelo sem estes componentes, observando-se a ocorrência de interatividade entre os dispositivos e não dos componentes simulados isoladamente.

Wood e Bauer (2003) procederam a trabalho com placas dispostas verticalmente na superfície frontal de um reboque, gerando vórtices e direcionando o fluxo para a traseira do reboque. A colocação de placas verticais objetivava gerar vórtices para minimizar o escoamento turbulento; os geradores de vórtices, posicionados de forma inclinada, na superfície lateral e superior do reboque, energizavam o escoamento através dos grandes vórtices originados pelos componentes. O direcionador de fluxo colocado na superfície inferior age como um duto convergente para acelerar o escoamento na traseira do reboque diminuindo a pressão de base. Mediante análise dos resultados 
obtidos observaram uma redução de arrasto em torno de $30 \%$, sendo que os três dispositivos eram operados em conjunto.

Para Hucho et al. (1987) que efetuou o estudo do arranjo de geradores de vórtices na redução da pressão de base na posição mediana à superfície traseira do modelo sem os dispositivos, proporcionando maior pressão. Ao adicionarem mecanismos geradores de vórtices, constatavam uma diminuição na pressão, demonstrando a influência dos vórtices na esteira, que ocasionava a redução do arrasto total do veículo.

Englar (2000) conduziu experimentos com um sistema pneumático de sopro situado na traseira e na parte frontal superior de um reboque (trailer) com o intuito de melhorar o desempenho, a economia e a segurança nos veículos comerciais e verificou que este sistema poderia adicionar uma variável na força de sustentação de veículo, aumentando ou diminuindo a resistência ao rolamento. $\mathrm{O}$ aumento da força acarretaria uma redução em torno de $30 \%$ da potencia do motor, requerida para impulsionar o veículo e conseqüentemente economia de combustível; o decréscimo da força propiciou ao veículo mais segurança nos requisitos e tração e frenagem (Figura 4).

Ainda para Englar (2000), a influência do arrasto, proveniente da separação do escoamento em torno do veículo é mais importante do que a força de sustentação, a força lateral, o momento de guinada e o momento de rolagem produzido pela incidência do escoamento no veículo. O sistema pneumático por ele empregado foi capaz de estabelecer o controle da separação do fluxo, reduzindo a pressão de base na superfície traseira, propiciando um decréscimo em torno de 50\% no arrasto para a configuração de um caminhão e um reboque (trailer). Para melhor visualização deste efeito na esteira, foi utilizada dinâmica de fluidos computacional com alterações nas equações que simulam o sistema pneumático (FIGURA 4). 


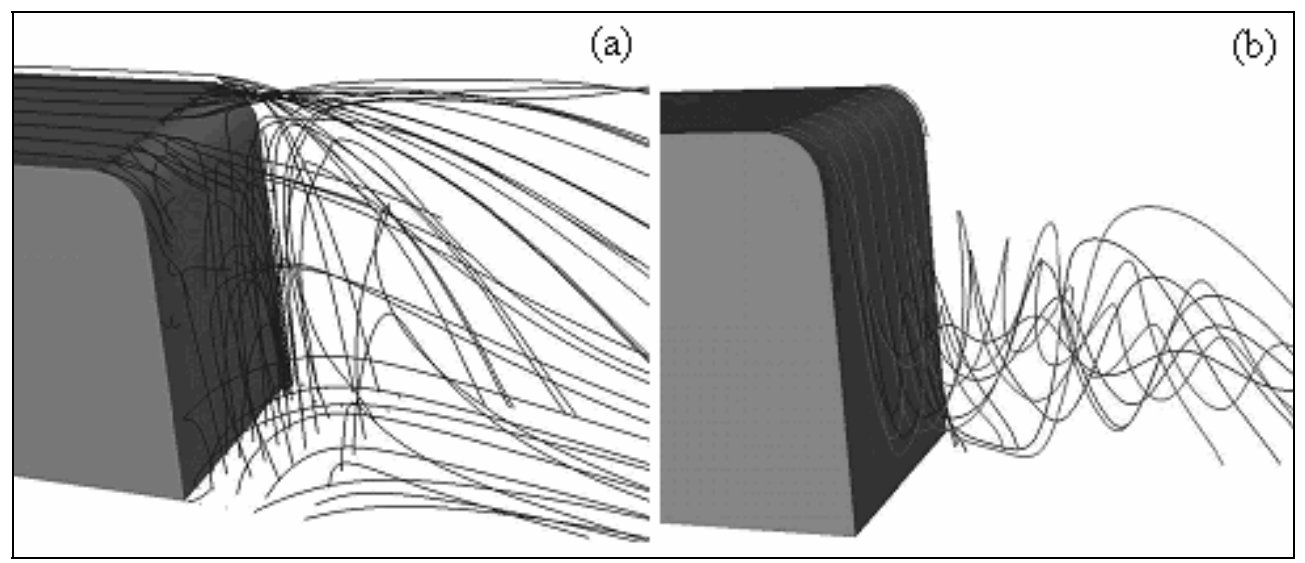

FIGURA 4 - Influência do sistema pneumático de sopro na esteira (Englar, 2000): (a) sistema desligado, grande região de escoamento separado; (b) sistema ligado, pequena região de escoamento separado.

\subsection{Aplicação da Dinâmica de Fluidos Computacional}

A indústria automobilística vem incorporando tecnologias digitais, para minimizar o tempo de desenvolvimento dos projetos. Uma destas ferramentas é a Dinâmica de Fluidos Computacional (Computational Fluid Dynamics). Esta ferramenta propicia aos engenheiros melhor entendimento do processo físico dos fluidos, aperfeiçoando a forma e o desempenho de carros, ônibus e caminhões. O cálculo das simulações dos escoamentos é obtido pelas equações de Navier-Stokes e ao acoplamento de modelos de turbulência a essas equações. Na seqüência serão citados alguns trabalhos que utilizaram esta ferramenta.

Han (1989) efetuou simulações com um modelo de veículo proposto por Ahmed, utilizando as equações de Reynolds averaged Navier-Stokes (RANS), juntamente com as equações do modelo de turbulência $\kappa-\varepsilon$ padrão e ao comparar-se os dados computacionais e experimentais observou a similaridade, em relação à região de formação de vórtices. Porém, a força de arrasto computacional de 0,33 em um ângulo de inclinação de $0^{\circ}$, era consideravelmente alta em relação ao valor experimental de 0,25. A diferença entre o coeficiente de arrasto experimental e o computacional deveu-se ao baixo valor da pressão de base, exigindo desenvolvimento maior no modelo de turbulência, o qual é fundamental para correta predição da pressão de base na simulação do escoamento. 
Roy e Srinivasan (2000), obtiveram resultados significativos com a simulação de duas configurações de caminhão, utilizando o modelo de turbulência $\kappa-\varepsilon$. Em uma delas se observava área crítica mais intensa de baixa e alta pressão, em decorrência de uma grande recirculação na traseira, na lateral, e a grande região de estagnação na parte frontal do caminhão. As modificações nas superfícies da outra configuração apresentaram diminuição nos valores das áreas críticas, ocasionando redução do arrasto. Ao avaliar os cálculos, constatou se estimativa em trono de $35 \%$ de economia de combustível para uma redução de $30 \%$ não arrasto.

Baysal e Bayraktar (2000), utilizaram equações de Reynolds averaged NavierStokes (RANS) e um modelo de turbulência Renormalization Group Theory (RNG) $\kappa-\varepsilon$, para a simulação do escoamento de ar ao redor de um caminhão tri-dimensional. As simulações foram constituídas por configurações, a presença e ausência de pneus, e em seguida com presença e ausência do solo. Analisando os resultados observou-se que a remoção dos pneus alterava drasticamente o escoamento entre o caminhão e o reboque, pois a esteira presente atrás do reboque tornava os vórtices simétricos em relação à configuração com pneus quanto o movimento do solo. $\mathrm{O}$ valor do arrasto com presença e ausência do pneu variou em torno de $6 \%$ e com a presença e a ausência do movimento do solo, em torno de $9 \%$.

Kim (2004), efetuou o estudo numérico das características da esteira de um ônibus utilizando um spoiler traseiro. A resolução numérica das equações de NavierStokes e do modelo de turbulência Renormalization Group Theory (RNG) $\kappa-\varepsilon$ foi realizada por um software comercial de volume finito. A análise dos resultados com a instalação do spoiler na parte superior indicou uma alteração na esteira do ônibus, ou seja, a presença do spoiler promove um deslocamento dos vórtices próximos à superfície traseira, à jusante da face posterior do ônibus. A instalação do spoiler acarretava uma redução do coeficiente de arrasto em $12 \%$, e o aumento da força de sustentação negativa oferecia uma maior estabilidade ao veículo em altas velocidades. Assim, para ônibus comerciais, dispositivos como spoiler traseiro seria uma forma de melhorar suas características aerodinâmicas, considerando seu formato de corpo rombudo. 


\subsection{Descrição do trabalho ora desenvolvido}

No presente trabalho, foi realizado um estudo experimental e computacional da distribuição de pressão, força de arrasto e força lateral, para diferentes direções do escoamento que incidia sobre a superfície de um modelo de ônibus em escala 1:17,5.

Os ensaios experimentais, com o modelo preconizado, foram conduzidos em um túnel de vento subsônico de seção aberta, e com uma configuração de mesa plana fixa. Para cada ângulo de guinada $(\beta)$ de -10 a $10^{\circ}$, as medidas das forças e dos momentos de guinada foram obtidos com o auxilio de uma balança aerodinâmica de dois componentes; para a obtenção das medidas de distribuição de pressão foi usada uma "scanivalve".

Para a melhor compreensão do escoamento, foram aplicadas técnicas de visualização, mediante a utilização de fios de lã ("tufts") e aplicação de um fluido viscoso na superfície do modelo. O emprego dos métodos de visualização possibilita a realização das seguintes análises: direção do escoamento, o descolamento da camada limite e a formação dos vórtices ao longo da superfície do modelo.

Para a simulação computacional foi utilizado um software comercial de Dinâmica de Fluidos Computacional. A resolução das equações matemáticas foi feita com o método de Reynolds averaged Naiver-Stokes (RANS) e o modelo de turbulência Renormalization Group Theory (RNG) $\kappa-\varepsilon$ integrados ao programa. Os resultados adquiridos das medidas de distribuição de pressão, das forças e dos momentos de guinada no modelo foram obtidos para cada ângulo de guinada $(\beta)$.

O trabalho foi realizado no Laboratório de Aerodinâmica (LAE), do Núcleo de Pesquisa em Aeronáutica (NPA), localizado na Escola de Engenharia de São Carlos (EESC). 


\section{APARATO E DESCRIÇÃO DOS EXPERIMENTOS}

Este capítulo contém a descrição dos procedimentos experimentais adotados, abrangendo: o projeto; a construção do modelo e a elaboração mesa automobilística; os equipamentos de aquisição e mensuração das forças, dos momentos e da distribuição de pressão; os métodos de visualização aplicados na superfície do modelo; a análise dos erros experimentais; o túnel aerodinâmico utilizado e o software comercial de dinâmica de fluidos computacional empregado para reproduzir o escoamento ao longo do modelo.

\subsection{Túnel de vento}

Foi utilizado um túnel de vento de circuito aberto. A seção de ensaio apresentou as dimensões de $500 \mathrm{~mm}$ x $500 \mathrm{~mm}$, com uma área de $0,25 \mathrm{~m}^{2}$. A máxima velocidade alcançada na seção de ensaio foi de aproximadamente, $16,7 \mathrm{~m} / \mathrm{s}$. Uma visão geral do equipamento é apresentada na FIGURA 5. As outras dimensões do túnel de vento estão registradas na TABELA 1.

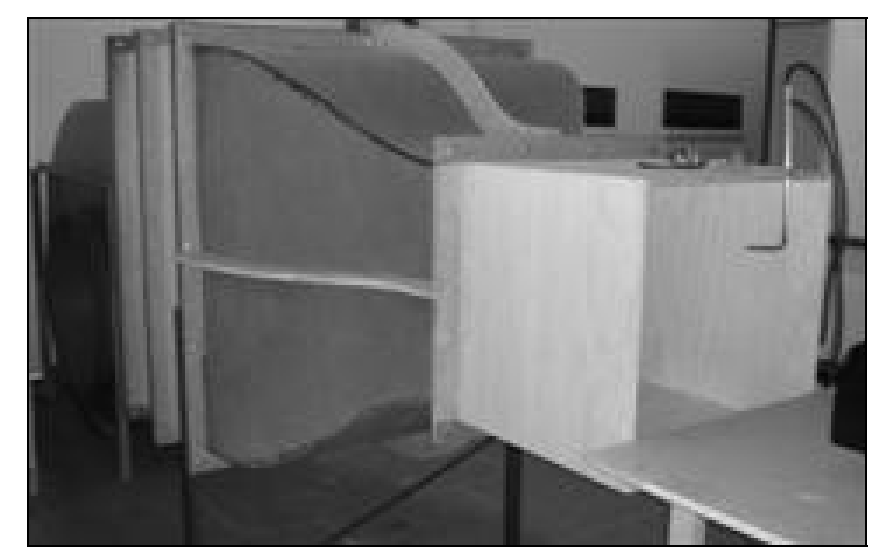

FIGURA 5 - Vista do túnel de vento subsônico tipo soprador. 


\begin{tabular}{|l|c|}
\hline \multicolumn{2}{|c|}{ Especificações do Túnel de Vento } \\
\hline Comprimento & $3,90(\mathrm{~m})$ \\
\hline Altura & $1,65(\mathrm{~m})$ \\
\hline Largura: $1,15 \mathrm{~m}$ & Largura: $1,15(\mathrm{~m})$ \\
\hline Tipo do Túnel de Vento & Soprador \\
\hline Potência do motor & $3,7(\mathrm{~kW})$ \\
\hline Controle de Velocidade & Inversor de freqüência \\
\hline Área da seção de ensaio & $0,25\left(\mathrm{~m}{ }^{2}\right)$ \\
\hline Velocidade máxima na seção de ensaio & $16,7(\mathrm{~m} / \mathrm{s})$ \\
\hline
\end{tabular}

TABELA 1 - Dimensões do túnel de vento.

No túnel de vento utilizado, o ar é soprado por um ventilador centrífugo, movido por motor elétrico de corrente alternada. $\mathrm{O}$ ar passa por um difusor no qual há uma série de telas de nylon com diferentes malhas. Neste momento, o ar sofre uma perda de pressão em decorrência das telas e do atrito com as paredes. A função das telas de nylon era diminuir as grandes perturbações (vórtices), proporcionando um escoamento mais uniforme e menos turbulento na saída do difusor. Após o difusor, o escoamento sofre uma aceleração, devido à presença de uma contração, na qual o escoamento sofre uma perda de pressão, isto é, converte-se em energia cinética (velocidade) que se dirige à seção de ensaio. A construção da estrutura (difusor e contração) do túnel aerodinâmico foi realizada nas dependências do Laboratório de Aerodinâmica (LAE), mediante as técnicas utilizadas por Catalano (1998).

\subsection{Projeto do modelo experimental do ônibus}

O experimento foi conduzido com um modelo confeccionado em madeira semelhante à carroceria de ônibus rodoviário. O modelo foi construído com uma razão de bloqueio de $13 \%$ da seção transversal da câmara de ensaio do túnel aerodinâmico. Para sua construção foi utilizada uma placa de madeira (MDF) de $15 \mathrm{~mm}$ de espessura; o espaço interno é vazado para permitindo a acomodação de tubos de plásticos na superfície do modelo e que foram utilizados para as tomadas de pressão; as arestas frontais e traseiras; e laterais foram arredondadas com 10 e $5 \mathrm{~mm}$, respectivamente. Após sua confecção, o modelo foi pintado externamente na cor preta, para melhor 
visualização do escoamento em sua superfície. Os procedimentos de construção foram os mesmos realizados por Câmara (1993) e Videira (2001).

As dimensões do modelo fabricado no Laboratório de Aerodinâmica (LAE) foram baseadas em um ônibus rodoviário de escala real. Na FIGURA 6 apresenta-se a planta do modelo e o modelo concluído. Na TABELA 2 estão exibidas as dimensões do modelo.

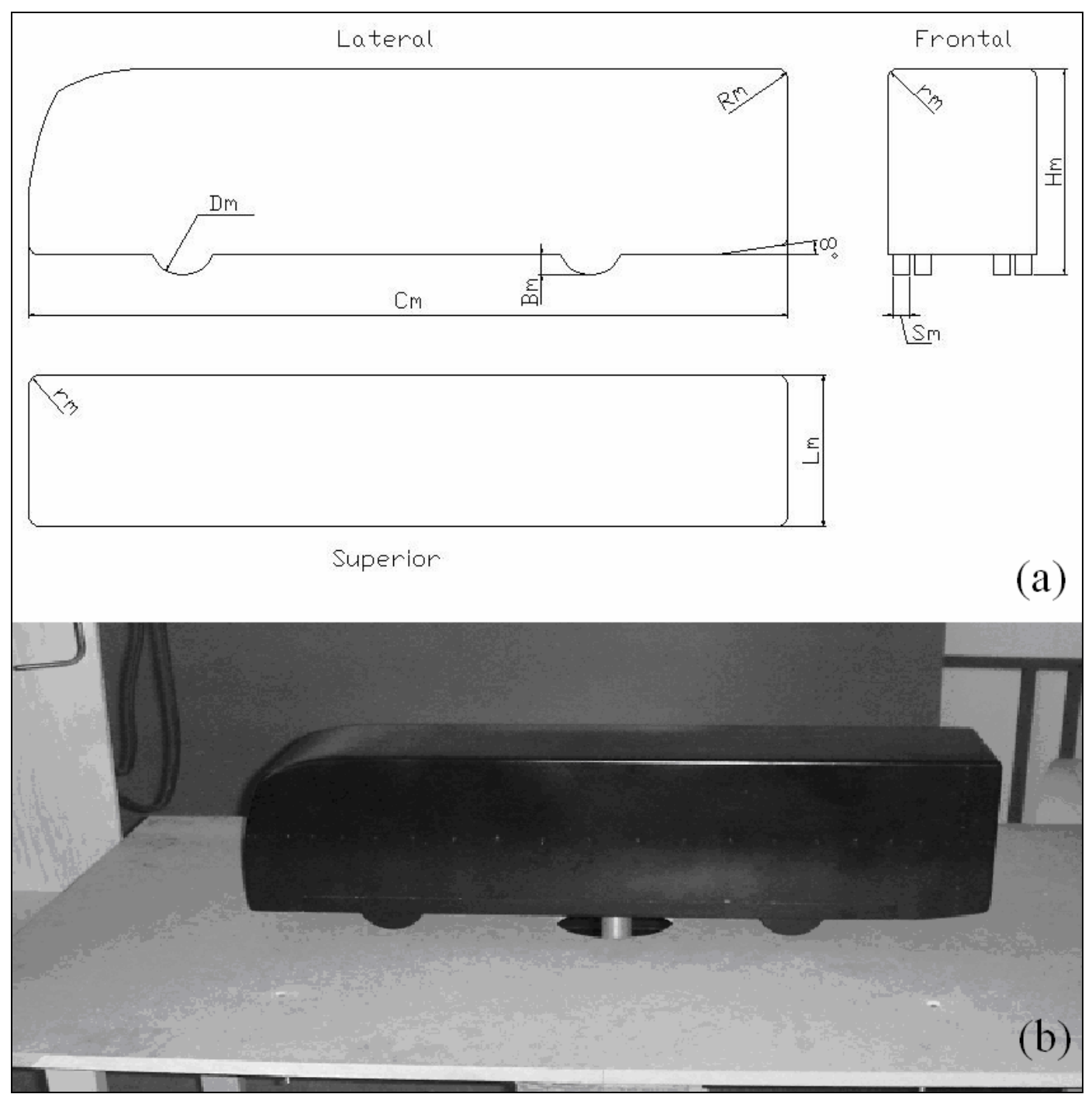

FIGURA 6 - Vista do modelo construído no LAE: (a) planta do modelo; (b) modelo concluído. 


\begin{tabular}{|l|c|}
\hline \multicolumn{2}{|c|}{ Dimensões do modelo em mm } \\
\hline Comprimento $(\mathrm{Cm})$ & $755(\mathrm{~mm})$ \\
\hline Altura $(\mathrm{Hm})$ & $208(\mathrm{~mm})$ \\
\hline Largura $(\mathrm{Lm})$ & $155(\mathrm{~mm})$ \\
\hline Vão do solo $(\mathrm{Bm})$ & $22(\mathrm{~mm})$ \\
\hline Espessura do pneu $(\mathrm{Sm})$ & $16(\mathrm{~mm})$ \\
\hline Diâmetro do pneu $($ Dm) & $65(\mathrm{~mm})$ \\
\hline Raio de arredondamento da aresta frontal e traseira $(\mathrm{Rm})$ & $10(\mathrm{~mm})$ \\
\hline Raio de arredondamento das arestas laterais $(\mathrm{rm})$ & $5(\mathrm{~mm})$ \\
\hline
\end{tabular}

TABELA 2 - Dimensões do modelo em escala 1:17,5.

\subsection{Configuração da mesa automobilística}

Para teste de um veículo, em túnel de vento, foi necessário reproduzir as condições reais de uma estrada. Todo o veículo se move através do ar parado. No entanto, não há formação de uma camada limite no solo. Ensaios aerodinâmicos em túnel de vento, necessitam da simulação da presença do solo de forma realística. Existem várias formas para simular o piso; algumas delas foram relatadas nos trabalhos descritos no capítulo 2 deste trabalho.

Os testes realizados no modelo em escala 1:17,5 foram conduzidos com uma configuração de piso plano fixo. A placa construída era fixada em uma armação de ferro e posicionada na frente da seção transversal do túnel de vento (soprador), a uma altura de $5 \mathrm{~cm}$ da parede inferior do túnel de vento, para que a camada limite da parede do túnel de vento não influenciasse na superfície da placa. Outra preocupação refere-se à distância entre a superfície inferior do modelo e a placa, evitando-se que a camada limite da mesa provocasse interferência no escoamento sobre a superfície inferior do modelo.

Para a realização do experimento foi calculada a espessura da camada limite $(\delta)$. Mediante a utilização da equação de Blasius, Anderson (2001), apresentada a seguir:

$$
\delta=\frac{5.0 * \mathrm{x}}{\sqrt{\operatorname{Re}_{\mathrm{x}}}}
$$


onde,

$\mathrm{Re}_{\mathrm{x}}$ : Número de Reynolds referente à distância x;

$\mathrm{x}$ : é a distancia do início da mesa até a parte frontal do modelo.

Obteve-se o valor de $\delta=2,53 \cdot 10^{-3} \mathrm{~m}$, como pode ser observado no Apêndice A. A altura do modelo, em relação ao solo (mesa automobilística) foi definida adicionando-se o valor da espessura da camada limite com o valor da distância do modelo em relação ao solo. Desta maneira, ao adicionarmos $\delta=2,53 \mathrm{~mm}$ na altura da superfície inferior do modelo com o solo de $22 \mathrm{~mm}$, obteve-se uma distância do vão igual a $24,53 \mathrm{~mm}$. No entanto, como a camada limite influenciaria no escoamento na parte inferior do modelo, devido a aproximação do modelo com a mesa e o objetivo era a obtenção de um escoamento mais uniforme, adotou-se um vão de $10 \mathrm{~mm}$ em relação aos pneus do modelo e a mesa automobilística.

\subsection{Monitoramento da pressão e velocidade}

Os testes foram conduzidos em um túnel aerodinâmico de seção aberta localizado no interior do Laboratório de Aerodinâmica (LAE), onde o escoamento apresentava variações, devido à recirculação do ar gerada dentro do recinto. $\mathrm{O}$ monitoramento da pressão e velocidade do escoamento era realizado a cada aquisição dos dados. Para o monitoramento da pressão dinâmica e da velocidade utilizou-se um micromanômetro digital, acoplado ao micromanômetro um tubo de "Pitot" estático convencional, o qual foi posicionado na parede superior da seção transversal do soprador a uma distância de aproximadamente $9 \mathrm{~cm}$.

Para a realização da leitura da pressão dinâmica e da velocidade do escoamento de ar era necessário inserir as condições de pressão e temperatura ambiente de cada experimento, no micromanômetro digital modelo 8705 DP-Calc de precisão $0,1(\mathrm{~Pa})$ para a pressão dinâmica e de $0,1(\mathrm{~m} / \mathrm{s})$ para a velocidade, como pode ser observado na FIGURA 7. Os valores das condições do ambiente eram extraídos de um Barômetro de Torricelli de precisão $1(\mathrm{~mm} \mathrm{Hg})$ para a pressão atmosférica e de $1\left({ }^{\circ} \mathrm{C}\right)$ para a temperatura ambiente localizado no interior do laboratório, como mostra a FIGURA 8. 


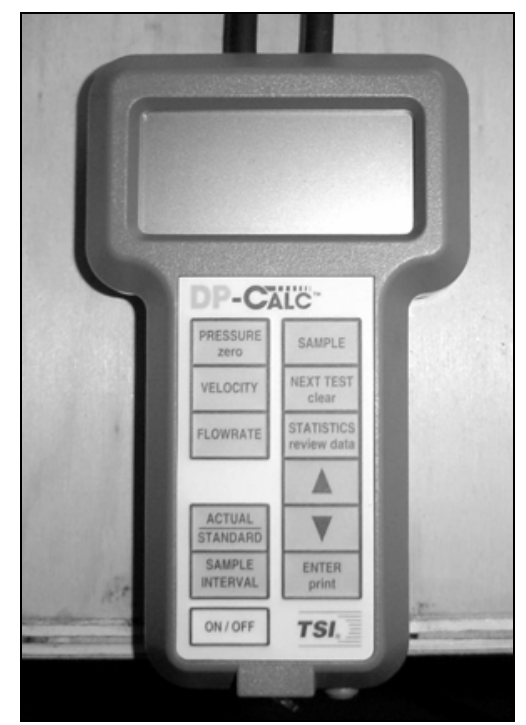

FIGURA 7 - Micromanômetro digital modelo 8705 DP-Calc usado nos experimentos.

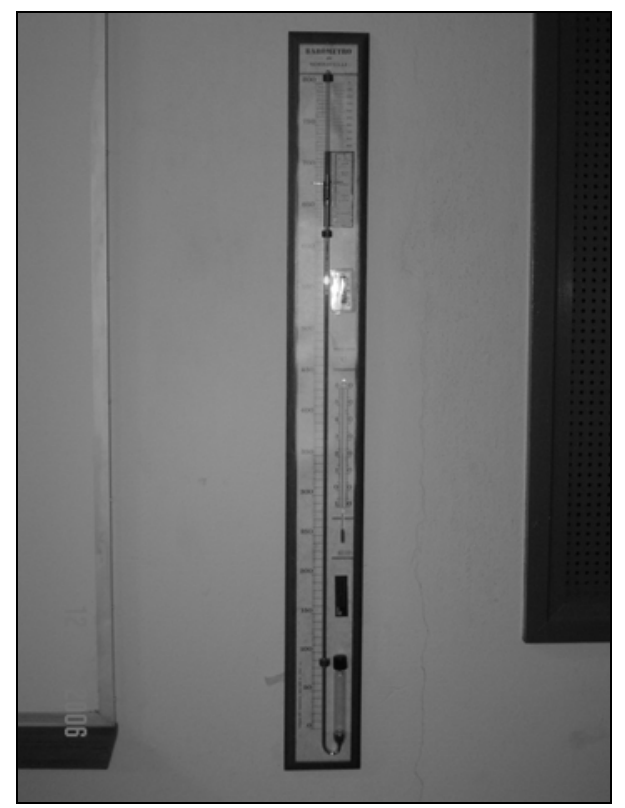

FIGURA 8 - Barômetro de Torricelli situado no LAE.

\subsection{Medição das forças e distribuição de pressão}

\subsubsection{Balança aerodinâmica}

Os veículos de passageiros e comerciais estão sujeitos a ação de forças e momentos, devido a condição do escoamento. Para um escoamento simétrico, ângulo de guinada $\beta=0$, a força de arrasto é acompanhada da força de sustentação e do momento de arfagem. No caso de um escoamento assimétrico, $\beta \neq 0$, ao redor de um veículo há 
adição de forças e momentos que correspondem aos momentos de rolamento, de guinada e da força lateral.

Um estudo adequado destas forças aerodinâmicas é realizado através da aplicação de coeficientes adimensionais, os quais possibilitam uma melhor análise. Os coeficientes adimensionais das forças e momentos aerodinâmicos estão definidos a seguir:

Coeficiente de Sustentação:

$$
C_{L}=\frac{L}{q_{\infty} A}
$$

Coeficiente de Arrasto:

$$
\mathrm{C}_{\mathrm{D}}=\frac{\mathrm{D}}{\mathrm{q}_{\infty} \mathrm{A}}
$$

Coeficiente de Momento de Arfagem: $\quad \mathrm{C}_{\mathrm{M}}=\frac{\mathrm{M}}{\mathrm{q}_{\infty} \mathrm{Al}}$

Coeficiente de Força Lateral:

$$
\mathrm{C}_{\mathrm{N}}=\frac{\mathrm{N}}{\mathrm{q}_{\infty} \mathrm{A}}
$$

Coeficiente de Momento de Rolamento: $\quad \mathrm{C}_{\mathrm{R}}=\frac{\mathrm{R}}{\mathrm{q}_{\infty} \mathrm{Al}}$

Coeficiente de Momento de Guinada:

$$
\mathrm{C}_{\mathrm{Y}}=\frac{\mathrm{Y}}{\mathrm{q}_{\infty} \mathrm{Al}}
$$

onde L, D, M, N, R e Y são as respectivas forças e momentos do veículo, A é a área frontal do veículo; $1 \mathrm{o}$ comprimento total do veículo e $\mathrm{q}_{\infty}$, a pressão dinâmica no escoamento livre, sendo:

$$
\mathrm{q}_{\infty}=\frac{1}{2} \rho_{\infty} \mathrm{V}_{\infty}^{2}
$$


Nos ensaios experimentais utilizou-se uma balança aerodinâmica com dois graus de liberdade projetada e construída por Maunsell (1977), a qual permanece no Laboratório de Aerodinâmica Experimental nas dependências da EESC - USP, pode-se ver na FIGURA 9 um esquema da balança aerodinâmica. O processo de medição das forças ocorre, mediante a presença de extensômetros ("strain gages”) fixados nas lâminas metálicas para que se possam medir as deformações originadas das forças aerodinâmicas, decorrentes do escoamento de ar incidente no modelo. Na vista lateral estão dispostos os extensômetros para medição da força lateral e na vista frontal para a força de arrasto.

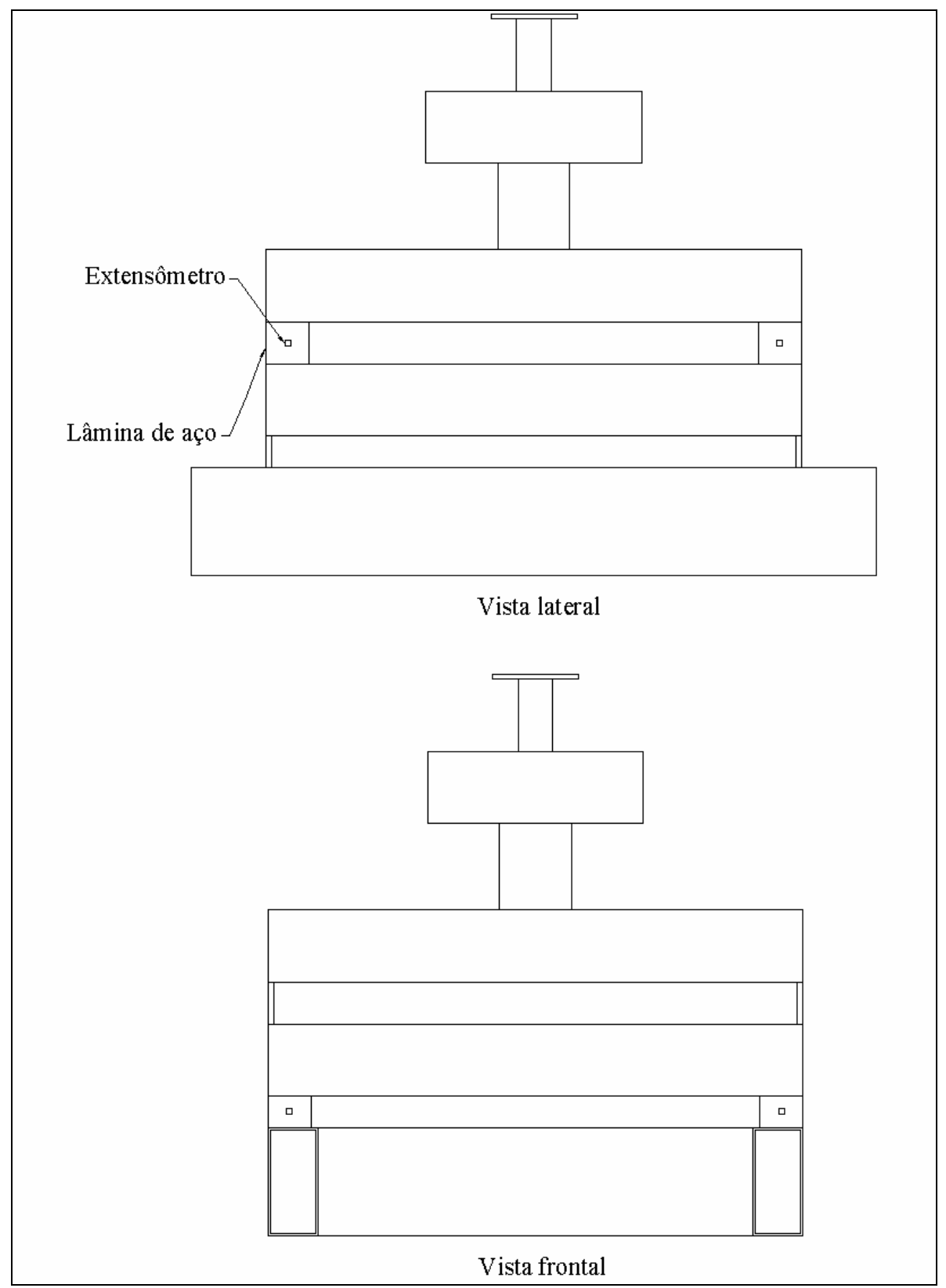

FIGURA 9 - Esquema da balança aerodinâmica. 
O funcionamento dos transdutores elétricos (extensômetros) está relacionado à deformação das lâminas metálicas, transformando-a em sinal elétrico. O circuito utilizado para detectar e converter esta deformação em sinal elétrico, na ordem de Volts; foi constituído de uma Ponte de "Wheatstone" completa para cada componente aerodinâmica medida na balança. O desenho esquemático de um circuito completo pode ser observado na FIGURA 10.

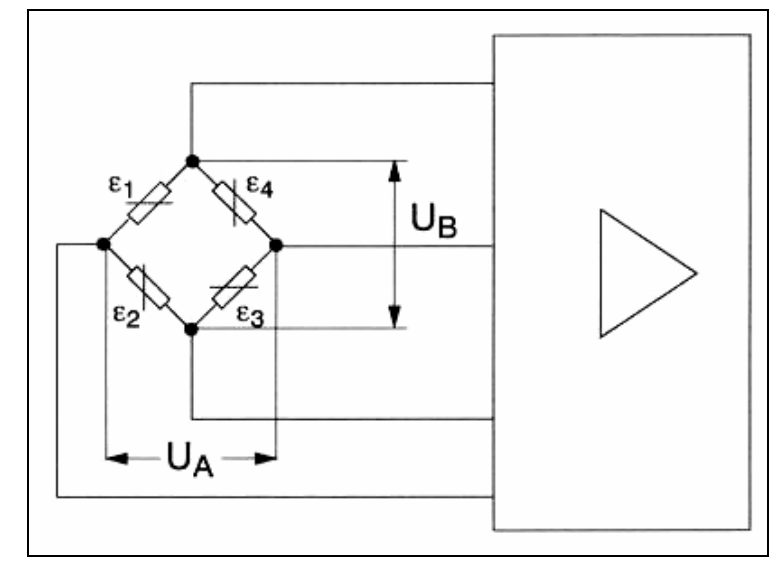

FIGURA 10 - Circuito de uma Ponte de "Wheatstone".

Inicialmente foi realizada uma calibração da balança aerodinâmica para as componentes das forças de arrasto e força lateral utilizando o mesmo procedimento de sistema de roldanas de Mello (1999) e Ceron-Muñoz (2004). A calibração era feita da seguinte maneira: uma extremidade de um fio de aço era conectada na flange presa ao modelo e a balança, e através de um suporte com roldana prendia-se a outra extremidade do fio em um prato de balança. Para a simulação das forças de arrasto e lateral foi adicionado progressivamente cargas e com o respectivo sinal elétrico produzido por cada massa era amplificado, por um condicionador amplificador de sinal Hottinger Baldwin Messtechnik (HBM) modelo MGCPlus e lido simultaneamente por uma placa de aquisição de dados, National Instruments modelo PCI-6036E, sendo registrado em um microcomputador.

Na calibração da balança para as duas componentes de força aerodinâmica não houve descarregamento das massas com intuito de averiguar a presença de histerese presente no sistema de medição; notou-se também uma pequena interferência nos sinais das tensões das forças de arrasto e força lateral indicando que a um acoplamento entres os sinais destas componentes. No Apêndice B estão registradas as curvas de calibração 
para as forças de arrasto e lateral, e os valores dos sinais correspondentes para cada variação de carga.

\subsubsection{Distribuição de pressão nas superfícies do modelo}

Para as medidas de pressão foram utilizados 92 orifícios os quais estavam distribuídos ao longo de cada superfície de testes. As tomadas de pressão compreendiam tubos de plástico de $1 \mathrm{~mm}$ de diâmetro interno, posicionados perpendicularmente às superfícies e estes estavam conectados a duas válvulas comutadoras de pressão tipo "scanivalve" modelo $\mathrm{D}$, com 48 tomadas de pressão cada e transdutores de pressão modelo PDCR23D. A aquisição de dados é feita com o auxílio de controladores de solenóide, decodificadores de sinal modelo SCSG2/ $\pm 5 \mathrm{~V} / \mathrm{VG}$ ligados as "scanivalves" e um microcomputador. As medições da pressão estática, total e das tomadas de pressão na superfície do modelo foram obtidas em Volts, ocasionando o cálculo do coeficiente de pressão (Cp) para cada tomada de pressão em um valor adimensional. A instrumentação do experimento é mostrada na FIGURA 11. Na FIGURA 12 são mostradas as posições das tomadas de pressão em cada superfície do modelo.
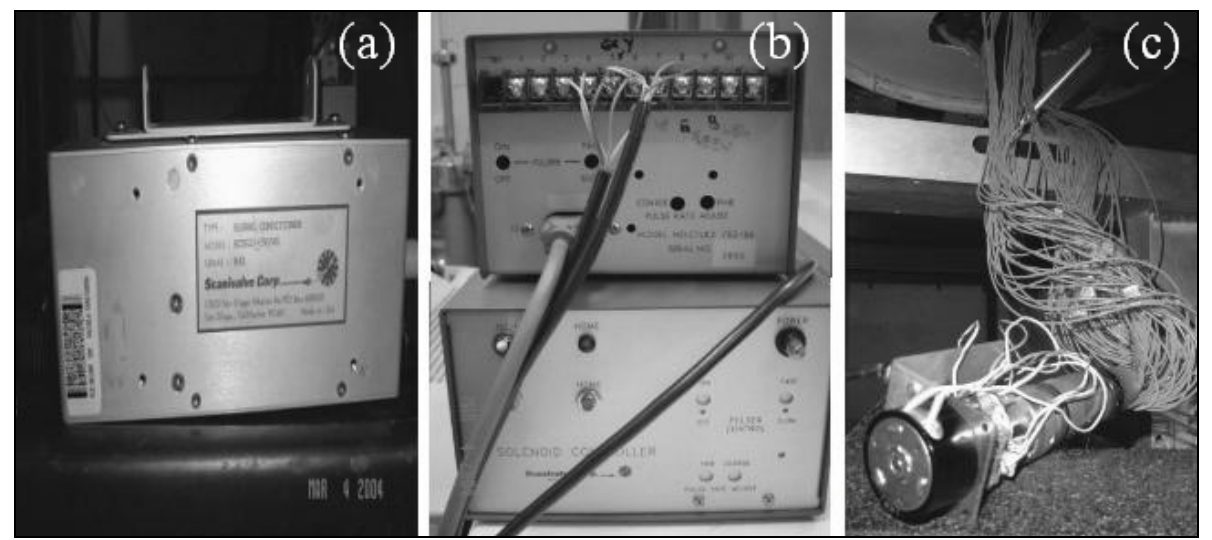

FIGURA 11 - Instrumentos de medição de pressão: (a) decodificador de sinal; (b) controlador de solenóide; (c) válvula comutadora de pressão tipo "scanivalve". 


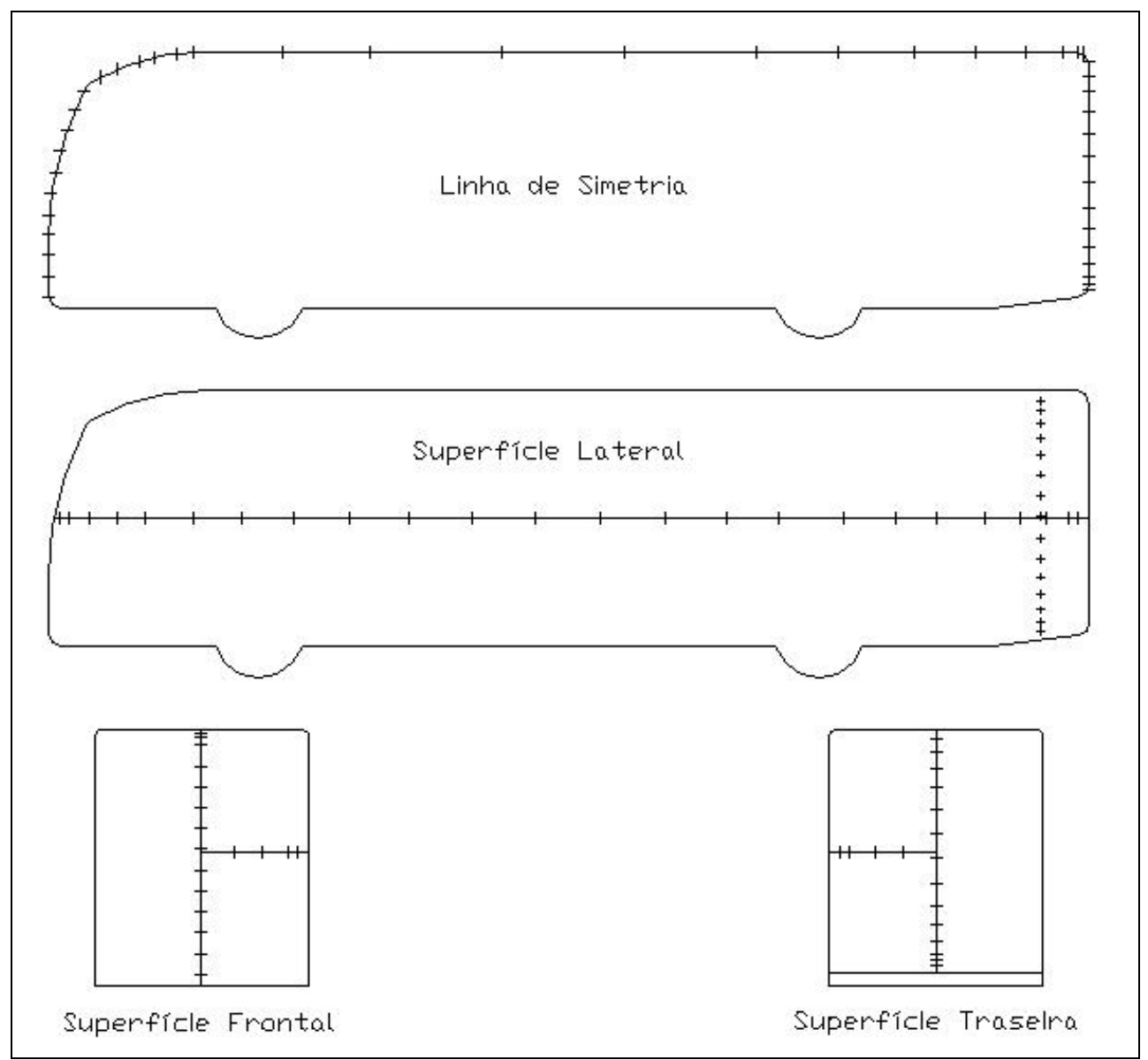

FIGURA 12 - Posição das tomadas de pressão em cada superfície.

\subsection{Ensaios de visualização}

O objetivo dos ensaios de visualização era de mostrar o comportamento do escoamento sobre a superfície do modelo. Neste trabalho foram aplicadas duas técnicas descritas por Pope (1999), para visualização do ponto de estagnação frontal, decorrente da grande área de bloqueio do modelo e a formação dos vórtices, devido ao descolamento da camada limite nas superfícies laterais, no teto e na traseira.

Para a primeira técnica de visualização foram usados pequenos fios de lã ("tufts") adesivados a todas as superfícies do modelo. Os testes foram desenvolvidos com a variação do ângulo de guinada $\beta$ igual a $-10^{\circ},-6^{\circ}, 0^{\circ}, 6^{\circ}$ e $10^{\circ}$, revelando as alterações do escoamento nas superfícies do veículo. Na FIGURA 13 está indicado o posicionamento dos fios de lã (tufts) no modelo. 


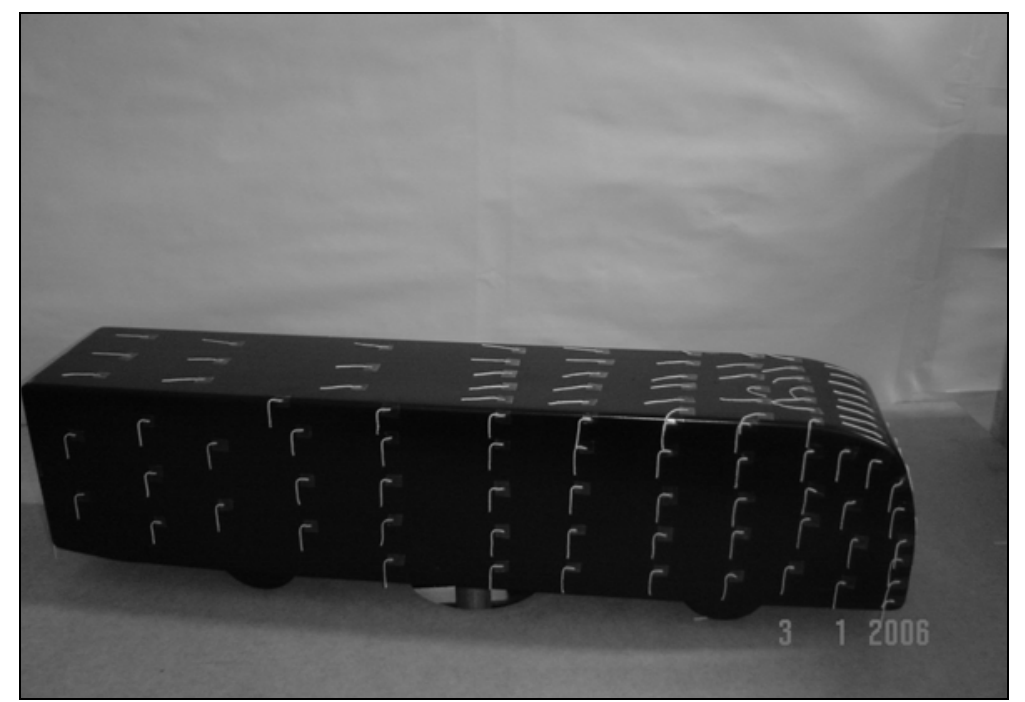

FIGURA 13 - Disposição dos fios de lã (“tufts”) na superfície do modelo.

Outra forma de visualização seria através de um composto líquido de óleo e dióxido de titânio $\left(\mathrm{TiO}_{2}\right)$, aplicado sobre a superfície do modelo como está registrado na FIGURA 14. O ensaio foi realizado com valores de ângulos $0^{\circ}, 4^{\circ}$ e $8^{\circ}$. Para os dois tipos de visualização a velocidade utilizada para os ensaios foi à máxima desenvolvida pelo soprador que corresponde entre 16,4 a $16,7 \mathrm{~m} / \mathrm{s}$ e os ângulos de ensaio foram escolhidos aleatoriamente.

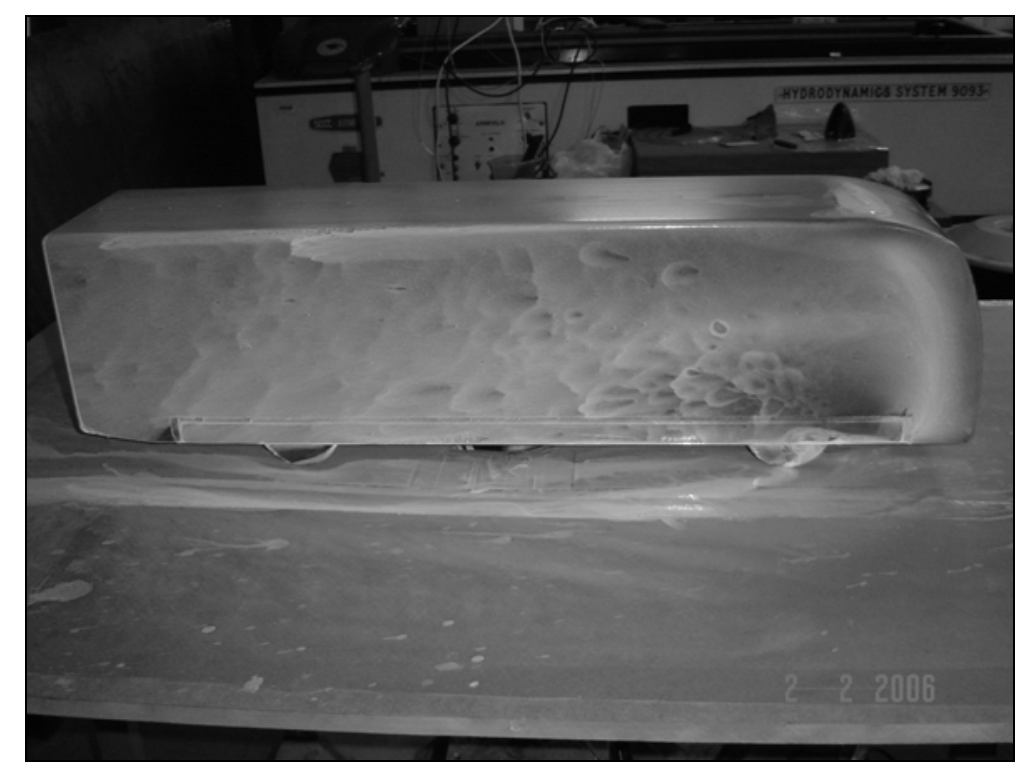

FIGURA 14 - Aplicação do composto de dióxido de titânio na superfície do modelo. 


\subsection{Simulação Numérica}

A simulação numérica foi realizada utilizando-se um programa comercial de Dinâmica dos Fluidos Computacional e um gerador de malha. Para a solução do problema foram executadas algumas operações: Inicialmente foi criado um modelo em um programa de CAD e este foi exportado, em extensão IGES, para o programa comercial ANSYS ${ }^{T M}$ ICEM $^{T M}$, em seguida foi criado um domínio com $2900 \mathrm{~mm}$ de comprimento, $1650 \mathrm{~mm}$ de largura e $1100 \mathrm{~mm}$ de altura, e gerado uma malha volumétrica computacional, com elementos tetraédricos, conforme imagem da . Na seqüência, foram especificadas as condições de contorno do domínio no programa comercial ANSYS ${ }^{T M}$ CFX $^{T M}$ CFD para reproduzir as condições do escoamento de ar nos ensaios experimentais.

Abaixo consta um extrato do arquivo do programa comercial com as configurações referente às propriedades o fluido, as condições de contorno, os métodos de resolução das equações, o modelo de turbulência e o período de processamento impostas no domínio computacional. A posição das paredes e do modelo são mostradas na FIGURA 15.

MATERIAL: Air at 25 C

Material Description $=$ Air at $25 \mathrm{C}$ and 1 atm (dry)

Material Group $=$ Air Data, Constant Property Gases

Option $=$ Pure Substance

Thermodynamic State $=$ Gas

PROPERTIES:

Option $=$ General Material

Thermal Expansivity $=0.003356\left[\mathrm{~K}^{\wedge}-1\right]$

ABSORPTION COEFFICIENT:

Absorption Coefficient $=0.01\left[\mathrm{~m}^{\wedge}-1\right]$

Option $=$ Value

DYNAMIC VISCOSITY:

Dynamic Viscosity $=1.831 \mathrm{E}-05\left[\mathrm{~kg} \mathrm{~m}^{\wedge}-1 \mathrm{~s}^{\wedge}-1\right]$

Option $=$ Value

EQUATION OF STATE: 
Density $=1.185\left[\mathrm{~kg} \mathrm{~m}^{\wedge}-3\right]$

Molar Mass $=28.96\left[\mathrm{~kg} \mathrm{kmol}^{\wedge}-1\right]$

Option $=$ Value

REFRACTIVE INDEX:

Option $=$ Value

Refractive Index $=1.0\left[\mathrm{~m} \mathrm{~m}^{\wedge}-1\right]$

SCATTERING COEFFICIENT:

Option $=$ Value

Scattering Coefficient $=0.0\left[\mathrm{~m}^{\wedge}-1\right]$

SPECIFIC HEAT CAPACITY:

Option $=$ Value

Reference Pressure $=1[\mathrm{~atm}]$

Reference Specific Enthalpy $=0 .[\mathrm{J} / \mathrm{kg}]$

Reference Specific Entropy $=0 .[\mathrm{J} / \mathrm{kg} / \mathrm{K}]$

Reference Temperature $=25[\mathrm{C}]$

Specific Heat Capacity $=1.0044 \mathrm{E}+03\left[\mathrm{~J} \mathrm{~kg}^{\wedge}-1 \mathrm{~K}^{\wedge}-1\right]$

Specific Heat Type $=$ Constant Pressure

THERMAL CONDUCTIVITY:

Option $=$ Value

Thermal Conductivity $=2.61 \mathrm{E}-02\left[\mathrm{~W} \mathrm{~m}^{\wedge}-1 \mathrm{~K}^{\wedge}-1\right]$

EXECUTION CONTROL:

PARTITIONER STEP CONTROL:

Multidomain Option $=$ Independent Partitioning

Runtime Priority $=$ Standard

MEMORY CONTROL:

Memory Allocation Factor $=1.0$

PARTITIONING TYPE:

MeTiS Type $=$ k-way

Option $=$ MeTiS

Partition Size Rule $=$ Automatic

RUN DEFINITION:

Interpolate Initial Values $=$ Off

Run Mode $=$ Full

SOLVER STEP CONTROL: 
Runtime Priority $=$ Standard

EXECUTABLE SELECTION:

Double Precision $=$ Off

MEMORY CONTROL:

Memory Allocation Factor $=1.0$

PARALLEL ENVIRONMENT:

Number of Processes $=1$

Start Method $=$ Serial

FLOW:

DOMAIN: Dominio

Coord Frame $=$ Coord 0

Domain Type $=$ Fluid

Fluids List $=$ Air at $25 \mathrm{C}$

Location $=\mathrm{BODY}$

BOUNDARY: entrada

Boundary Type $=$ INLET

Location $=$ INLET

BOUNDARY CONDITIONS:

FLOW REGIME:

Option $=$ Subsonic

MASS AND MOMENTUM:

Normal Speed $=16\left[\mathrm{~m} \mathrm{~s}^{\wedge}-1\right]$

Option $=$ Normal Speed

TURBULENCE:

Option $=$ Medium Intensity and Eddy Viscosity Ratio

BOUNDARY: saida

Boundary Type $=$ OPENING

Location $=$ OUTLET

BOUNDARY CONDITIONS:

FLOW DIRECTION:

Option $=$ Normal to Boundary Condition

FLOW REGIME: 


\section{Option $=$ Subsonic \\ MASS AND MOMENTUM:}

Option $=$ Opening Pressure and Direction

Relative Pressure $=0$ [atm $]$

TURBULENCE:

Option $=$ Medium Intensity and Eddy Viscosity Ratio

BOUNDARY: lateral

Boundary Type $=$ OPENING

Location $=$ SIDE WALL A,SIDE WALL B BOUNDARY CONDITIONS:

FLOW REGIME:

Option $=$ Subsonic

MASS AND MOMENTUM:

Option $=$ Static Pressure for Entrainment

Relative Pressure $=0$ [atm]

TURBULENCE:

Option $=$ Zero Gradient

BOUNDARY: superior

Boundary Type $=$ OPENING

Location $=$ UPPER WALL

BOUNDARY CONDITIONS:

FLOW REGIME:

Option $=$ Subsonic

END

MASS AND MOMENTUM:

Option $=$ Static Pressure for Entrainment

Relative Pressure $=0$ [atm]

TURBULENCE:

Option $=$ Zero Gradient

BOUNDARY: inferior

Boundary Type $=$ WALL 
Location $=$ DOWN WALL

BOUNDARY CONDITIONS:

WALL INFLUENCE ON FLOW:

Option $=$ No Slip

WALL ROUGHNESS:

Option $=$ Smooth Wall

BOUNDARY: Modelo

Boundary Type $=$ WALL

Location $=$ MODEL

BOUNDARY CONDITIONS:

WALL INFLUENCE ON FLOW:

Option $=$ No Slip

WALL ROUGHNESS:

Option $=$ Smooth Wall

DOMAIN MODELS:

BUOYANCY MODEL:

Option $=$ Non Buoyant

DOMAIN MOTION:

Option $=$ Stationary

MESH DEFORMATION:

Option $=$ None

REFERENCE PRESSURE:

Reference Pressure $=1$ [atm]

FLUID MODELS:

COMBUSTION MODEL:

Option $=$ None

HEAT TRANSFER MODEL:

Fluid Temperature $=300[\mathrm{~K}]$

Option $=$ Isothermal

THERMAL RADIATION MODEL:

Option $=$ None

TURBULENCE MODEL: 
$\mathrm{C}_{\mu \mathrm{RNG}}$ Coefficient $=0.085$

Option $=$ RNG k epsilon

RNG EPSILON COEFFICIENTS:

$\beta$ Coefficient $=0.012$

$\mathrm{C}_{\varepsilon 1 \mathrm{RNG}}$ Coefficient $=1.42$

$\mathrm{C}_{\varepsilon 2 \mathrm{RNG}}$ Coefficient $=1.68$

$\eta$ Coefficient $=4.38$

TURBULENT WALL FUNCTIONS:

Option $=$ Scalable

INITIALISATION:

Option $=$ Automatic

INITIAL CONDITIONS:

Velocity Type $=$ Cartesian

CARTESIAN VELOCITY COMPONENTS:

Option $=$ Automatic with Value

$\mathrm{U}=16\left[\mathrm{~m} \mathrm{~s}^{\wedge}-1\right]$

$\mathrm{V}=0\left[\mathrm{~m} \mathrm{~s}^{\wedge}-1\right]$

$\mathrm{W}=0\left[\mathrm{~m} \mathrm{~s}^{\wedge}-1\right]$

EPSILON:

Option $=$ Automatic

$\mathrm{K}$ :

Option $=$ Automatic

STATIC PRESSURE:

Option $=$ Automatic with Value

Relative Pressure $=0$ [atm]

OUTPUT CONTROL:

RESULTS:

File Compression Level $=$ Default

Option $=$ Standard

TRANSIENT RESULTS: Transient Results 1

File Compression Level $=$ Default

Include Mesh $=$ No

Option $=$ Selected Variables 
Output Variables List $=$ Pressure, Velocity, Vorticity

Time Interval $=0.001[\mathrm{~s}]$

SIMULATION TYPE:

Option $=$ Transient

INITIAL TIME:

Option $=$ Automatic with Value

Time $=0[\mathrm{~s}]$

TIME DURATION:

Option $=$ Total Time

Total Time $=0.3[\mathrm{~s}]$

TIME STEPS:

Option $=$ Timesteps

Timesteps $=0.001[\mathrm{~s}]$

SOLUTION UNITS:

Angle Units $=[\mathrm{rad}]$

Length Units $=[\mathrm{m}]$

Mass Units $=[\mathrm{kg}]$

Solid Angle Units $=[\mathrm{sr}]$

Temperature Units $=[\mathrm{K}]$

Time Units $=[\mathrm{s}]$

SOLVER CONTROL:

ADVECTION SCHEME:

Option $=$ High Resolution

CONVERGENCE CONTROL:

Maximum Number of Coefficient Loops $=15$

Timescale Control $=$ Coefficient Loops

CONVERGENCE CRITERIA:

Residual Target $=1$.E-4

Residual Type $=$ RMS

EQUATION CLASS: continuity

ADVECTION SCHEME:

Option $=$ High Resolution

TRANSIENT SCHEME:

Option $=$ First Order Backward Euler 
EQUATION CLASS: ed

ADVECTION SCHEME:

Option $=$ Upwind

TRANSIENT SCHEME:

Option $=$ First Order Backward Euler

EQUATION CLASS: ke

ADVECTION SCHEME:

Option $=$ Upwind

TRANSIENT SCHEME:

Option $=$ First Order Backward Euler

EQUATION CLASS: momentum

ADVECTION SCHEME:

Option $=$ High Resolution

TRANSIENT SCHEME:

Option $=$ First Order Backward Euler TRANSIENT SCHEME:

Option $=$ First Order Backward Euler 


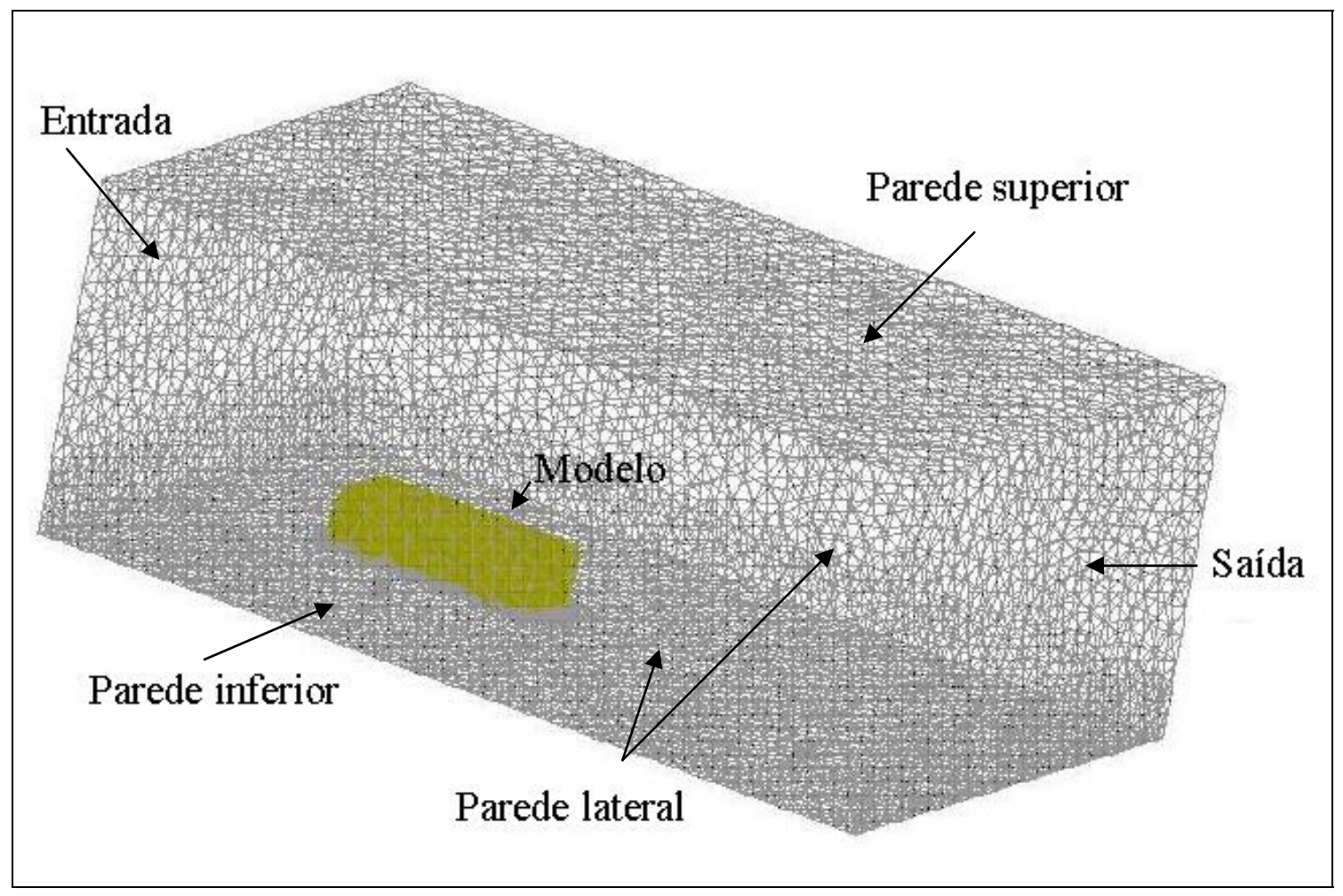

FIGURA 15 - Domínio computacional com a respectiva malha tetraédrica e sua dimensão: 2900 x 1650 x 1100 (mm).

\subsubsection{Equacionamento matemático da simulação numérica}

A solução numérica foi realizada através do método de Reynolds averaged Navier-Stokes (RANS) acoplado a um modelo de turbulência. As equações de continuidade e momento foram discretizadas pelo método High-resolution que reduzia a descontinuidade das oscilações numéricas na solução das equações (Anderson, 1995). As equações de dissipação e energia cinética turbulenta foram discretizadas pelo método Upwind. O emprego deste esquema introduz uma forte difusão numérica na solução. Essa difusão numérica evitava o aparecimento de soluções numéricas oscilatórias, dispersivas, ao suavizar a solução mediante redução dos gradientes (Fortuna, 2000).

As equações de transporte aplicadas eram derivadas das equações de RANS. As equações de continuidade e momento foram escritas na forma de coordenadas cartesianas, como segue.

Equação da Continuidade: 


$$
\frac{\partial \rho}{\partial \mathrm{t}}+\nabla *(\rho \overline{\mathrm{V}})=0
$$

Equação de Momento:

$$
\frac{\partial(\rho \overline{\mathrm{V}})}{\partial \mathrm{t}}+\nabla *(\rho \overline{\mathrm{V}} \otimes \overline{\mathrm{V}})=\nabla *(\tau-\rho \overline{\mathrm{v} \otimes v})+S_{M}
$$

onde $\rho$ é a densidade do ar, $\overline{\mathrm{V}}$ é a componente média do vetor velocidade, $v$ é a componente do vetor velocidade variando no tempo, $\rho \overline{v \otimes v}$ é o tensor da tensões de Reynolds, $\tau$ é o tensor de tensões, $S_{M}$ é o momento de origem e $\otimes$ é o produto tensor, definido como

$$
\mathrm{U} \otimes \mathrm{V}=\left[\begin{array}{ccc}
\mathrm{U}_{\mathrm{x}} \mathrm{V}_{\mathrm{x}} & \mathrm{U}_{\mathrm{x}} \mathrm{V}_{\mathrm{y}} & \mathrm{U}_{\mathrm{x}} \mathrm{V}_{\mathrm{z}} \\
\mathrm{U}_{\mathrm{y}} \mathrm{V}_{\mathrm{x}} & \mathrm{U}_{\mathrm{y}} \mathrm{V}_{\mathrm{y}} & \mathrm{U}_{\mathrm{y}} \mathrm{V}_{\mathrm{z}} \\
\mathrm{U}_{\mathrm{z}} \mathrm{V}_{\mathrm{x}} & \mathrm{U}_{\mathrm{z}} \mathrm{V}_{\mathrm{y}} & \mathrm{U}_{\mathrm{z}} \mathrm{V}_{\mathrm{z}}
\end{array}\right]
$$

O modelo a ser adotado para a simulação do escoamento turbulento foi baseado em um modelo de duas equações. O modelo RNG $\kappa-\varepsilon$ é uma variante do modelo $\kappa-\varepsilon$, sendo derivada a partir da Teoria do Grupo de Renormalização, que deve-se ao fato de que constantes e funções surgem no modelo de forma teórica, e não de forma empírica como é o caso do modelo $\kappa-\varepsilon$ tradicional. O modelo RNG $\kappa-\varepsilon$ oferece um espectro de aplicação maior, fornecendo previsões mais precisas do que o modelo $\kappa-\varepsilon$, em situações de escoamento incluindo separação, linhas de correntes curvas e regiões de estagnação (Deschamps, 2000).

A implementação do modelo de turbulência RNG $\kappa-\varepsilon$ promovia a adição de duas variáveis nas equações de continuidade e momento. A equação da continuidade não sofria alterações, mas a equação de momento tornava-se.

$$
\frac{\partial(\rho \overline{\mathrm{V}})}{\partial \mathrm{t}}+\nabla^{*}(\rho \overline{\mathrm{V}} \otimes \overline{\mathrm{V}})-\nabla *\left(\mu_{\mathrm{eff}} \nabla \overline{\mathrm{V}}\right)=\nabla \mathrm{p}^{\prime}+\nabla *\left(\mu_{\mathrm{eff}} \nabla \overline{\mathrm{V}}\right)^{\mathrm{T}}
$$

onde $\mu_{\text {eff }}$ é a viscosidade efetiva, $\mu+\mu_{t}$, e p' é a pressão modificada, dada por 
$\mathrm{p}^{\prime}=\mathrm{p}+\frac{2}{3} \rho \kappa$

A equação das variáveis do modelo RNG $\kappa-\varepsilon$ foram as mesmas para o modelo $\kappa$ $\varepsilon$. As equações de governo para a energia cinética turbulenta e para dissipação eram como seguem.

Equação da energia cinética turbulenta:

$$
\frac{\partial(\rho \kappa)}{\partial \mathrm{t}}+\nabla *(\rho \overline{\mathrm{V}} \kappa)=\nabla\left[\left(\mu+\frac{\mu_{\mathrm{t}}}{\sigma_{\kappa_{\mathrm{RNG}}}}\right) \nabla \kappa\right]+\mathrm{P}_{\kappa}-\rho \varepsilon
$$

Equação da dissipação:

$$
\frac{\partial(\rho \varepsilon)}{\partial \mathrm{t}}+\nabla *(\rho \overline{\mathrm{V}} \varepsilon)=\nabla\left[\left(\mu+\frac{\mu_{\mathrm{t}}}{\sigma_{\varepsilon_{\mathrm{RNG}}}}\right) \nabla \varepsilon\right]+\frac{\varepsilon}{\kappa}\left(\mathrm{C}_{\varepsilon 1_{\mathrm{RNG}}} \mathrm{P}_{\kappa}-\mathrm{C}_{\varepsilon 2_{\mathrm{RNG}}} \rho \varepsilon\right)
$$

onde $\mathrm{C}_{\varepsilon 1_{\mathrm{RNG}}}, \mathrm{C}_{\varepsilon 2_{\mathrm{RNG}}}, \sigma_{\kappa_{\mathrm{RNG}}}$ e $\sigma_{\varepsilon_{\mathrm{RNG}}}$ são constantes. $\mathrm{P}_{\kappa}$ representa a produção turbulenta devido as forças viscosas, utilizadas em escoamento incompressível, sendo calculada por

$$
\mathrm{P}_{\kappa}=\mu_{\mathrm{t}} \nabla \overline{\mathrm{V}} *\left(\overline{\mathrm{V}}+\overline{\mathrm{V}}^{\mathrm{T}}\right)-\frac{2}{3} \nabla * \overline{\mathrm{V}}\left(\mu_{\mathrm{t}} \nabla \overline{\mathrm{V}}+\rho \kappa\right)
$$

onde $\mu_{t}$ é a viscosidade turbulenta. Os coeficientes das Equações (14) e (15) são definidos como

$$
\sigma_{\kappa_{\mathrm{RNG}}}=\sigma_{\varepsilon_{\mathrm{RNG}}}=0,719, \mathrm{C}_{\varepsilon 1_{\mathrm{RNG}}}=1,42-\mathrm{f}_{\eta}, \mathrm{C}_{\varepsilon 2_{\mathrm{RNG}}}=1,68
$$

$\mathrm{e}$

$$
\mathrm{f}_{\eta}=\frac{\eta\left(1-\frac{\eta}{4,38}\right)}{1+\beta_{\mathrm{RNG}} \eta^{3}}
$$




$$
\eta=\sqrt{\frac{P_{\kappa}}{\rho C_{\mu_{R N G}} \varepsilon}}
$$

onde

$$
\beta_{\mathrm{RNG}}=0,012, \mathrm{C}_{\mu_{\mathrm{RNG}}}=0,085
$$

\subsection{Erros experimentais}

Os resultados quantitativos obtidos em ensaios experimentais apresentam pequenas discrepâncias (erros) que são decorrentes da calibração dos instrumentos de medição. Segundo Vuolo (1996), além do erro na calibração do instrumento, deve ser observado que a calibração pode se alterar em função de diversos fatores, tais como temperatura, alteração das características dos materiais e componentes, desgaste de partes móveis e outros. No presente trabalho foram realizadas cinco medições das variáveis (forças, pressão e temperatura), para cada ângulo de guinada $(\beta)$ de $-10^{\circ}$ a $10^{\circ}$ e para cada configuração de vão livre (com e sem vão livre). O procedimento para estimar a confiabilidade dos resultados foi realizado o emprego do cálculo estatístico, utilizando o critério de distribuição de Gauss para um valor de desvio padrão $(\sigma)$ de $95 \%$, isto é, $\pm 2 \sigma$.

Para o cálculo dos intervalos de incerteza utilizou-se o método apresentado por Kline e Mcclintock (1953), que se baseia na escala dos instrumentos e nos procedimentos experimentais, os intervalos das incertezas foram obtidos pela equação a seguir:

$$
\Delta_{\mathrm{V}}=\sqrt{\left(\frac{\partial \mathrm{R}}{\partial \mathrm{v}_{1}} * \Delta \mathrm{v}_{1}\right)^{2}+\left(\frac{\partial \mathrm{R}}{\partial \mathrm{v}_{2}} * \Delta \mathrm{v}_{2}\right)^{2}+\ldots . .+\left(\frac{\partial \mathrm{R}}{\partial \mathrm{v}_{\mathrm{n}}} * \Delta \mathrm{v}_{\mathrm{n}}\right)^{2}}
$$

Onde, $\mathrm{R}$ uma função de variáveis independentes $\left(\mathrm{v}_{1}, \mathrm{v}_{2} \ldots \mathrm{v}_{\mathrm{n}}\right)$, isto é

$$
\mathrm{R}=\mathrm{R}\left(\mathrm{v}_{1}, \mathrm{v}_{2} \ldots \mathrm{v}_{\mathrm{n}}\right)
$$

No Apêndice C estão apresentados todos os resultados e respectivos procedimentos para os cálculos dos intervalos de incerteza deste trabalho. 


\section{RESULTADOS E DISCUSSÃO}

Neste capítulo estão apresentadas as análises dos resultados obtidos no ensaio experimental e computacional. Em cada uma das situações, com e sem vão livre entre o modelo e mesa, foram realizadas cinco medições correspondente a variação de ângulos de guinada $\beta$ entre $-10^{\circ}$ a $10^{\circ}$. Os resultados estão registrados em tabelas e gráficos que contém os seguintes valores de velocidade de escoamento, as forças aerodinâmicas de arrasto e lateral e seus coeficientes.

\subsection{Apresentação dos resultados}

Os dados referentes a cada medição, são expostos nas tabelas e gráficos a seguir, onde constam os respectivos valores de temperatura e pressão atmosférica relativa à condição ambiente para cada ensaio.

\subsubsection{Resultados com vão livre entre o modelo e a mesa.}

\section{MEDIÇÃO 1}

Condições do ensaio:

Valor do vão livre: $10 \mathrm{~mm}$

Temperatura ambiente: $25^{\circ} \mathrm{C}=298 \mathrm{~K}$

Pressão atmosférica: $691 \mathrm{mmHg}=92125 \mathrm{~Pa}$

Densidade do ar $(\rho): 1,075 \mathrm{Kg} / \mathrm{m}^{3}$

Viscosidade dinâmica $(\mu)$ : 1,803 x $10^{-5} \mathrm{~N} . \mathrm{s} / \mathrm{m}^{2}$

Número de Reynolds (Re): 184000 


\begin{tabular}{|c|c|c|c|c|c|c|}
\hline $\begin{array}{c}\text { Ângulo } \\
\text { de } \\
\text { guinda } \beta \\
\left({ }^{\circ}\right)\end{array}$ & $\begin{array}{c}\text { Força de } \\
\text { Arrasto }\end{array}$ & $\begin{array}{c}\text { Força } \\
\text { Lateral }\end{array}$ & $\begin{array}{c}\text { Velocidade } \\
\text { do } \\
\text { escoamento } \\
(\mathrm{m} / \mathrm{s})\end{array}$ & $\begin{array}{c}\text { Pressão } \\
\text { dinâmica }\end{array}$ & $\begin{array}{c}\text { Coeficiente } \\
\text { de arrasto }\end{array}$ & $\begin{array}{c}\text { Coeficiente } \\
\text { Lateral }\end{array}$ \\
\hline-8 & 4,188 & 2,337 & 16,71 & 149,70 & 0,971 & $\mathrm{C}_{\mathrm{D}}$ \\
\hline-6 & 3,793 & 1,288 & 16,70 & 150,60 & 0,874 & 0,542 \\
\hline-4 & 3,537 & 0,353 & 16,72 & 149,70 & 0,820 & 0,082 \\
\hline-2 & 3,363 & $-0,402$ & 16,72 & 150,70 & 0,774 & $-0,093$ \\
\hline 0 & 3,142 & $-1,454$ & 16,72 & 151,00 & 0,722 & $-0,334$ \\
\hline 2 & 3,115 & $-1,776$ & 16,72 & 150,30 & 0,719 & $-0,410$ \\
\hline 4 & 3,170 & $-2,777$ & 16,70 & 150,00 & 0,733 & $-0,642$ \\
\hline 6 & 3,354 & $-3,561$ & 16,68 & 149,70 & 0,777 & $-0,825$ \\
\hline 8 & 3,613 & $-4,578$ & 16,65 & 149,80 & 0,837 & $-1,060$ \\
\hline 10 & 3,995 & $-5,489$ & 16,59 & 149,00 & 0,930 & $-1,278$ \\
\hline 12 & 4,412 & $-5,968$ & 16,60 & 149,00 & 1,027 & $-1,390$ \\
\hline
\end{tabular}

TABELA 3 - Valores correspondentes a diferentes ângulos de guinada $\beta$ da Medição 1 com vão livre entre o modelo e a mesa.

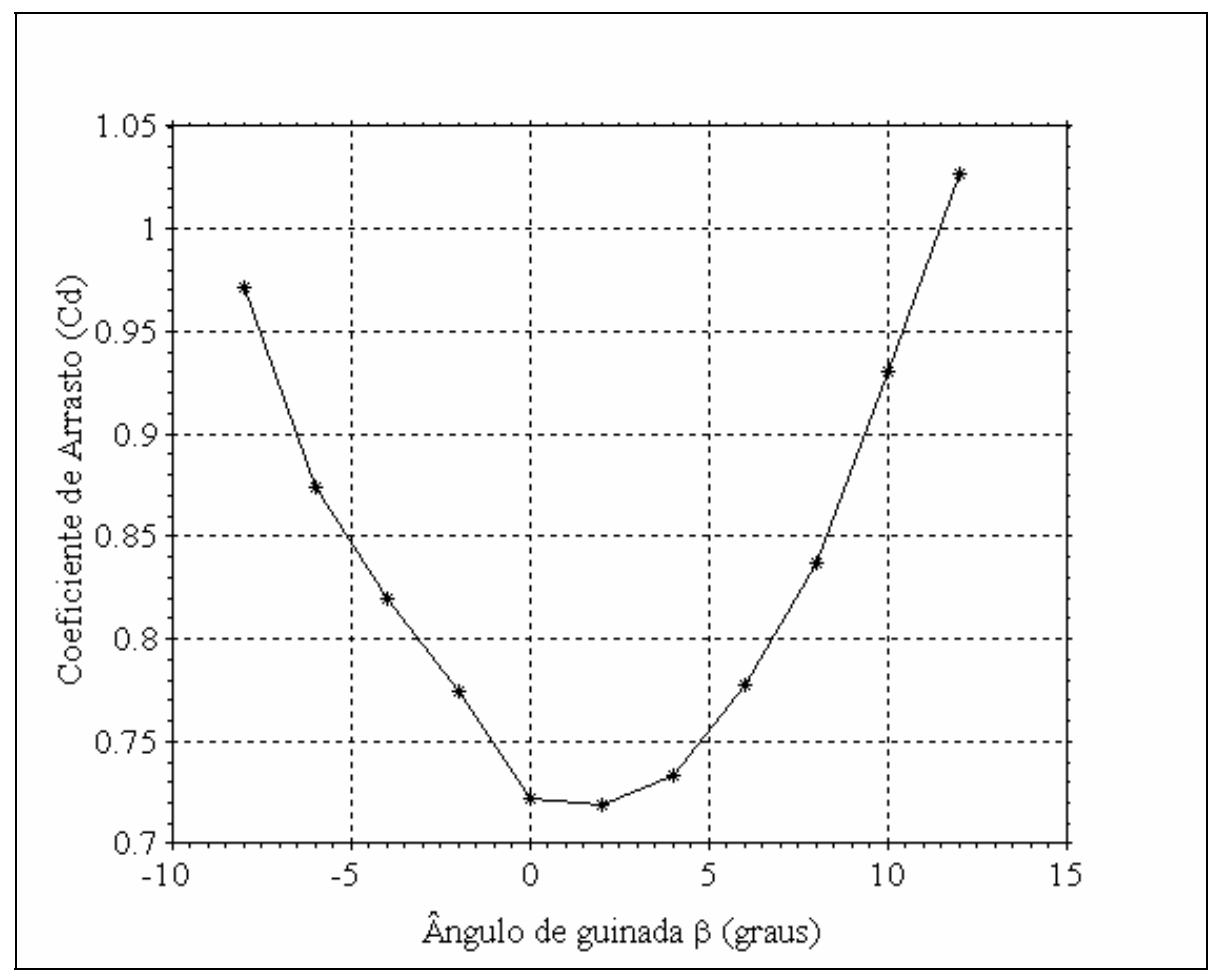

FIGURA 16 - Curva do coeficiente de arrasto $C_{D}$ em função do ângulo de guinada para a Medição 1 com vão livre entre o modelo e a mesa. 


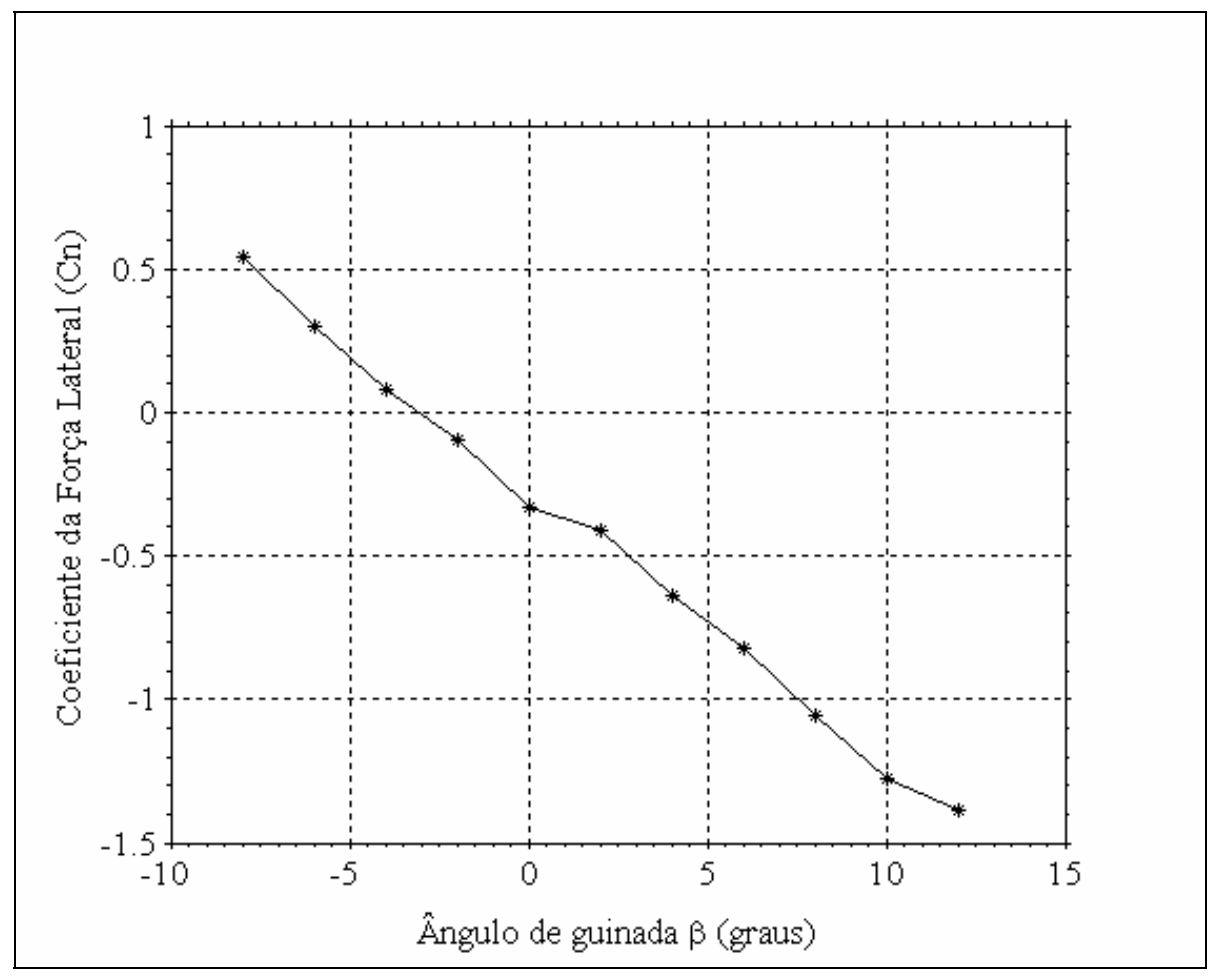

FIGURA 17 - Curva do coeficiente de força lateral $\mathrm{C}_{\mathrm{N}}$ em função do ângulo de guinada para a Medição 1 com vão livre entre o modelo e a mesa.

\section{MEDIÇÃO 2}

Condições do ensaio:

Valor do vão livre: $10 \mathrm{~mm}$

Temperatura ambiente: $26^{\circ} \mathrm{C}=299 \mathrm{~K}$

Pressão atmosférica: $691 \mathrm{mmHg}=92125 \mathrm{~Pa}$

Densidade do ar $(\rho): 1,071 \mathrm{Kg} / \mathrm{m}^{3}$

Viscosidade dinâmica $(\mu): 1,807 \times 10^{-5} \mathrm{~N} . \mathrm{s} / \mathrm{m}^{2}$

Número de Reynolds (Re): 183000 


\begin{tabular}{|c|c|c|c|c|c|c|}
\hline $\begin{array}{c}\text { Ângulo } \\
\text { de } \\
\text { guinda } \beta \\
\left({ }^{\circ}\right)\end{array}$ & $\begin{array}{c}\text { Força de } \\
\text { Arrasto }\end{array}$ & $\begin{array}{c}\text { Força } \\
\text { Lateral }\end{array}$ & $\begin{array}{c}\text { Velocidade } \\
\text { do } \\
\text { escoamento } \\
(\mathrm{m} / \mathrm{s})\end{array}$ & $\begin{array}{c}\text { Pressão } \\
\text { dinâmica }\end{array}$ & $\begin{array}{c}\text { Coeficiente } \\
\text { de arrasto }\end{array}$ & $\begin{array}{c}\text { Coeficiente } \\
\text { Lateral }\end{array}$ \\
\hline-8 & 4,246 & 2,632 & 16,60 & 148,10 & 0,995 & $\mathrm{C}_{\mathrm{D}}$ \\
\hline-6 & 3,848 & 1,694 & 16,62 & 148,50 & 0,899 & 0,617 \\
\hline-4 & 3,459 & 0,739 & 16,57 & 147,40 & 0,814 & 0,396 \\
\hline-2 & 3,259 & 0,092 & 16,57 & 148,00 & 0,764 & 0,022 \\
\hline 0 & 3,128 & $-0,926$ & 16,58 & 147,40 & 0,736 & $-0,218$ \\
\hline 2 & 3,093 & $-1,181$ & 16,59 & 148,00 & 0,725 & $-0,277$ \\
\hline 4 & 3,149 & $-1,983$ & 16,59 & 147,90 & 0,739 & $-0,465$ \\
\hline 6 & 3,359 & $-2,342$ & 16,61 & 146,70 & 0,795 & $-0,554$ \\
\hline 8 & 3,563 & $-3,483$ & 16,59 & 147,80 & 0,836 & $-0,818$ \\
\hline 10 & 3,886 & $-4,147$ & 16,56 & 147,70 & 0,913 & $-0,974$ \\
\hline 12 & 4,227 & $-4,867$ & 16,58 & 148,10 & 0,990 & $-1,140$ \\
\hline
\end{tabular}

TABELA 4 - Valores correspondentes a diferentes ângulos de guinada $\beta$ da Medição 2 com vão livre entre o modelo e a mesa.

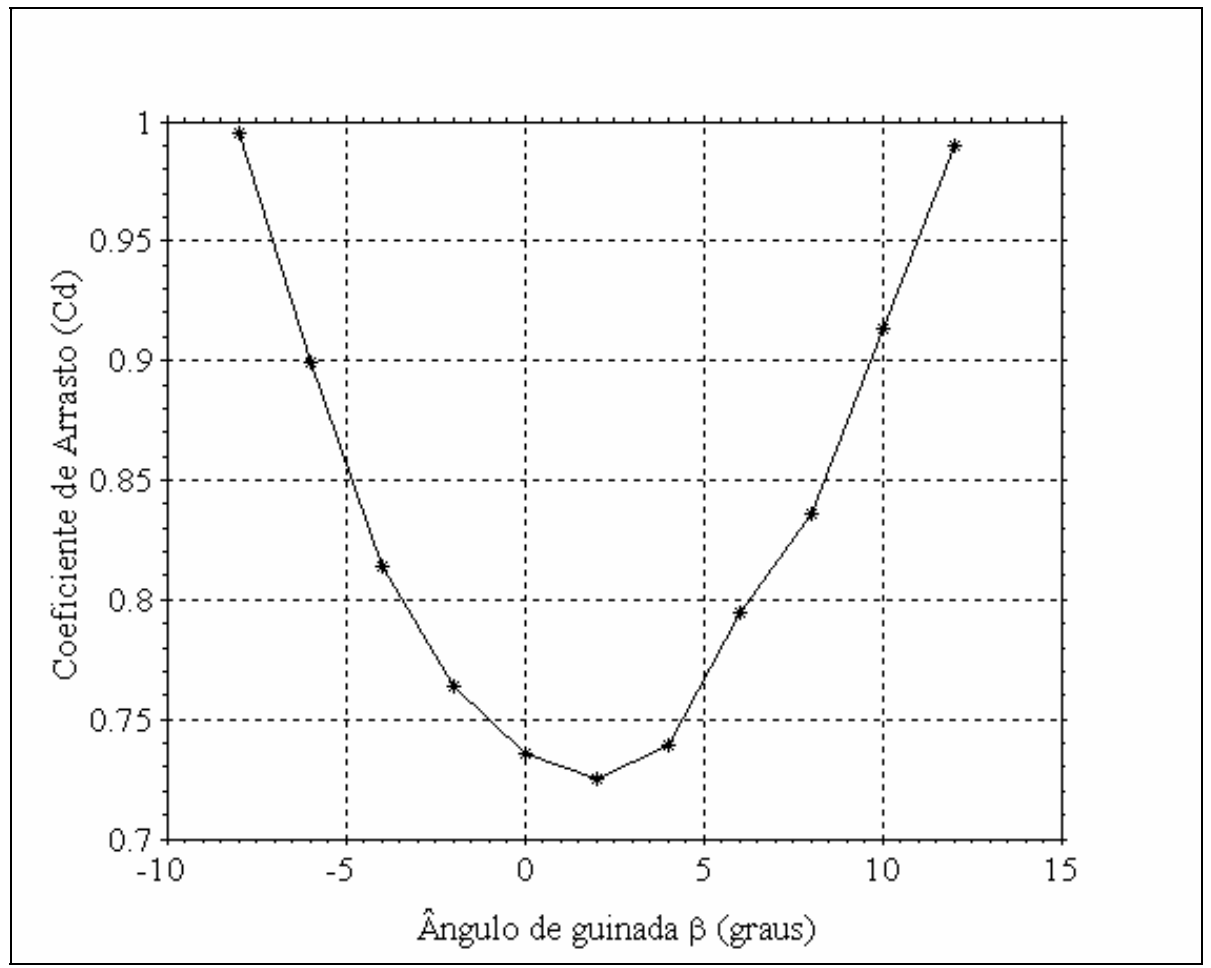

FIGURA 18 - Curva do coeficiente de arrasto $C_{D}$ em função do ângulo de guinada para a Medição 2 com vão livre entre o modelo e a mesa. 


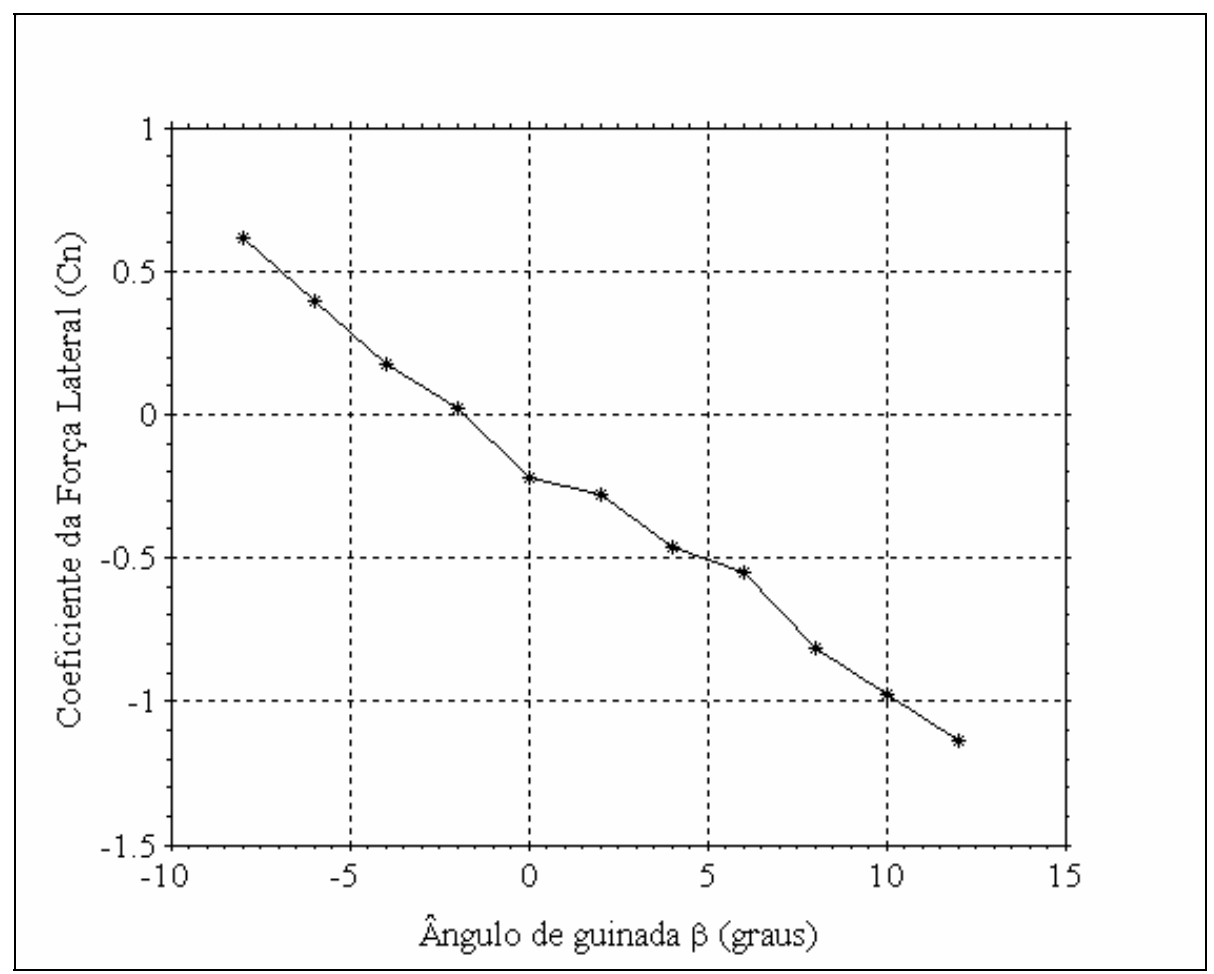

FIGURA 19 - Curva do coeficiente de força lateral $\mathrm{C}_{\mathrm{N}}$ em função do ângulo de guinada para a Medição 2 com vão livre entre o modelo e a mesa.

\section{MEDIÇÃO 3}

Condições do ensaio:

Valor do vão livre: $10 \mathrm{~mm}$

Temperatura ambiente: $26^{\circ} \mathrm{C}=299 \mathrm{~K}$

Pressão atmosférica: $691 \mathrm{mmHg}=92125 \mathrm{~Pa}$

Densidade do ar $(\rho): 1,071 \mathrm{Kg} / \mathrm{m}^{3}$

Viscosidade dinâmica $(\mu): 1,807 \times 10^{-5} \mathrm{~N} . \mathrm{s} / \mathrm{m}^{2}$

Número de Reynolds (Re): 183000 


\begin{tabular}{|c|c|c|c|c|c|c|}
\hline $\begin{array}{c}\text { Angulo } \\
\text { de } \\
\text { guinda } \beta \\
\left({ }^{\circ}\right)\end{array}$ & $\begin{array}{c}\text { Força de } \\
\text { Arrasto }\end{array}$ & $\begin{array}{c}\text { Força } \\
\text { Lateral }\end{array}$ & $\begin{array}{c}\text { Velocidade } \\
\text { do } \\
\text { escoamento } \\
(\mathrm{m} / \mathrm{s})\end{array}$ & $\begin{array}{c}\text { Pressão } \\
\text { dinâmica }\end{array}$ & $\begin{array}{c}\text { Coeficiente } \\
\text { de arrasto }\end{array}$ & $\begin{array}{c}\text { Coeficiente } \\
\text { Lateral }\end{array}$ \\
\hline-8 & 3,988 & 3,051 & 16,51 & 147,40 & 0,939 & $\mathrm{C}_{\mathrm{D}}$ \\
\hline-6 & 3,812 & 2,037 & 16,57 & 147,90 & 0,894 & 0,718 \\
\hline-4 & 3,459 & 1,050 & 16,62 & 147,90 & 0,811 & 0,478 \\
\hline-2 & 3,200 & 0,206 & 16,57 & 148,90 & 0,746 & 0,048 \\
\hline 0 & 3,090 & $-0,574$ & 16,63 & 147,40 & 0,727 & $-0,135$ \\
\hline 2 & 3,135 & $-1,237$ & 16,62 & 147,20 & 0,739 & $-0,292$ \\
\hline 4 & 3,274 & $-1,593$ & 16,64 & 147,50 & 0,770 & $-0,375$ \\
\hline 6 & 3,480 & $-2,409$ & 16,64 & 148,80 & 0,812 & $-0,562$ \\
\hline 8 & 3,671 & $-2,801$ & 16,62 & 149,10 & 0,854 & $-0,652$ \\
\hline 10 & 4,039 & $-3,784$ & 16,65 & 148,50 & 0,944 & $-0,884$ \\
\hline 12 & 4,418 & $-4,984$ & 16,65 & 148,00 & 1,036 & $-1,168$ \\
\hline
\end{tabular}

TABELA 5 - Valores correspondentes a diferentes ângulos de guinada $\beta$ da Medição 3 com vão livre entre o modelo e a mesa.

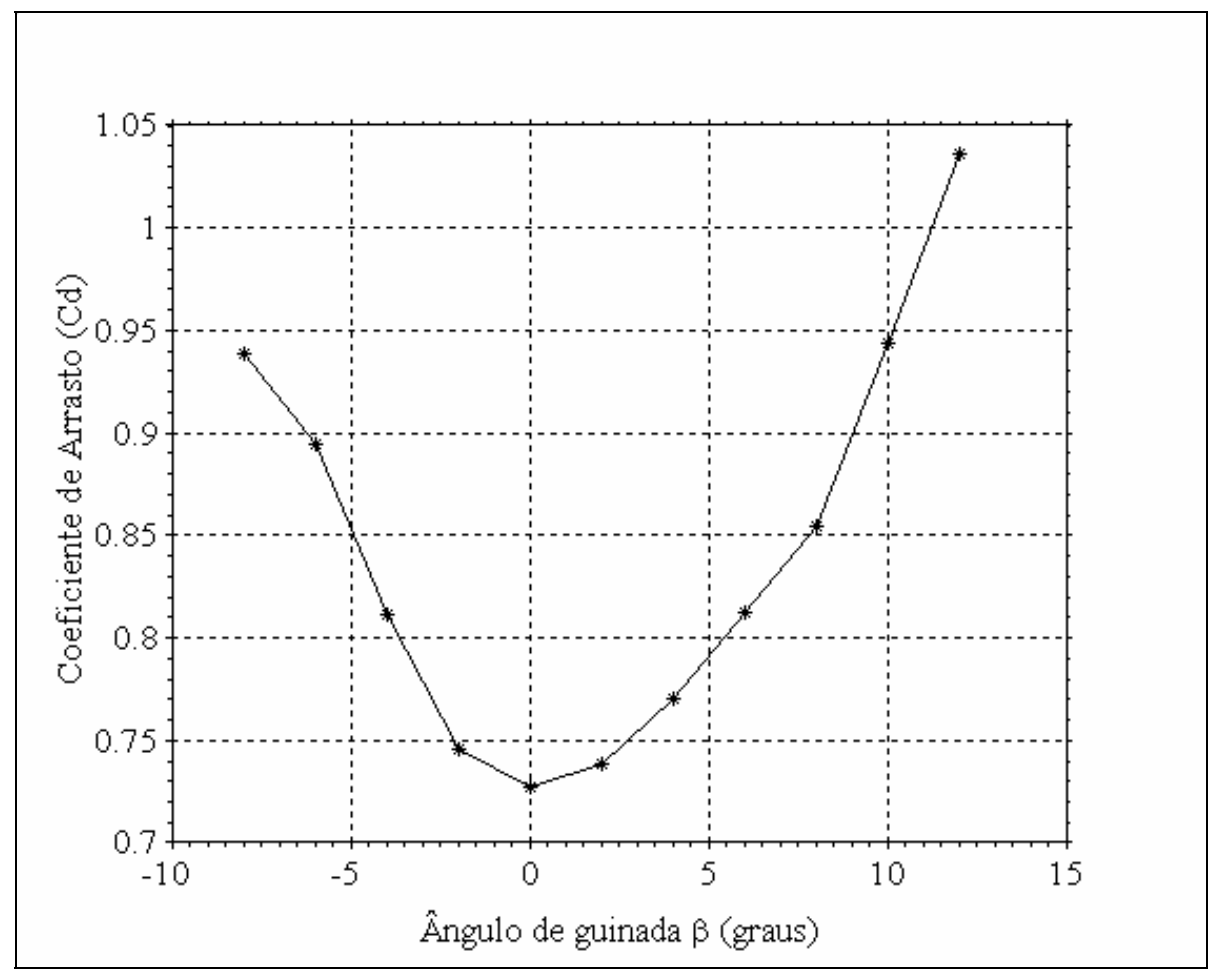

FIGURA 20 - Curva do coeficiente de arrasto $C_{D}$ em função do ângulo de guinada para a Medição 3 com vão livre entre o modelo e a mesa. 


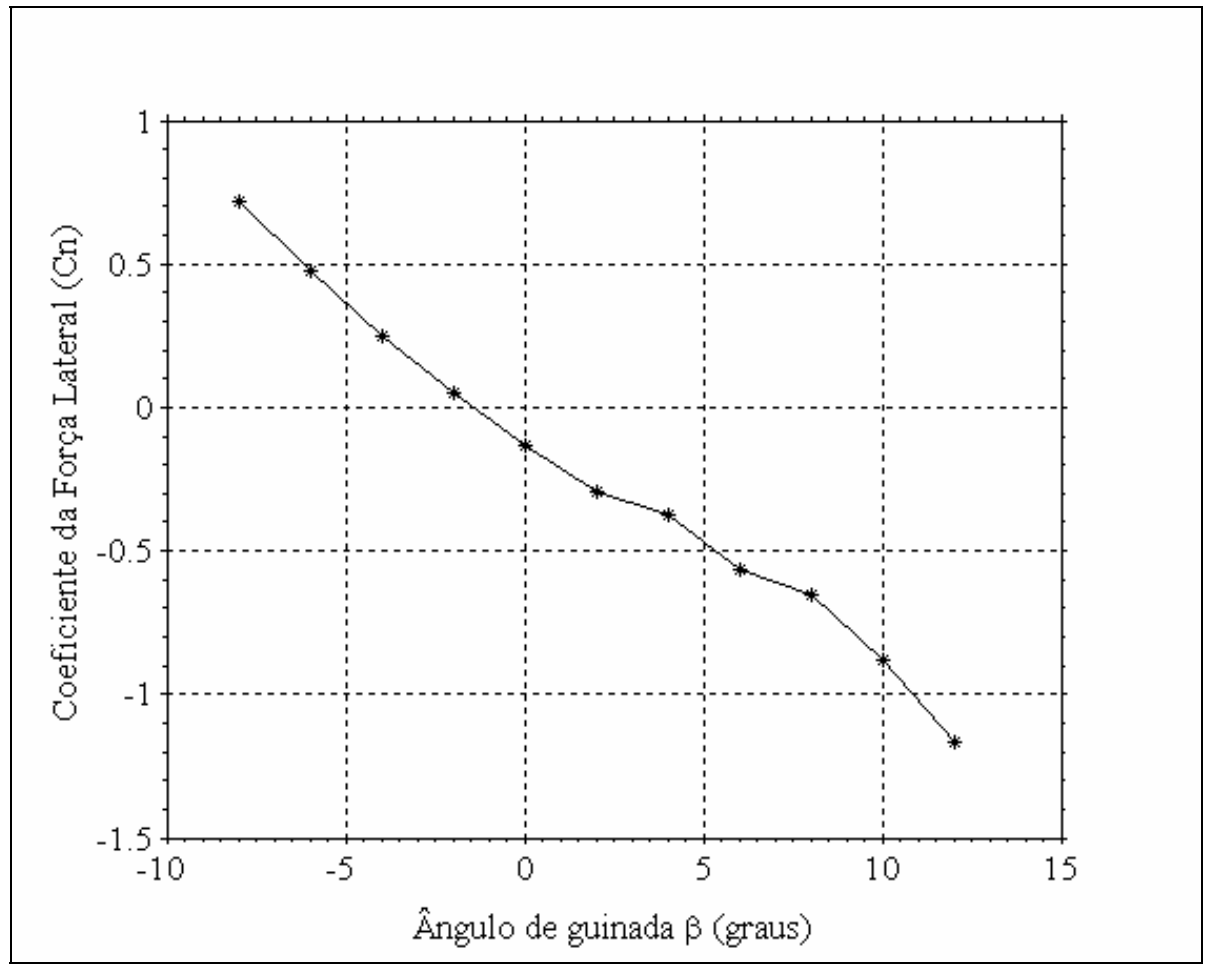

FIGURA 21 - Curva do coeficiente de força lateral $\mathrm{C}_{\mathrm{N}}$ em função do ângulo de guinada para a Medição 3 com vão livre entre o modelo e a mesa.

\section{MEDIÇÃO 4}

Condições do ensaio:

Valor do vão livre: $10 \mathrm{~mm}$

Temperatura ambiente: $22^{\circ} \mathrm{C}=295 \mathrm{~K}$

Pressão atmosférica: $691 \mathrm{mmHg}=92125 \mathrm{~Pa}$

Densidade do ar $(\rho): 1,086 \mathrm{Kg} / \mathrm{m}^{3}$

Viscosidade dinâmica $(\mu): 1,789 \times 10^{-5} \mathrm{~N} . \mathrm{s} / \mathrm{m}^{2}$

Número de Reynolds (Re): 187000 


\begin{tabular}{|c|c|c|c|c|c|c|}
\hline $\begin{array}{c}\text { Ângulo } \\
\text { de } \\
\text { guinda } \beta \\
\left({ }^{\circ}\right)\end{array}$ & $\begin{array}{c}\text { Força de } \\
\text { Arrasto }\end{array}$ & $\begin{array}{c}\text { Força } \\
\text { Lateral }\end{array}$ & $\begin{array}{c}\text { Velocidade } \\
\text { do } \\
\text { escoamento } \\
(\mathrm{m} / \mathrm{s})\end{array}$ & $\begin{array}{c}\text { Pressão } \\
\text { dinâmica }\end{array}$ & $\begin{array}{c}\text { Coeficiente } \\
\text { de arrasto }\end{array}$ & $\begin{array}{c}\text { Coeficiente } \\
\text { Lateral }\end{array}$ \\
\hline-8 & 4,204 & 2,993 & 16,71 & 151,30 & 0,964 & $\mathrm{C}_{\mathrm{D}}$ \\
\hline-6 & 3,759 & 2,122 & 16,67 & 152,00 & 0,858 & 0,686 \\
\hline-4 & 3,378 & 1,373 & 16,70 & 151,20 & 0,775 & 0,484 \\
\hline-2 & 3,114 & 0,700 & 16,71 & 152,20 & 0,710 & 0,160 \\
\hline 0 & 2,915 & $-0,225$ & 16,67 & 151,30 & 0,668 & $-0,052$ \\
\hline 2 & 2,793 & $-0,945$ & 16,72 & 152,20 & 0,637 & $-0,216$ \\
\hline 4 & 2,917 & $-1,660$ & 16,64 & 150,80 & 0,671 & $-0,382$ \\
\hline 6 & 3,142 & $-2,403$ & 16,69 & 151,70 & 0,719 & $-0,550$ \\
\hline 8 & 3,230 & $-2,936$ & 16,69 & 151,20 & 0,741 & $-0,674$ \\
\hline 10 & 3,627 & $-3,789$ & 16,71 & 151,80 & 0,829 & $-0,866$ \\
\hline 12 & 3,974 & $-4,571$ & 16,71 & 150,90 & 0,914 & $-1,051$ \\
\hline
\end{tabular}

TABELA 6 - Valores correspondentes a diferentes ângulos de guinada $\beta$ da Medição 4 com vão livre entre o modelo e a mesa.

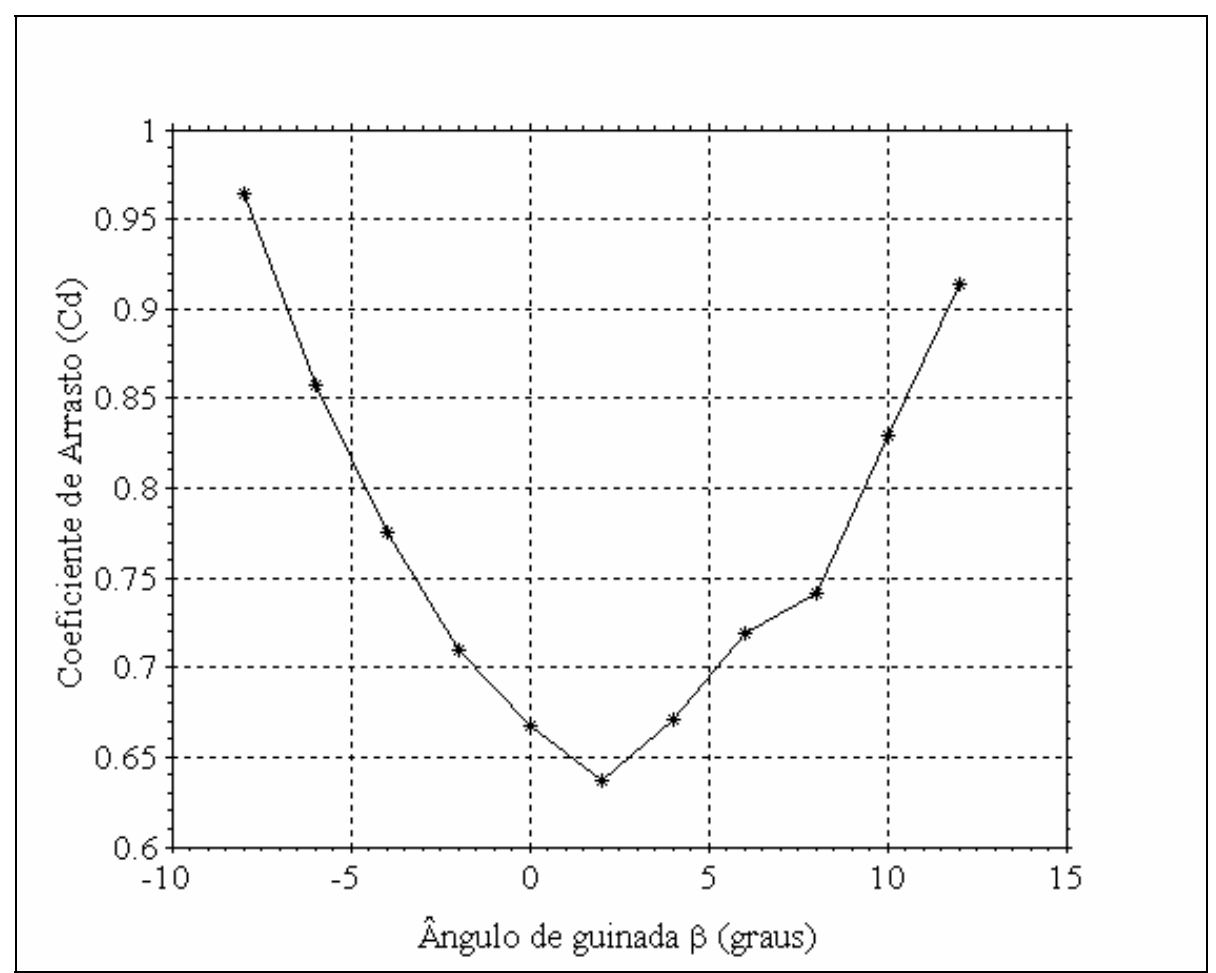

FIGURA 22 - Curva do coeficiente de arrasto $C_{D}$ em função do ângulo de guinada para a Medição 4 com vão livre entre o modelo e a mesa. 


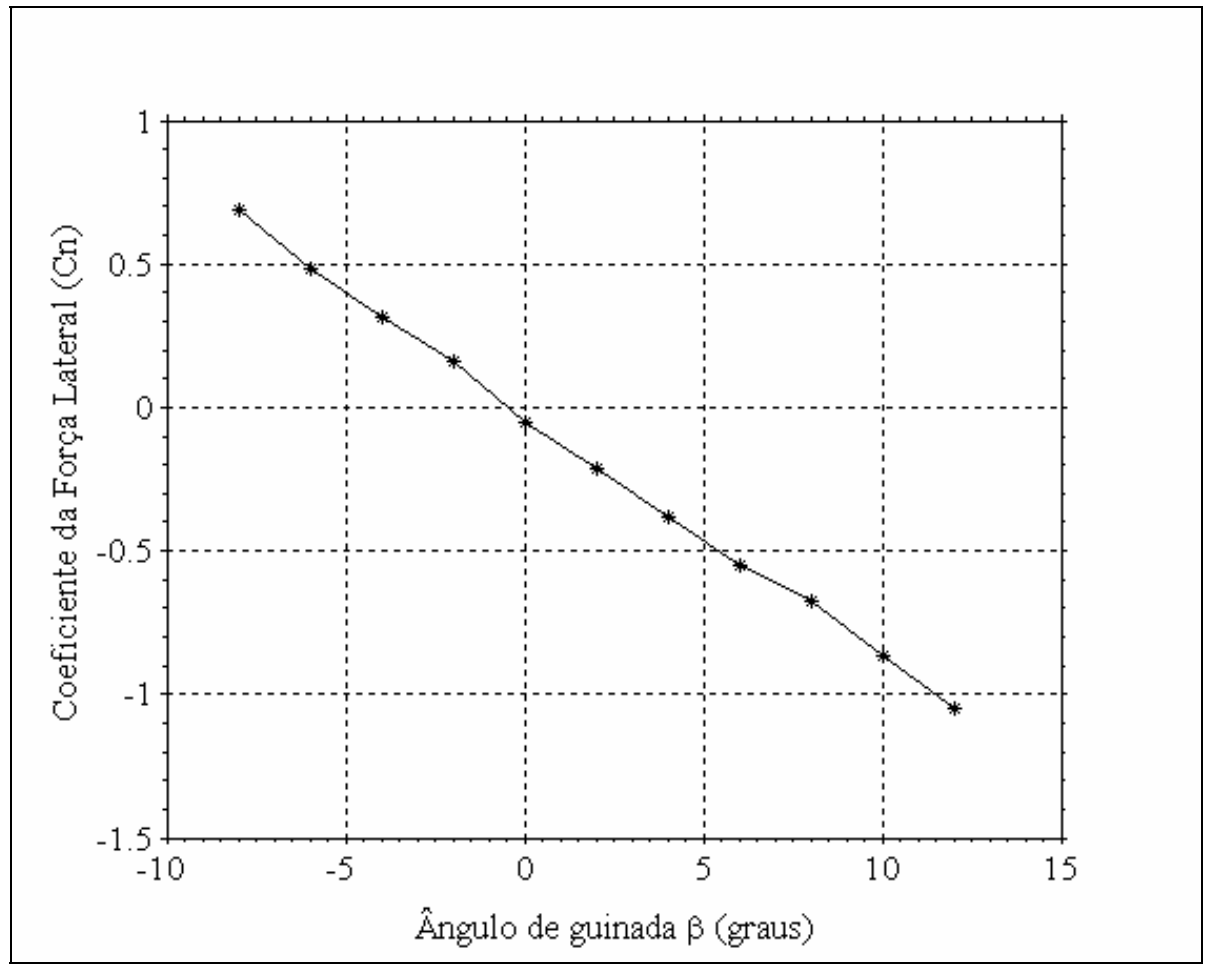

FIGURA 23 - Curva do coeficiente de força lateral $\mathrm{C}_{\mathrm{N}}$ em função do ângulo de guinada para a Medição 4 com vão livre entre o modelo e a mesa.

\section{MEDIÇÃO 5}

Condições do ensaio:

Valor do vão livre: $10 \mathrm{~mm}$

Temperatura ambiente: $23^{\circ} \mathrm{C}=296 \mathrm{~K}$

Pressão atmosférica: $691 \mathrm{mmHg}=92125$ PA

Densidade do ar $(\rho): 1,083 \mathrm{Kg} / \mathrm{m}^{3}$

Viscosidade dinâmica $(\mu): 1,794 \times 10^{-5} \mathrm{~N} . \mathrm{s} / \mathrm{m}^{2}$

Número de Reynolds (Re): 186000 


\begin{tabular}{|c|c|c|c|c|c|c|}
\hline $\begin{array}{c}\text { Ângulo } \\
\text { de } \\
\text { guinda } \beta \\
\left({ }^{\circ}\right)\end{array}$ & $\begin{array}{c}\text { Força de } \\
\text { Arrasto }\end{array}$ & $\begin{array}{c}\text { Força } \\
\text { Lateral }\end{array}$ & $\begin{array}{c}\text { Velocidade } \\
\text { do } \\
\text { escoamento } \\
(\mathrm{m} / \mathrm{s})\end{array}$ & $\begin{array}{c}\text { Pressão } \\
\text { dinâmica }\end{array}$ & $\begin{array}{c}\text { Coeficiente } \\
\text { de arrasto }\end{array}$ & $\begin{array}{c}\text { Coeficiente } \\
\text { Lateral }\end{array}$ \\
\hline-8 & 4,009 & 3,144 & 16,55 & 149,90 & 0,928 & $\mathrm{C}_{\mathrm{D}}$ \\
\hline-6 & 3,460 & 2,067 & 16,63 & 149,90 & 0,801 & 0,728 \\
\hline-4 & 3,203 & 1,765 & 16,51 & 150,00 & 0,741 & 0,478 \\
\hline-2 & 2,923 & 0,767 & 16,64 & 149,60 & 0,678 & 0,178 \\
\hline 0 & 2,737 & $-0,117$ & 16,65 & 149,10 & 0,637 & $-0,027$ \\
\hline 2 & 2,700 & $-0,857$ & 16,41 & 150,00 & 0,625 & $-0,198$ \\
\hline 4 & 2,843 & $-1,466$ & 16,64 & 149,20 & 0,661 & $-0,341$ \\
\hline 6 & 3,074 & $-2,258$ & 16,63 & 150,00 & 0,711 & $-0,522$ \\
\hline 8 & 3,368 & $-3,082$ & 16,62 & 149,90 & 0,780 & $-0,713$ \\
\hline 10 & 3,532 & $-4,049$ & 16,62 & 149,70 & 0,819 & $-0,939$ \\
\hline 12 & 3,952 & $-4,612$ & 16,62 & 148,10 & 0,926 & $-1,080$ \\
\hline
\end{tabular}

TABELA 7 - Valores correspondentes a diferentes ângulos de guinada $\beta$ da Medição 5 com vão livre entre o modelo e a mesa.

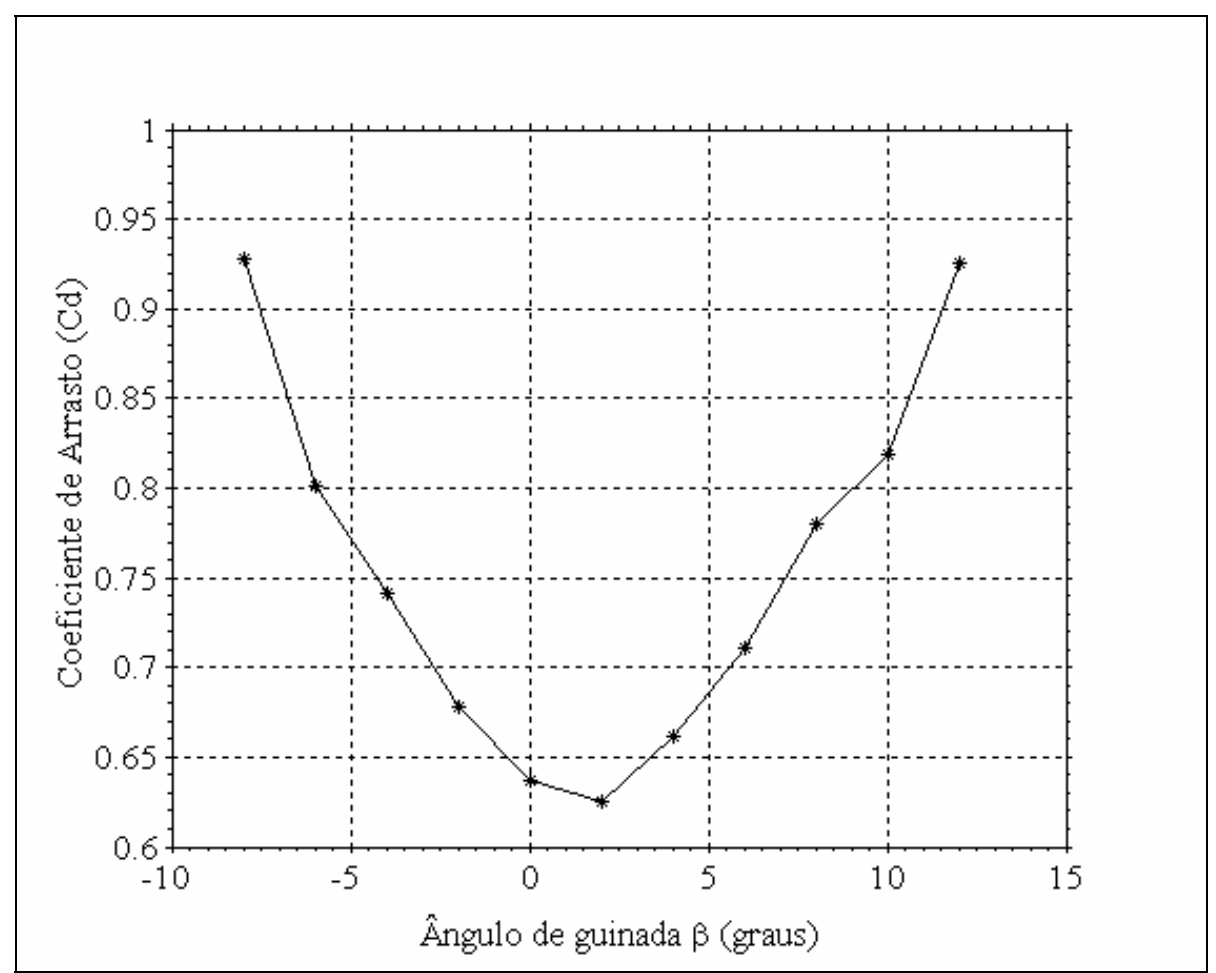

FIGURA 24 - Curva do coeficiente de arrasto $C_{D}$ em função do ângulo de guinada para a Medição 5 com vão livre entre o modelo e a mesa. 


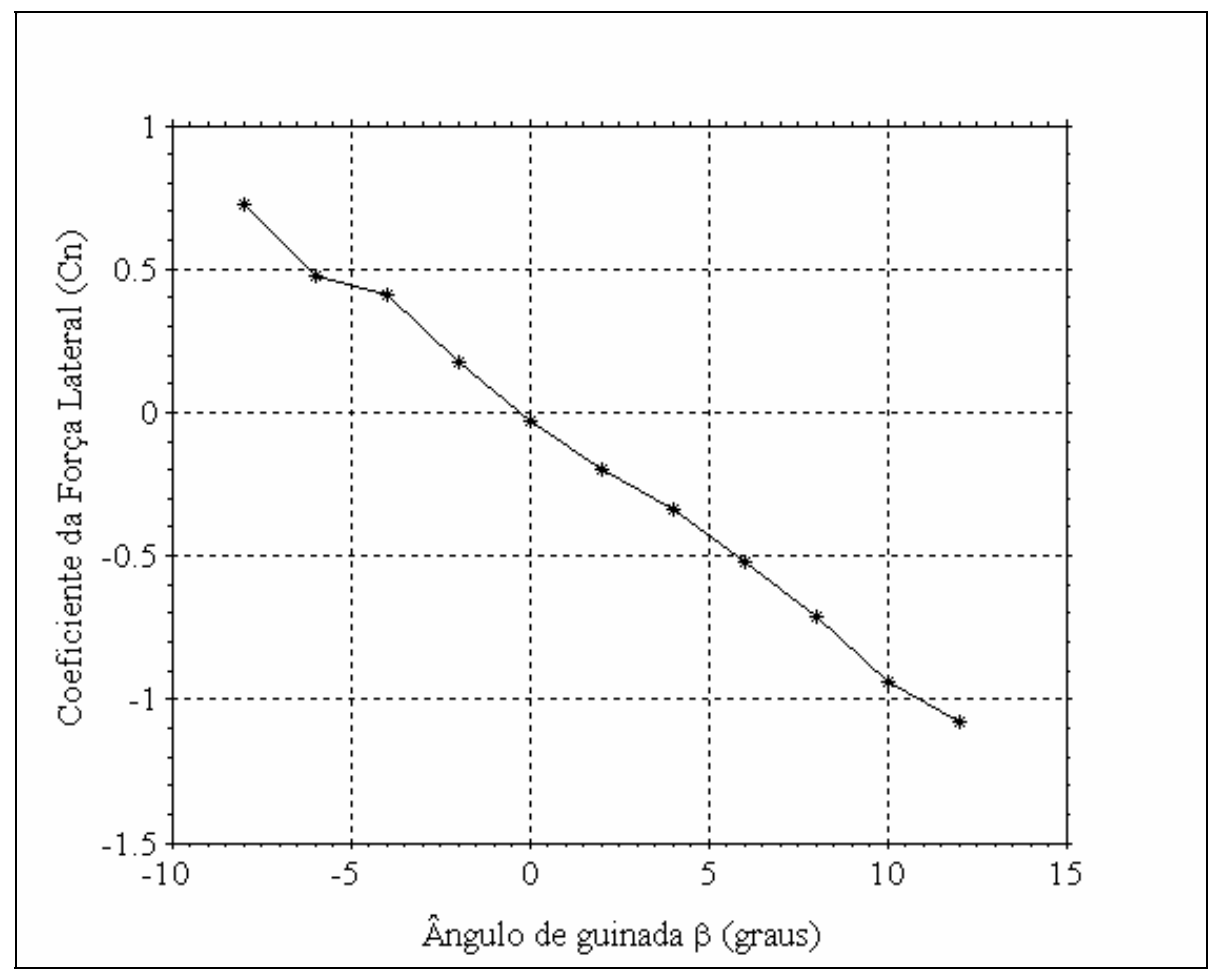

FIGURA 25 - Curva do coeficiente de força lateral $\mathrm{C}_{\mathrm{N}}$ em função do ângulo de guinada para a Medição 5 com vão livre entre o modelo e a mesa.

\subsubsection{Resultados sem vão livre entre o modelo e a mesa.}

\section{MEDIÇÃO 1}

Condições do ensaio:

Temperatura ambiente: $25^{\circ} \mathrm{C}=298 \mathrm{~K}$

Pressão atmosférica: $691 \mathrm{mmHg}=92125 \mathrm{~Pa}$

Densidade do ar $(\rho): 1,075 \mathrm{Kg} / \mathrm{m}^{3}$

Viscosidade dinâmica $(\mu): 1,803 \times 10^{-5} \mathrm{~N} . \mathrm{s} / \mathrm{m}^{2}$

Número de Reynolds (Re): 184000 


\begin{tabular}{|c|c|c|c|c|c|c|}
\hline $\begin{array}{c}\text { Ângulo } \\
\text { de } \\
\text { guinda } \beta \\
\left({ }^{\circ}\right)\end{array}$ & $\begin{array}{c}\text { Força de } \\
\text { Arrasto }\end{array}$ & $\begin{array}{c}\text { Força } \\
\text { Lateral }\end{array}$ & $\begin{array}{c}\text { Velocidade } \\
\text { do } \\
\text { escoamento } \\
(\mathrm{m} / \mathrm{s})\end{array}$ & $\begin{array}{c}\text { Pressão } \\
\text { dinâmica }\end{array}$ & $\begin{array}{c}\text { Coeficiente } \\
\text { de arrasto }\end{array}$ & $\begin{array}{c}\text { Coeficiente } \\
\text { Lateral }\end{array}$ \\
\hline-8 & 3,854 & 3,279 & 16,57 & 148,80 & 0,899 & $\mathrm{C}_{\mathrm{D}}$ \\
\hline-6 & 3,540 & 1,779 & 16,61 & 148,80 & 0,826 & 0,772 \\
\hline-4 & 3,160 & 0,755 & 16,61 & 148,40 & 0,739 & 0,420 \\
\hline-2 & 2,987 & $-0,150$ & 16,50 & 148,50 & 0,698 & $-0,035$ \\
\hline 0 & 2,846 & $-0,657$ & 16,64 & 148,90 & 0,663 & $-0,155$ \\
\hline 2 & 2,801 & $-1,918$ & 16,59 & 147,80 & 0,658 & $-0,453$ \\
\hline 4 & 2,835 & $-2,361$ & 16,63 & 149,10 & 0,660 & $-0,556$ \\
\hline 6 & 2,966 & $-2,998$ & 16,54 & 148,50 & 0,693 & $-0,705$ \\
\hline 8 & 3,121 & $-4,452$ & 16,61 & 148,80 & 0,728 & $-1,047$ \\
\hline 10 & 3,533 & $-5,151$ & 16,61 & 148,80 & 0,824 & $-1,208$ \\
\hline 12 & 4,164 & $-7,615$ & 16,58 & 148,40 & 0,974 & $-1,791$ \\
\hline
\end{tabular}

TABELA 8 - Valores correspondentes a diferentes ângulos de guinada $\beta$ da Medição 1 sem vão livre entre o modelo e a mesa.

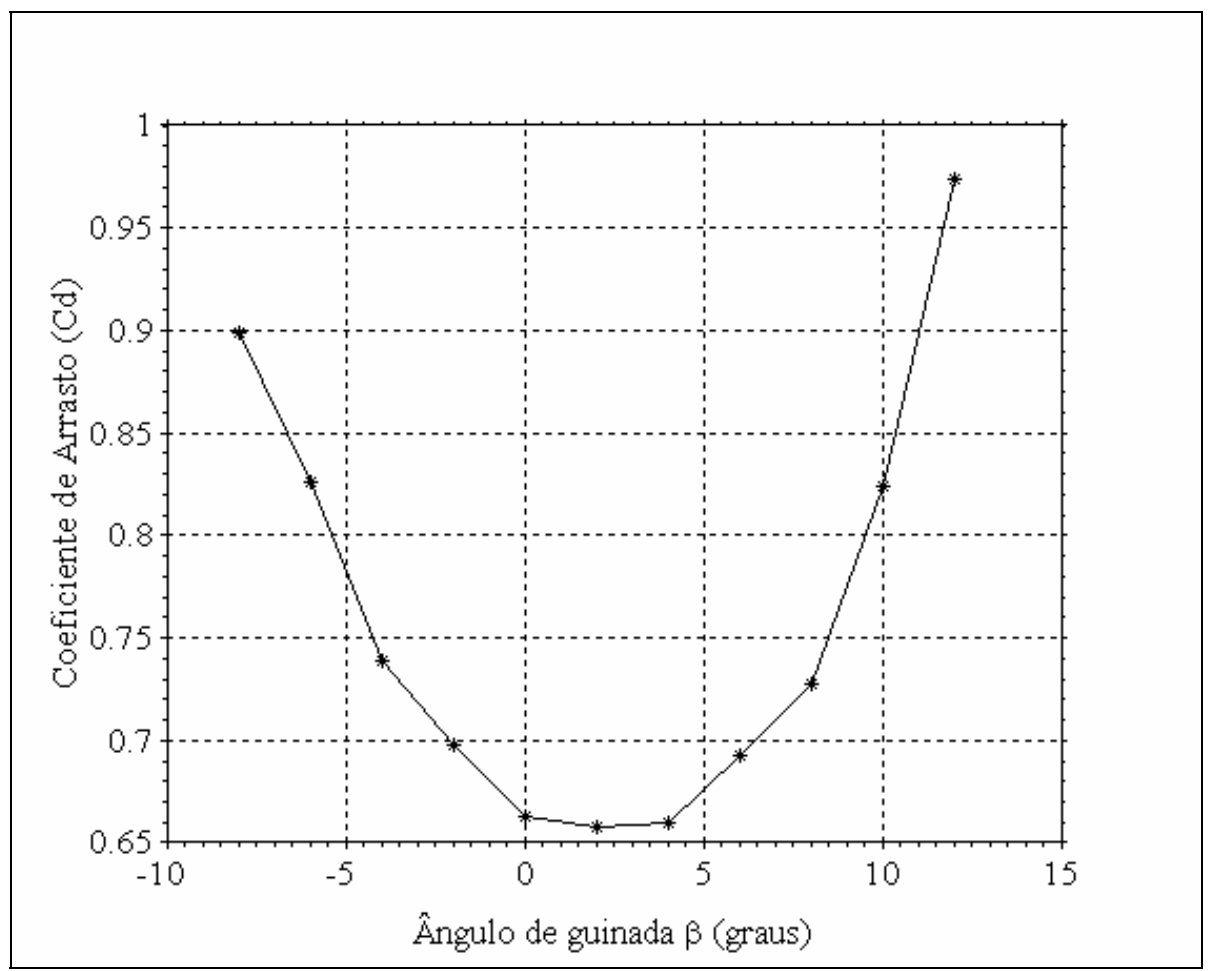

FIGURA 26 - Curva do coeficiente de arrasto $C_{D}$ em função do ângulo de guinada para a Medição 1 sem vão livre entre o modelo e a mesa. 


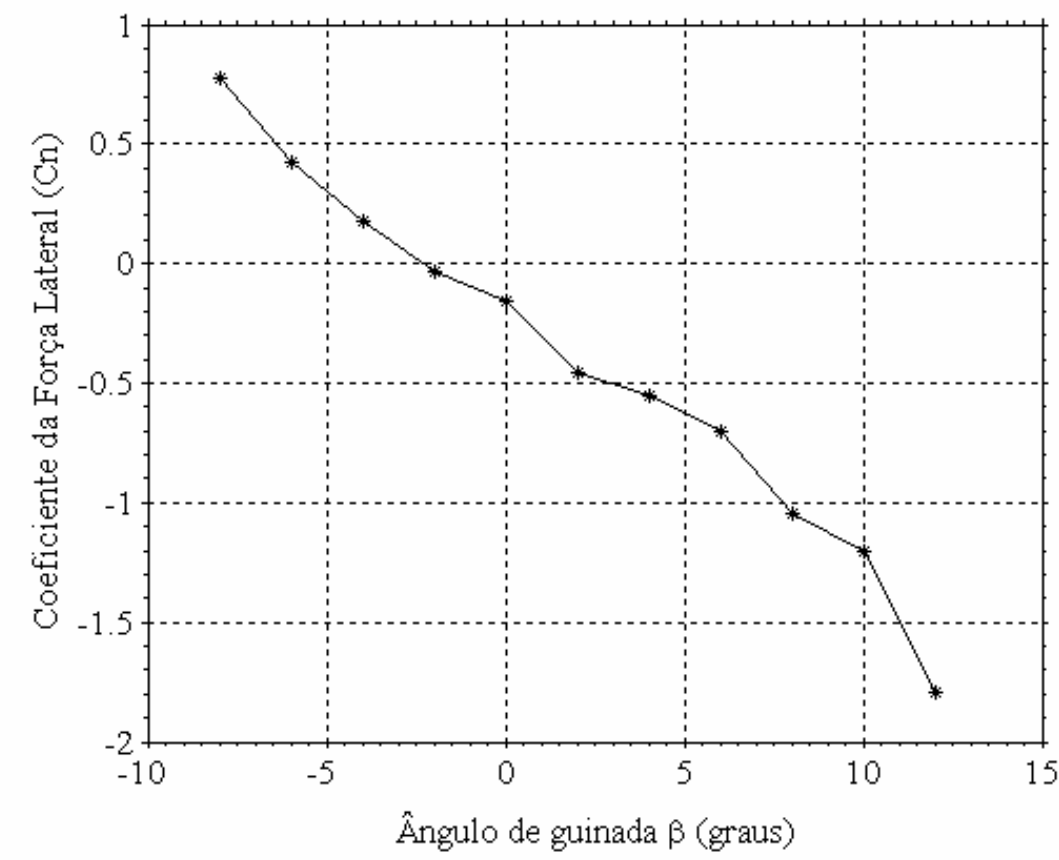

FIGURA 27 - Curva do coeficiente de força lateral $C_{N}$ em função do ângulo de guinada para a Medição 1 sem vão livre entre o modelo e a mesa.

\section{MEDIÇÃO 2}

Condições do ensaio:

Temperatura ambiente: $26^{\circ} \mathrm{C}=299 \mathrm{~K}$

Pressão atmosférica: $691 \mathrm{mmHg}=92125 \mathrm{~Pa}$

Densidade do ar $(\rho): 1,071 \mathrm{Kg} / \mathrm{m}^{3}$

Viscosidade dinâmica $(\mu): 1,807 \times 10^{-5} \mathrm{~N} . \mathrm{s} / \mathrm{m}^{2}$

Número de Reynolds (Re): 183000 


\begin{tabular}{|c|c|c|c|c|c|c|}
\hline $\begin{array}{c}\text { Angulo } \\
\text { de } \\
\text { guinda } \beta \\
\left({ }^{\circ}\right)\end{array}$ & $\begin{array}{c}\text { Força de } \\
\text { Arrasto }\end{array}$ & $\begin{array}{c}\text { Força } \\
\text { Lateral }\end{array}$ & $\begin{array}{c}\text { Velocidade } \\
\text { do } \\
\text { escoamento } \\
(\mathrm{m} / \mathrm{s})\end{array}$ & $\begin{array}{c}\text { Pressão } \\
\text { dinâmica }\end{array}$ & $\begin{array}{c}\text { Coeficiente } \\
\text { de arrasto }\end{array}$ & $\begin{array}{c}\text { Coeficiente } \\
\text { Lateral }\end{array}$ \\
\hline-8 & 3,600 & 2,869 & 16,53 & 147,30 & 0,848 & $\mathrm{C}_{\mathrm{D}}$ \\
\hline-6 & 3,464 & 1,664 & 16,57 & 147,10 & 0,817 & 0,676 \\
\hline-4 & 3,039 & 0,710 & 16,54 & 147,50 & 0,715 & 0,167 \\
\hline-2 & 2,942 & $-0,219$ & 16,55 & 147,50 & 0,692 & $-0,052$ \\
\hline 0 & 2,822 & $-0,983$ & 16,54 & 147,10 & 0,666 & $-0,232$ \\
\hline 2 & 2,677 & $-1,435$ & 16,54 & 147,10 & 0,631 & $-0,338$ \\
\hline 4 & 2,768 & $-2,527$ & 16,52 & 147,30 & 0,652 & $-0,595$ \\
\hline 6 & 2,912 & $-3,009$ & 16,58 & 147,50 & 0,685 & $-0,708$ \\
\hline 8 & 3,224 & $-3,420$ & 16,59 & 147,60 & 0,758 & $-0,804$ \\
\hline 10 & 3,459 & $-5,081$ & 16,56 & 147,90 & 0,812 & $-1,192$ \\
\hline 12 & 4,257 & $-7,078$ & 16,58 & 147,50 & 1,001 & $-1,665$ \\
\hline
\end{tabular}

TABELA 9 - Valores correspondentes a diferentes ângulos de guinada $\beta$ da Medição 2 sem vão livre entre o modelo e a mesa.

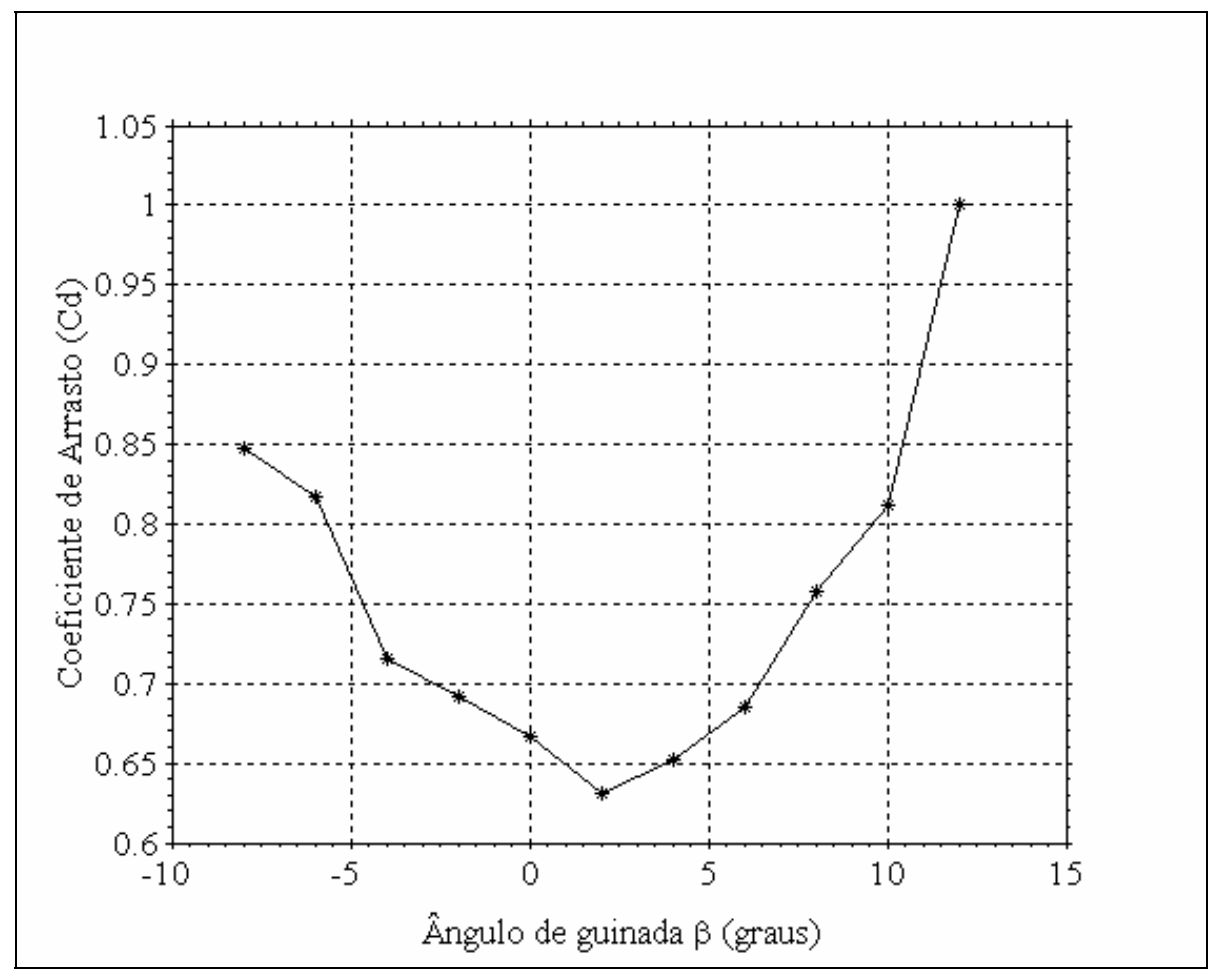

FIGURA 28 - Curva do coeficiente de arrasto $C_{D}$ em função do ângulo de guinada para a Medição 2 sem vão livre entre o modelo e a mesa. 


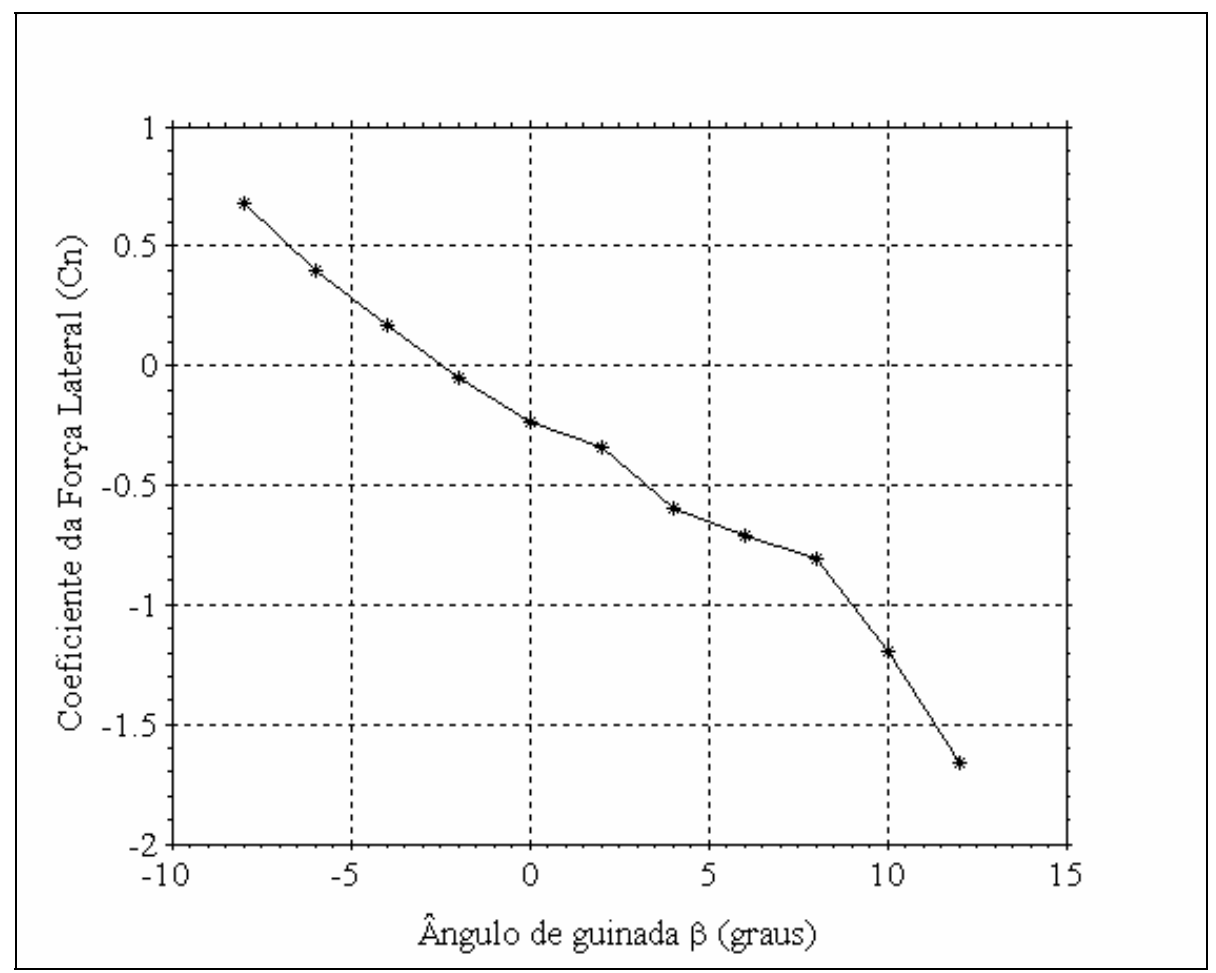

FIGURA 29 - Curva do coeficiente de força lateral $C_{N}$ em função do ângulo de guinada para a Medição 2 sem vão livre entre o modelo e a mesa.

\section{MEDIÇÃO 3}

Condições do ensaio:

Temperatura ambiente: $27^{\circ} \mathrm{C}=300 \mathrm{~K}$

Pressão atmosférica: $691 \mathrm{mmHg}=92125 \mathrm{~Pa}$

Densidade do ar $(\rho): 1,068 \mathrm{Kg} / \mathrm{m}^{3}$

Viscosidade dinâmica $(\mu): 1,812 \times 10^{-5} \mathrm{~N} . \mathrm{s} / \mathrm{m}^{2}$

Número de Reynolds (Re): 182000 


\begin{tabular}{|c|c|c|c|c|c|c|}
\hline $\begin{array}{c}\text { Ângulo } \\
\text { de } \\
\text { guinda } \beta \\
\left({ }^{\circ}\right)\end{array}$ & $\begin{array}{c}\text { Força de } \\
\text { Arrasto }\end{array}$ & $\begin{array}{c}\text { Força } \\
\text { Lateral }\end{array}$ & $\begin{array}{c}\text { Velocidade } \\
\text { do } \\
\text { escoamento } \\
(\mathrm{m} / \mathrm{s})\end{array}$ & $\begin{array}{c}\text { Pressão } \\
\text { dinâmica }\end{array}$ & $\begin{array}{c}\text { Coeficiente } \\
\text { de arrasto }\end{array}$ & $\begin{array}{c}\text { Coeficiente } \\
\text { Lateral }\end{array}$ \\
\hline-8 & 4,012 & 2,827 & 16,50 & 145,50 & 0,957 & $\mathrm{C}_{\mathrm{D}}$ \\
\hline-6 & 3,877 & 1,678 & 16,55 & 146,80 & 0,916 & 0,674 \\
\hline-4 & 3,545 & 0,903 & 16,56 & 146,60 & 0,839 & 0,397 \\
\hline-2 & 3,364 & 0,070 & 16,56 & 146,80 & 0,795 & 0,017 \\
\hline 0 & 3,276 & $-1,166$ & 16,59 & 146,90 & 0,774 & $-0,275$ \\
\hline 2 & 3,131 & $-1,967$ & 16,59 & 147,90 & 0,735 & $-0,461$ \\
\hline 4 & 3,141 & $-2,759$ & 16,55 & 147,20 & 0,740 & $-0,650$ \\
\hline 6 & 3,388 & $-3,487$ & 16,60 & 147,60 & 0,796 & $-0,820$ \\
\hline 8 & 3,573 & $-4,201$ & 16,56 & 147,50 & 0,841 & $-0,988$ \\
\hline 10 & 3,874 & $-5,294$ & 16,57 & 147,70 & 0,910 & $-1,244$ \\
\hline 12 & 3,894 & $-7,309$ & 16,56 & 147,80 & 0,914 & $-1,716$ \\
\hline
\end{tabular}

TABELA 10 - Valores correspondentes a diferentes ângulos de guinada $\beta$ da Medição 3 sem vão livre entre o modelo e a mesa.

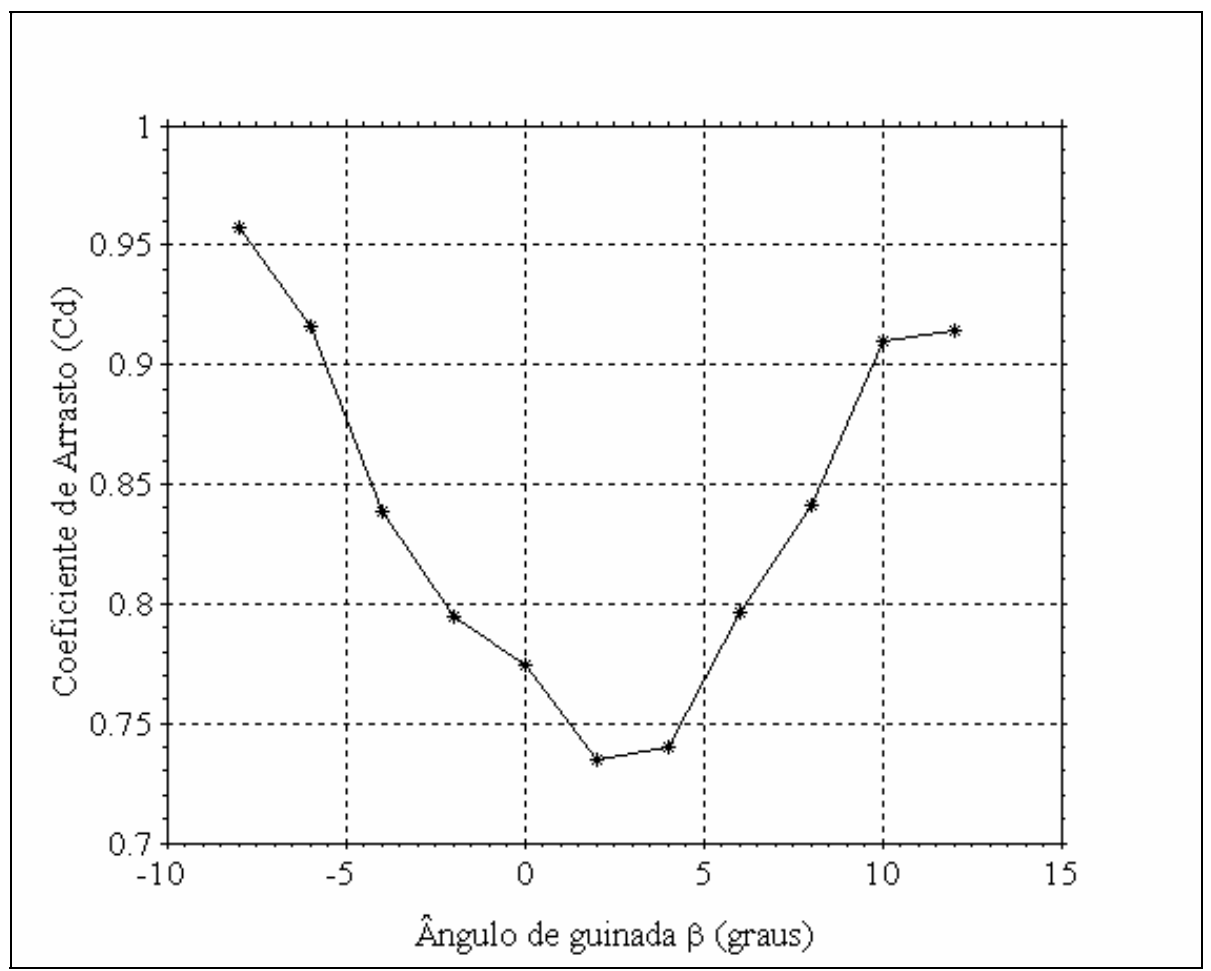

FIGURA 30 - Curva do coeficiente de arrasto $C_{D}$ em função do ângulo de guinada para a Medição 3 sem vão livre entre o modelo e a mesa. 


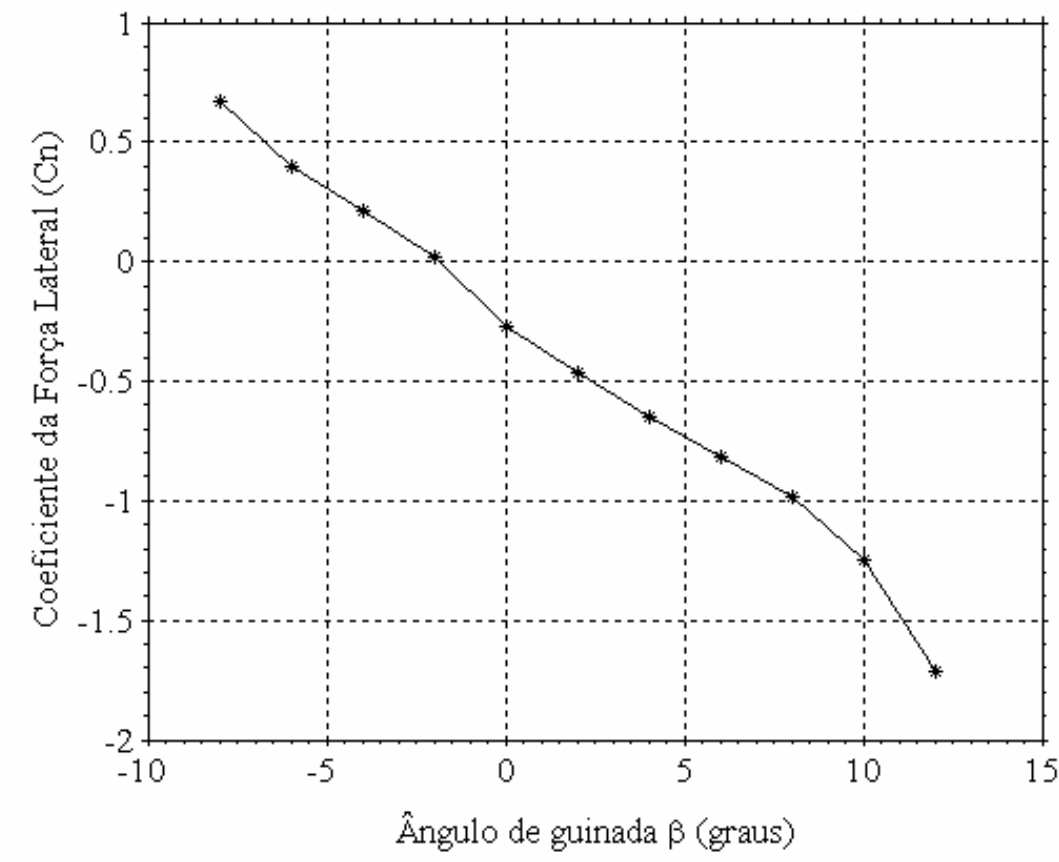

FIGURA 31 - Curva do coeficiente de força lateral $\mathrm{C}_{\mathrm{N}}$ em função do ângulo de guinada para a Medição 3 sem vão livre entre o modelo e a mesa.

\section{MEDIÇÃO 4}

Condições do ensaio:

Temperatura ambiente: $27^{\circ} \mathrm{C}=300 \mathrm{~K}$

Pressão atmosférica: $691 \mathrm{mmHg}=92125 \mathrm{~Pa}$

Densidade do ar $(\rho): 1,068 \mathrm{Kg} / \mathrm{m}^{3}$

Viscosidade dinâmica $(\mu): 1,812 \times 10^{-5} \mathrm{~N} . \mathrm{s} / \mathrm{m}^{2}$

Número de Reynolds (Re): 182000 


\begin{tabular}{|c|c|c|c|c|c|c|}
\hline $\begin{array}{c}\text { Ângulo } \\
\text { de } \\
\text { guinda } \beta \\
\left({ }^{\circ}\right)\end{array}$ & $\begin{array}{c}\text { Força de } \\
\text { Arrasto }\end{array}$ & $\begin{array}{c}\text { Força } \\
\text { Lateral }\end{array}$ & $\begin{array}{c}\text { Velocidade } \\
\text { do } \\
\text { escoamento } \\
(\mathrm{m} / \mathrm{s})\end{array}$ & $\begin{array}{c}\text { Pressão } \\
\text { dinâmica }\end{array}$ & $\begin{array}{c}\text { Coeficiente } \\
\text { de arrasto }\end{array}$ & $\begin{array}{c}\text { Coeficiente } \\
\text { Lateral }\end{array}$ \\
\hline-8 & 4,002 & 3,139 & 16,56 & 146,80 & 0,946 & $\mathrm{C}_{\mathrm{D}}$ \\
\hline-6 & 3,763 & 2,206 & 16,59 & 147,40 & 0,886 & 0,742 \\
\hline-4 & 3,479 & 1,277 & 16,57 & 147,30 & 0,819 & 0,519 \\
\hline-2 & 3,316 & 0,541 & 16,56 & 146,30 & 0,786 & 0,128 \\
\hline 0 & 3,242 & $-0,479$ & 16,59 & 146,90 & 0,766 & $-0,113$ \\
\hline 2 & 3,160 & $-1,328$ & 16,56 & 146,60 & 0,748 & $-0,314$ \\
\hline 4 & 3,190 & $-2,065$ & 16,52 & 146,60 & 0,755 & $-0,489$ \\
\hline 6 & 3,351 & $-2,856$ & 16,54 & 146,30 & 0,795 & $-0,677$ \\
\hline 8 & 3,600 & $-3,178$ & 16,60 & 146,00 & 0,856 & $-0,755$ \\
\hline 10 & 3,938 & $-4,482$ & 16,56 & 146,60 & 0,932 & $-1,061$ \\
\hline 12 & 4,221 & $-5,551$ & 16,55 & 146,10 & 1,002 & $-1,318$ \\
\hline
\end{tabular}

TABELA 11 - Valores correspondentes a diferentes ângulos de guinada $\beta$ da Medição 4 sem vão livre entre o modelo e a mesa.

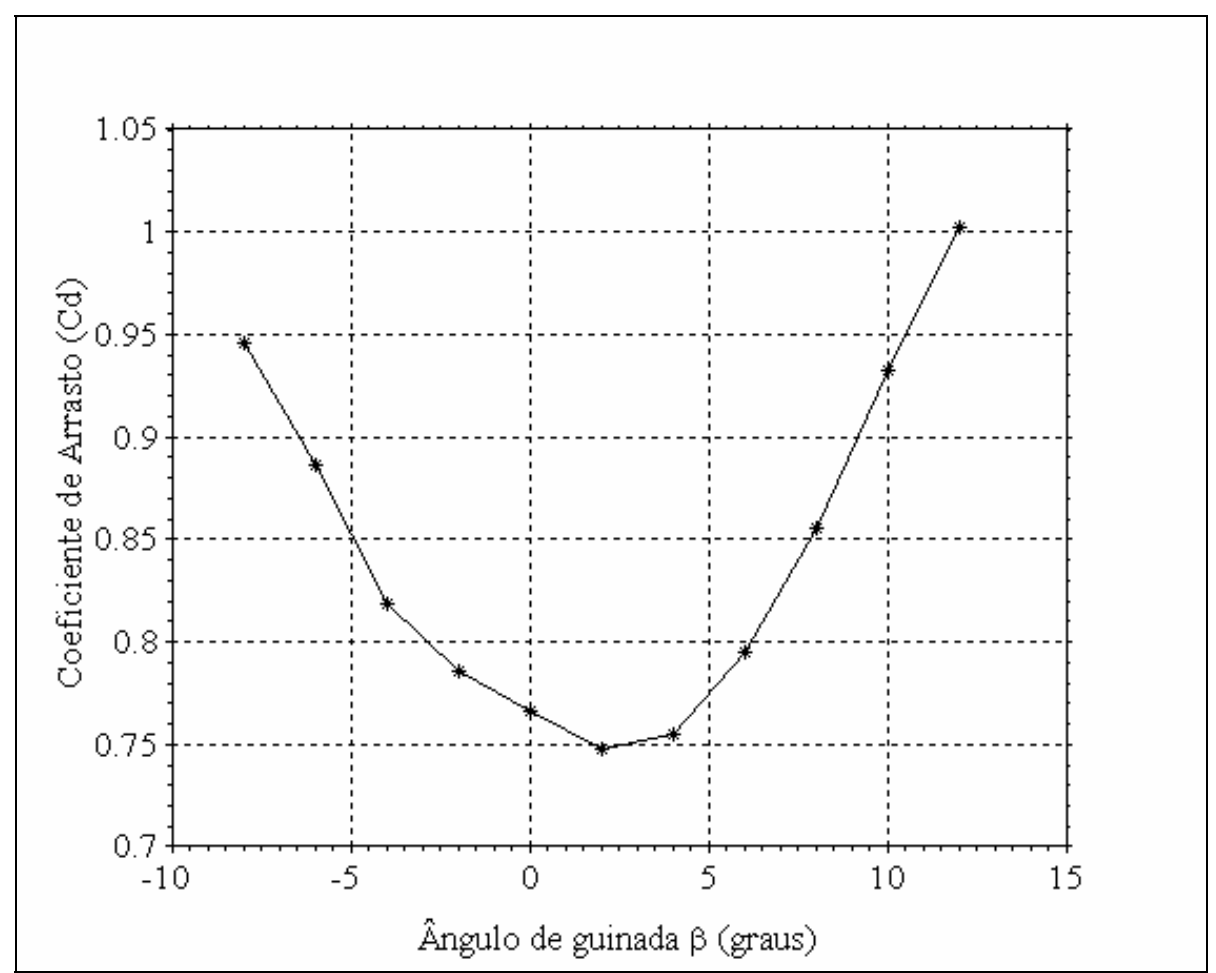

FIGURA 32 - Curva do coeficiente de arrasto $C_{D}$ em função do ângulo de guinada para a Medição 4 sem vão livre entre o modelo e a mesa. 


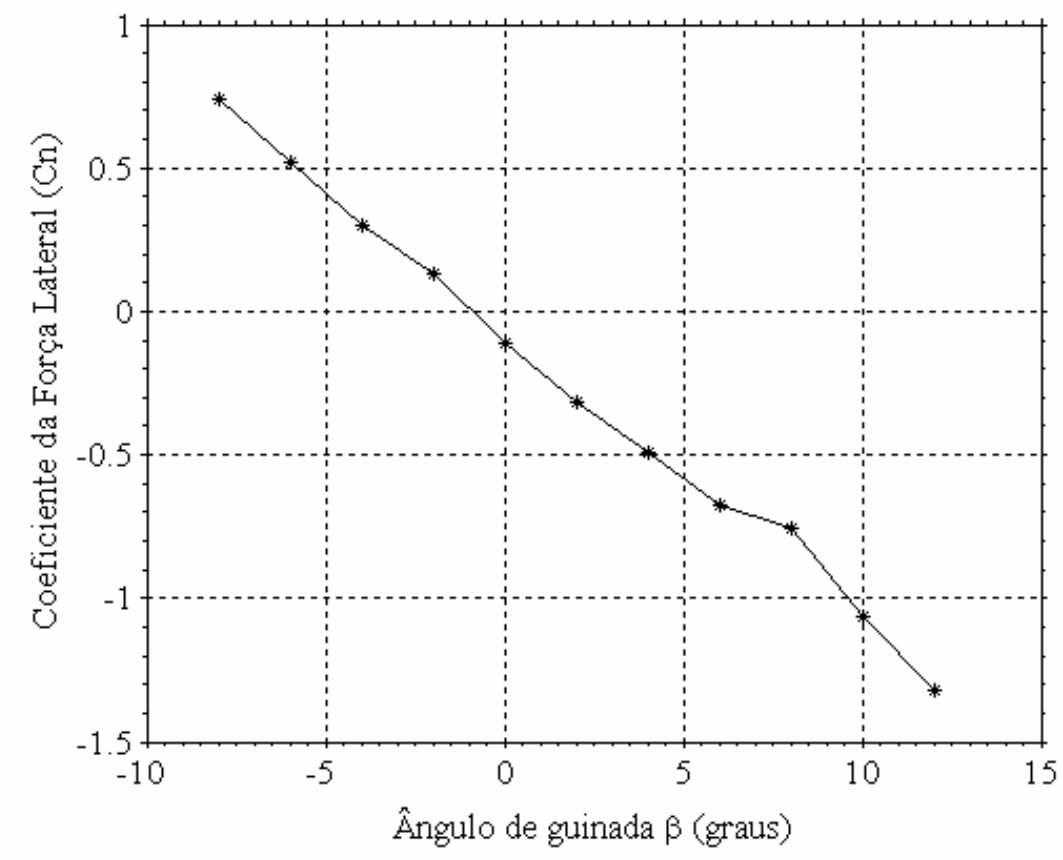

FIGURA 33 - Curva do coeficiente de força lateral $\mathrm{C}_{\mathrm{N}}$ em função do ângulo de guinada para a Medição 4 sem vão livre entre o modelo e a mesa.

\section{MEDIÇÃO 5}

Condições do ensaio:

Temperatura ambiente $(\mathrm{T}): 27^{\circ} \mathrm{C}=300 \mathrm{~K}$

Pressão atmosférica $\left(\mathrm{P}_{\mathrm{atm}}\right): 690 \mathrm{mmHg}=91992 \mathrm{PA}$

Densidade do ar $(\rho): 1,066 \mathrm{Kg} / \mathrm{m}^{3}$

Viscosidade dinâmica $(\mu): 1,812 \times 10^{-5} \mathrm{~N} . \mathrm{s} / \mathrm{m}^{2}$

Número de Reynolds (Re): 182000 


\begin{tabular}{|c|c|c|c|c|c|c|}
\hline $\begin{array}{c}\text { Ângulo } \\
\text { de } \\
\text { guinda } \beta \\
\left({ }^{\circ}\right)\end{array}$ & $\begin{array}{c}\text { Força de } \\
\text { Arrasto }\end{array}$ & $\begin{array}{c}\text { Força } \\
\text { Lateral }\end{array}$ & $\begin{array}{c}\text { Velocidade } \\
\text { do } \\
\text { escoamento } \\
(\mathrm{m} / \mathrm{s})\end{array}$ & $\begin{array}{c}\text { Pressão } \\
\text { dinâmica }\end{array}$ & $\begin{array}{c}\text { Coeficiente } \\
\text { de arrasto }\end{array}$ & $\begin{array}{c}\text { Coeficiente } \\
\text { Lateral }\end{array}$ \\
\hline-8 & 3,908 & 2,824 & 16,60 & 147,50 & 0,919 & $\mathrm{C}_{\mathrm{D}}$ \\
\hline-6 & 3,732 & 2,127 & 16,59 & 147,40 & 0,879 & 0,664 \\
\hline-4 & 3,376 & 1,360 & 16,60 & 147,30 & 0,795 & 0,501 \\
\hline-2 & 3,176 & 0,322 & 16,62 & 147,70 & 0,746 & 0,076 \\
\hline 0 & 3,109 & $-0,368$ & 16,62 & 147,50 & 0,731 & $-0,087$ \\
\hline 2 & 3,133 & $-1,366$ & 16,59 & 147,20 & 0,739 & $-0,322$ \\
\hline 4 & 3,152 & $-2,261$ & 16,61 & 147,80 & 0,740 & $-0,531$ \\
\hline 6 & 3,292 & $-3,194$ & 16,63 & 147,50 & 0,775 & $-0,751$ \\
\hline 8 & 3,454 & $-3,762$ & 16,63 & 147,80 & 0,811 & $-0,883$ \\
\hline 10 & 3,826 & $-4,525$ & 16,62 & 147,80 & 0,898 & $-1,062$ \\
\hline 12 & 4,214 & $-5,591$ & 16,62 & 147,80 & 0,989 & $-1,313$ \\
\hline
\end{tabular}

TABELA 12 - Valores correspondentes a diferentes ângulos de guinada $\beta$ da Medição 5 sem vão livre entre o modelo e a mesa.

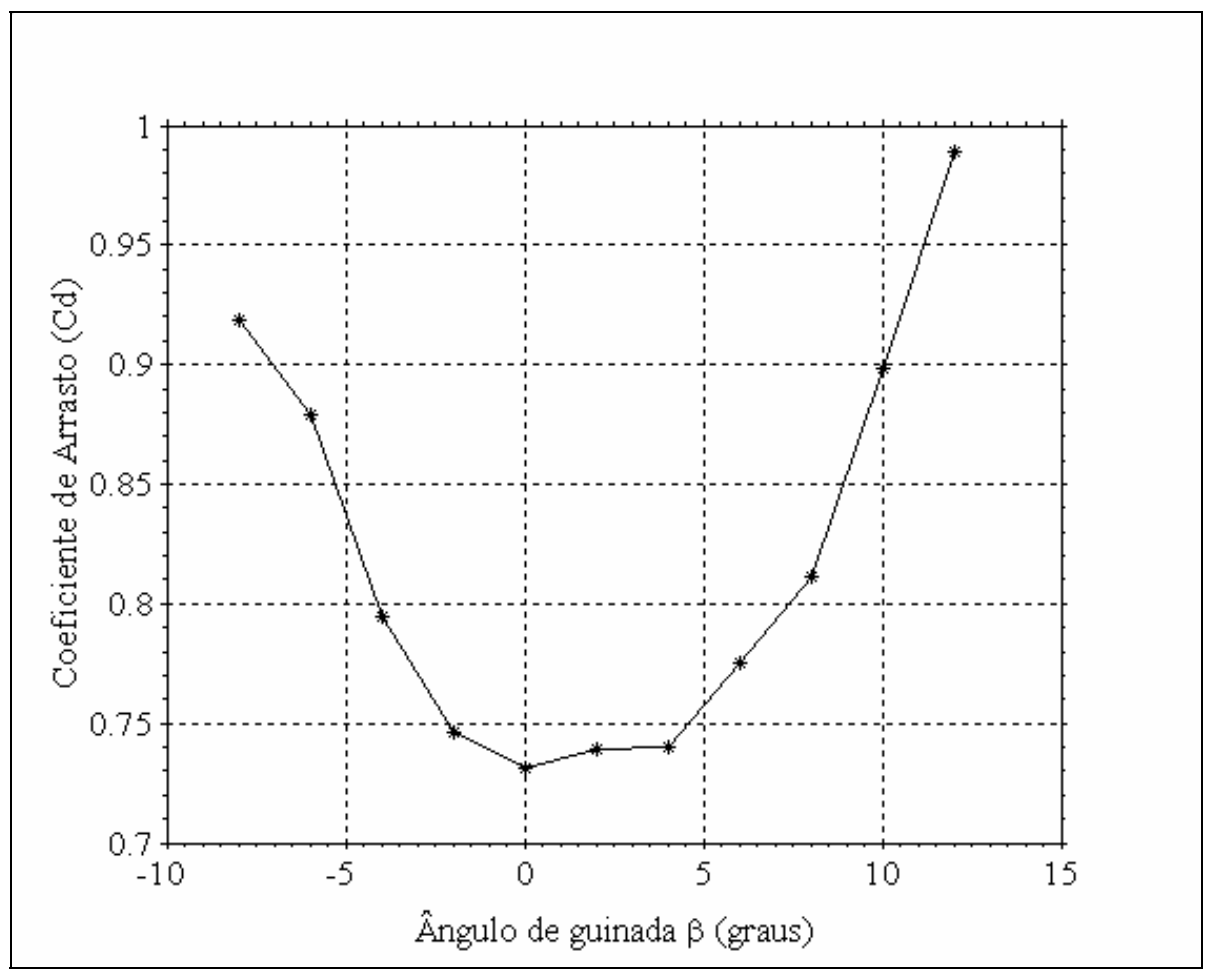

FIGURA 34 - Curva do coeficiente de arrasto $C_{D}$ em função do ângulo de guinada para a Medição 5 sem vão livre entre o modelo e a mesa. 


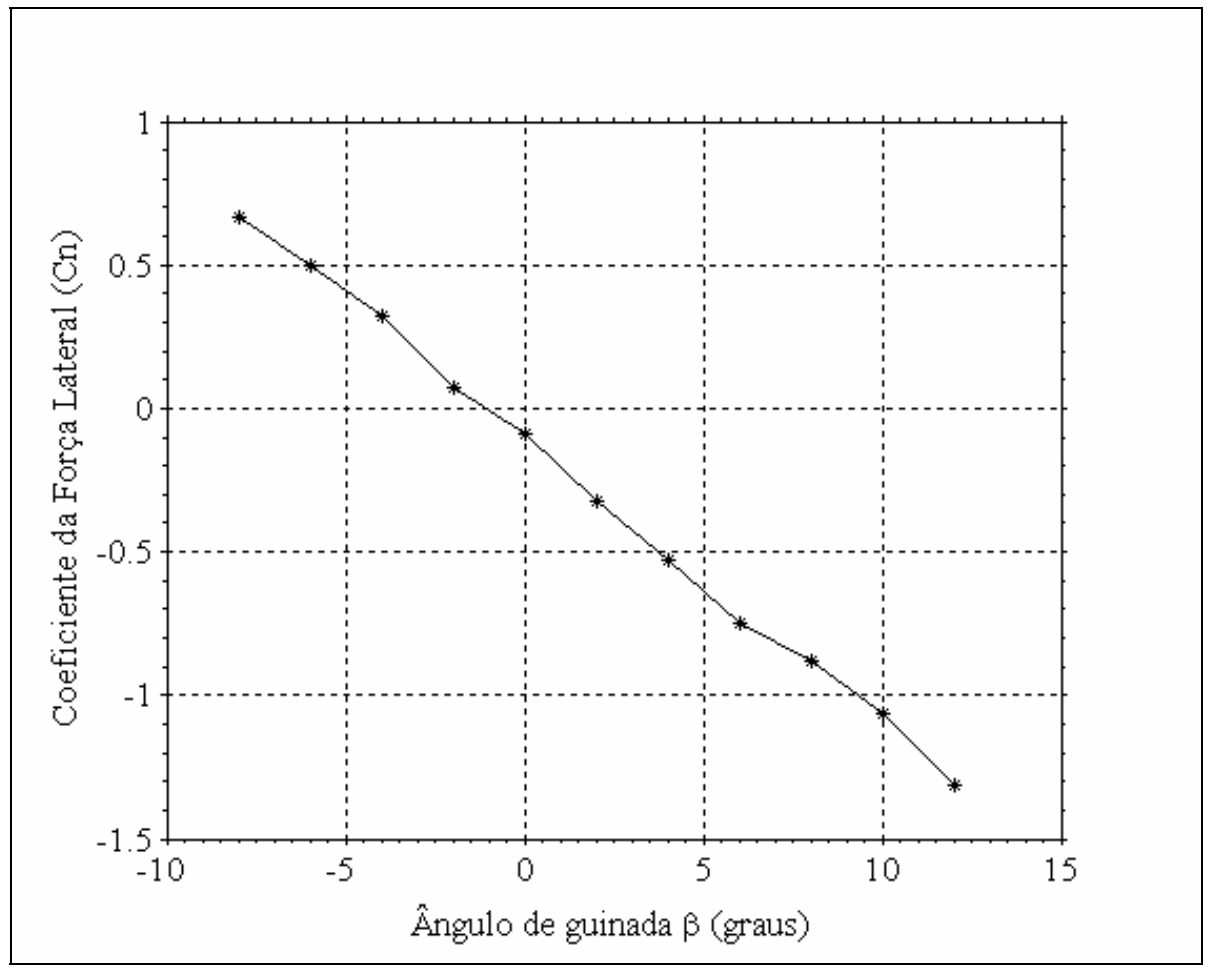

FIGURA 35 - Curva do coeficiente de força lateral $\mathrm{C}_{\mathrm{N}}$ em função do ângulo de guinada para a Medição 5 sem vão livre entre o modelo e a mesa

\subsubsection{Resultados Computacionais.}

Os resultados abaixo são referentes às condições da simulação numérica para melhor reproduzir o regime de funcionamento do túnel aerodinâmico (soprador). Sendo assim, utilizou-se um modelo de fluido "Ar a $25^{\circ} \mathrm{C}$ " existente no banco de dados do programa comercial com as seguintes propriedades, indicadas abaixo.

Temperatura ambiente: $25^{\circ} \mathrm{C}=298 \mathrm{~K}$

Pressão atmosférica: $1 \mathrm{~atm}$

Densidade do ar ( $\left.\rho_{\text {computacional }}\right): 1,185 \mathrm{Kg} / \mathrm{m}^{3}$

Viscosidade dinâmica ( $\left.\mu_{\text {computacional }}\right): 1,831 \times 10^{-5} \mathrm{~N} . \mathrm{s} / \mathrm{m}^{2}$

Número de Reynolds (Re): 192600 


\begin{tabular}{|c|c|c|c|c|c|c|}
\hline $\begin{array}{c}\text { Ângulo } \\
\text { de } \\
\text { guinda } \beta \\
\left({ }^{\circ}\right)\end{array}$ & $\begin{array}{c}\text { Força de } \\
\text { Arrasto }\end{array}$ & $\begin{array}{c}\text { Força } \\
\text { Lateral }\end{array}$ & $\begin{array}{c}\text { Velocidade } \\
\text { do } \\
\text { escoamento } \\
(\mathrm{m} / \mathrm{s})\end{array}$ & $\begin{array}{c}\text { Pressão } \\
\text { dinâmica }\end{array}$ & $\begin{array}{c}\text { Coeficiente } \\
\text { de arrasto }\end{array}$ & $\begin{array}{c}\text { Coeficiente } \\
\text { Lateral }\end{array}$ \\
\hline-10 & 3,910 & 4,516 & 16,00 & 151,62 & 0,895 & $\mathrm{C}_{\mathrm{D}}$ \\
\hline-8 & 3,551 & 3,507 & 16,00 & 151,62 & 0,813 & 1,034 \\
\hline-6 & 3,184 & 2,592 & 16,00 & 151,64 & 0,729 & 0,803 \\
\hline-4 & 2,857 & 1,711 & 16,00 & 151,64 & 0,654 & 0,393 \\
\hline-2 & 2,732 & 0,785 & 16,00 & 151,64 & 0,625 & 0,180 \\
\hline 0 & 2,530 & 0,006 & 16,00 & 151,64 & 0,579 & 0,001 \\
\hline 2 & 2,711 & $-0,762$ & 16,00 & 151,64 & 0,620 & $-0,174$ \\
\hline 4 & 2,883 & $-1,635$ & 16,00 & 151,64 & 0,660 & $-0,374$ \\
\hline 6 & 3,160 & $-2,615$ & 16,00 & 151,64 & 0,723 & $-0,598$ \\
\hline 8 & 3,510 & $-3,515$ & 16,00 & 151,62 & 0,803 & $-0,804$ \\
\hline 10 & 3,896 & $-4,588$ & 16,00 & 151,62 & 0,892 & $-1,050$ \\
\hline
\end{tabular}

TABELA 13 - Valores computacionais correspondentes a diferentes ângulos de guinada $(\beta)$.

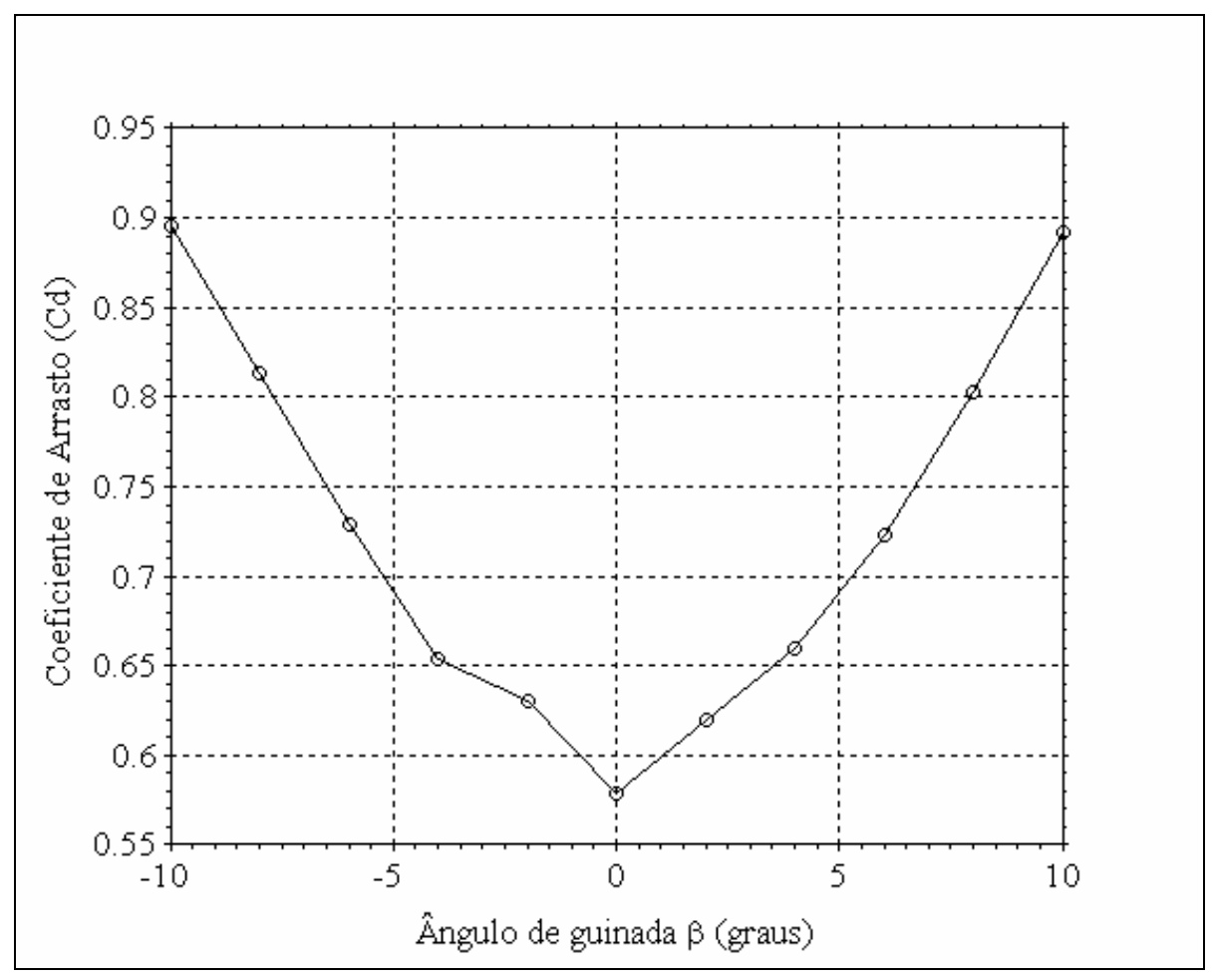

FIGURA 36 - Curva do coeficiente de arrasto computacional $C_{\mathrm{Dc}}$ em função do ângulo de guinada $\beta$. 


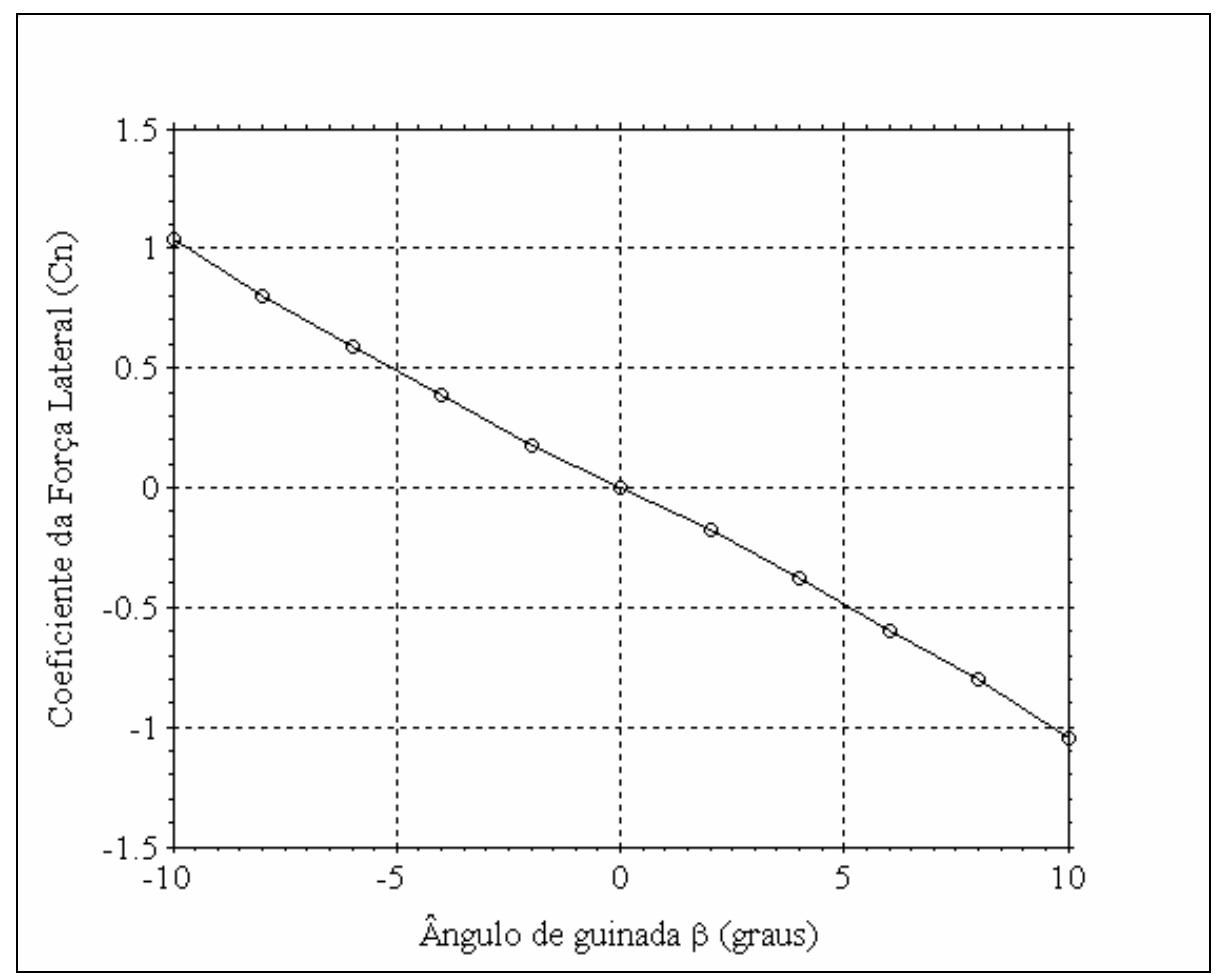

FIGURA 37 - Curva do coeficiente de força lateral computacional $\mathrm{C}_{\mathrm{Nc}}$ em função do ângulo de guinada $\beta$.

\subsection{Discussão dos resultados}

No presente trabalho, o objetivo foi de comparar os resultados computacionais e experimentais de um modelo de ônibus de escala 1:17,5, analisando parâmetros que estão relacionados ao seu desempenho e conforto, como a variação do coeficiente de arrasto e força lateral diante da incidência do escoamento de ar sobre a carroceria do ônibus. No modelo utilizado foram incorporados uma curvatura na parte frontal e arredondamento das arestas. $\mathrm{Na}$ fase experimental o modelo foi submetido ao escoamento de ar do túnel de vento com ângulos de guinada $(\beta)$ de $-10^{\circ}$ a $10^{\circ}$ com uma progressão gradual de dois em dois graus. Na fase computacional o modelo também foi sujeito a uma variação do ângulo de guinada de dois em dois graus, sendo simulado com um programa comercial de dinâmica dos fluidos computacional. A análise imposta no trabalho também foi simulada por alguns pesquisadores que conduziram seus trabalhos utilizando diferentes configurações de autoveículos.

Os coeficientes de arrasto $\left(C_{D}\right)$ e de força lateral $\left(C_{N}\right)$ experimental foram analisados com as curvas médias para cada configuração simulada. A obtenção da curva média para os coeficientes de arrasto e força lateral foi decorrente da balança utilizada 
nas mensurações das componentes aerodinâmicas não apresentar uma precisão adequada. As curvas dos coeficientes de arrasto e força lateral expostas nas Figuras C.1, C.2, C.3 e C.4 no Apêndice C para cada medição efetuada apresentaram-se dentro do intervalo de incerteza calculado com a presença e ausência do vão livre. No decorrer da análise dos resultados experimentais, foi observado que o modelo não estava corretamente alinhado com o escoamento de ar, com isso teve-se que ajustar os valores dos ângulos de guinada ( $\beta$ ). Para o ajuste dos ângulos de guinada foi necessário o auxílio de uma figura computacional e experimental do ponto de estagnação, com a análise do posicionamento dos pontos de estagnação concluiu-se que o ângulo de guinada $\beta=0^{\circ}$ marcado na escala graduada da balança aerodinâmica correspondia a $\beta=2^{\circ}$, diante disto foi somado mais dois graus para obter o valor correto do ângulo de guinada para os valores correspondentes das componentes aerodinâmicas.

Diante das curvas média dos coeficientes de arrasto $\left(C_{D}\right)$ experimentais apresentadas na FIGURA 38 e FIGURA 39, notou-se que a curva experimental deslocase em relação à curva computacional, isto é, devido ao ajuste feito nos ângulos de guinada ocasionando este deslocamento da curva para a direita. Apesar do deslocamento a curva é simétrica em relação ao ângulo de guinada nulo $\left(\beta=0^{\circ}\right)$, desassemelhando-se com o trabalho de Videira (2001) que obteve uma assimetria com a curva de coeficiente de arrasto, podendo ser resultado da influência do alinhamento do modelo com relação ao escoamento de ar, pelo alinhamento da balança com relação ao modelo; e decorrente da pequena interferência entre os sinais das tensões das componentes medidas pela balança.

Quanto a curva de coeficiente de arrasto computacional apresentadas na FIGURA 38 e FIGURA 39 observou se uma simetria relacionados aos valores referentes a cada ângulo de guinada $\beta$. Mediante a comparação das curvas médias de coeficiente de arrasto experimental e computacional foi possível constatar que a variação entre as curvas é de pelo menos um intervalo de incerteza. Tal variação obtida entre o valor teórico e real médio pode ser decorrente da resolução das equações, dos parâmetros do modelo de turbulência utilizados para reproduzir o escoamento turbulento, das condições de ambiente impostas no decorrer do trabalho, e da ausência de perturbações externas, mas a simulação numérica esta submetida a erros de exatidão nos cálculos das componentes aerodinâmicas, da variação de pressão ao redor do veículo, segundo Han (1989) estão relacionados ao modelo de turbulência, e aos modelos de discretização utilizados para a resolução das equações. 


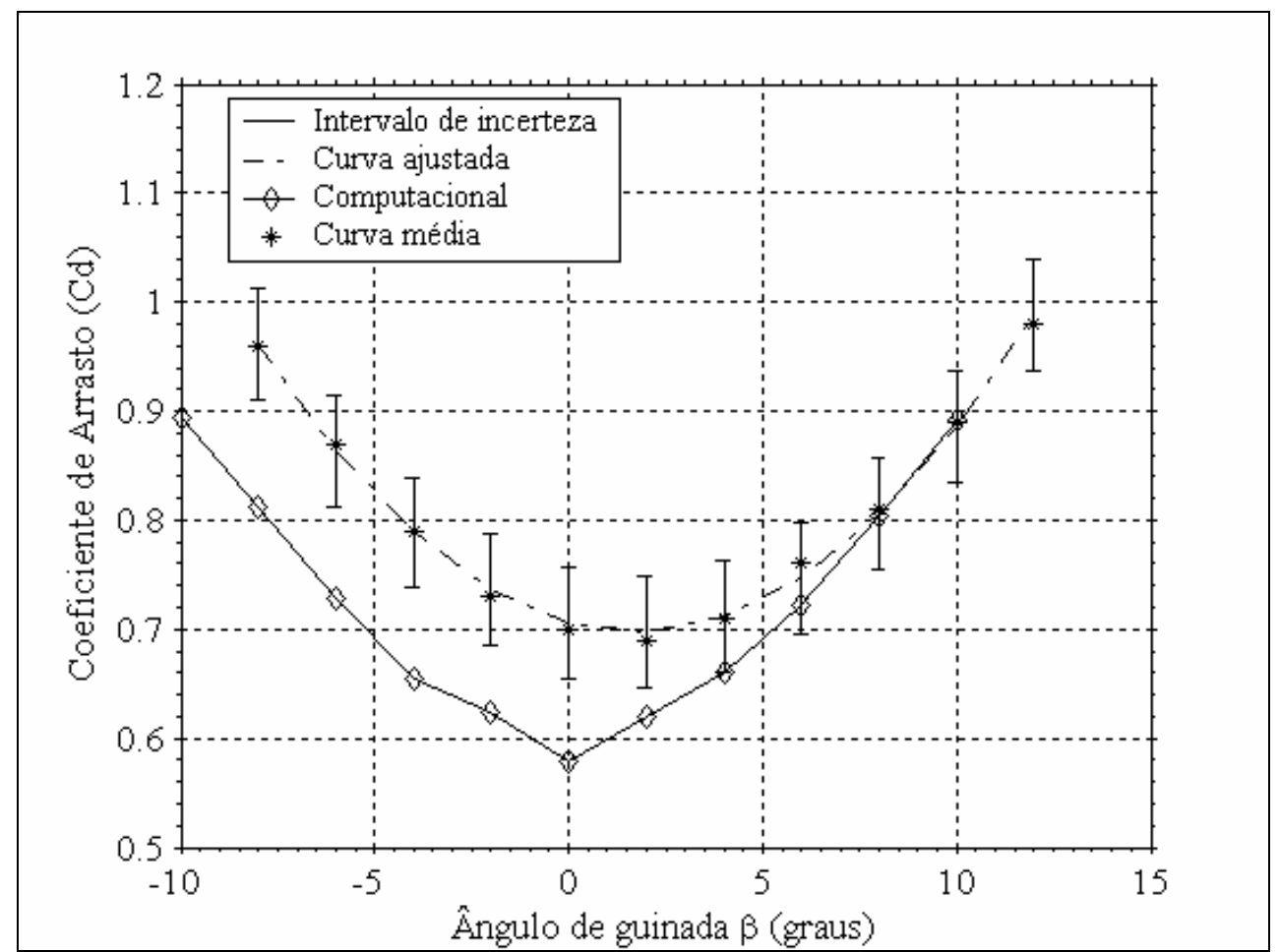

FIGURA 38 - Curva média do coeficiente de arrasto $C_{D}$ experimental e computacional em função do ângulo de guinada com vão livre entre o modelo e a mesa.

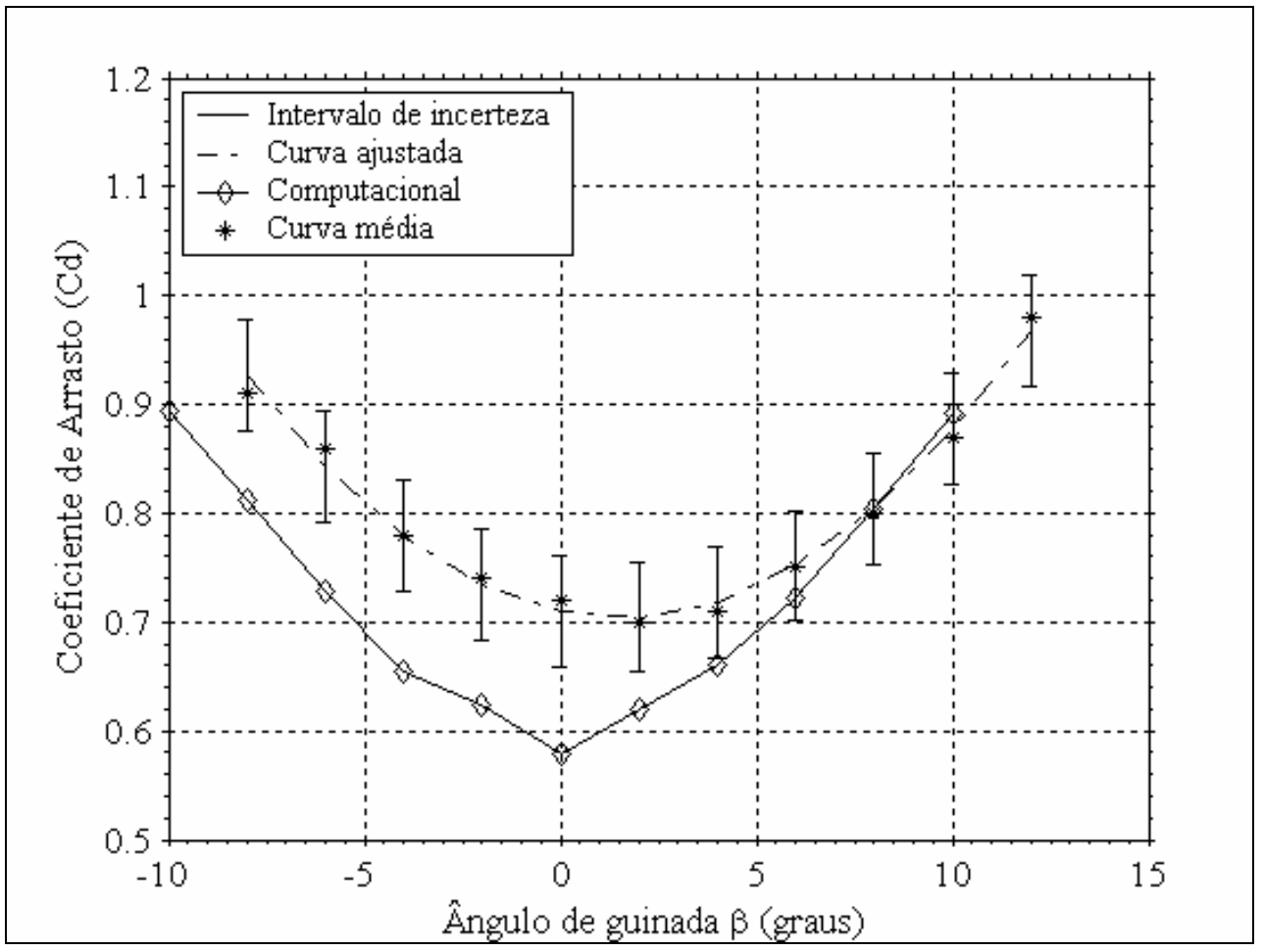

FIGURA 39 - Curva média do coeficiente de arrasto $C_{D}$ experimental e computacional em função do ângulo de guinada sem vão livre entre o modelo e a mesa 
Relacionando as curvas médias dos coeficientes de arrasto com a presença do vão livre e a ausência do vão livre entre o modelo e a mesa, como mostra a FIGURA 40, reparou-se que não há uma variação excessiva entre alguns valores dos coeficientes de arrasto para as configurações (presença e ausência do vão livre) simuladas no presente trabalho, contradizendo os estudos de Diuzet (1986) sobre a distância entre a superfície inferior do modelo e o solo, e Sardou (1986) referente à simulação das rodas sem rotação, ocasionando um aumento do coeficiente de arrasto aerodinâmico.

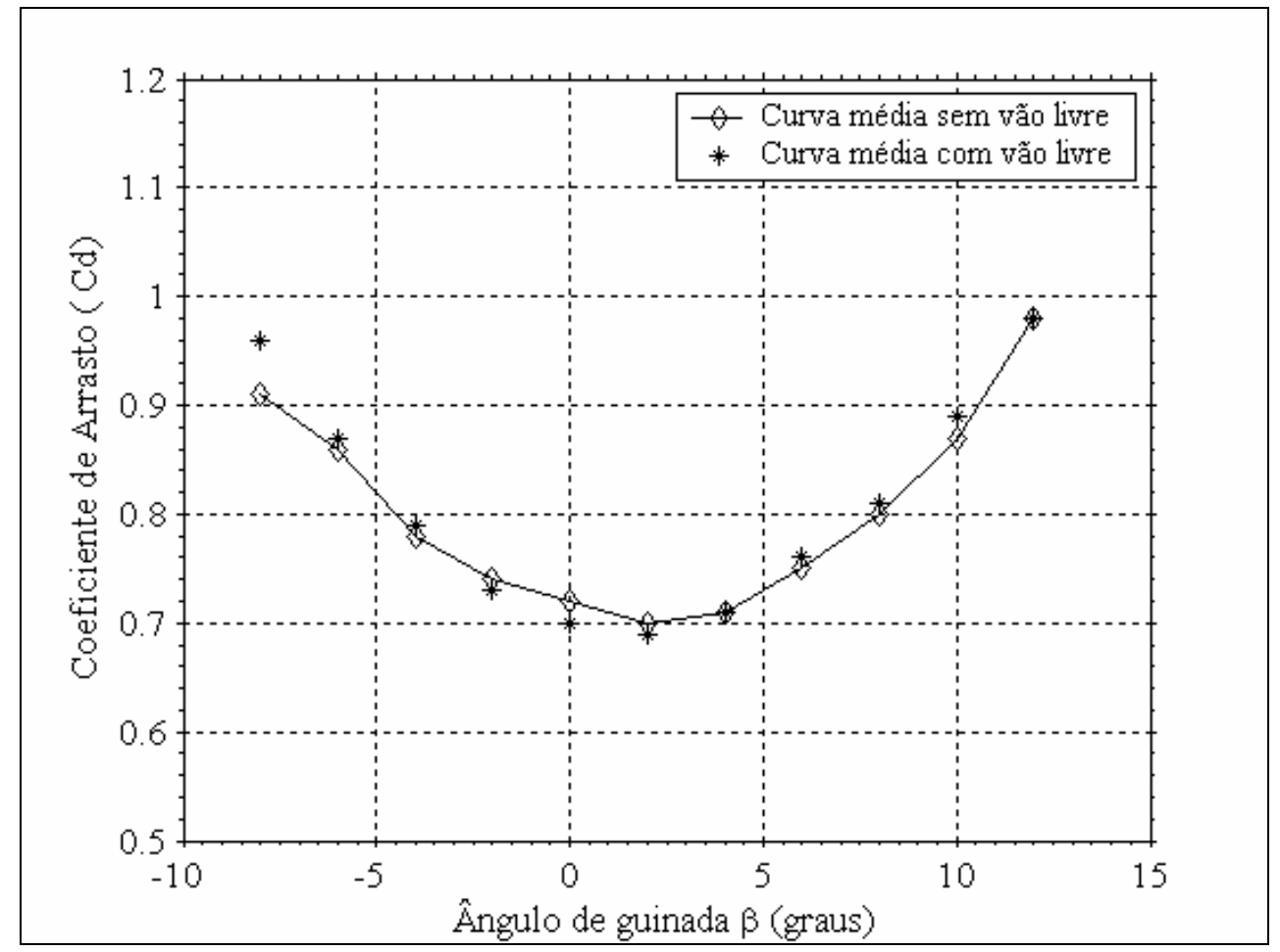

FIGURA 40 - Comparação das curvas médias dos coeficientes de arrasto com e sem vão livre.

Outro parâmetro analisado neste trabalho é a força lateral aerodinâmica em função das variações do ângulo de guinada $(\beta)$. Os valores dos coeficientes de força lateral são muito importantes, quando se estuda a estabilidade de um autoveículo. Uma grande sensibilidade a ventos laterais pode gerar problemas de estabilidade gerando redução na segurança e desconforto aos passageiros.

Na FIGURA 41 e FIGURA 42, observa-se que com os ajustes dos ângulos e guinada $(\beta)$ e o deslocamento das curvas médias dos coeficientes de força lateral experimental com a presença e ausência do vão livre para a direita, apontam uma 
pequena variação com os resultados computacionais. Ainda analisando a FIGURA 41 e FIGURA 42, verificou-se que os resultados dos coeficientes de força lateral computacional não tiveram nenhuma perturbação externa obtendo uma curva linear, isto é decorrente da resolução das equações, dos parâmetros utilizados para reproduzir o escoamento turbulento, das condições de ambiente imposta no decorrer do trabalho, como proposto por Han (1989) anteriormente, estas condições devem ser aperfeiçoadas de tal forma que diminuam os erros numéricos.

$\mathrm{Na}$ medição da força lateral experimental para os ângulos de guinada houve algumas interferências na sua mensuração como: no sinal elétrico da componente lateral, à imprecisão na simetria do modelo, a forma de posicionamento do modelo incidente ao escoamento de ar do túnel, que ocasionou a imprecisão dos valores e a necessidade de ajustar às curvas dos coeficientes de arrasto e força lateral. Comparando a variação entre as curvas referentes para cada medição realizada do trabalho ora proposto com o de Videira (2001) observou-se uma similaridade entre a disposição das curvas, sendo que para as modificações frontais feitas pelo autor propuseram uma pequena contribuição para os valores de coeficiente de força lateral.

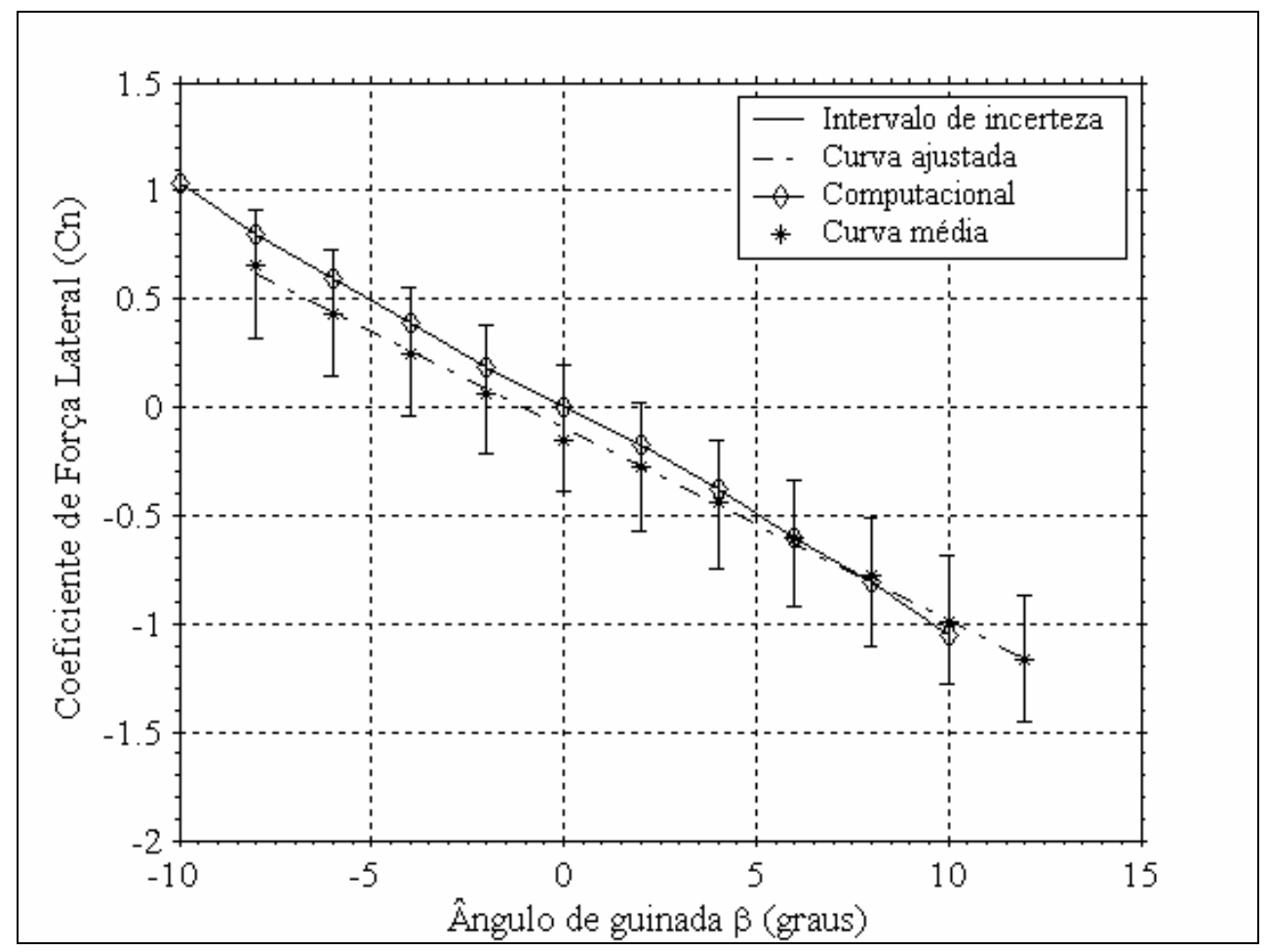

FIGURA 41 - Curva média do coeficiente da força lateral $\mathrm{C}_{\mathrm{N}}$ experimental e computacional em função do ângulo de guinada com vão livre entre o modelo e a mesa. 


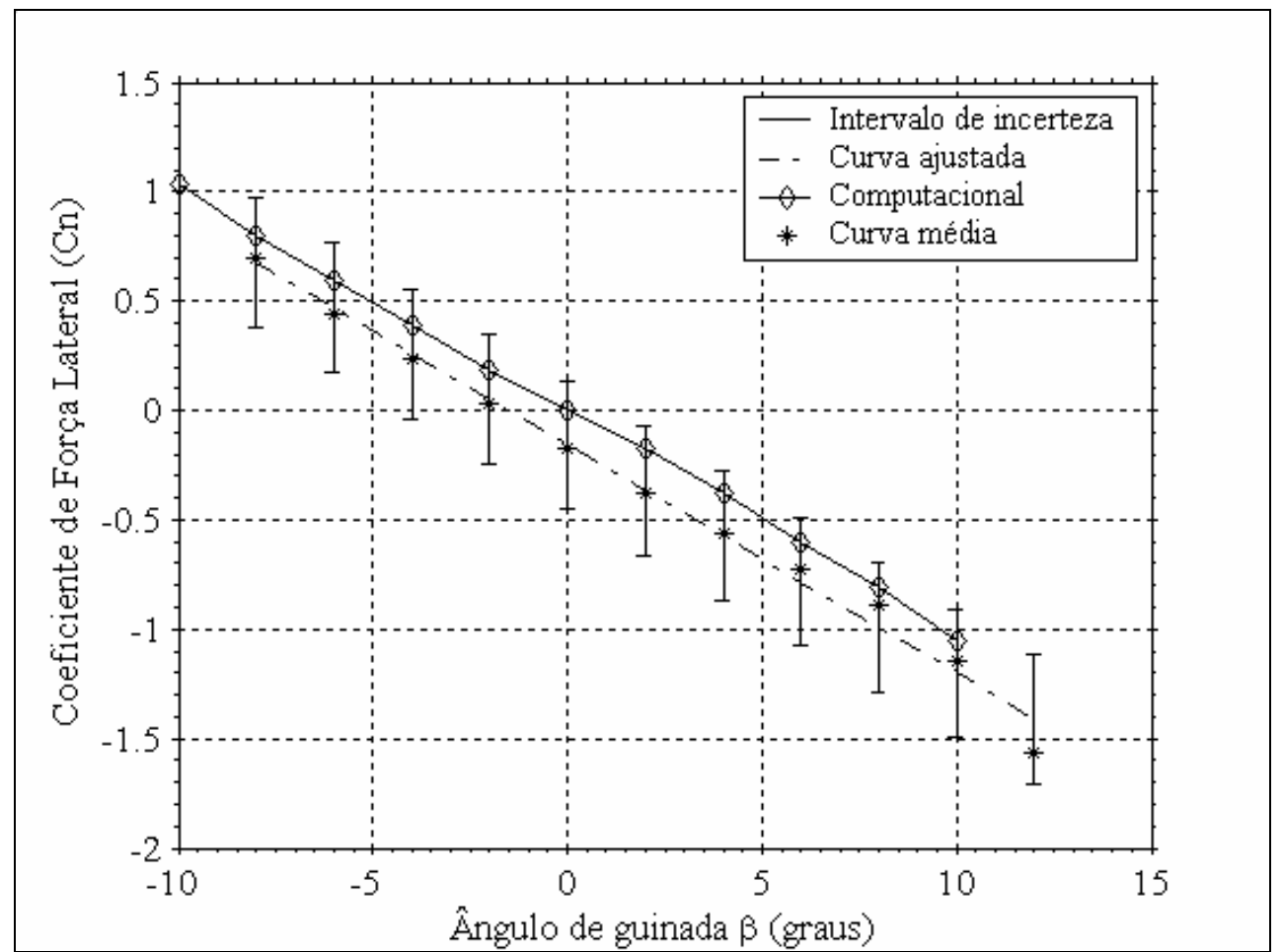

FIGURA 42 - Curva média do coeficiente da força lateral $\mathrm{C}_{\mathrm{N}}$ experimental e computacional em função do ângulo de guinada sem vão livre entre o modelo e a mesa.

Relacionando as curvas médias dos coeficientes de força lateral com a presença do vão livre e ausência do vão livre entre o modelo e a mesa, como mostra a FIGURA 43 , reparou-se que os valores para os ângulos de guinada com sinal positivo possuem uma variação, isto pode estar relacionado ao modo de calibração, a imprecisão da balança e ao posicionamento do modelo. 


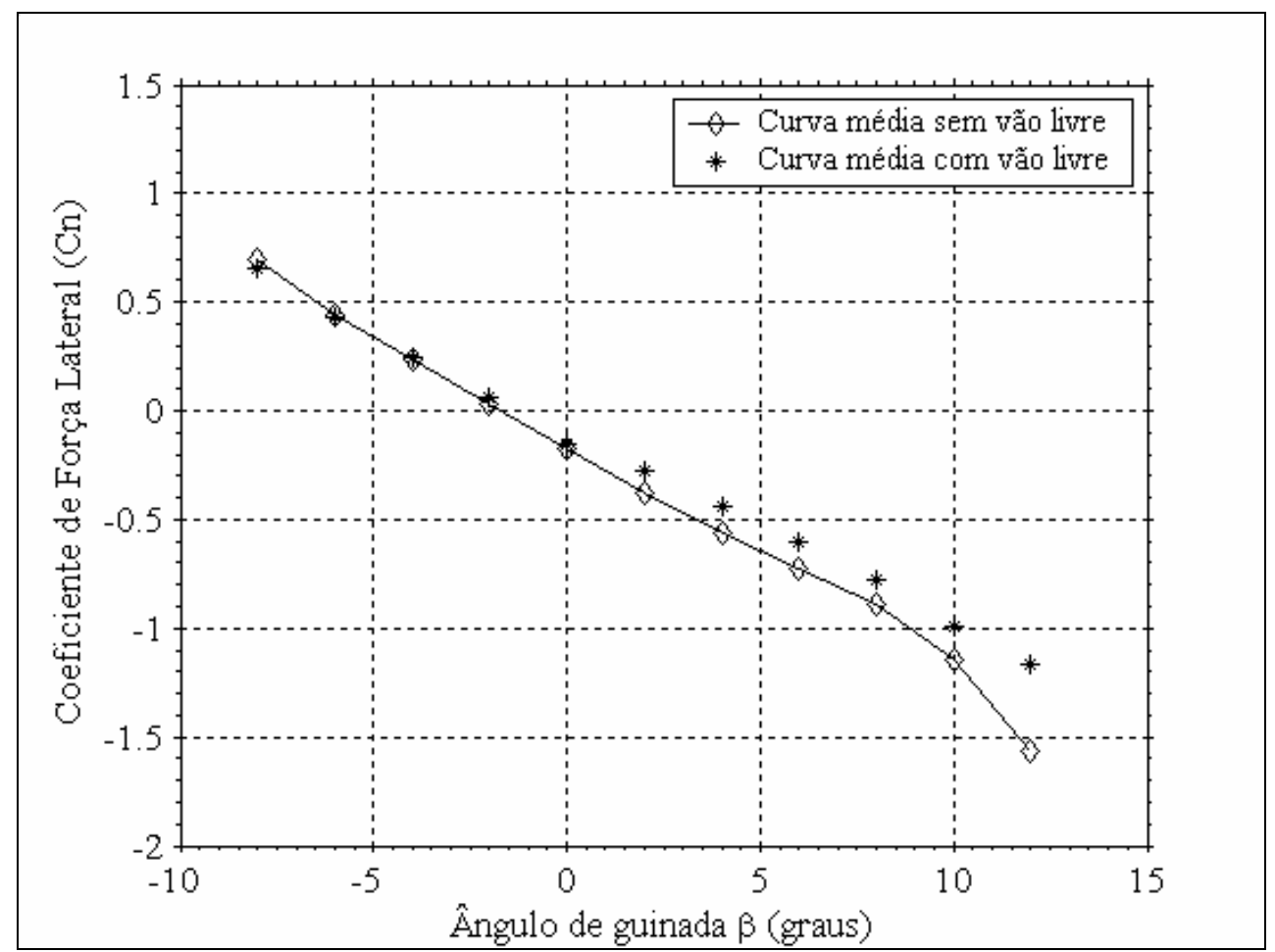

FIGURA 43 - Comparação das curvas médias dos coeficientes de força lateral com e sem vão livre.

Os valores dos coeficientes de arrasto e força lateral mensurado para todas as amostras encontraram-se dentro do intervalo de incerteza. A incerteza do coeficiente de arrasto é de $\pm 0,051$, para o coeficiente de força lateral o intervalo de incerteza foi de \pm 0,295, no Apêndice C estão demonstrados os cálculos realizados para obter os intervalos de incertezas e os seus respectivos valores.

Os efeitos decorrente da variação do ângulo de guinada $\beta$, requerem um aumento da potência do motor necessária para ganhar ou manter a velocidade do veículo. A necessidade de extrair mais potência do motor faz com que haja um consumo de combustível maior acarretando uma elevada emissão de poluente no ar atmosférico. É interessante que um veículo apresente uma baixa variação do coeficiente de arrasto $\left(C_{D}\right)$ em função do ângulo de guinada $(\beta)$, pois um veículo trafegando em uma estrada, certamente estará sujeito a ventos de direções diferentes a de sua trajetória. Com isso, mais trabalhos devem ser realizados na parte frontal e traseira, com a implementação de dispositivos que alteram o escoamento de ar ou modificações nas superfícies que diminuam as regiões de separação sobre a carroceria do ônibus, para que possam ser utilizá-los comercialmente. 


\subsection{Apresentação dos ensaios de visualização}

Os ensaios realizados com composto de dióxido de titânio e fios de lã (tufts) têm a finalidade de visualizar o escoamento sobre as superfícies do modelo, e observar as regiões de recirculação, decorrente a posição desordenada dos fios de lã (tufts). Os ensaios utilizando "tufts" foram realizados com ângulos de guinada $\beta$ de $0^{\circ}, 6^{\circ}$ e $10^{\circ}$, mesmo procedimento de visualização feito por Mello (1999) em um veículo de passeio; e com ângulos de guinada $0^{\circ}, 4^{\circ}$ e $8^{\circ}$ para a visualização com o composto de dióxido de titânio.

$\mathrm{O}$ aumento na incidência do escoamento no ônibus mostra crescimento das regiões de recirculação, ocasionando um aumento significativo nos coeficientes das forças aerodinâmicas. Na FIGURA 44(b), FIGURA 45(b) e FIGURA 46(b) pode-se observar o aumento da região de recirculação com o aumento do ângulo de guinada. As figuras também mostram a formação de um vórtice na quina superior do modelo, devido à movimentação desordenada dos fios de lã (tufts).

Na FIGURA 44(a), FIGURA 45(a) e FIGURA 46(a) pode-se observar a presença de uma região de estagnação na parte frontal do modelo pelo posicionamento dos fios de lã que estão direcionados para as laterais, para baixo e para cima. A FIGURA 44(c), FIGURA 45(c) e FIGURA 46(c) mostram total separação do escoamento de ar na parte traseira do modelo, diante da atividade desordenada dos "tufts" colocados nas extremidades da parte traseira.

Outra visualização para melhor observarmos o comportamento do escoamento nas superfícies do veículo é com um composto de dióxido de titânio, mostrando as regiões de recirculação através de linhas deixadas na superfície do modelo. Na FIGURA 50(a) e FIGURA 52(a) verificou-se a presença de uma região de recirculação na lateral do modelo. Diante da FIGURA 52(a) observou-se a formação de dois vórtices, um na parte superior e outro na parte inferior de maior intensidade em relação à FIGURA 50(a) com ângulo de guinada $\beta=0^{\circ}$.

Na FIGURA 49 nota-se o ponto de estagnação na parte frontal do modelo. Analisando outros fenômenos ocorridos nas superfícies notou-se a formação de uma bolha de separação no início da parte superior do modelo. A variação do ângulo de guinada ( $\beta$ ) faz com que a bolha se desloque para a lateral, como pode ser visto na FIGURA 50(b), FIGURA 51(a) e FIGURA 52(b). Verificou também a formação de 
vórtices ao longo da quina entre a superfície superior e lateral nos dois lados do modelo. A FIGURA 51(b) e FIGURA 52(c) mostra o aumento gradativo da intensidade dos vórtices com a variação do ângulo de guinada $\beta$ o que gera aumento no arrasto. Na notase o ponto de estagnação na parte frontal do modelo.

Para a comparação com os resultados de visualização com "tufts" e o composto de dióxido de titânio, uma análise foi feita com os resultados computacionais na superfície do modelo com linhas de corrente (streamlines) gerada com o auxílio do programa comercial ANSYS ${ }^{T M} \mathrm{CFX}^{T M}$ CFD. Comparando a FIGURA 53 a FIGURA 58 com a FIGURA 44 a FIGURA 52, verificou-se uma similaridade na estrutura do escoamento de ar experimental e computacional com variação do ângulo de guinada $\beta$. No entanto, para a FIGURA 48 e FIGURA 59 observou-se uma desassemelhança no escoamento de ar experimental e computacional incidente na superfície lateral do modelo. Na visualização experimental com fios de lã pode-se ver a movimentação desordenada do "tufts", indicando uma região de recirculação e na visualização computacional isto não pode ser visto, tal ausência do descolamento do escoamento de ar na superfície lateral para os dados computacionais pode ser referente a escolha do modelo de turbulência ou a incapacidade na precisão numérica das equações para prever qualquer variação nos cálculos matemáticos. 


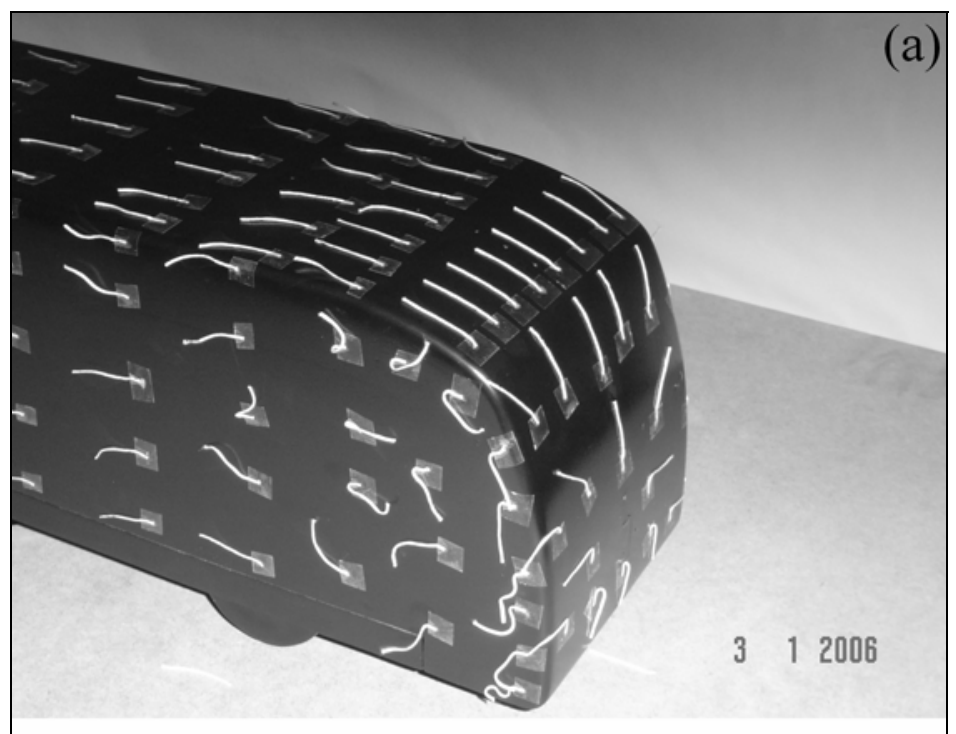

(b)
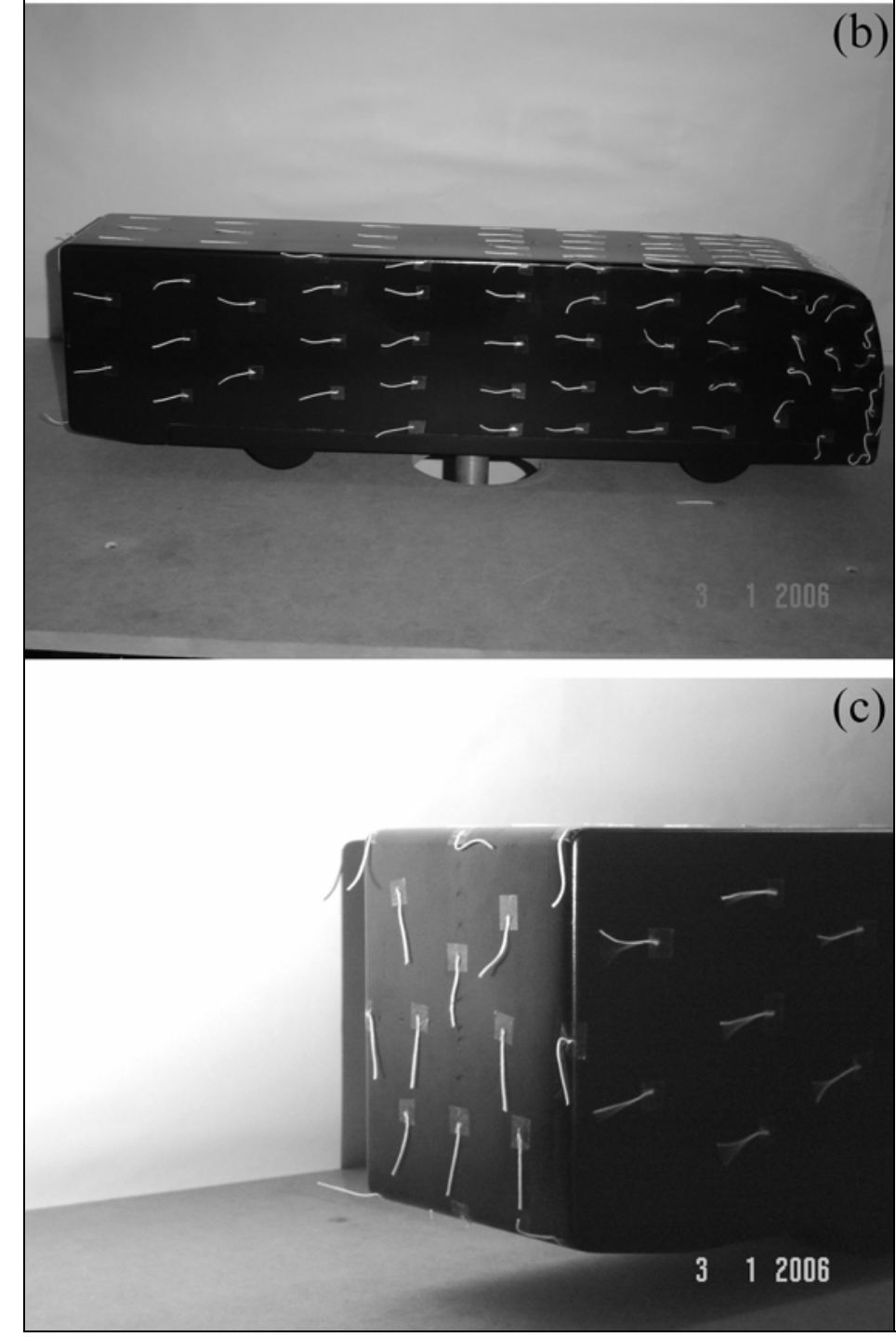

FIGURA 44 - Visualização do escoamento com “tufts", para $\beta=0^{\circ}$. 


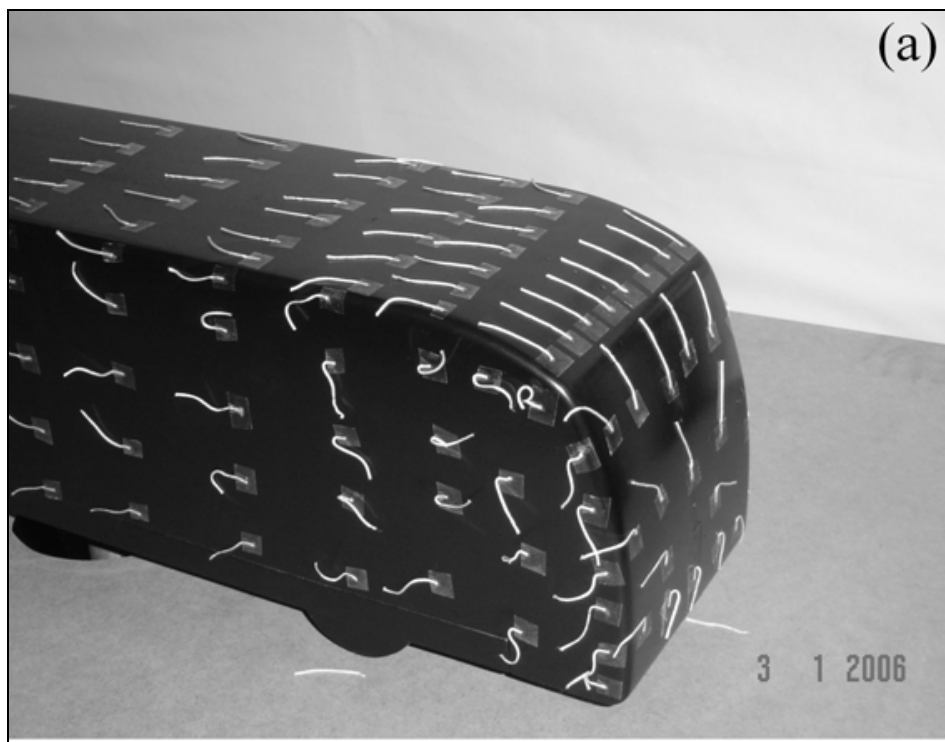

(a)

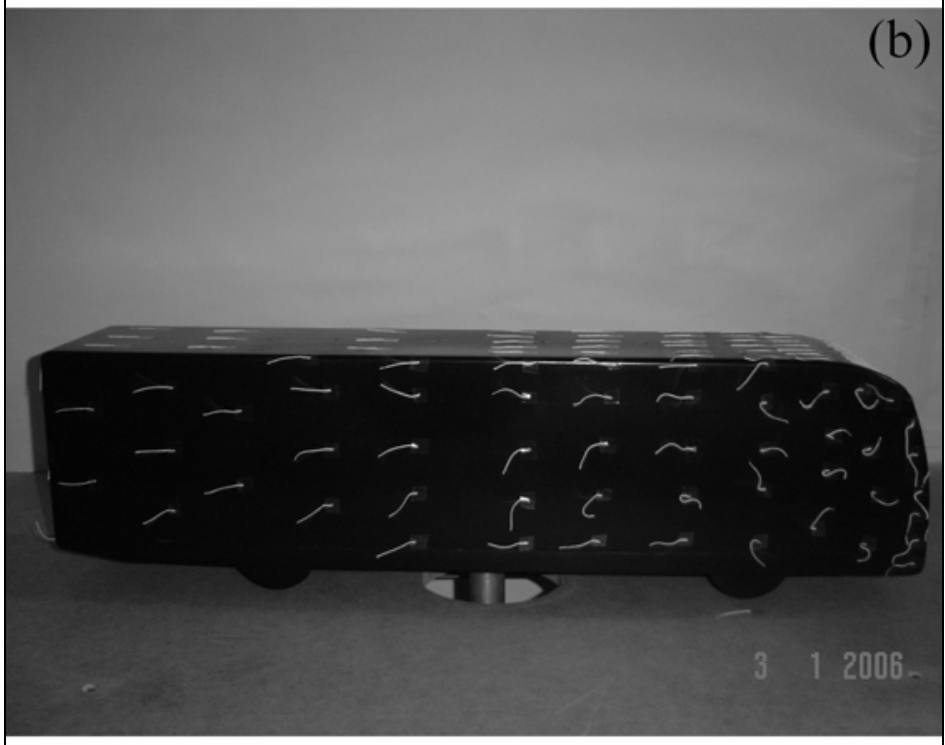

(b)

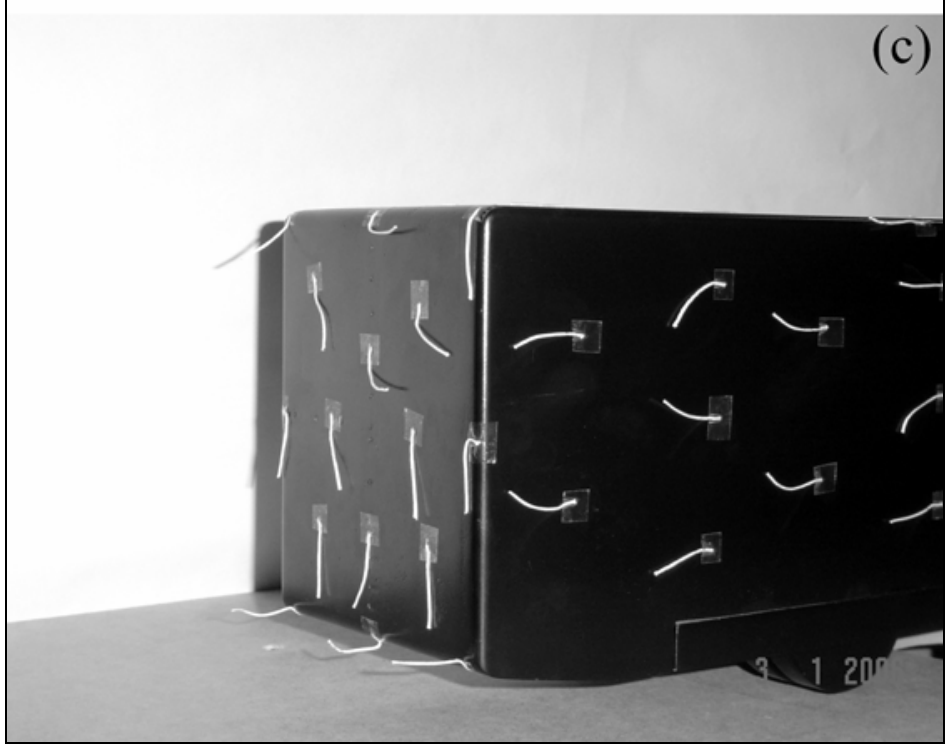

FIGURA 45 - Visualização do escoamento com "tufts", para $\beta=6^{\circ}$. 

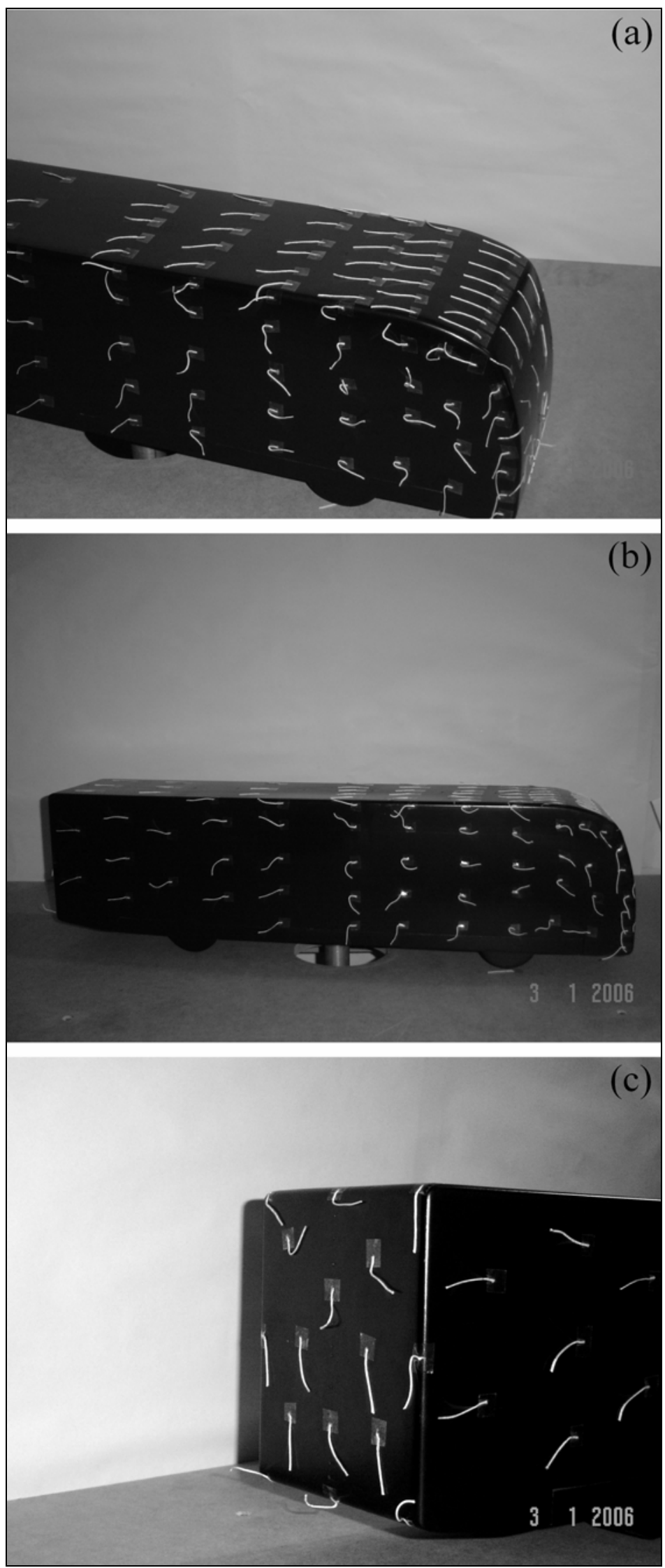

FIGURA 46 - Visualização do escoamento com "tufts", para $\beta=10^{\circ}$. 


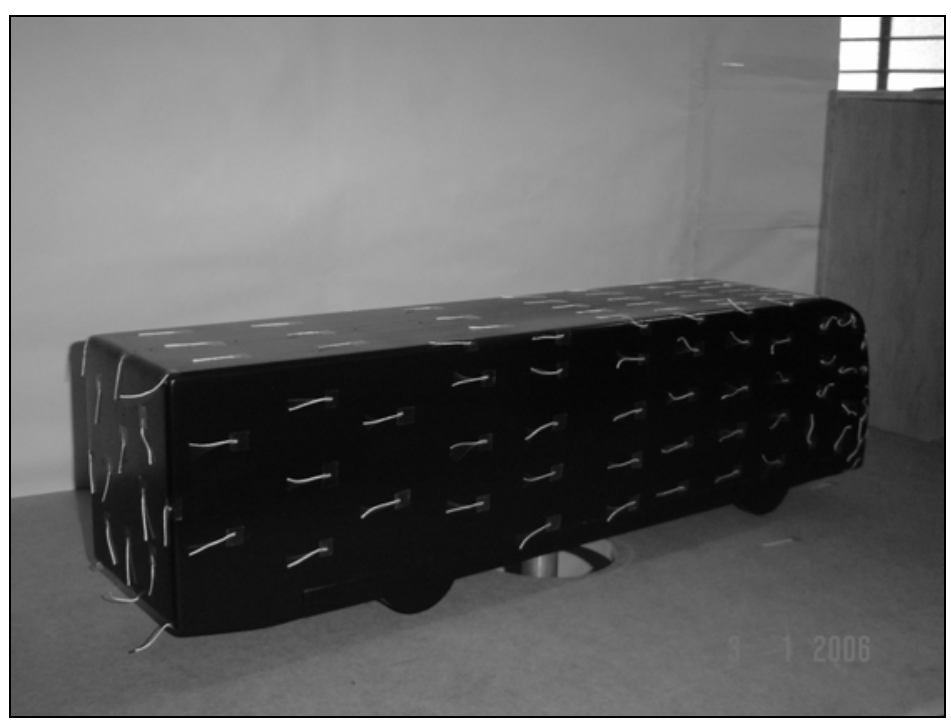

FIGURA 47 - Visualização do escoamento com "tufts", para $\beta=-6^{\circ}$.

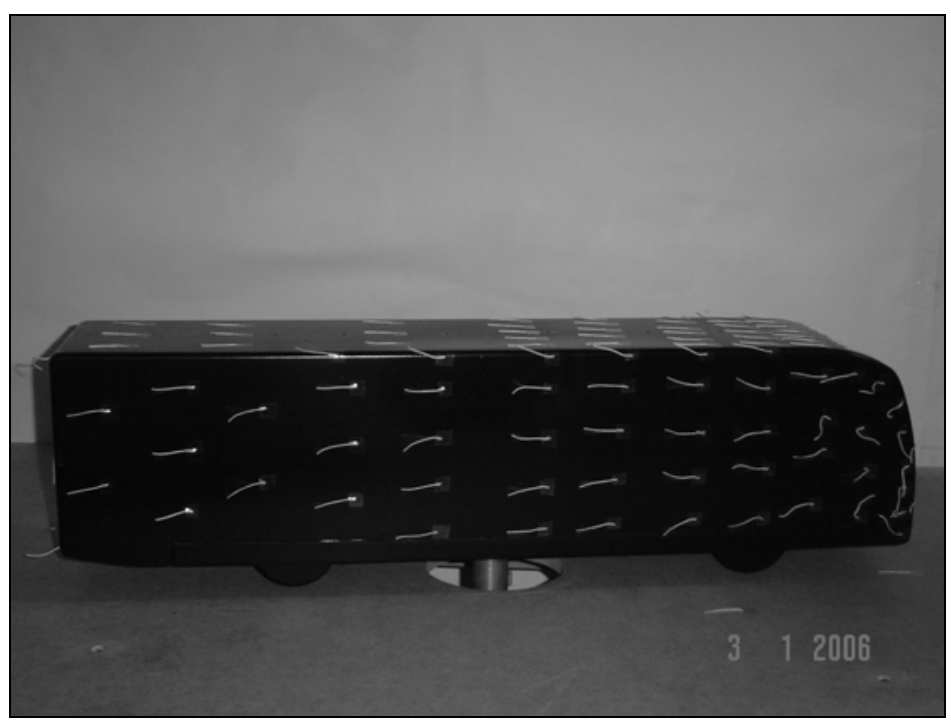

FIGURA 48 - Visualização do escoamento com "tufts", para $\beta=-10^{\circ}$. 


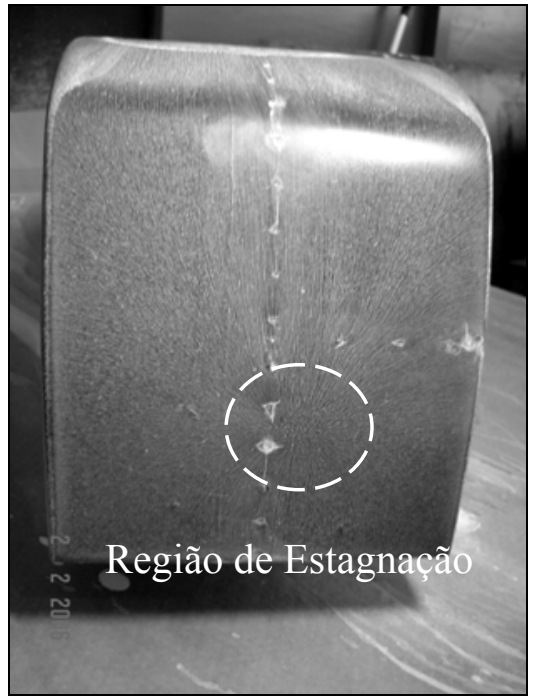

FIGURA 49 - Visualização do ponto de estagnação.

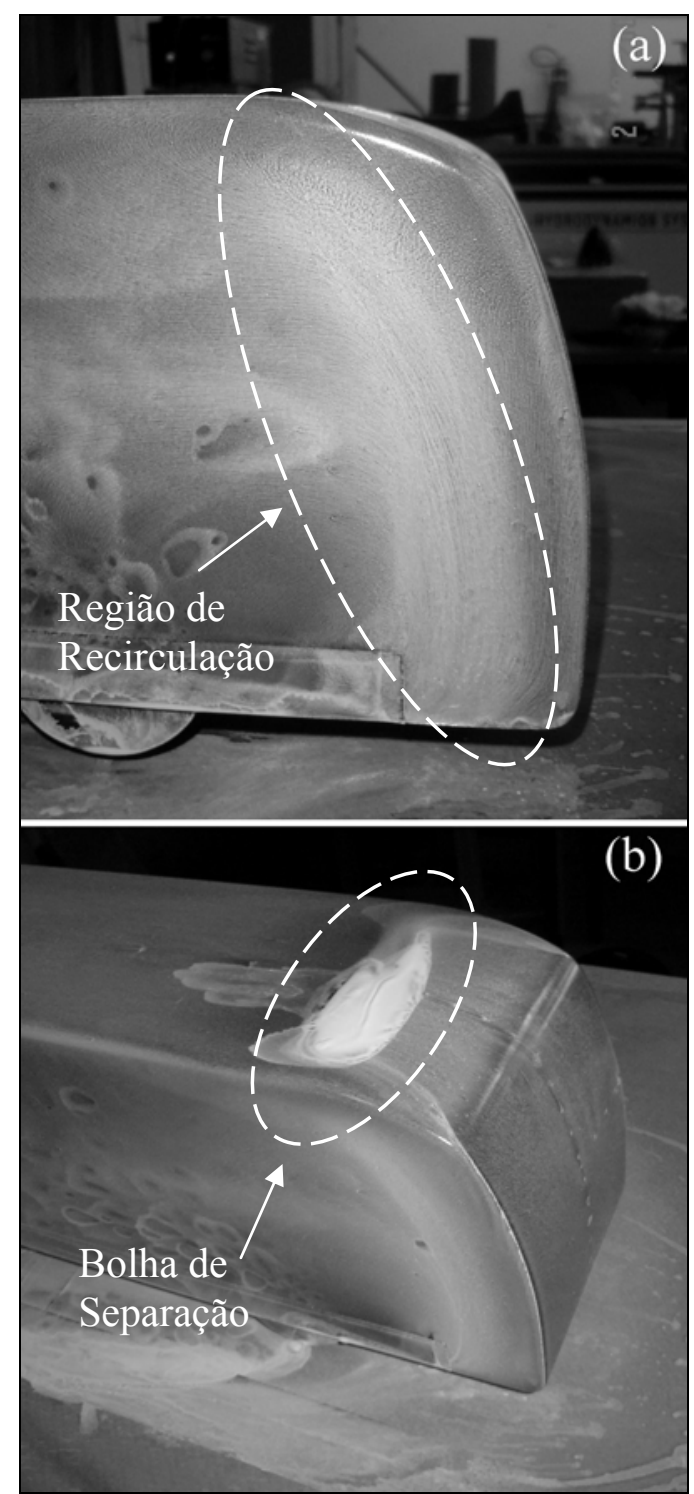

FIGURA 50 - Visualização do escoamento com composto de dióxido de titânio, para $\beta=0^{\circ}$. 

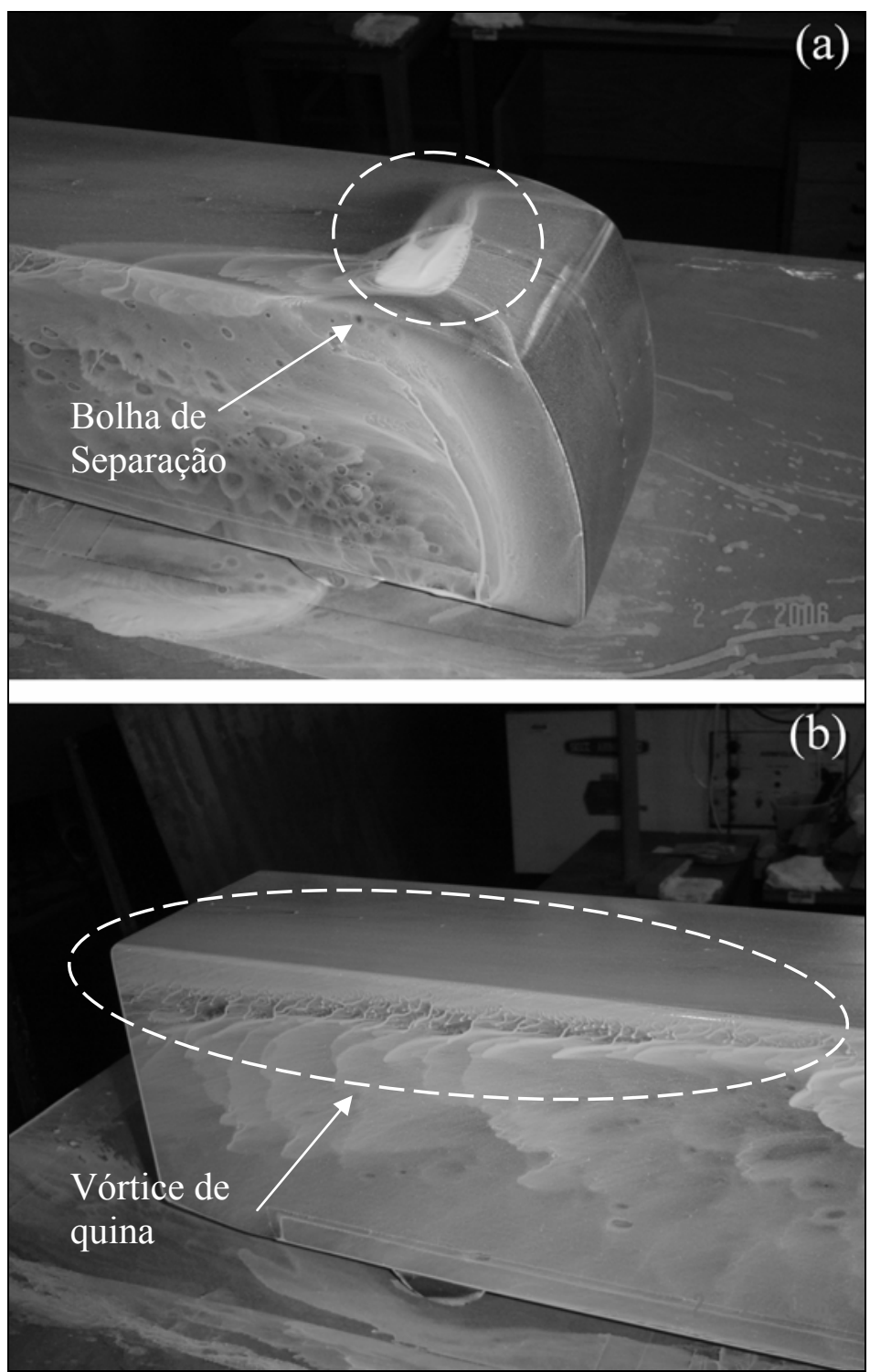

FIGURA 51 - Visualização do escoamento com composto de dióxido de titânio, para $\beta=4^{\circ}$. 

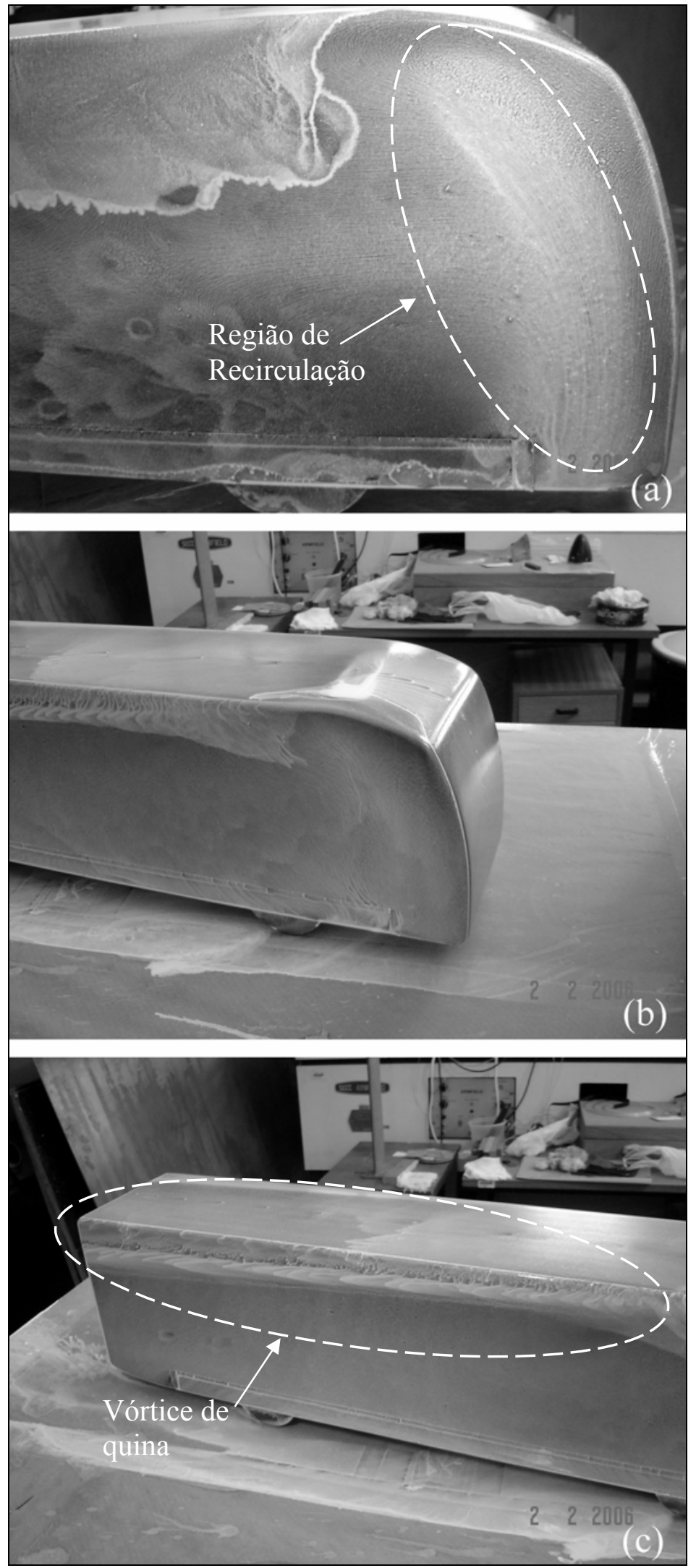

FIGURA 52 - Visualização do escoamento com composto de dióxido de titânio, para $\beta=8^{\circ}$. 


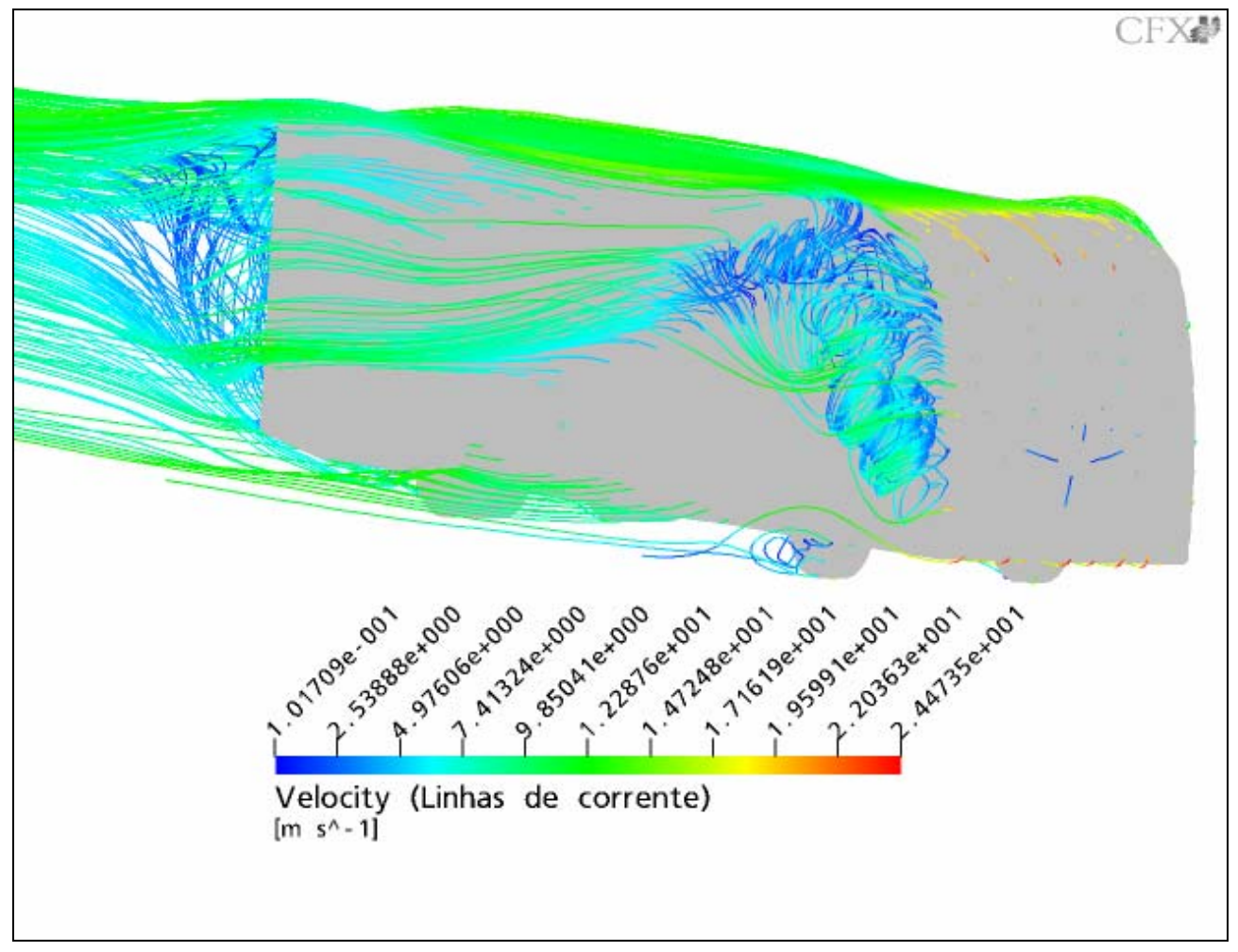

FIGURA 53 - Linhas de corrente de escoamento sobre o modelo, para $\beta=0^{\circ}$.

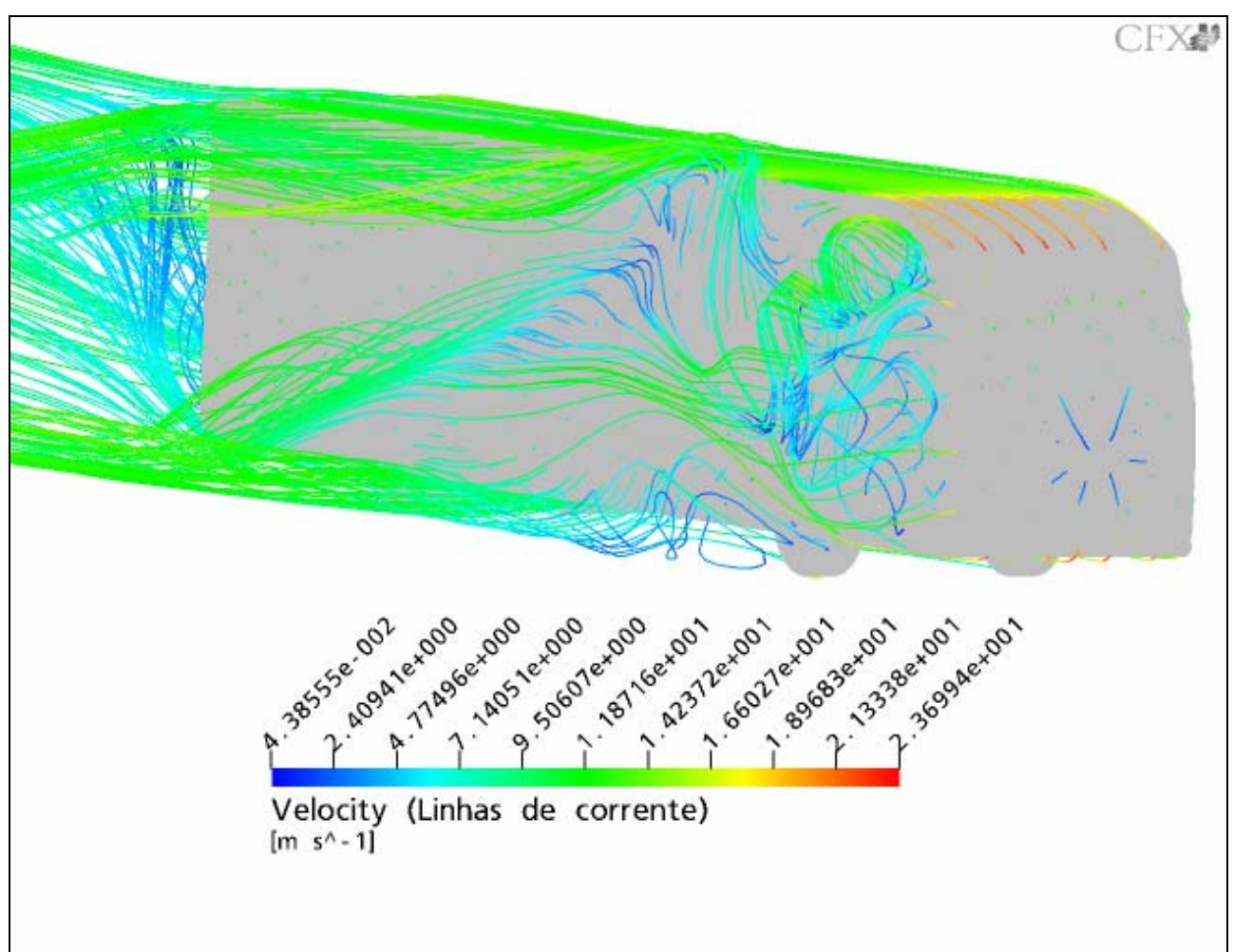

FIGURA 54 - Linhas de corrente do escoamento sobre o modelo, para $\beta=4^{\circ}$. 


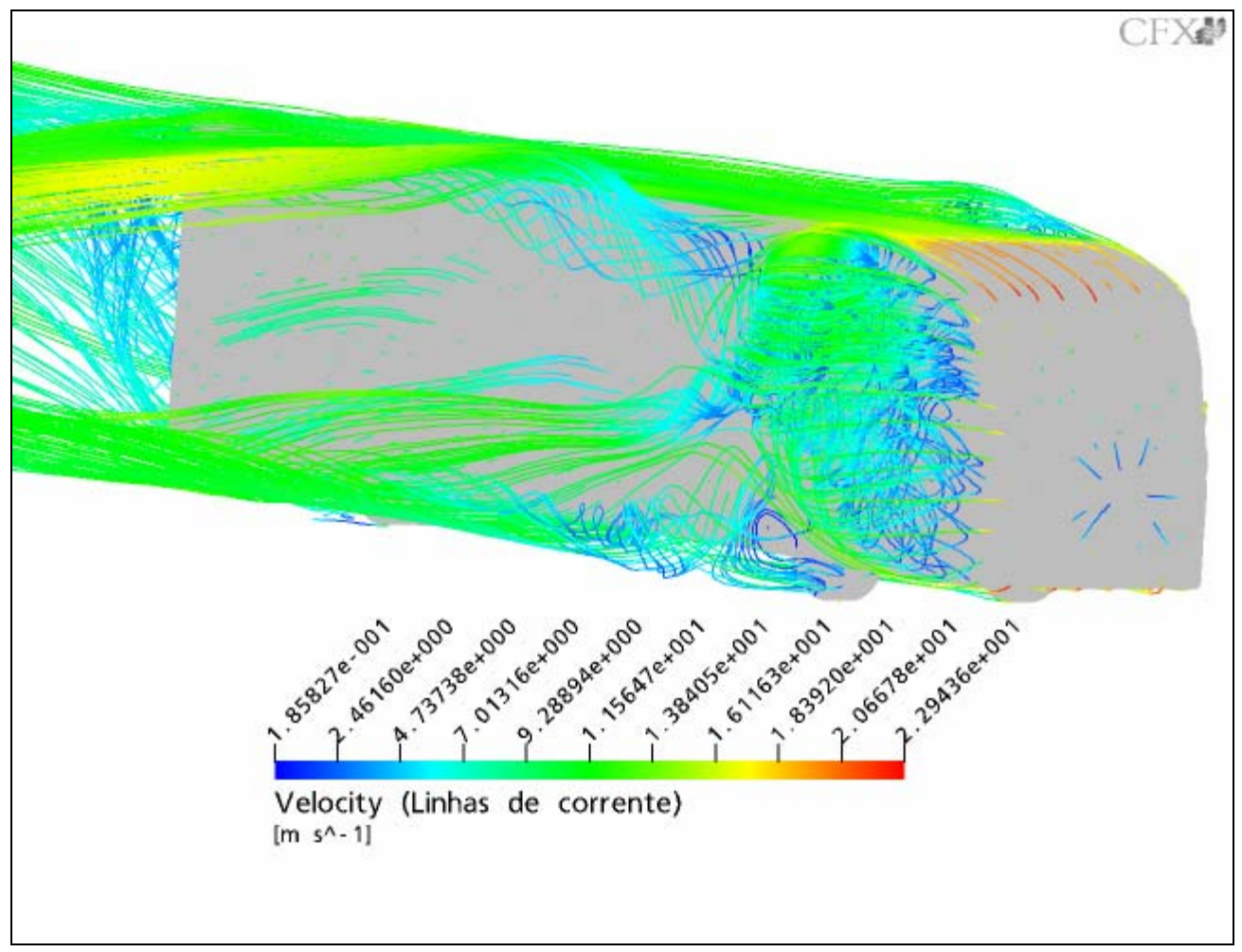

FIGURA 55 - Linhas de corrente do escoamento sobre o modelo, para $\beta=6^{\circ}$.

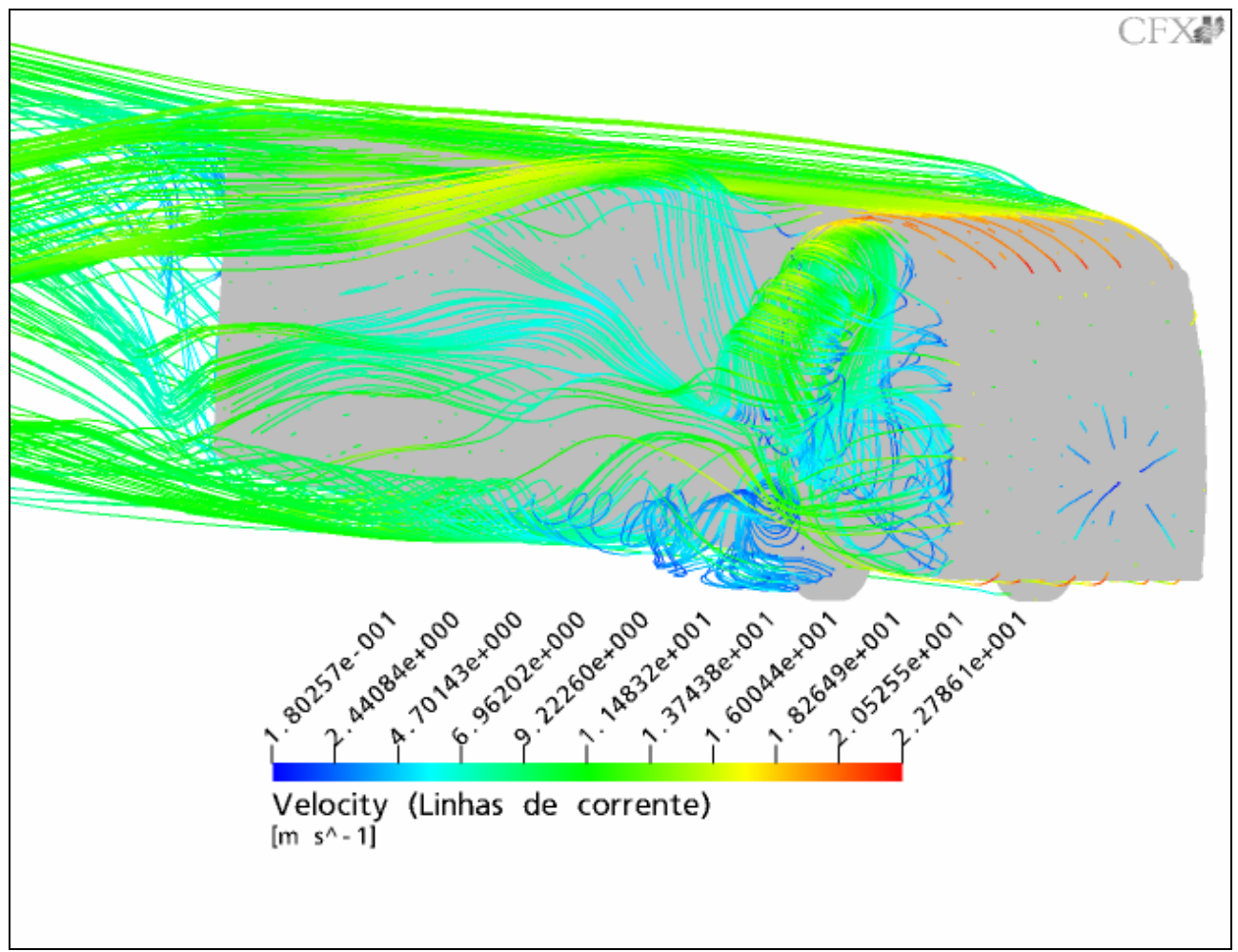

FIGURA 56 - Linhas de corrente do escoamento sobre o modelo, para $\beta=8^{\circ}$. 


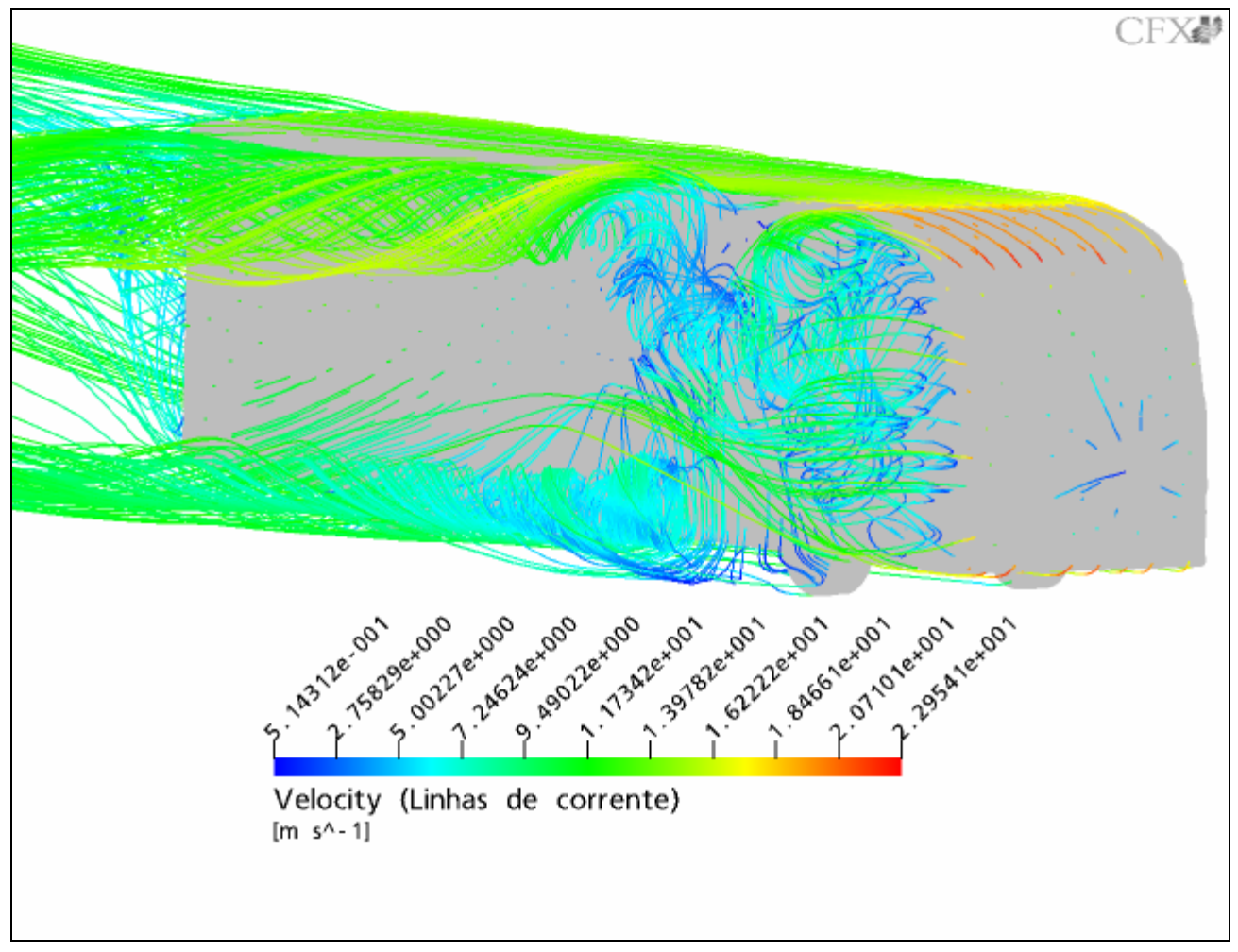

FIGURA 57 - Linhas de corrente do escoamento sobre o modelo, para $\beta=10^{\circ}$.

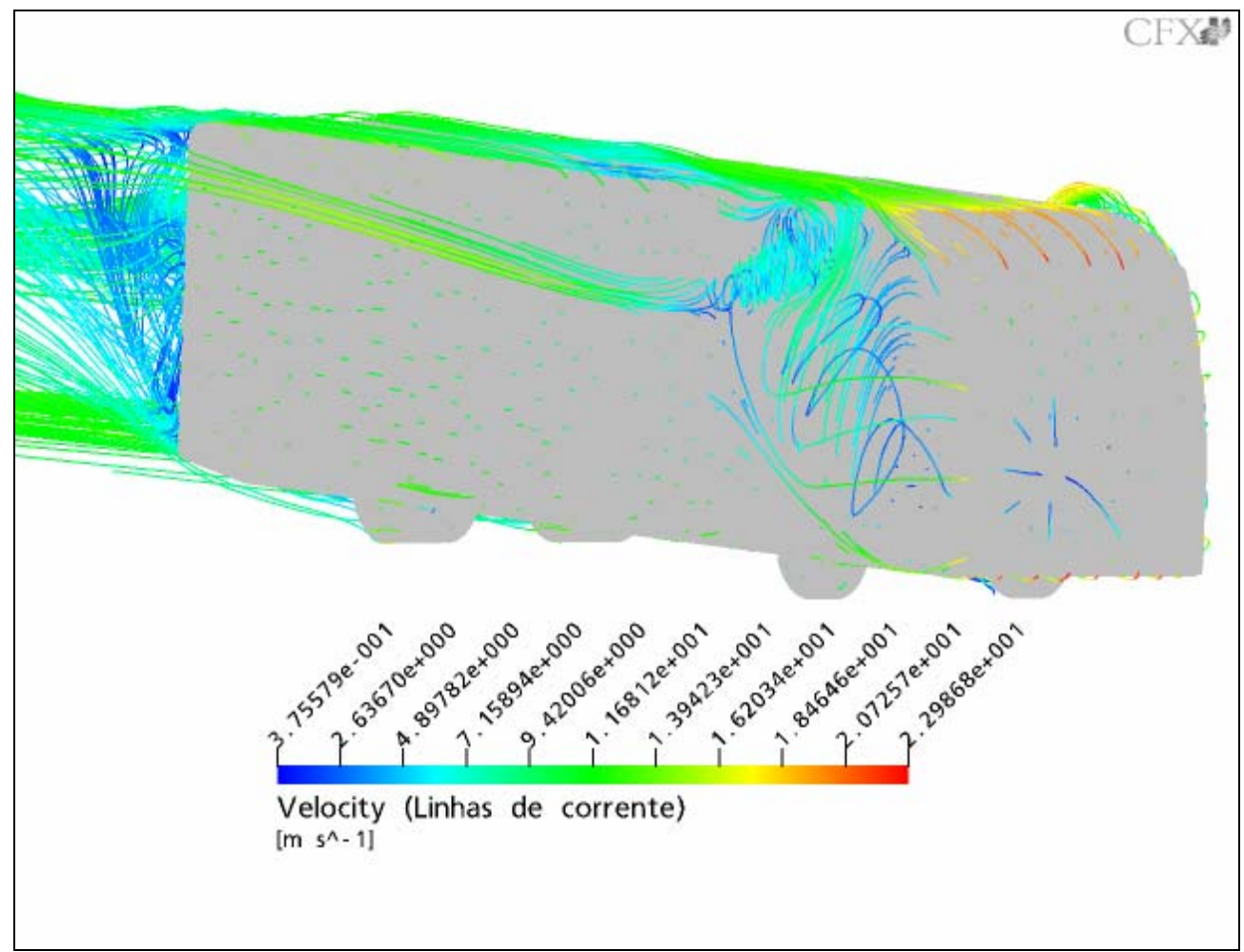

FIGURA 58 - Linhas de corrente do escoamento sobre o modelo, para $\beta=-6^{\circ}$. 


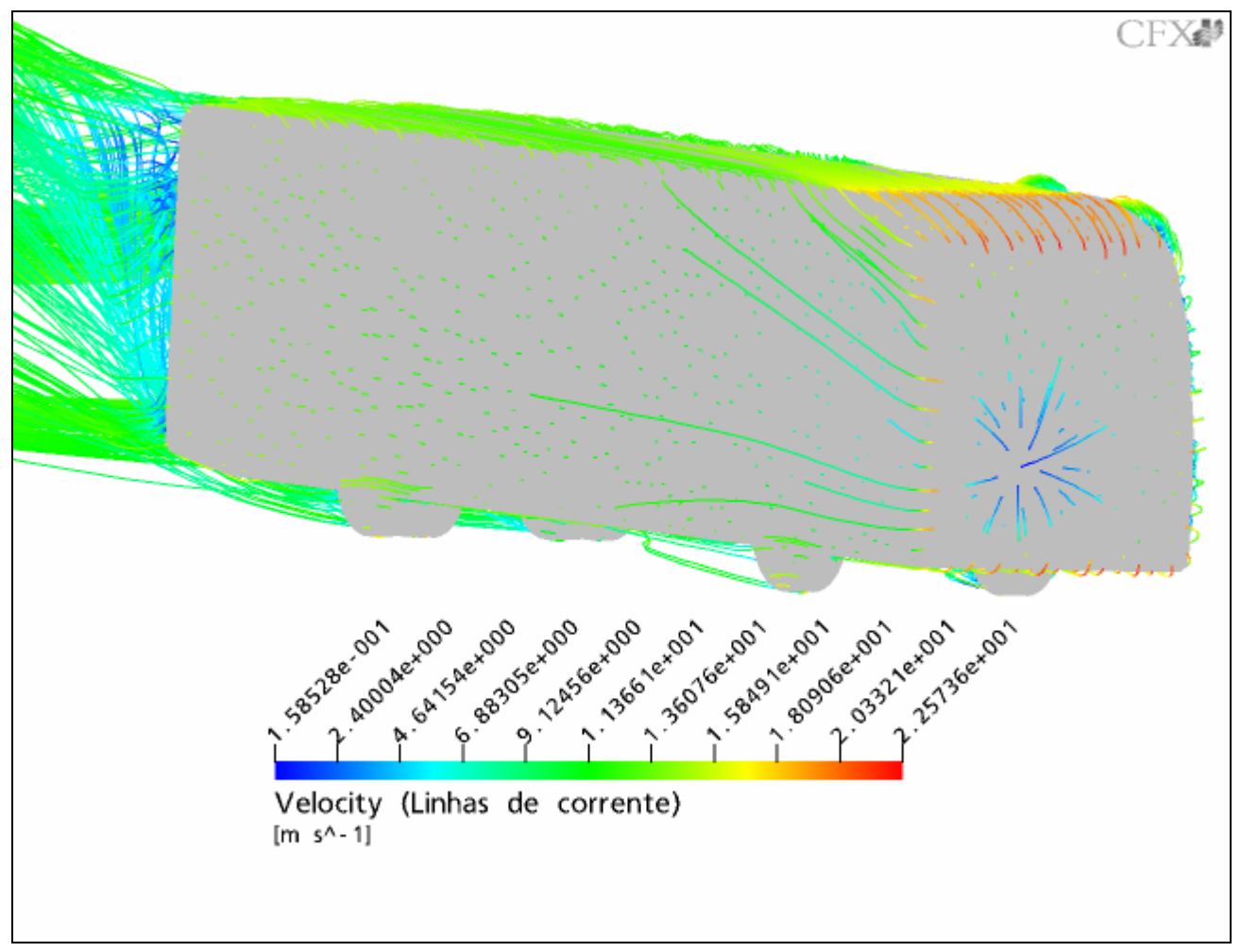

FIGURA 59 - Linhas de corrente do escoamento sobre o modelo, para $\beta=-10^{\circ}$.

\subsection{Apresentação dos ensaios de pressão}

Os ensaios de pressão nas superfícies do modelo são importantes para a análise do escoamento de ar para identificar regiões de recirculação sobre a carroceria que não possam ser vistas, quando o modelo é submetido a um escoamento de ar com ângulo de guinada $\beta \neq 0$, ocorre uma diferença na distribuição de pressão nas superfícies laterais do modelo em relação ao plano de simetria, resultando o surgimento de regiões de baixa pressão. Os resultados obtidos com a variação do ângulo de guinada $\beta$ de $0^{\circ}, 4^{\circ}$ e $8^{\circ}$ são mostrados a seguir no formato de gráficos. Na FIGURA 60 estão expostas as tomadas de pressão na linha de simetria do modelo. As tomadas de pressão na linha frontal, lateral e traseira do modelo são mostradas na FIGURA 64.

Pela FIGURA 61 a FIGURA 63, observou-se que as curvas dos coeficientes de pressão na linha de simetria do modelo para os dados experimentais e computacionais possuem uma similaridade. Analisando as curvas nota-se que a variação do ângulo de guinada $\beta$ não possui nenhuma influência na distribuição de pressão na simetria do modelo. Na região frontal o escoamento se encontra estagnado, devido a grande área de bloqueio e o alto valor do coeficiente de pressão. $\mathrm{Na}$ transição entre a parte frontal e a 
curvatura o fluxo acelera diminuindo o coeficiente de pressão. Mais adiante a presença de uma bolha de separação aumenta o coeficiente de pressão. Na parte superior do modelo o coeficiente de pressão se torna praticamente constante devido ao recolamento do escoamento de ar. Ao contrário, na traseira, os coeficientes de pressão ficam constantes devido à região de baixa pressão, propiciada pela presença de vórtices.

Nas FIGURA 65 a FIGURA 67, verificou-se uma mudança do ponto de estagnação para a lateral do modelo, nos dados experimentais, devido a variação do ângulo de guinada $\beta$. Na análise do restante da curva lateral de coeficiente de pressão, observa-se uma aceleração do escoamento e logo em seguida uma separação. O escoamento ao longo da superfície lateral recola e permanece uniforme. Na traseira o fluxo se separa gerando vórtices próximos à superfície ocasionando uma baixa pressão.

Outra análise foi feita verticalmente com tomadas de pressão no final da superfície lateral, onde está situado o motor do ônibus. O objetivo desta análise foi a preocupação da refrigeração do motor que não está sujeito às mesmas condições de caminhões e veículos de passageiros, onde o motor posicionado na frente sofre uma refrigeração forçada sem o constante funcionamento da ventoinha, isto é, devido as altas velocidades desenvolvidas pelo veículo. Observou-se na FIGURA 65 a FIGURA 67 que os coeficientes de pressão (“+ Lateral Traseira Vert.") são relativamente baixos, isto é, a velocidade do escoamento ao longo desta região é alta, diminuindo a refrigeração do motor do ônibus, o que pode, por sua vez, requerer refrigeração forçada através de ventoinha. Este assunto requer um melhor estudo a fim de aprimorar componentes para aumentar a eficiência do sistema de arrefecimento do motor.

Diante da FIGURA 68 a FIGURA 75, pode-se melhor entender as regiões de separação e a região de estagnação ocorrida sobre o modelo. Os coeficientes de pressão podem ser vistos ao longo do modelo na FIGURA 68 a FIGURA 72 com a variação do ângulo de guinada $\beta$. Quando o modelo é sujeito a um escoamento de ar com ângulo de guinada $\beta \neq 0^{\circ}$, surgi uma diferença de pressão na superfície lateral oposta do modelo propiciando uma maior região de baixa pressão, como pode ser observado na FIGURA 70 e FIGURA 72. No plano de simetria, para $\beta=0^{\circ}$ pode ser visto a distribuição de pressão sobre todo o modelo, como mostra a FIGURA 73, ainda no plano de simetria observa-se à região de separação do escoamento na parte traseira ocasionando a formação de vórtices, um superior e outro inferior, como mostra a FIGURA 74 e FIGURA 75. 


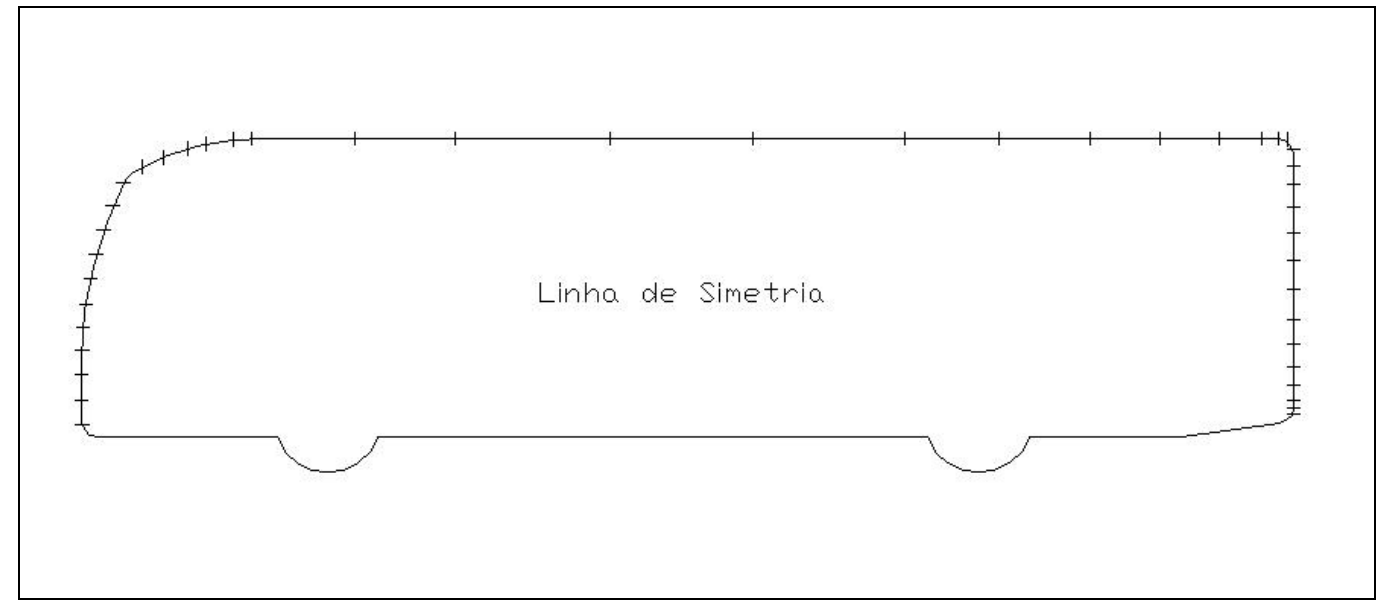

FIGURA 60 - Posição das tomadas de pressão na linha de simetria do modelo.

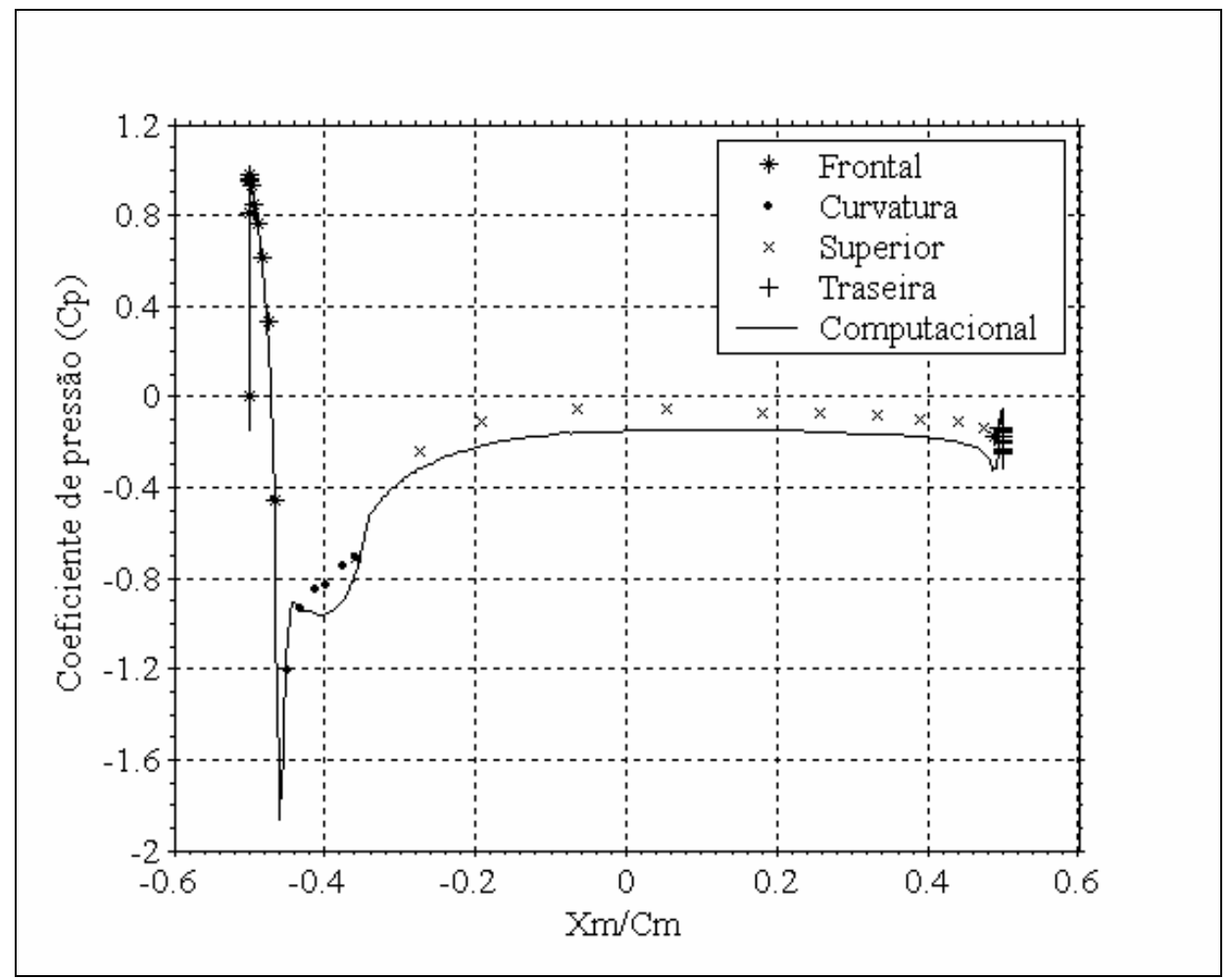

FIGURA 61 - Valores adimensionais dos coeficientes de pressão no plano de simetria do modelo, para $\beta=0^{\circ}$. 


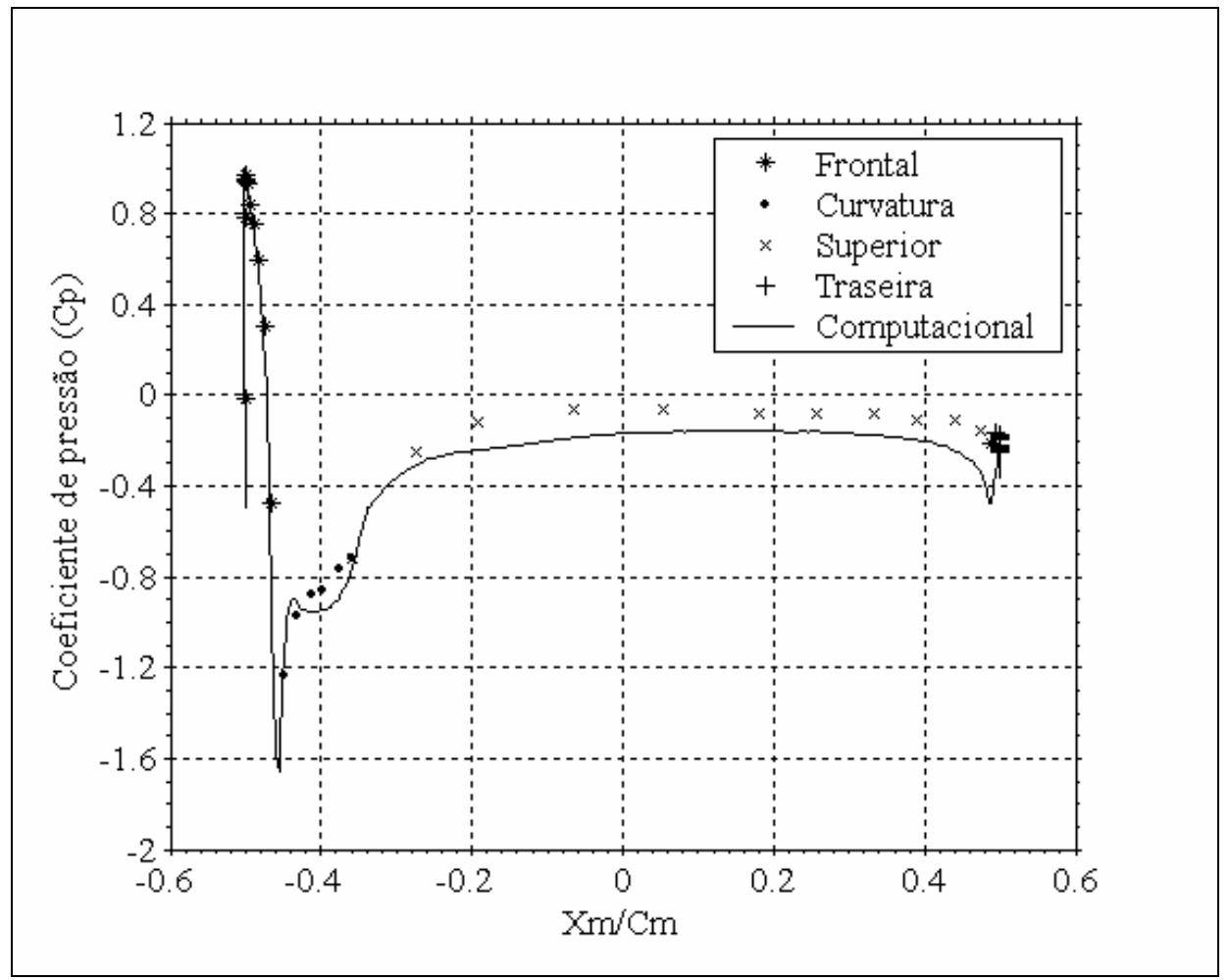

FIGURA 62 - Valores adimensionais dos coeficientes de pressão no plano de simetria do modelo, para $\beta=4^{\circ}$.

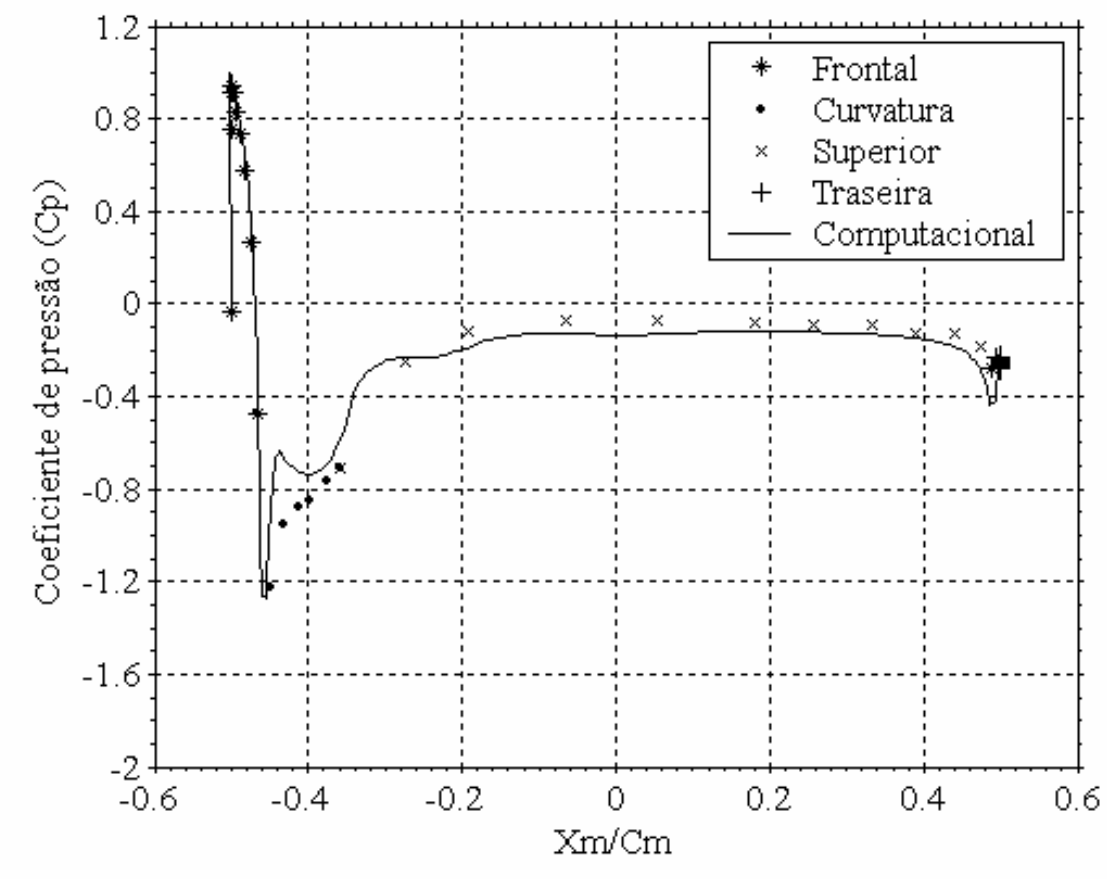

FIGURA 63 - Valores adimensionais dos coeficientes de pressão no plano de simetria do modelo, para $\beta=8^{\circ}$. 


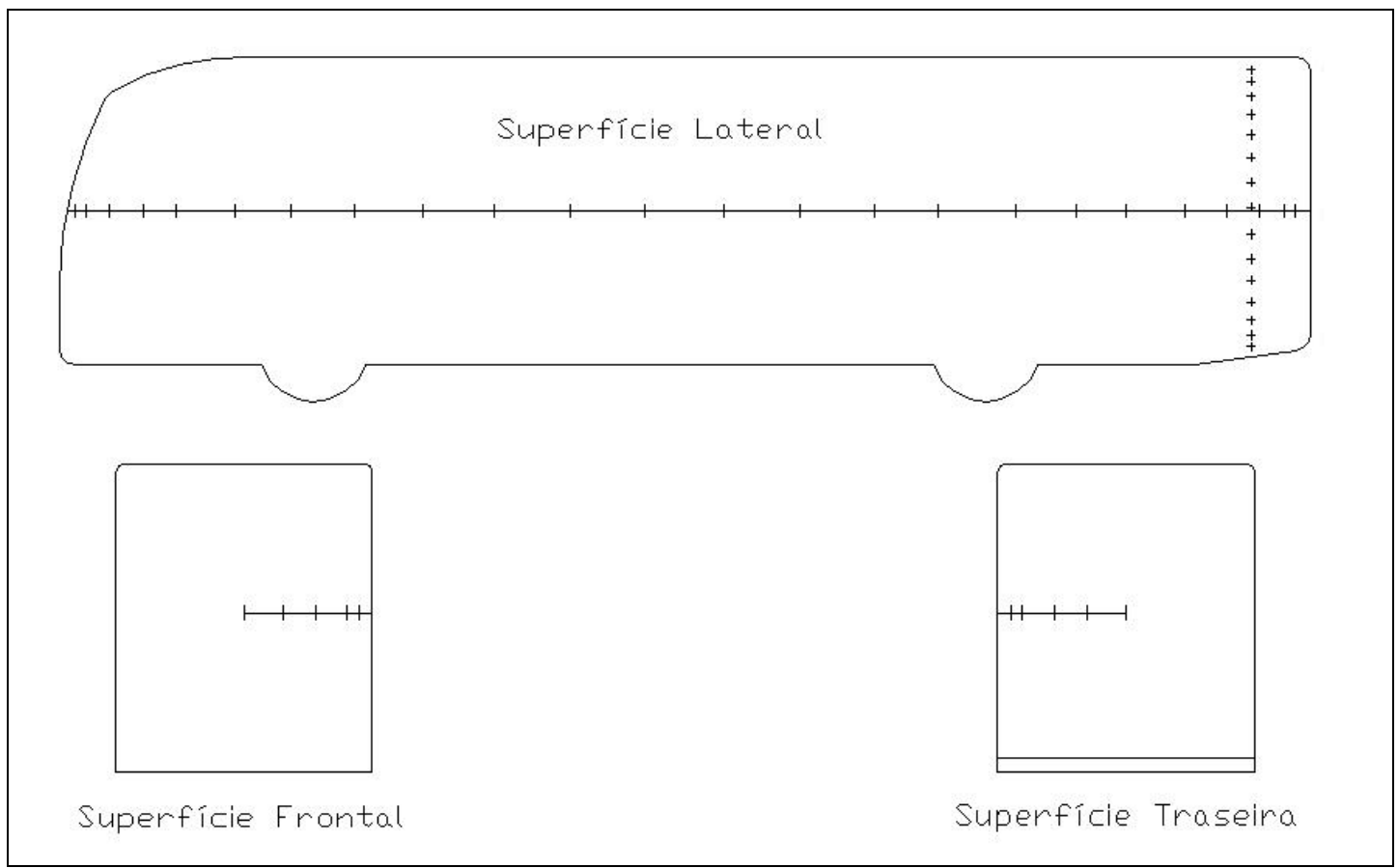

FIGURA 64 - Posição das tomadas de pressão na linha frontal, lateral e traseira do modelo.

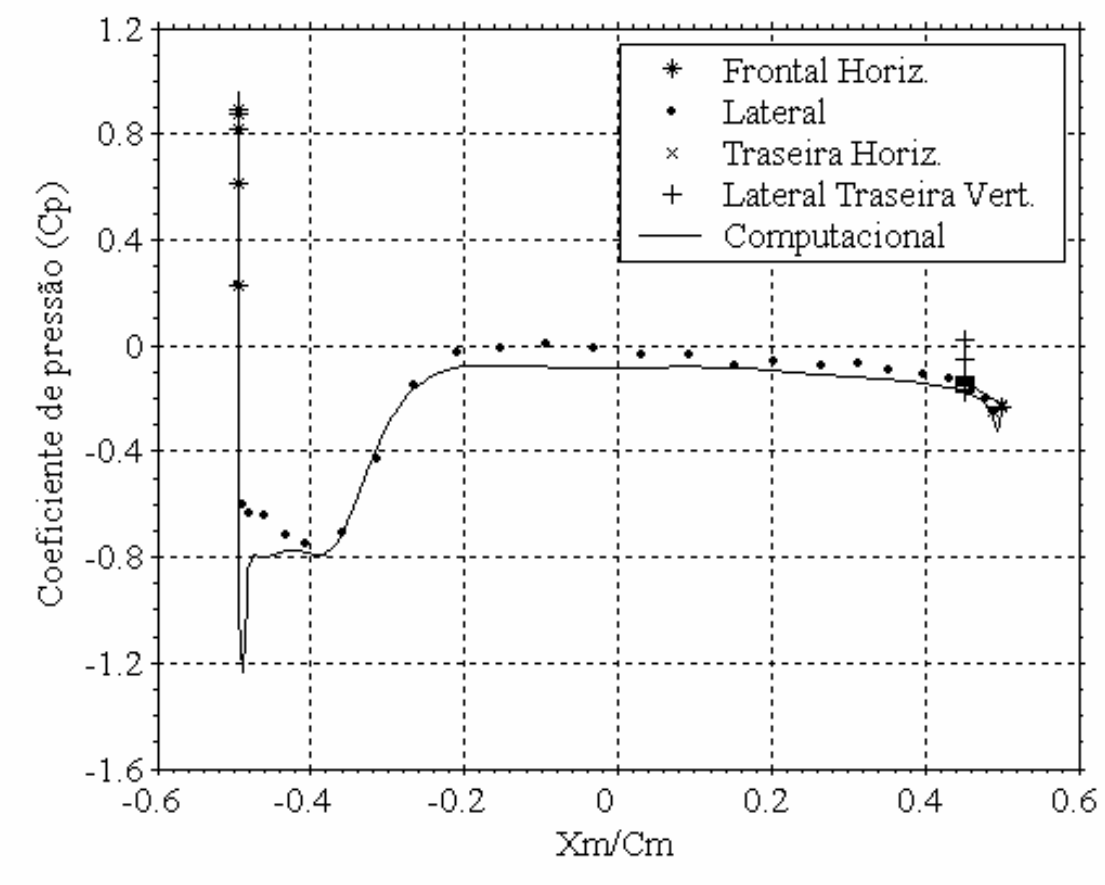

FIGURA 65 - Valores adimensionais dos coeficientes de pressão na lateral modelo, para $\beta=0^{\circ}$. 


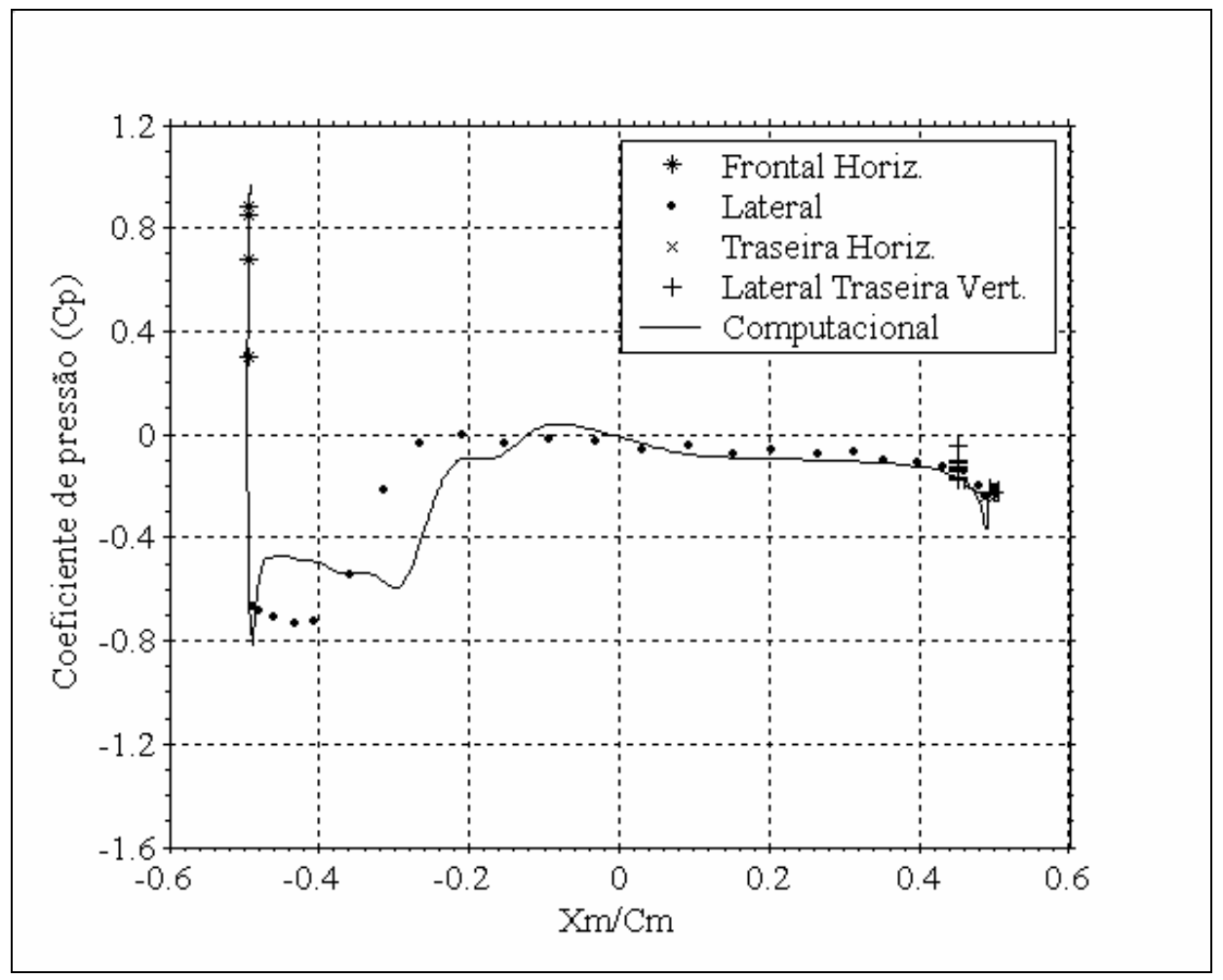

FIGURA 66 - Valores adimensionais dos coeficientes de pressão na lateral do modelo, para $\beta=4^{\circ}$.

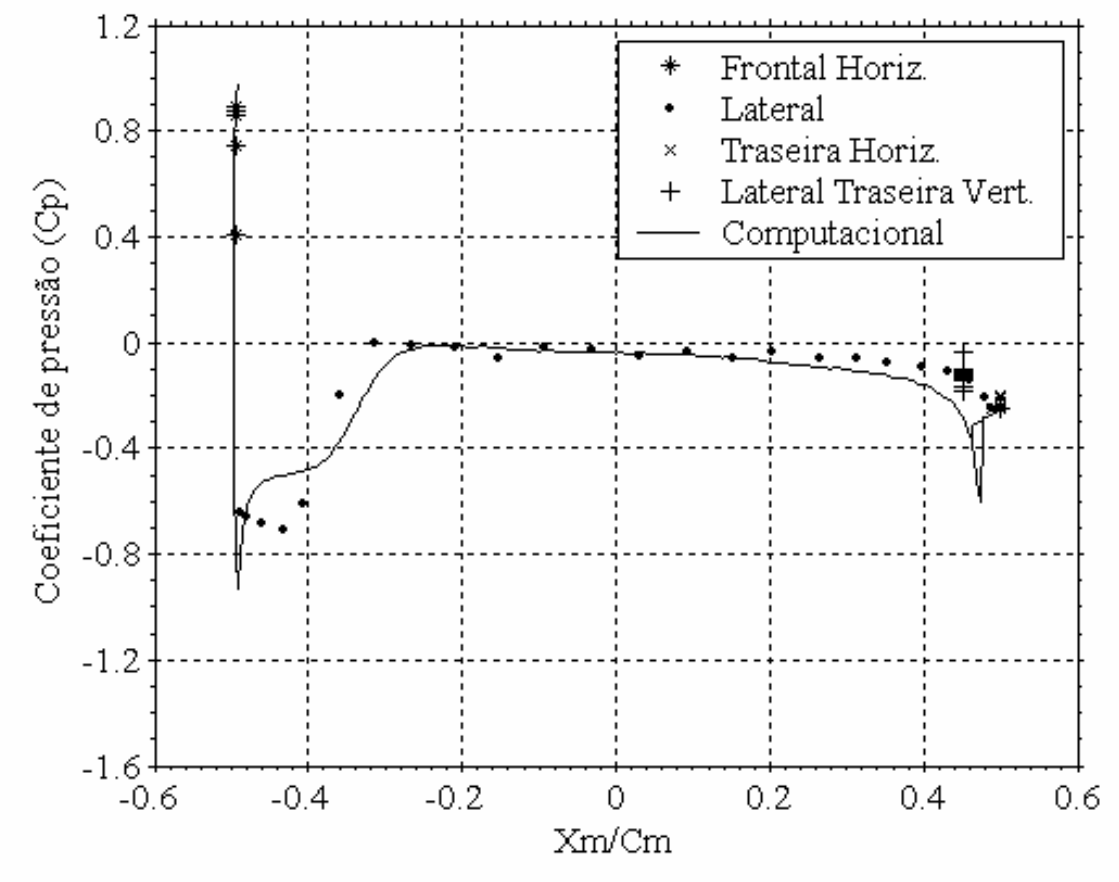

FIGURA 67 - Valores adimensionais dos coeficientes de pressão na lateral do modelo, para $\beta=8^{\circ}$. 


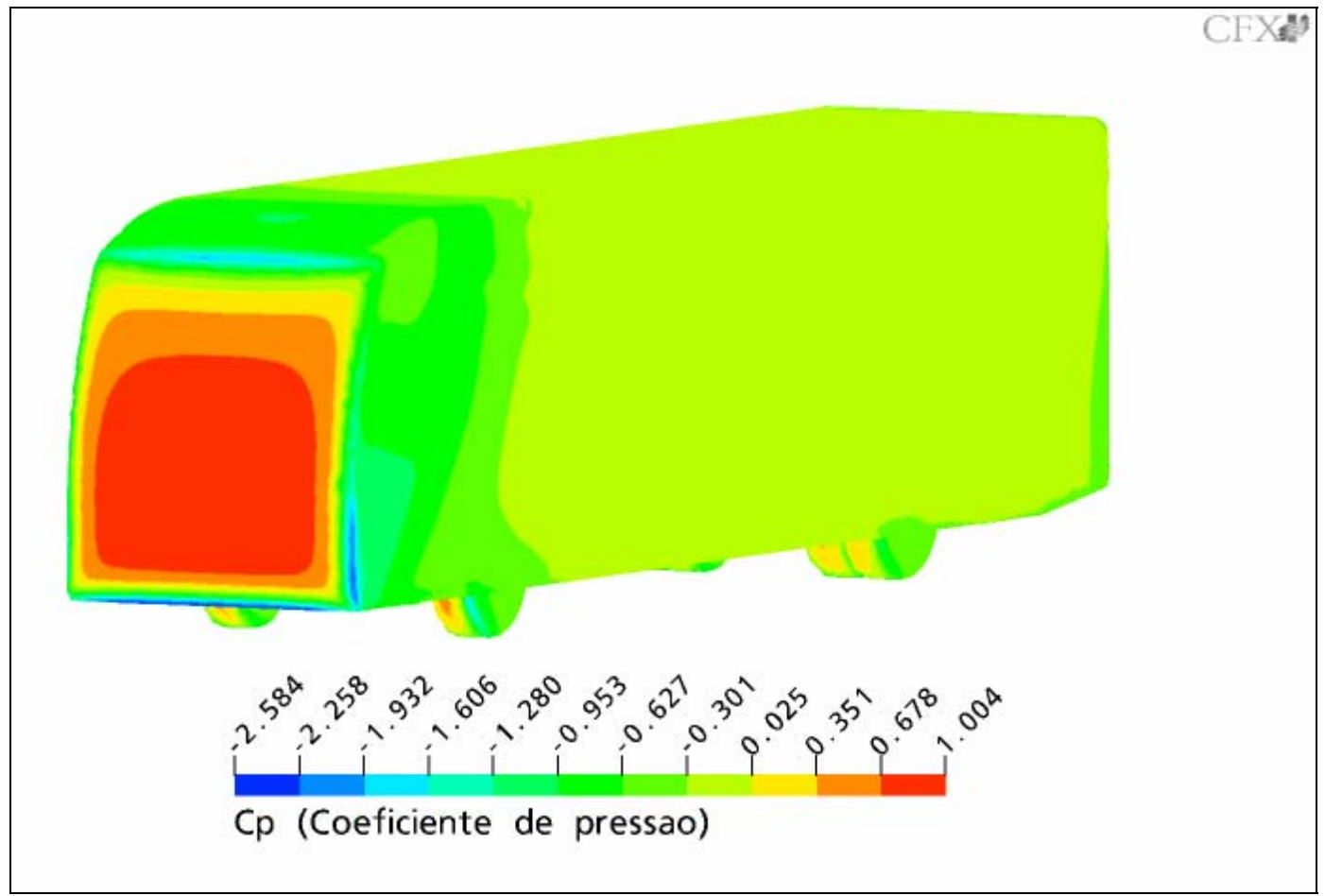

FIGURA 68 - Valores computacionais de coeficiente de pressão no modelo, para $\beta=0^{\circ}$.

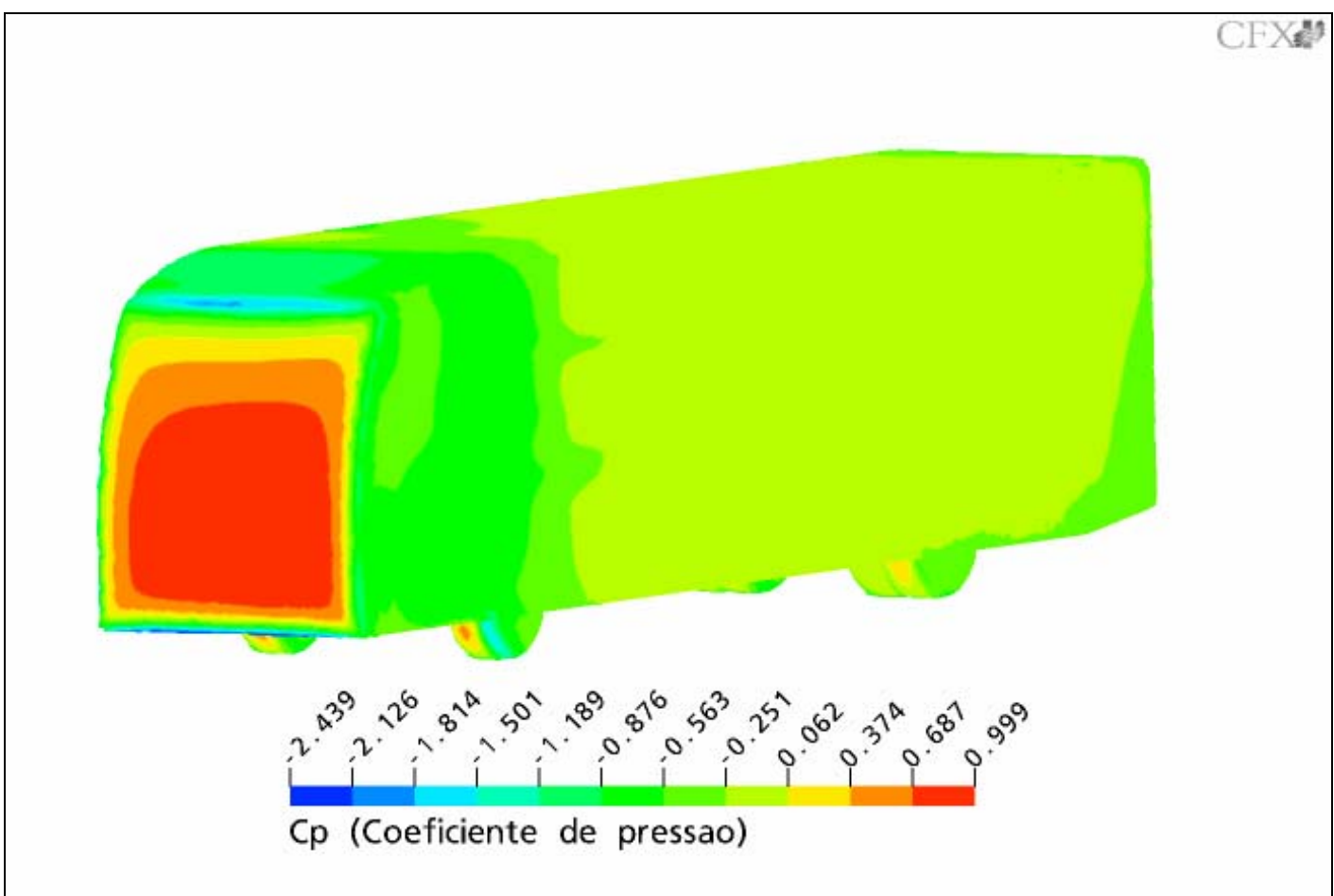

FIGURA 69 - Valores computacionais de coeficiente de pressão no modelo, para $\beta=4^{\circ}$. 


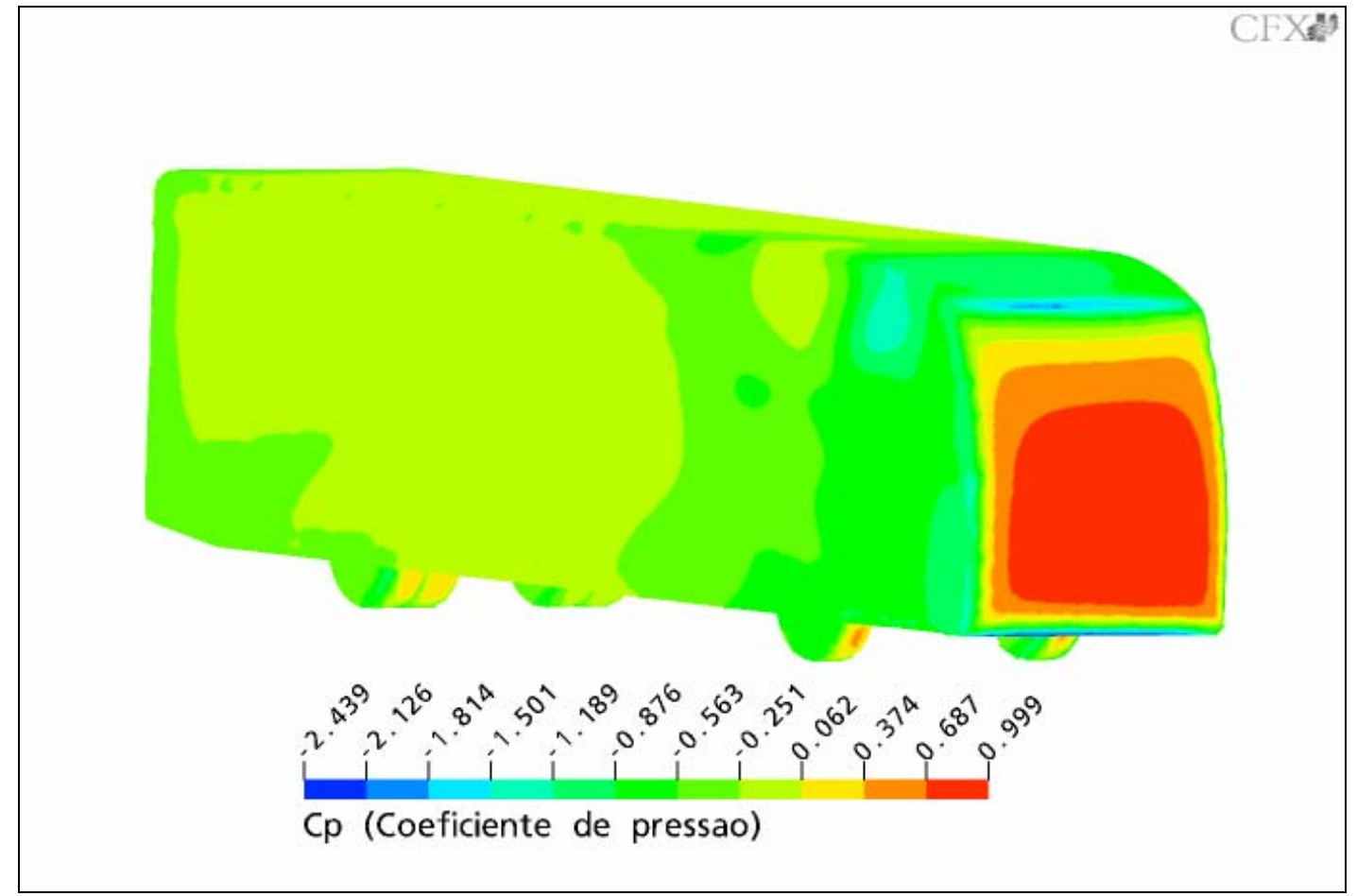

FIGURA 70 - Valores computacionais de coeficiente de pressão no lado oposto do modelo, para $\beta=4^{\circ}$.

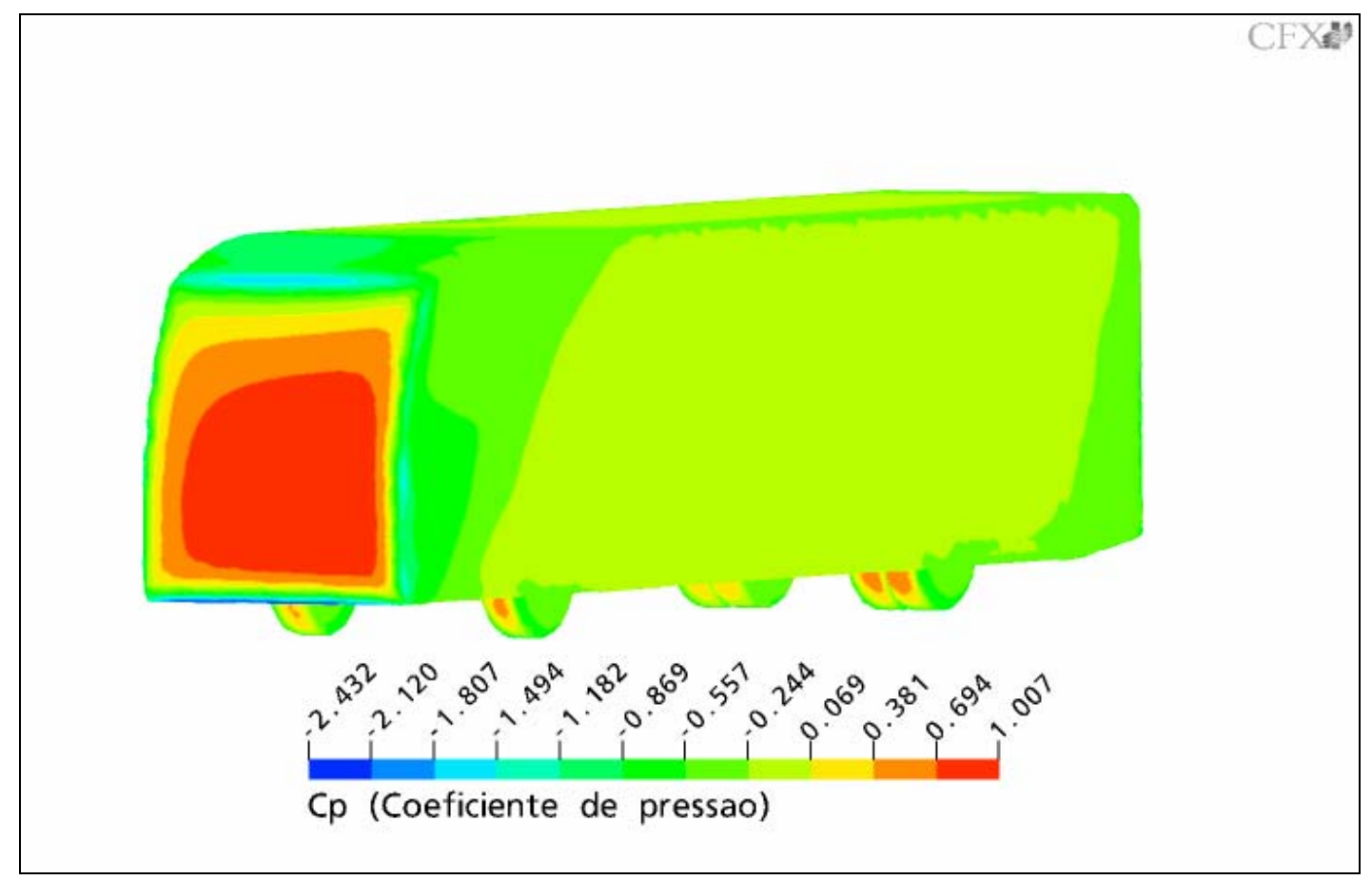

FIGURA 71 - Valores computacionais de coeficiente de pressão no modelo, para $\beta=8^{\circ}$. 


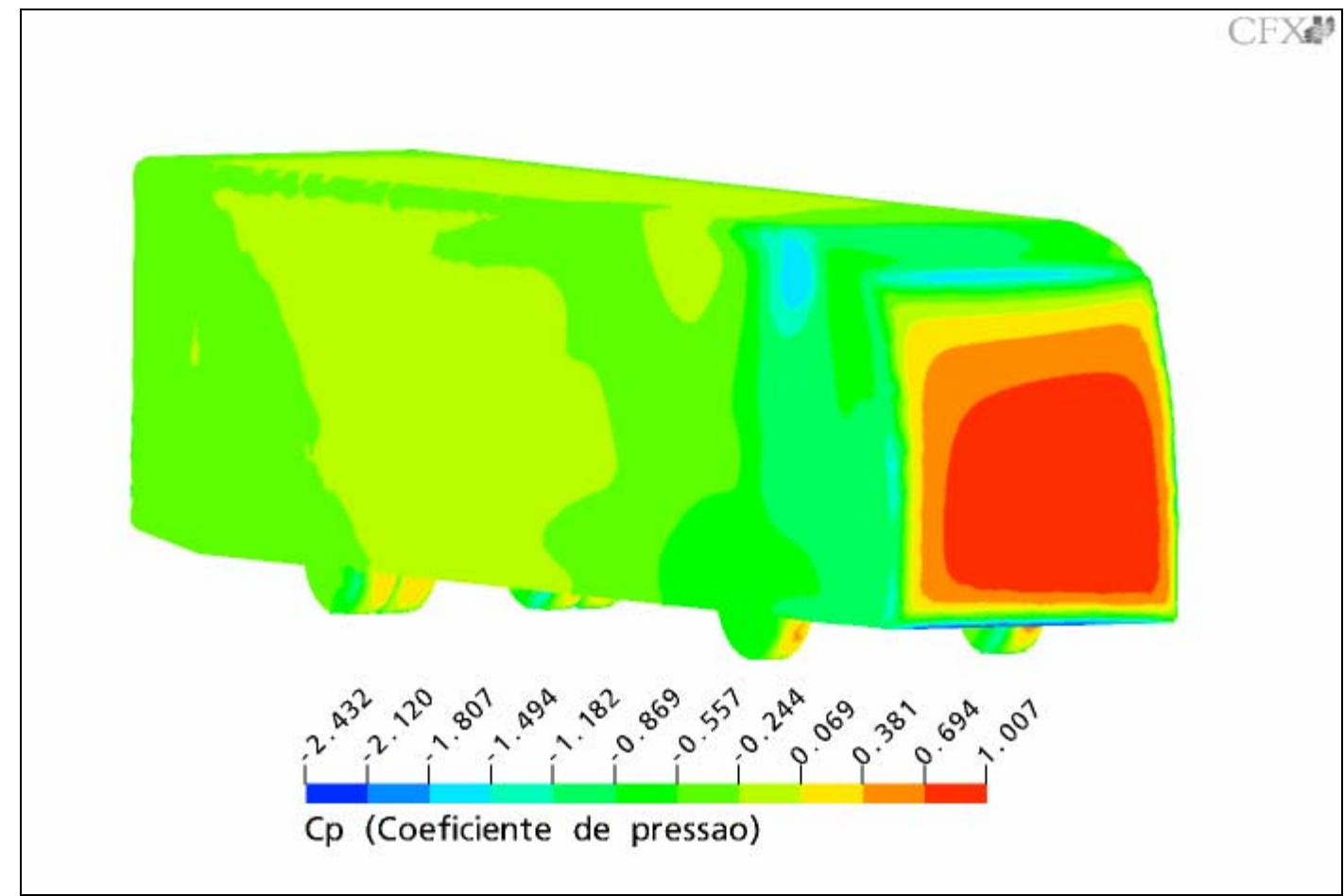

FIGURA 72 - Valores computacionais de coeficiente de pressão no lado oposto do modelo, para $\beta=8^{\circ}$.

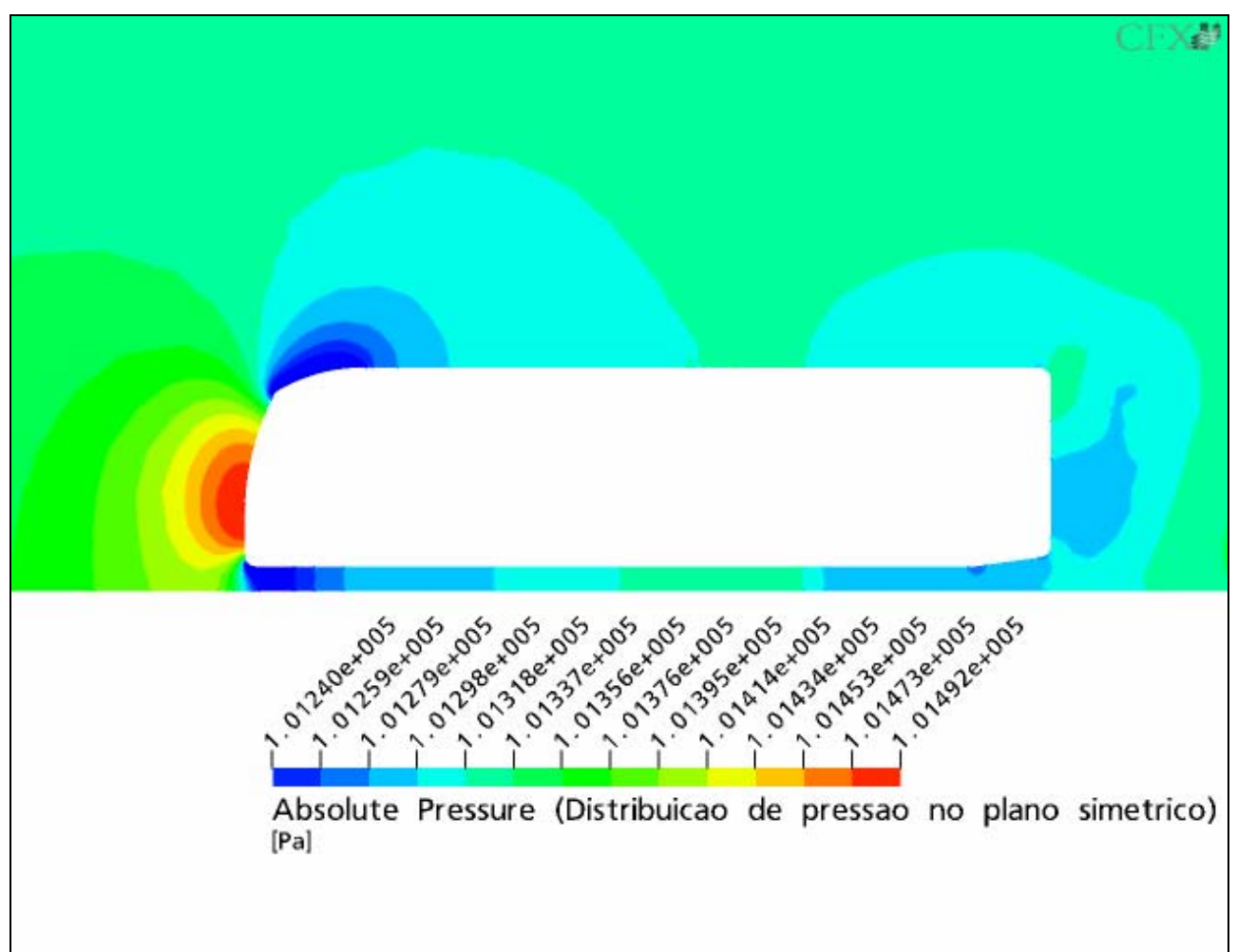

FIGURA 73 - Valores de distribuição de pressão no plano simétrico do modelo, para $\beta=0^{\circ}$. 


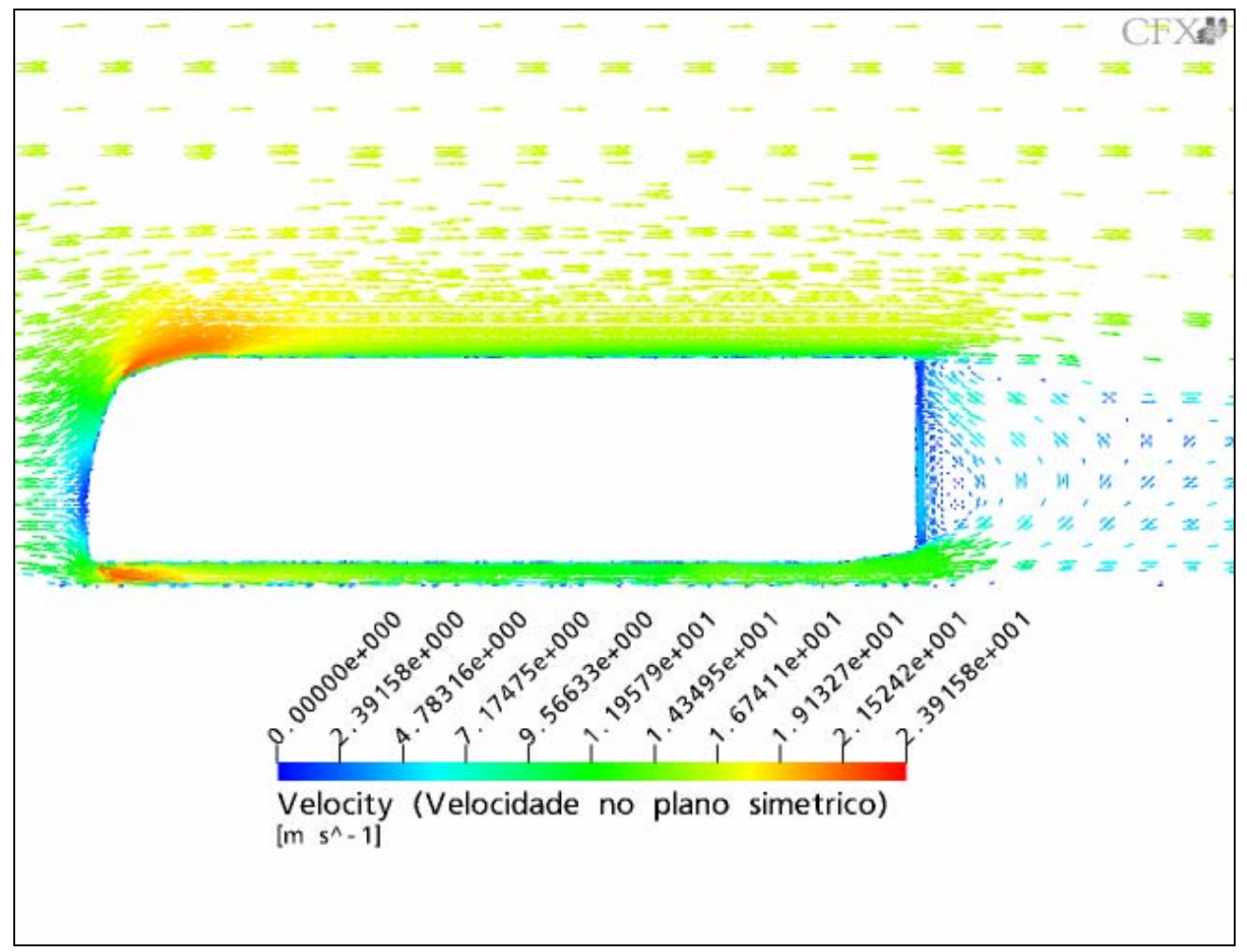

FIGURA 74 - Valores de velocidade no plano simétrico do modelo, para $\beta=0^{\circ}$.

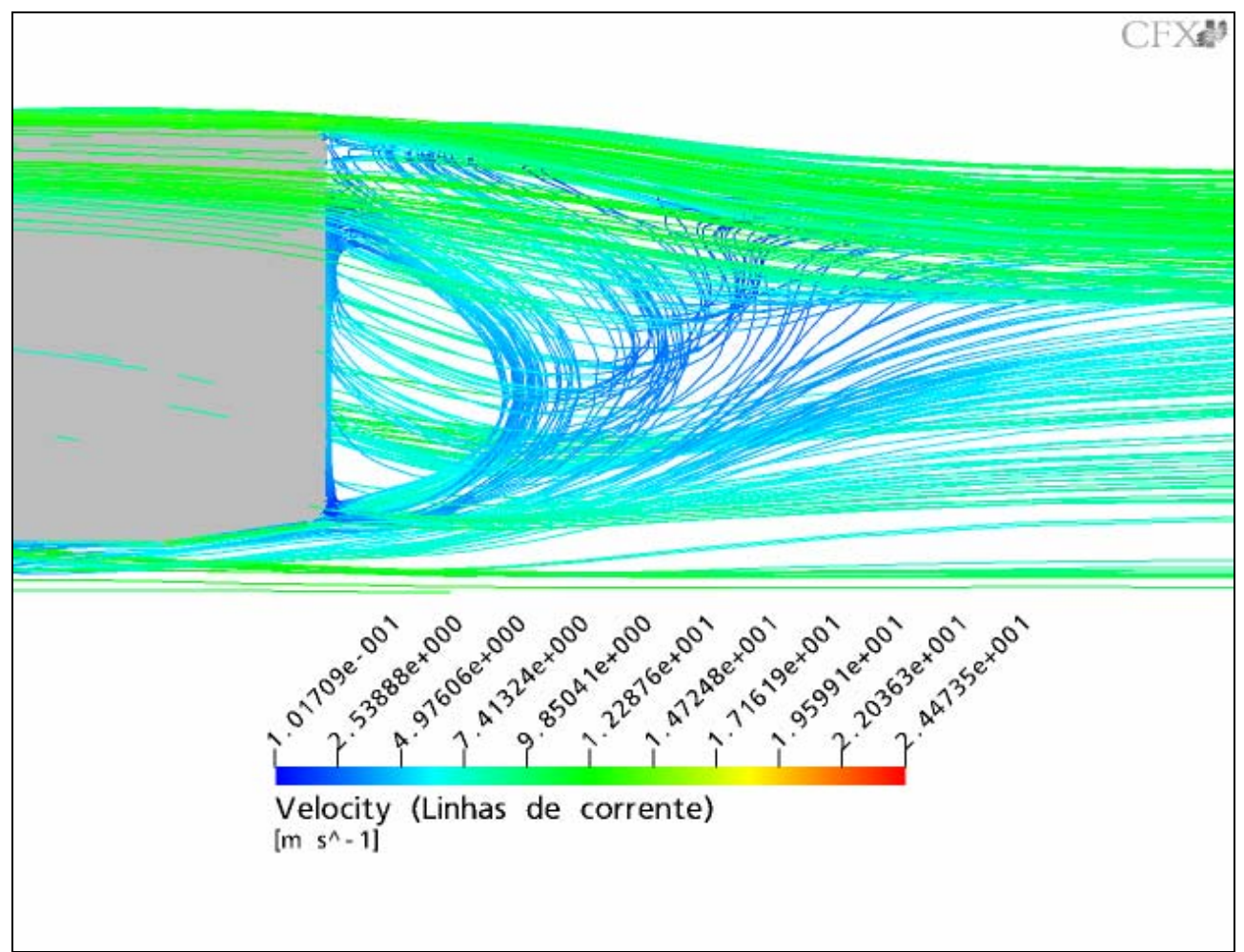

FIGURA 75 - Linhas de corrente do escoamento na traseira do modelo, para $\beta=0^{\circ}$. 


\section{CONCLUSÕES}

A resistência aerodinâmica é uma parte importante que o veículo tem que vencer quando trafega em uma estrada de rodagem, sendo responsável por metade do consumo de combustível para um veículo pesado a uma velocidade de $80 \mathrm{~km} / \mathrm{h}$. É evidente que existem limites para o quanto podemos reduzir o coeficiente de arrasto $\left(C_{D}\right)$ para um caminhão e ônibus, por razões de eficiência de transporte de carga e passageiros não podendo ser muito diferente do formato de um paralelepípedo.

A preocupação das empresas e universidades com o desenvolvimento e a introdução de novas ferramentas e formas geométricas nos veículos comerciais e de passeio, para minimizar o tempo de projeto e o excessivo consumo de combustível propiciado pela utilização de sistemas de transporte de mercadorias e passageiros, vem se intensificando a cada ano, trazendo benefícios a organizações comerciais, pela redução de custos no desenvolvimento de novos produtos e ao meio ambiente pela redução das emissões de poluentes no ar atmosférico.

No presente trabalho foi estudada a característica aerodinâmica sobre um ônibus rodoviário. As variações da direção do escoamento incidente sobre a superfície do modelo e as simulações numéricas foram realizadas nas instalações do Laboratório de Aerodinâmica Experimental. Todas as simulações realizadas no túnel de vento tipo soprador, com um modelo em escala 1:17,5 demonstraram uma variação das forças aerodinâmicas de arrasto e lateral com variação do ângulo de guinada $(\beta)$.

O estudo dos coeficientes aerodinâmicos, devido à variação dos ângulos de guinada são de importância na análise das características aerodinâmicas que influem na estabilidade e consumo de combustível do veículo. Neste trabalho as variações dos coeficientes de arrasto e de força lateral foram analisados, devido as variações ocorridas no ângulo de guinada $\beta$. As comparações dos resultados computacionais e 
experimentais apresentaram uma similaridade no escoamento de ar sobre as superfícies do modelo.

Os experimentos realizados com a variação do ângulo de guinada, respeitaram um intervalo de $-10^{\circ} \leq \beta \leq+10^{\circ}$. Os resultados mostraram como o coeficiente de arrasto e de força lateral variam em relação ao ângulo de guinada $\beta=0^{\circ}$. Os resultados computacionais das forças aerodinâmicas têm uma concordância quantitativa em relação ao experimental.

No trabalho, o solo foi simulado através de uma placa plana fixa. Os resultados foram concedidos com duas configurações, uma com vão livre de $10 \mathrm{~mm}$ em relação aos pneus e outro sem vão livre entre a placa e o modelo. Concluiu-se que as forças aerodinâmicas não sofreram influência significativa do vão livre, com pequena variação nos valores dos coeficientes de arrasto e força lateral. Para as simulações numéricas também foram respeitados os critérios de simulação do piso com uma placa plana, e os resultados acabaram sendo satisfatórios.

Neste trabalho foram realizados ensaios com a finalidade de visualizar o escoamento sobre a superfície do modelo. Observaram-se as regiões de separação, formação de vórtices nas laterais e o ponto de estagnação na parte frontal do modelo. As direções do escoamento puderam ser vistas através do posicionamento dos "tufts" na parte frontal, lateral e superior. Outro ensaio foi conduzido com um composto de dióxido de titânio aplicado sobre a superfície do modelo em escala. Verificou-se a presença de uma bolha de separação no início da parte superior, regiões de recirculação nas partes laterais e vórtices nas quinas superiores do modelo. As visualizações dos resultados computacionais ajudaram a melhor entender a estrutura do escoamento de ar envolto ao modelo, mesmo que alguns resultados experimentais e computacionais não tiveram total concordância, devido a erros experimentais e numéricos.

No presente trabalho foram utilizados programas comerciais, ANSYS ${ }^{T M}$ ICEM $^{T M}$ (um gerador de malha) e ANSYS ${ }^{T M}$ CFX $^{T M}$ CFD (um programa de códigos de Dinâmica dos Fluidos Computacional). O uso de programas comerciais de dinâmica de fluidos computacional está tendo um progressivo acesso diante das condições de facilidade de manuseio e baixo custo. Oferece grande flexibilidade para testar diferentes configurações com baixo custo quando comparado aos métodos experimentais. Mas engenheiros e pesquisadores ainda não confiam inteiramente nestes programas, que estão em constante aperfeiçoamento para reproduzir por igual às condições reais de trabalho, com isso adotando os ensaios experimentais em túneis de vento e testes em 
campo, como principal ferramenta para os estudos físicos do escoamento de ar ao redor de um autoveículo.

Num trabalho futuro, com esta mesma configuração, podem-se comparar dados experimentais e computacionais com a análise de dispositivos que contribuem para o aumento ou diminuição dos coeficientes de aerodinâmicos. Este estudo pode ser realizado envolvendo:

- Espelhos externos e equipamento de ar condicionado.

- A simulação do piso e a movimentação das rodas.

- Aletas curvadas "vanes", instalados nas superfícies frontal e traseira capaz de direcionar o escoamento de ar diminuindo as regiões de separação e formação de vórtices presentes no escoamento de ar envolto ao modelo.

- Introdução de um jato de ar na esteira. 


\section{REFERÊNCIAS BIBLIOGRÁFICAS}

AHMED, S. R. (1981). Wake Structure of Typical Automobile Shapes. Journal of Fluids Engineering, Vol. 103, Mar. 1981.

AHMED, S. R. (1983). Influence of Base Slant on the Wake Structure and Drag of Road Vehicles. Journal of Fluids Engineering, Vol. 105, Dec. 1983.

ANDERSON, J. D. (2001). Fundamentals of Aerodynamics. 3ed., McGraw-Hill.

ANDERSON, J. D. (1995). Computational Fluid Dynamics - The Basic with Aplications. 1ed., McGraw-Hill.

BARLOW, J. B.; RAE, W. H.; POPE, A. (1999). Low-Speed Wind Tunnel Testing. 3 ed., John Wiley \& Sons, INC.

BAYSAL, O.; BAYRAKTAR, I. (2000). Computational Simulations for the External Aerodynamics of Heavy Trucks. SAE Paper, nº. 2000-01-3501.

BEARMAN, P. W. (1965). Investigation of the Flow Behind a Two-dimensional Model with a Blunt Trailing Edge and Fitted with Splitter Plates. Journal Fluid Mechanic, Vol. 21, parte 2, pp. 241-255.

CÂMARA, E. F. (1993). Estudo Aerodinâmico do Escoamento sobre o Modelo de um Ônibus. Dissertação (Mestrado), ITA - Instituto Tecnológico de Aeronáutica. 
CERON-MUÑOZ, H. D. (2004). Análise Experimental das Características Aerodinâmicas de Multi-winglets Adaptativas. Dissertação (Mestrado), Escola de Engenharia de São Carlos, Universidade de São Paulo.

CATAlAnO, F. M. (1988). Projeto, Construção e Calibração em Túnel Aerodinâmico de Circuito Aberto Tipo N.P.L. de Seccção Transversal Hexagonal. Dissertação (Mestrado), Escola de Engenharia de São Carlos, Universidade de São Paulo.

DESCHAMPS, C. J. (2002). Turbulência. ABCM - Associação Brasileira de Ciências Mecânicas, Cap. 3, pp. 101-155.

DIUZET, M. (1986). The Moving-belt of the I.A.T. Long Test Section Wind Tunnel. Journal of Wind Engineering and Industrial Aerodynamics, Vol. 22, pp. 237-244.

ENGLAR, R. J. (2000). Development of Pneumatic Aerodynamic Devices to Improve the Performance, Economics, and Safety of Heavy Vehicles. SAE Paper, $n^{\circ}$. 2000-01-2208.

FLETCHER, C. A. J.; STEWART, G. D. H. (1986). Bus Drag Reduction by the Trapped Vortex Concept for a Single Bus and Two Buses in Tandem. Journal of Wind Engineering and Industrial Aerodynamics, Vol. 24, pp. 143-168.

FORTUNA, A. O. (2000). Técnicas Computacionais para Dinâmica dos Fluidos - Conceitos Básicos e Aplicações. EDUSP, Editora da Universidade de São Paulo, Brasil.

GARRY, K. P. (1981). Development of Container-mounted Devices for Reducing the Aerodynamic Drag of Commercial Vehicles. Journal of Wind Engineering and Industrial Aerodynamics, Vol. 9, pp. 113-124. 
GARRY, K. P.; STOLLERY, J. L. (1982). Reducing the Aerodynamic Drag of Commercial Vehicles. International Journal Vehicle Design, Vol. 3, nº. 2.

GILHAUS, A. (1981). The Influence of Cab Shape on Air Drag of Trucks. Journal of Wind Engineering and Industrial Aerodynamics, Vol. 9, pp. 77-87.

HAN, T. (1989). Computational Analysis of Three-Dimensional Turbulent Flow Around a Bluff Body in Ground Proximity. AIAA Journal, Vol. 27, n . 9, Sept. 1989.

HUCHO, W. H. (1987). Aerodynamics of Road Vehicles. 1ed. Butterworth.

KLINE, S. J.; MCCLINTOCK, F. A. (1953). Describing Uncertainties in SingleSample Experiments. Mechanical Engineering, Jan. 1953.

KIM, M.-H. (2004). Numerical Study on the Wake Flow Characteristics and Drag Reduction of Large-sized Bus using Rear-spoiler. International Journal Vehicle Design, Vol. 34, $\mathrm{n}^{\circ} .3$.

LAJOS, T.; PRESZLER, L. (1986). Effect of Moving Ground Simulation on the Flow Past Bus Models. Journal of Wind Engineering and Industrial Aerodynamics, Vol. 22, pp. 271-277.

MARKS, C. H.; BUCKLEY JR., F. T. (1978). A Wind-Tunnel Study of the Effect of Turning Vanes on the Aerodynamic Drag of Tractor-Trailer Trucks. Journal of Fluids Engineering, Dec. Vol. 100.

MAUNSELL, M. G. (1977). Desenvolvimento, Construção e Ensaios de uma Balança Aerodinâmica. Dissertação (Mestrado), Escola de Engenharia de São Carlos, Universidade de São Paulo.

MCDONALD, A. T.; PALMER, G. M. (1980). Aerodynamic Drag Reduction of Intercity Buses. SAE Paper, $n^{\circ} .801404$. 
MELLO, H. C. M (1999). Uma Avaliação Experimental da Influência de Ventos Laterais nas Forças Aerodinâmicas em Veículos de Passageiros. Dissertação (Mestrado), Escola de Engenharia de São Carlos, Universidade de São Paulo.

PAWLOWSKI, F. W. (1930). Wind Resistance of Automobiles. SAE Journal, Vol. 27, nº. 1, Jul. 1930.

ROY, S.; SRINIVASAN, P. (2000). External Flow Analysis of a Truck for Drag Reduction. SAE Paper, $n^{\circ}$. 2000-01-3500.

SARDOU, M. (1986). "Reynolds Effect" and "Moving Ground Effect" Tested in a Quarter Sacle Wind Tunnel Over a High Speed Moving Belt. Journal of Wind Engineering and Industrial Aerodynamics, Vol. 22, pp. 245-270.

SCHLICHTING, H. (1979). Boundary Layer Theory. 7ed., McGraw-Hill.

VIDEIRA, L. C. P. (2001). Estudo Experimental de um Modelo de Ônibus com Ênfase no Escoamento da Esteira. Dissertação (Mestrado), ITA - Instituto Tecnológico de Aeronáutica.

VUOLO, J. H. (1996). Fundamentos da Teoria de Erros. 2ed., Edgard Blucher.

WHITE, F. M. (2002). Mecânica dos Fluidos. 4ed., McGraw-Hill.

WONG, H. Y.; COX, R. N.; RAJAN, A. (1981). Drag Reduction of TrailerTractor Configuration by Aerodynamic Means. Journal of Wind Engineering and Industrial Aerodynamics, Vol. 9, pp. 101-111.

WOOD, R. M.; BAUER, S. X. S. (2003). Simple and Low-Cost Aerodynamic Drag Reduction Devices for Tractor-Trailer Trucks. SAE Paper, $n^{\circ}$. 2003-013377. 
APÊNDICE A

CÁLCULO DA ESPESSURA DA CAMADA LIMITE DA MESA AUTOMOBILÍSTICA 
Neste Apêndice, é mostrado o cálculo da espessura da camada limite, para obtenção do vão do modelo em relação à placa plana fixa.

Para a determinação das variáveis da densidade e viscosidade dinâmica, integradas a fórmula do Número de Reynolds, serão utilizadas as seguintes equações:

Equação do Gás Perfeito:

$$
\mathrm{P}=\rho^{*} \mathrm{R} * \mathrm{~T}
$$

onde,

$\rho$ - é a densidade do ar $\left(\mathrm{Kg} / \mathrm{m}^{3}\right)$;

$\mathrm{R}$ - constante dos gases igual a $287,3(\mathrm{~J} / \mathrm{KgK})$

$\mathrm{T}$ - temperatura ambiente $\left({ }^{\circ} \mathrm{C}\right)$;

$\mathrm{P}$ - pressão atmosférica $(\mathrm{Pa})$.

Substituindo os valores na Equação (A.1), tem-se $\rho=1,076 \mathrm{Kg} / \mathrm{m}^{3}$.

O cálculo da viscosidade dinâmica é proposto por POPE (1999) entre relação da viscosidade dinâmica com a temperatura do ar em condição padrão:

$$
\frac{\mu}{\mu_{0}}=\left(\frac{T}{T_{o}}\right)^{0.76}
$$

onde,

$\mu$ - viscosidade dinâmica;

$\mathrm{T}$ - temperatura ambiente;

$\mu_{\mathrm{o}}$ - viscosidade dinâmica do ar em condição padrão;

$\mathrm{T}_{\mathrm{o}}$ - temperatura do ar em condição padrão.

Os valores correspondentes à condição padrão do ar são: $\mu_{0}=1,757 \times 10^{-5} \mathrm{~N} . \mathrm{s} / \mathrm{m}^{2}$ e $T_{0}=15^{\circ}$ C. Substituindo os valores na Equação (A.2) encontra-se que $\mu=1,803 \times 10^{-5}$ N.s $/ \mathrm{m}^{2}$.

Aplicando os valores na equação do Número de Reynolds, tem-se:

$$
\mathrm{Re}_{\mathrm{x}}=254069,2
$$


A espessura da camada limite foi calculada com a equação de Blasius, ANDERSON (2001), apresentada a seguir:

$$
\delta=\frac{5.0^{*} \mathrm{x}}{\sqrt{\mathrm{Re}_{\mathrm{x}}}}
$$

onde,

$\mathrm{Re}_{\mathrm{x}}$ : Número de Reynolds referente à distância $\mathrm{x}$;

$\mathrm{x}$ : é a distância do início da mesa até a parte frontal do modelo $(0,255 \mathrm{~m})$.

Substituindo os valores na Equação (A.3), obtém-se:

$$
\delta=2,53 \mathrm{~mm}
$$




\section{APÊNDICE B}

CURVAS DE CALIBRAÇÃO DA BALANÇA AERODINÂMICA 
Na Tabela B.1 e B.2 estão expostos os valores das cargas utilizadas para a calibração da balança aerodinâmica, a carga combinada (Pc) é a somatória de cada carga (P) no decorrer do carregamento e o sinal elétrico emitido por cada carga combinada.

\section{B.1 - Curva de calibração da força de arrasto}

\begin{tabular}{|c|c|c|c|}
\hline Carga $(\mathrm{P})(\mathrm{g})$ & $\begin{array}{c}\text { Carga Combinada } \\
(\mathrm{Pc})(\mathrm{g})\end{array}$ & Força $(\mathrm{N})$ & Leitura (Volts) \\
\hline 0,00 & 0,00 & 0,000 & 0,002 \\
\hline 264,92 & 264,92 & 2,60 & 1,030 \\
\hline 40,18 & 305,10 & 2,99 & 1,179 \\
\hline 40,18 & 345,28 & 3,39 & 1,399 \\
\hline 40,09 & 385,37 & 3,78 & 1,536 \\
\hline 50,04 & 435,40 & 4,27 & 1,671 \\
\hline 50,04 & 485,44 & 4,76 & 1,855 \\
\hline 50,04 & 535,48 & 5,25 & 1,928 \\
\hline 100,03 & 635,50 & 6,23 & 2,302 \\
\hline 100,03 & 735,53 & 7,22 & 2,566 \\
\hline 100,03 & 835,56 & 8,20 & 2,922 \\
\hline 200,01 & 1035,56 & 10,16 & 3,576 \\
\hline 200,01 & 1235,57 & 12,12 & 4,273 \\
\hline 200,01 & 1435,58 & 14,08 & 5,011 \\
\hline 499,95 & 1935,52 & 18,99 & 6,914 \\
\hline 646,23 & 2581,75 & 25,33 & 9,124 \\
\hline
\end{tabular}

Tabela B.1 - Valores referentes à calibração da força de arrasto.

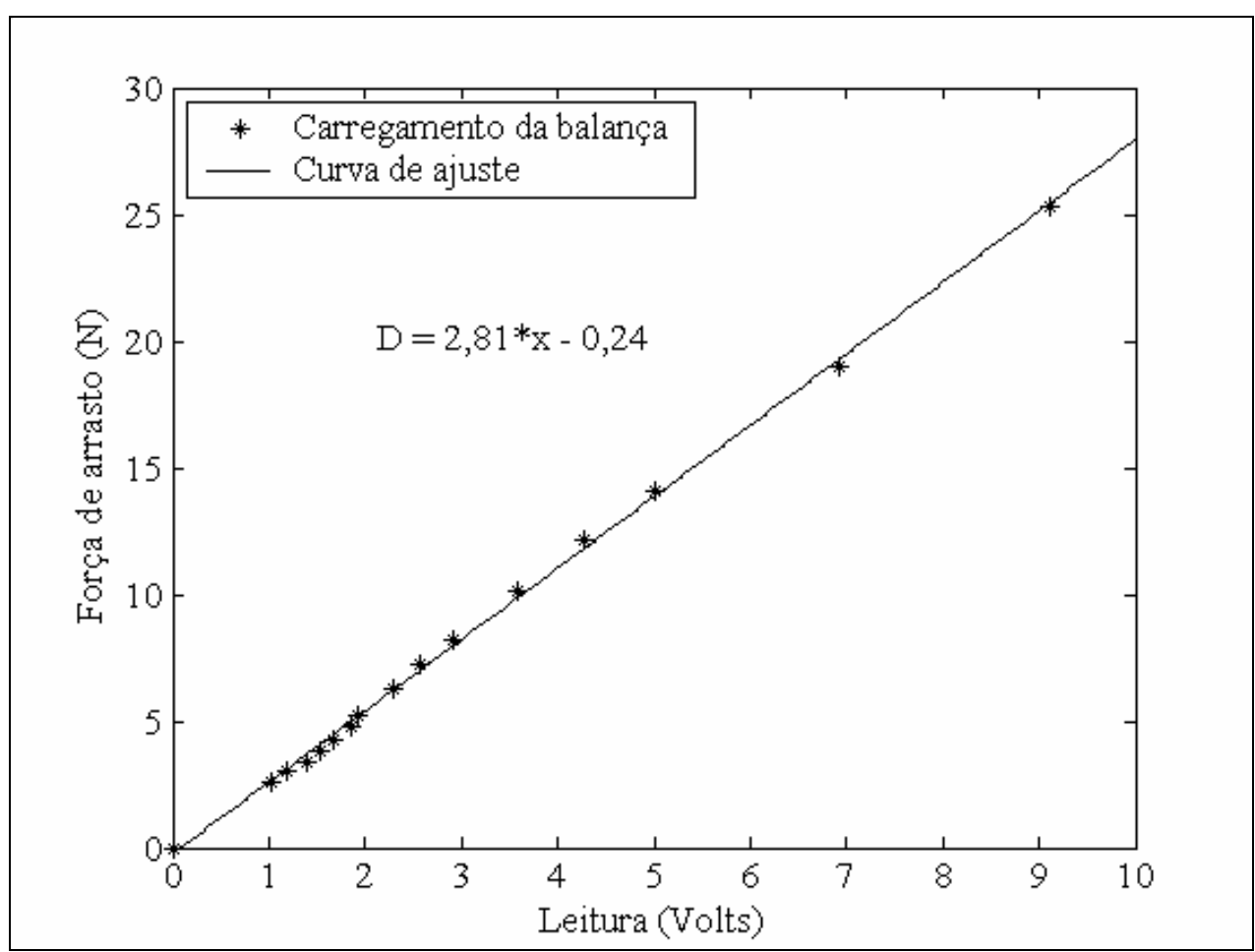

Figura B.1 - Curva de calibração da força de arrasto. 


\section{B.2 - Curva de calibração da força lateral}

\begin{tabular}{|c|c|c|c|}
\hline Carga $(\mathrm{P})(\mathrm{g})$ & $\begin{array}{c}\text { Carga Combinada } \\
(\mathrm{Pc})(\mathrm{g})\end{array}$ & Força $(\mathrm{N})$ & Leitura (Volts) \\
\hline 0,00 & 0,00 & 0,00 & $-0,007$ \\
\hline 264,92 & 264,92 & 2,60 & $-0,467$ \\
\hline 40,18 & 305,10 & 2,99 & $-0,601$ \\
\hline 40,18 & 345,28 & 3,39 & $-0,724$ \\
\hline 40,09 & 385,37 & 3,78 & $-0,750$ \\
\hline 50,04 & 435,40 & 4,27 & $-0,897$ \\
\hline 50,04 & 485,44 & 4,76 & $-0,944$ \\
\hline 50,04 & 535,48 & 5,25 & $-1,176$ \\
\hline 100,03 & 635,50 & 6,23 & $-1,345$ \\
\hline 100,03 & 735,53 & 7,22 & $-1,511$ \\
\hline 100,03 & 835,56 & 8,20 & $-1,685$ \\
\hline 200,01 & 1035,56 & 10,16 & $-2,337$ \\
\hline 200,01 & 1235,57 & 12,12 & $-2,576$ \\
\hline 200,01 & 1435,58 & 14,08 & $-3,101$ \\
\hline 499,95 & 1935,52 & 18,99 & $-4,233$ \\
\hline 646,23 & 2581,75 & 25,33 & $-5,764$ \\
\hline
\end{tabular}

Tabela B.2 - Valores referentes à calibração da força lateral.

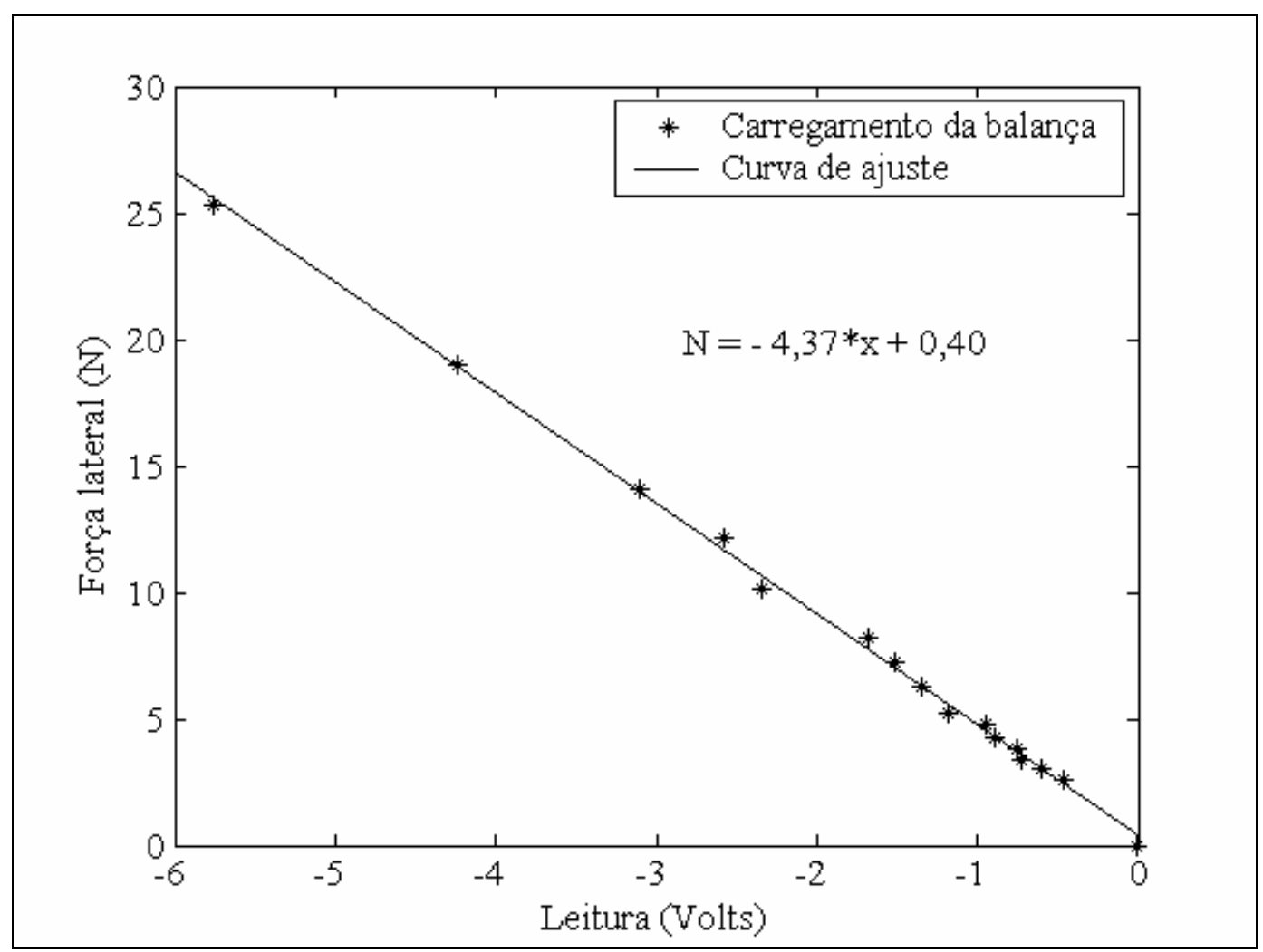

Figura B.2 - Curva de calibração da força lateral. 
APÊNDICE C

CÁLCULO DAS INCERTEZAS 
Neste Apêndice, são mostrados os cálculos dos valores das incertezas presentes na medição das forças aerodinâmicas, velocidade, número de Reynolds e distribuição de pressão.

\section{C.1 - Erro na determinação da velocidade do ar}

Verificando o erro na medida de velocidade, tem-se que:

$$
\Delta V=\sqrt{\left(\frac{\partial V}{\partial \rho_{\mathrm{ar}}} * \Delta \rho_{\mathrm{ar}}\right)^{2}+\left(\frac{\partial \mathrm{V}}{\partial \mathrm{q}_{\infty}} * \Delta \mathrm{q}_{\infty}\right)^{2}}
$$

onde,

$\Delta \mathrm{q}_{\infty}$ é o desvio padrão das medições da pressão dinâmica, sendo igual a 0,304 ;

$\Delta \rho_{\mathrm{ar}}$ é a incerteza na medição da densidade do ar, usando a equação (02) da seção 3.9, e é dada por:

$$
\Delta \rho_{\mathrm{ar}}=\sqrt{\left(\frac{\partial \rho_{\mathrm{ar}}}{\partial \mathrm{Pa}} * \Delta \mathrm{Pa}\right)^{2}+\left(\frac{\partial \rho_{\mathrm{ar}}}{\partial \mathrm{Ta}} * \Delta \mathrm{Ta}\right)^{2}}
$$

Para os valores tem-se:

$\mathrm{Pa}=92126 \mathrm{~N} / \mathrm{m}^{2} ; \mathrm{Ta}=297,6^{\circ} \mathrm{K}$ com $\mathrm{R}=287,3 \mathrm{~J} / \mathrm{KgK}$, obtém-se:

$\partial \rho \operatorname{ar} / \partial \mathrm{Pa}=1,170 \times 10^{-5}$

$\partial \rho \operatorname{ar} / \partial \mathrm{Ta}=0,004$

Substituindo estes valores na Equação (C.2) encontra-se que $\Delta \rho_{\mathrm{ar}}= \pm 0,0035 \mathrm{~kg} / \mathrm{m}^{3}$.

Finalmente, pode-se encontrar o valor de incerteza para a velocidade através da Equação (C.1), então o intervalo de incerteza é de

$$
\Delta \mathrm{V}= \pm 0,056 \mathrm{~m} / \mathrm{s}
$$

\section{C.2 - Incertezas para os Coeficientes de Arrasto $\left(C_{D}\right)$ e Lateral}




\section{C.2.1 Cálculo das incertezas para o coeficiente lateral}

O coeficiente lateral é determinado pela seguinte equação:

$$
\mathrm{C}_{\mathrm{N}}=\frac{\mathrm{N}}{\mathrm{q}_{\infty} * \mathrm{~A}_{\mathrm{f}}}
$$

onde,

$\mathrm{N}$ é a força lateral;

$\mathrm{q}_{\infty}$ é a pressão dinâmica no túnel;

Af é a área frontal do modelo adotada como referência.

Aplicando a Equação (8), tem-se:

$$
\Delta \mathrm{C}_{\mathrm{N}}=\sqrt{\left(\frac{\partial \mathrm{C}_{\mathrm{N}}}{\partial \mathrm{N}} * \Delta \mathrm{N}\right)^{2}+\left(\frac{\partial \mathrm{C}_{\mathrm{N}}}{\partial \mathrm{q}_{\infty}} * \Delta \mathrm{q}_{\infty}\right)^{2}+\left(\frac{\partial \mathrm{C}_{\mathrm{N}}}{\partial \mathrm{Af}} * \Delta \mathrm{Af}\right)^{2}}
$$

onde:

$\Delta \mathrm{N}$ é a incerteza para a força lateral da balança;

$\Delta \mathrm{A}_{\mathrm{f}}$ é a incerteza para a área de referência.

Usando a mesma metodologia,

$$
\begin{gathered}
\Delta \mathrm{A}_{\mathrm{f}}=\sqrt{\left(\frac{\partial \mathrm{A}_{\mathrm{f}}}{\partial \mathrm{L}} * \Delta \mathrm{L}\right)^{2}+\left(\frac{\partial \mathrm{A}_{\mathrm{f}}}{\partial \mathrm{H}} * \Delta \mathrm{H}\right)^{2}} \\
\Delta \mathrm{A}_{\mathrm{f}}= \pm 1,2 \times 10^{-4} \mathrm{~m}^{2}
\end{gathered}
$$

Substituindo os valores na Equação (C.4), tem-se o valor para a incerteza do coeficiente de força lateral: 


$$
\Delta \mathrm{C}_{\mathrm{N}}= \pm 0,295
$$

Abaixo nas Figuras C.1 e C.2 pode-se visualizar a disposição das curvas em relação a curva com o intervalo de incerteza e a curva média.

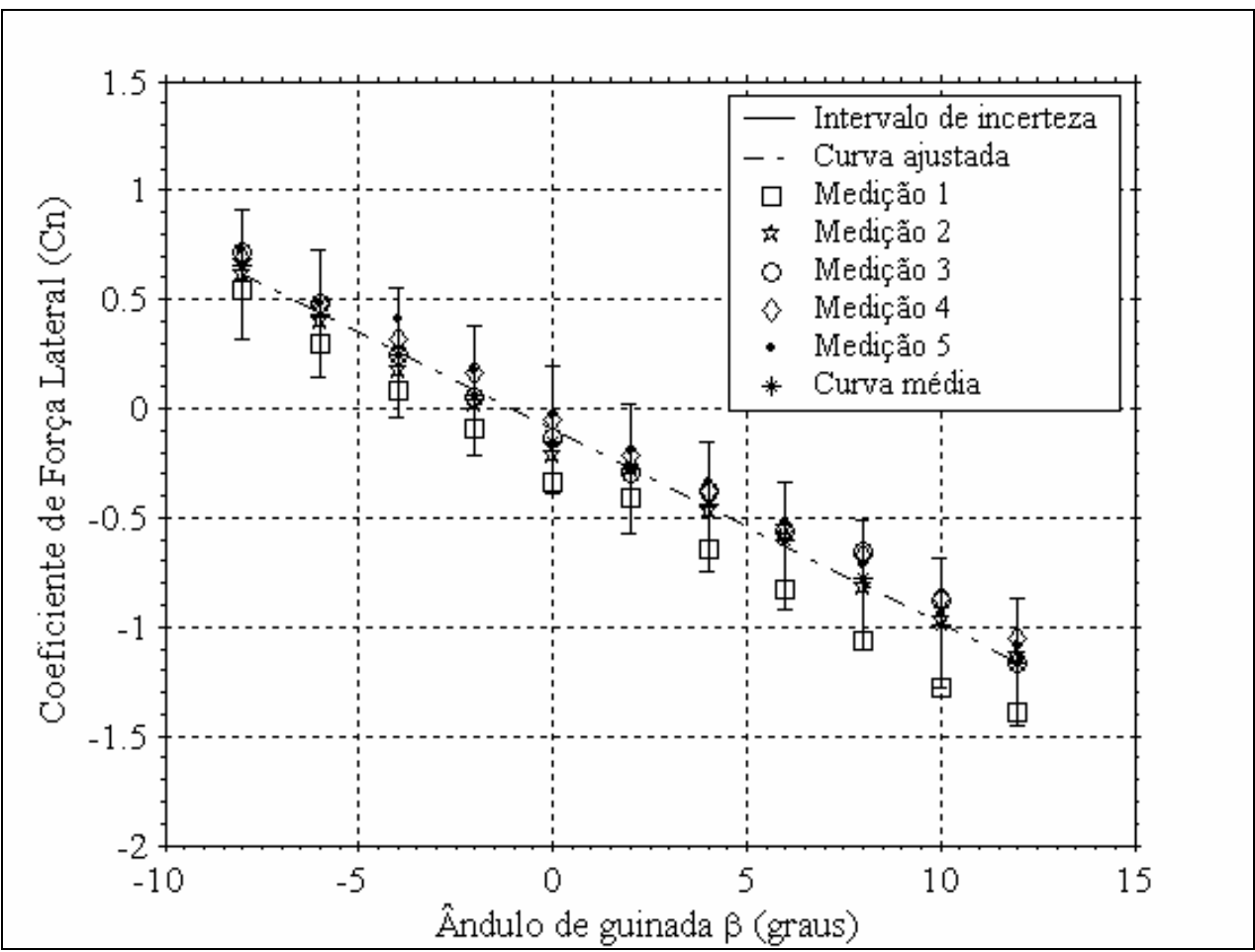

Figura C.1 - Curva de intervalo de incerteza com vão livre.

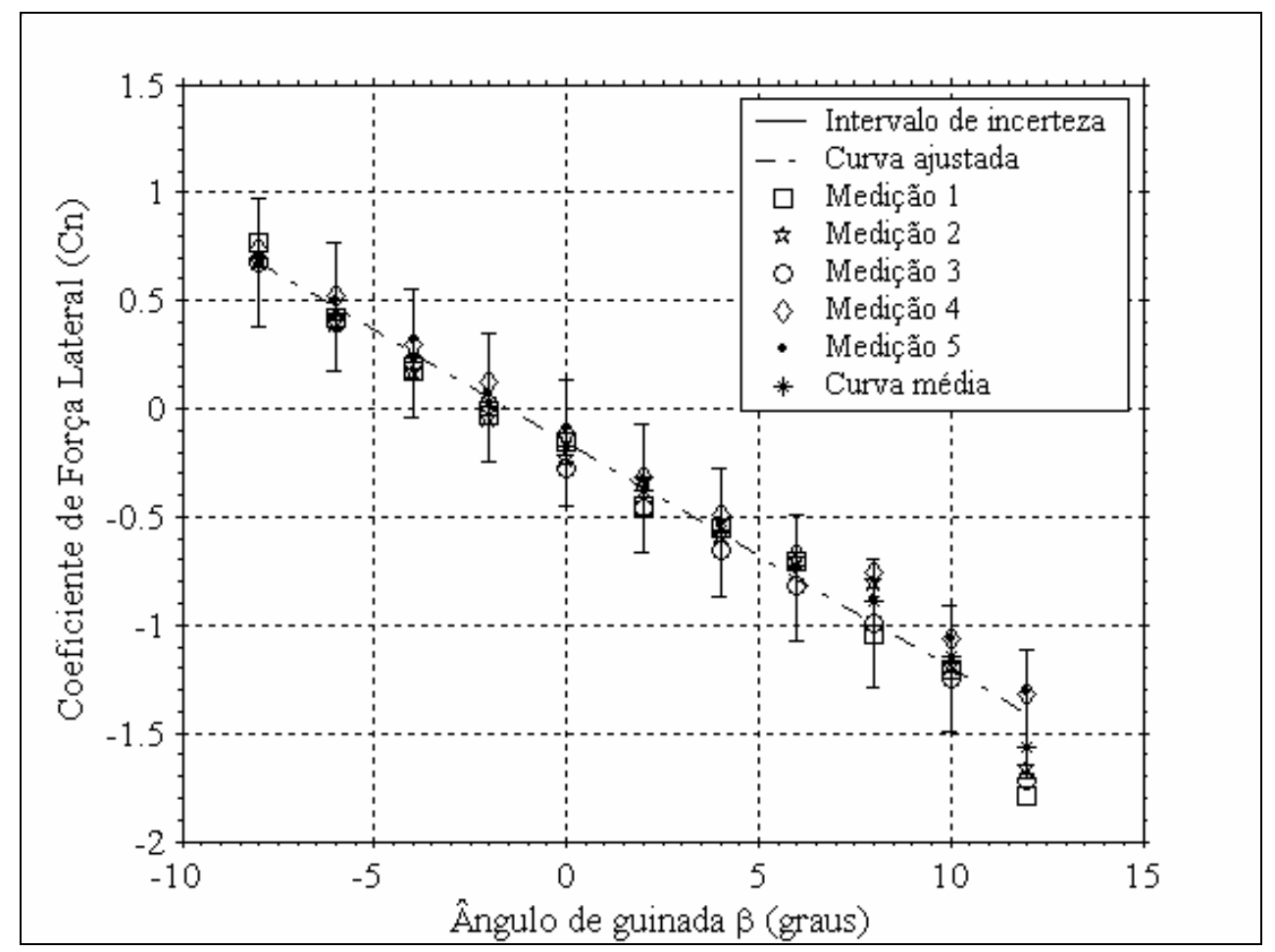

Figura C.2 - Curva de intervalo de incerteza sem vão livre. 


\section{C.2.2 Cálculo das incertezas para o coeficiente de arrasto}

O coeficiente lateral é determinado pela seguinte equação:

$$
C_{D}=\frac{D}{q_{\infty} * A_{f}}
$$

onde,

D é a força de arrasto;

$\mathrm{q}_{\infty}$ é a pressão dinâmica no túnel;

Af é a área frontal do modelo adotada como referência.

Aplicando a Equação (8), tem-se:

$$
\Delta \mathrm{C}_{\mathrm{D}}=\sqrt{\left(\frac{\partial \mathrm{C}_{\mathrm{D}}}{\partial \mathrm{D}} * \Delta \mathrm{D}\right)^{2}+\left(\frac{\partial \mathrm{C}_{\mathrm{D}}}{\partial \mathrm{q}_{\infty}} * \Delta \mathrm{q}_{\infty}\right)^{2}+\left(\frac{\partial \mathrm{C}_{\mathrm{D}}}{\partial \mathrm{Af}} * \Delta \mathrm{Af}\right)^{2}}
$$

onde:

$\Delta \mathrm{D}$ é a incerteza para a força de arrasto da balança;

$\Delta \mathrm{A}_{\mathrm{f}}$ é a incerteza para a área de referência.

$\Delta \mathrm{L}$ e $\Delta \mathrm{H}$ são as incertezas da largura e altura do modelo, o instrumento utilizado para a medição foi uma trena, com um intervalo de incerteza de $\pm 1 \mathrm{~mm}$.

Usando a mesma metodologia,

$$
\begin{gathered}
\Delta \mathrm{A}_{\mathrm{f}}=\sqrt{\left(\frac{\partial \mathrm{A}_{\mathrm{f}}}{\partial \mathrm{L}} * \Delta \mathrm{L}\right)^{2}+\left(\frac{\partial \mathrm{A}_{\mathrm{f}}}{\partial \mathrm{H}} * \Delta \mathrm{H}\right)^{2}} \\
\Delta \mathrm{A}_{\mathrm{f}}= \pm 1,2 \times 10^{-4} \mathrm{~m}^{2}
\end{gathered}
$$


Substituindo os valores na Equação (C.7), tem-se o valor para a incerteza do coeficiente de arrasto:

$$
\Delta \mathrm{C}_{\mathrm{D}}= \pm 0,051
$$

Abaixo nas Figuras C.3 e C.4 pode-se visualizar a disposição das curvas em relação a curva com o intervalo de incerteza e a curva média.

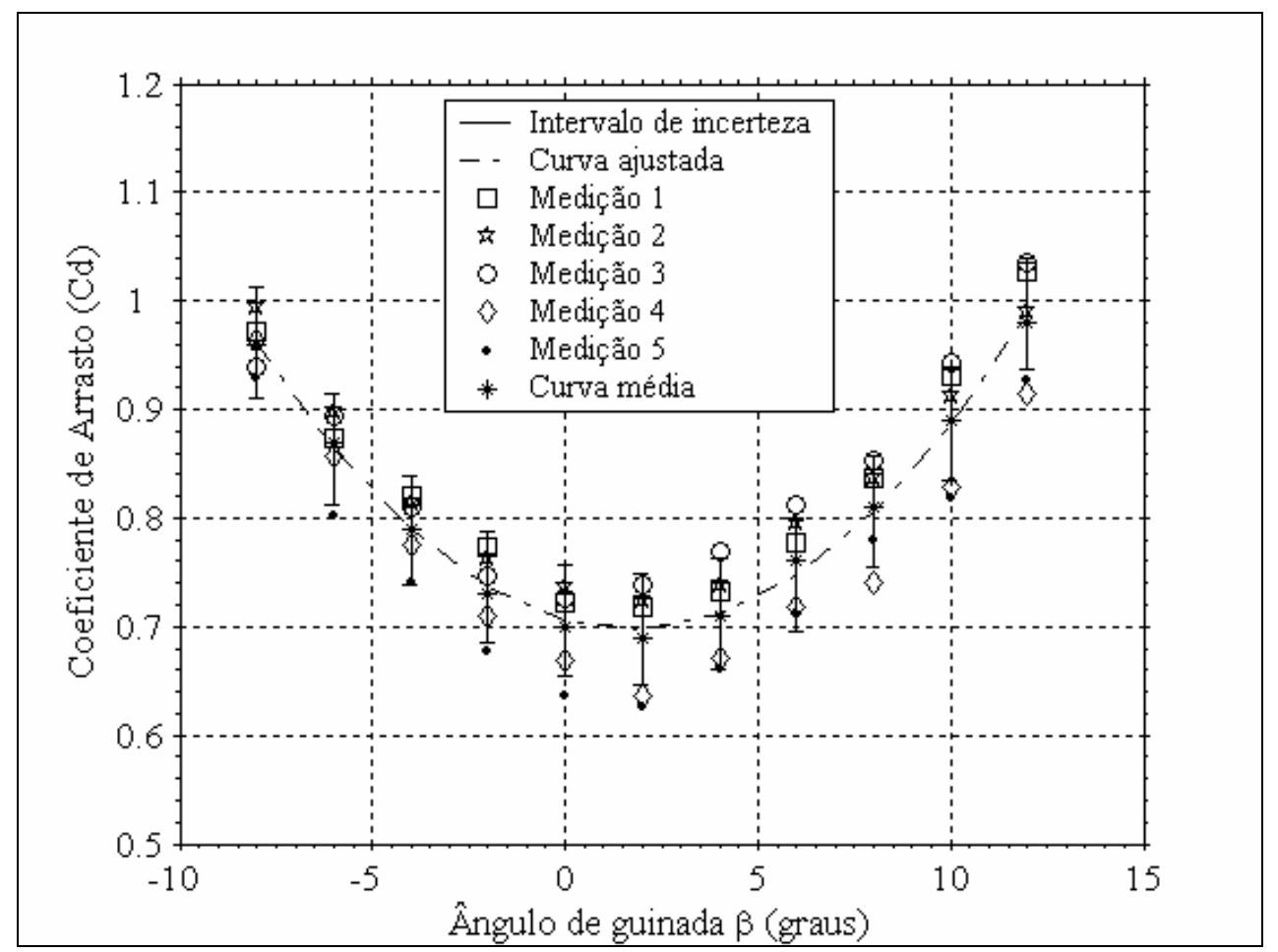

Figura C.3 - Curva de intervalo de incerteza com vão livre. 


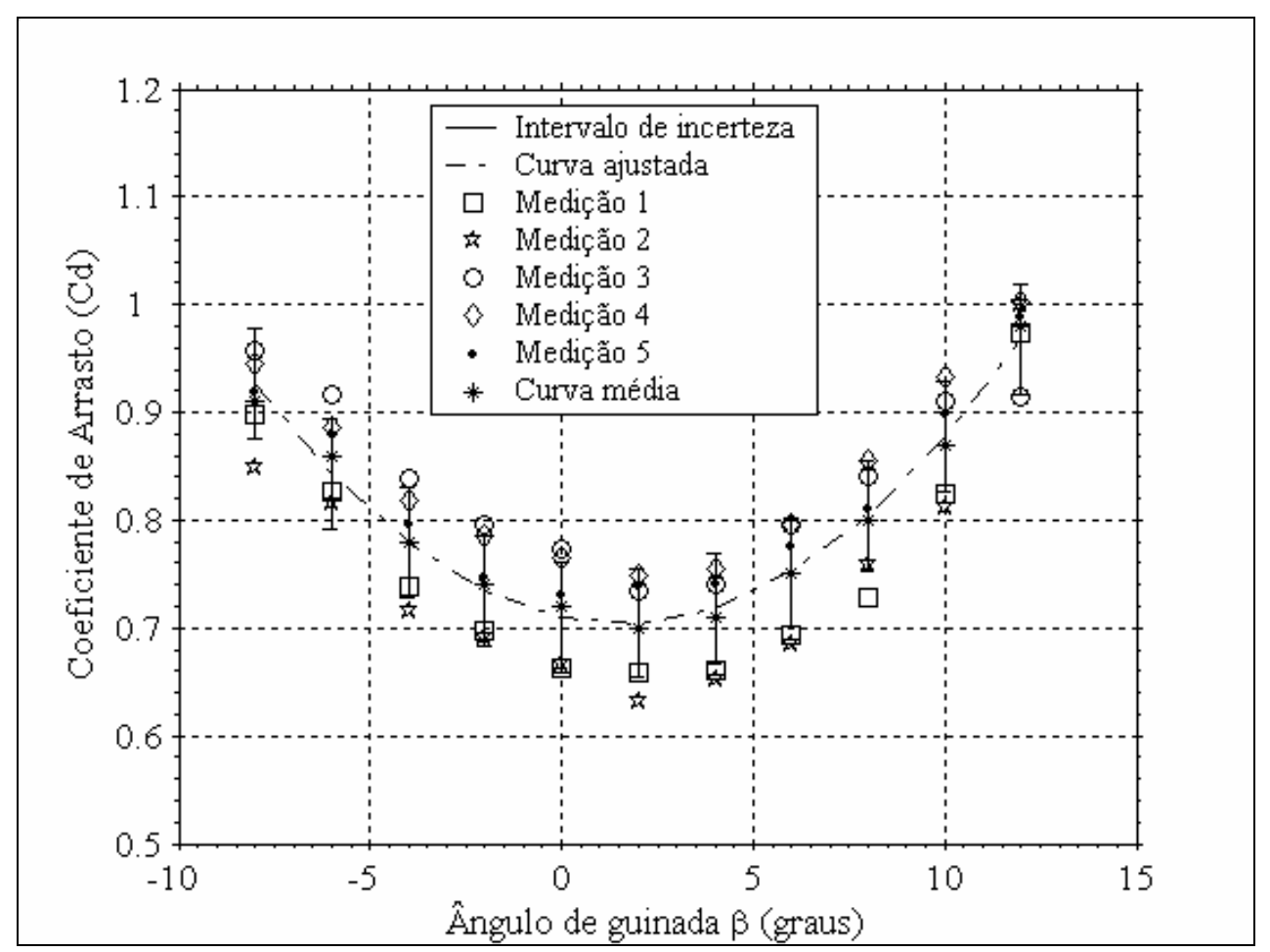

Figura C.4 - Curva de intervalo de incerteza sem vão livre.

\section{C.3 - Incertezas para o Número de Reynolds}

\section{C.3.1 Cálculo das incertezas para a viscosidade dinâmica do ar}

A incerteza da viscosidade dinâmica é estimada segundo a seguinte equação:

$$
\Delta \mu=\left|\frac{\partial \mu}{\partial \mathrm{T}_{\mathrm{a}}} * \Delta \mathrm{T}_{\mathrm{a}}\right|
$$

Para Ta $=297,6^{\circ} \mathrm{K}$, tem-se $\mu=1,80 \times 10^{-5} \mathrm{~N} . \mathrm{s} / \mathrm{m}^{2}$. Substituindo os valores na Equação (C.9), obtém-se:

$$
\Delta \mu= \pm 0,0055 \times 10^{-5} \mathrm{~N} . \mathrm{s} / \mathrm{m}^{2}
$$

\section{C.3.2 Cálculo das incertezas para o Número de Reynolds}


O Número de Reynolds é cálculo pela seguinte equação:

$$
\mathrm{Re}=\frac{\rho_{\mathrm{ar}}^{*} \mathrm{~V} * \mathrm{H}}{\mu}
$$

onde, $\mathrm{H}$ é a altura do modelo $(0,186 \mathrm{~m})$

Aplicando a Equação (8), tem-se:

$$
\Delta \mathrm{Re}=\sqrt{\left(\frac{\partial \mathrm{Re}}{\partial \rho_{\mathrm{ar}}} * \Delta \rho_{\mathrm{ar}}\right)^{2}+\left(\frac{\partial \mathrm{Re}}{\partial \mathrm{V}_{\infty}} * \Delta \mathrm{V}_{\infty}\right)^{2}+\left(\frac{\partial \mathrm{Re}}{\partial \mathrm{H}} * \Delta \mathrm{H}\right)^{2}+\left(\frac{\partial \mathrm{Re}}{\partial \mu} * \Delta \mu\right)^{2}}
$$

Os valores anteriores encontrados das incertezas, substituídos na Equação (C.11), determinam o valor da incerteza para o número de Reynolds, obtém-se:

$$
\Delta \operatorname{Re}= \pm 1152
$$

\section{C.4 - Incerteza para a distribuição de pressão}

$\mathrm{O}$ valor da incerteza para os resultados do parâmetro $\mathrm{Cp}$ estão relacionados à precisão do instrumento utilizado para medição. O cálculo do coeficiente de pressão (Cp) é um valor adimensional, segundo a Equação (C.12), onde as pressões estáticas, totais e o valor correspondente às tomadas de pressão são obtidos em Volts.

$$
\mathrm{C}_{\mathrm{P}}=\frac{\mathrm{P}_{\mathrm{i}}-\mathrm{P}_{\infty}}{\mathrm{P}_{\mathrm{T}}-\mathrm{P}_{\infty}}
$$

onde,

$\mathrm{P}_{\mathrm{T}}$ é a pressão total;

$\mathrm{P}_{\infty}$ é a pressão estática;

$\mathrm{P}_{\mathrm{i}}$ é a pressão referente a cada tomada de pressão. 
O intervalo de incerteza para o coeficiente de pressão corresponde à precisão do transdutor de pressão modelo PDCR23D, que esta na ordem de:

$$
\Delta \mathrm{Cp}= \pm 0,003 \text { Volts }
$$

